Christian Rüsch

\title{
Wohnungsbau- und Wohneigentumspolitik im Rahmen der Einkommensteuer
}




\section{Wohnungsbau- und Wohneigentumspolitik im Rahmen der Einkommensteuer}

Die akute Wohnraumverknappung Ende der achtziger Jahre veranlaßte den Gesetzgeber zu einer Reihe von Maßnahmen im Rahmen der Einkommensteuer. Im Vordergrund stand das Ziel der raschen Vergrößerung des Wohnraumangebotes. Die Förderung erfolgt mit Milliardenaufwand. In dieser Arbeit wird untersucht, inwieweit diese Mittel effizient eingesetzt werden, wem diese Maßnahmen hauptsächlich zugute kommen und ob sie mit den Zielen der Einkommensteuer vereinbar sind. Formale Inzidenzüberlegungen stehen im Vordergrund. Die Maßnahmen werden qualitativ erörtert, daneben werden die Subventionswirkungen auch quantitativ anhand von Investitionsmodellen ermittelt.

Christian Rüsch wurde 1962 geboren und verbrachte seine Schulzeit in Rheinfelden/ Baden. Er studierte von 1982 bis 1989 Volkswirtschaftslehre an der Albert-LudwigsUniversität in Freiburg i.Br. Studienbegleitend lagen Tätigkeiten in der Bau- und Immobilienwirtschaft. Von 1991 bis 1995 war er Wissenschaftlicher Mitarbeiter am Lehrstuhl für Finanzwissenschaft der Universität Freiburg bei Professor Dr. Alois Oberhauser, von 1990 bis 1995 Lehrbeauftragter für verschiedene volkswirtschaftliche Lehrveranstaltungen an der Staatlichen Berufsakademie Lörrach. 1994 erfolgte die Promotion bei Professor Oberhauser. Seit Herbst 1995 ist er in einer Steuerberatungs- und Wirtschaftsprüfungsgesellschaft in Freiburg i.Br. tätig. 
Wohnungsbau- und Wohneigentumspolitik im Rahmen der Einkommensteuer Eine Analyse unter steuersystematischen, verteilungspolitischen und fiskalischen Aspekten 


\section{FINANZWISSENSCHAFTLICHE SCHRIFTEN}

Herausgegeben von den Professoren

Albers, Krause-Junk, Littmann, Oberhauser, Pohmer, Schmidt

Band 72

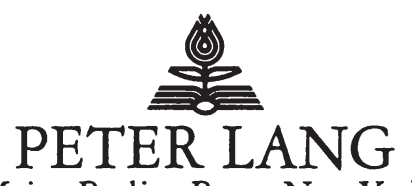

Frankfurt am Main - Berlin · Bern · New York · Paris - Wien 


\section{Christian Rüsch}

\section{Wohnungsbau- und Wohneigentumspolitik im Rahmen der Einkommensteuer}

Eine Analyse unter steuersystematischen, verteilungspolitischen und fiskalischen Aspekten

\section{(4)

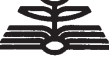 \\ PETER LANG \\ Europäischer Verlag der Wissenschaften}


Die Deutsche Bibliothek - CIP-Einheitsaufnahme

Rüsch, Christian:

Wohnungsbau- und Wohneigentumspolitik im Rahmen der Einkommensteuer : eine Analyse unter steuersystematischen, verteilungspolitischen und fiskalischen Aspekten / Christian Rüsch. - Frankfurt am Main ; Berlin ; Bern ; New York ; Paris ; Wien : Lang, 1996

(Finanzwissenschaftliche Schriften ; Bd. 72)

Zugl.: Freiburg (Breisgau), Univ., Diss., 1994

ISBN 3-631-47937-9

NE: GT

Open Access: The online version of this publication is published on www.peterlang.com and www.econstor.eu under the international Creative Commons License CC-BY 4.0. Learn more on how you can use and share this work: http://creativecommons.org/ licenses/by/4.0.

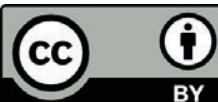

This book is available Open Access thanks to the kind support of ZBW - Leibniz-Informationszentrum Wirtschaft.

D 25

ISSN 0170-8252

ISBN 3-631-47937-9

ISBN 978-3-631-75254-8 (eBook)

(C) Peter Lang GmbH

Europäischer Verlag der Wissenschaften

Frankfurt am Main 1996

Alle Rechte vorbehalten.

Das Werk einschließlich aller seiner Teile ist urheberrechtlich geschützt. Jede Verwertung außerhalb der engen Grenzen des Urheberrechtsgesetzes ist ohne Zustimmung des Verlages unzulässig und strafbar. Das gilt insbesondere für

Vervielfältigungen, Übersetzungen, Mikroverfilmungen und die Einspeicherung und Verarbeitung in elektronischen Systemen. 


\section{Meinen Großeltern}

Karl Rüsch und Waltraud Rüsch-Drechsle

aus Inzlingen/Baden 
Christian Rüsch - 978-3-631-75254-8

Downloaded from PubFactory at 01/11/2019 06:40:21AM

via free access 


\section{Vorwort des Verfassers}

Die vorliegende Arbeit entstand während meiner Tätigkeit als Wissenschaftlicher Mitarbeiter am Institut für Finanzwissenschaft der Albert-Ludwigs-Universität Freiburg bei Professor Dr. Alois Oberhauser. Sie wurde 1994 als Dissertation von der Wirtschaftswissenschaftlichen Fakultät angenommen.

Die akute Wohnraumverknappung Ende der achtziger Jahre veranlaßte den Gesetzgeber zu einer Reihe von Maßnahmen im Rahmen der Einkommensteuer. Im Vordergrund stand das Ziel der raschen Vergrößerung des Wohnraumangebotes. Die Förderung erfolgt mit einem Milliardenaufwand. Dies war für mich Anlaß zu untersuchen, inwieweit diese Mittel effizient eingesetzt werden, wem diese Maßnahmen hauptsächlich zugute kommen und ob sie mit den Zielen der Einkommensteuer vereinbar sind. Im Laufe der Untersuchung zeigte sich, daß es zur abschließenden Beurteilung dieser Fragen notwendig ist, die gesamte Besteuerung der Erträge von Wohnimmobilien mit einer kritischen Würdigung zu unterziehen.

Die einzelnen Regelungen unterliegen zum Teil einer raschen Änderung durch den Gesetzgeber. Wenn Änderungen sich auch in der Förderintensität niederschlagen, so bleiben die Mittel oft die gleichen. Deshalb wurde neben der quantitativen Betrachtung Wert auf die qualitative Erörterung der eingesetzten Mittel gelegt. Diese hat Gültigkeit über die zeitliche Begrenzung der einzelnen Maßnahmen hinaus.

Mein großer Dank gebührt Herrn Professor Alois Oberhauser. Er gab mir nicht nur die Möglichkeit zu dieser Dissertation, sondern beteiligte mich im Rahmen von gemeinsamen Untersuchungen darüber hinaus an seinen Arbeiten auf dem Gebiet der staatlichen Wohnungspolitik. Neben dem dazugewonnen Fachwissen wird mir die Tätigkeit an seinem Institut aufgrund seiner besonderen menschlichen Eigenschaften in angenehmer Erinnerung bleiben.

Meiner Lebensgefährtin, Frau Dr. Elvira Röthele, danke ich dafür, daß sie die Entbehrungen, die mit einer solchen Arbeit zeitweise verbunden sind, mit getragen hat. Herrn Professor Dr. Hans-Hermann Francke danke ich für die schnelle Übernahme des Zweitgutachtens und die wohlwollende Begutachtung. Herrn Privatdozenten Dr. habil. Wolfgang Scherf danke ich für die interessanten und lehrreichen Diskussionen, die sich während unserer gemeinsamen Tätigkeit am Institut und danach ergeben haben. Frau Dr. Barbara Petrick hat mir sehr geholfen. Sie hat sich kritisch mit dem Manuskript auseinandergesetzt, wofür ich ihr dankbar bin. Mein herzlicher Dank gilt auch Frau Ingeborg Häfner für die unkonventionell rasche Erstellung der Druckvorlage.

Freiburg, im Juli 1995

Christian Rüsch 
Christian Rüsch - 978-3-631-75254-8

Downloaded from PubFactory at 01/11/2019 06:40:21AM

via free access 


\section{Inhaltsverzeichnis}

1. Problemstellung 17

2. Abgrenzung des Untersuchungsgegenstandes und Aufbau der Arbeit 19

Teil 1: Grundlagen

A. Charakteristischer Liquiditäts- und Renditeverlauf einer Immobilieninvestition

1. Liquiditätsverlauf

2. Renditeverlauf

B. Grundlagen der Einkommensbesteuerung

1. Das Prinzip der Besteuerung nach der Leistungsfähigkeit

2. Determinaten einer objektiven Bemessungsgrundlage der Einkommensteuer

3. Die Berücksichtigung der persönlichen Lebensverhältnisse

4. Das Prinzip der progressiven Einkommensbesteuerung

5. Der Subventionsbegriff

C. Steuerliche Erfassung der Aufwendungen und Erträge von Wohnimmobilien im Privatvermögen

1. Wohnimmobilien im steuerlichen Privatvermögen

2. Der Einfluß der synthetischen Einkommensbesteuerung auf die Immobilieninvestition

3. Die Problematik der Nichterfassung von Wertsteigerungen

Teil 2: Maßnahmen zur Förderung des Mietwohnungsbaus

A. Kritische Würdigung der linearen Abschreibung 71

1. Der Sinn von Abschreibungen 71

2. Die lineare Abschreibung nach $\S 7$ Abs. 4 EStG 75

3. Die Berücksichtigung von Instandsetzungsmaßnahmen 85 
B. Kritische Würdigung der speziellen Fördermaßnahmen 90

1. Die Fördermaßnahmen $\quad 91$

2. Steuersystematische und verteilungspolitische Beurteilung 93

3. Quantitative Ermittlung der Subventionswirkungen 98

3.1. Erfassung der Subventionswirkungen am Beispiel der degressiven Abschreibung nach $\$ 7$ Abs. 5 EStG 98

3.2. Subventionswirkungen der sonstigen Abschreibungsvergünstigungen

a. Die Vergünstigungen zur Erweiterung des Wohnungsangebotes (§ 7k EStG und § 4 FördergebietsG)

b. Die Vergünstigungen zur Erhaltung des Wohnungsbestandes ( $\$ 7 \mathrm{c}, \mathrm{h}, \mathrm{i}$ EStG)

3.3. Die Subventionswirkungen bei der Verwendung von Abschreibungsvergünstigungen als Finanzierungsmittel

C. Gesamteffekte einer Förderung der Erstellung neuen Wohnraums im frei finanzierten Wohnungsbau

Teil 3: Maßnahmen zur Förderung der Nutzung und des Erwerbs selbstgenutzten Wohneigentums

A. Die Befreiung der Mietwerte von der Einkommensteuer

1. Selbstgenutztes Wohneigentum: Konsum oder Investition?

2. Zur steuerlichen Erfassung der Mietwerte

3. Überblick über die historische Entwicklung der steuerlichen Wohneigentumspolitik

B. Die Förderung des Erwerbs selbstgenutzten Wohneigentums

1. Die zentralen Fördermaßnahmen ( $\S 10$ e und 34f EStG) 165

2. Kritische Würdigung 170

2.1. Steuersystematische Beurteilung 172

2.2. Verteilungspolitische Beurteilung 178

2.3. Beurteilung der familienorientierten Ausgestaltung 188

3. Quantitative Erfassung der Subventionswerte 190

3.1. Beim Erwerb neuerstellten Wohneigentums 191

3.2. Beim Erwerb aus dem Bestand 201

a. Subventionswerte bis Ende $1993 \quad 201$

b. Die Einschränkung der Maßnahmen ab $1994 \quad 202$ 
c. Die Wirkung in Verbindung mit der gesonderten Veranlagung für Steuerpflichtige mit geringem Einkommen

4. Die abgeleiteten Fördermaßnahmen ( $\S 10 \mathrm{f} / \mathrm{h}$ EStG und $\S 7$ FördergebietsG)
A. Ergebnisse
213
B. Schlußbemerkungen

Literaturverzeichnis 
Christian Rüsch - 978-3-631-75254-8

Downloaded from PubFactory at 01/11/2019 06:40:21AM

via free access 


\section{Verzeichnis der Übersichten und Tabellen}

Übersicht 1: Steuerliche Förderung der Erstellung und Erhaltung von vermieteten Wohnungen

Übersicht 2: Steuerliche Förderung des Erwerbs selbstgenutzten Wohneigentums

Tabelle 1: Subventionswerte der Abschreibungsvergünstigungen nach § 7 EStG und \& 4 FördergebietsG

Kalkulationszinssatz 8 v.H.

Tabelle 2: Subventionswerte der Abschreibungsvergünstigungen nach § 7 EStG und \& 4 FördergebietsG versteuerter Kalkulationszinssatz 8 v.H.

Tabelle 3: Maximale fiskalische Gesamtbelastung der Erstellung eines Quadratmeters Wohnraum im frei finanzierten Wohnungsbau, Förderung über degressive Abschreibung nach $\$ 7$ Abs. 5 EStG

Tabelle 4: Maximale fiskalische Gesamtbelastung der Erstellung einer Wohnung mit 80 Quadratmetern im frei finanzierten Wohnungsbau, Förderung über degressive Abschreibung nach $\S 7$ Abs. 5 EStG

Tabelle 5: Renditen der ersten Jahre im frei finanzierten Wohnungsbau unter dem Einfluß der Besteuerung, Förderung über degressive Abschreibung nach $\$ 7$ Abs.5 EStG

Tabelle 6: Subventionswerte der Sonderausgabenabzüge nach $\S 10 e$ EStG in Abhängigkeit von der Familiensituation Erwerb neu erstellten Wohneigentums

Tabelle 7: Baukindergeld nach § $34 \mathrm{f} \mathrm{EStG}$ in Abhängigkeit von der Anzahl der Kinder

Erwerb neu erstellten Wohneigentums 
Tabelle 8: $\quad$ Subventionswerte der Sonderaugabenabzüge nach $\S 10$ e EStG in Abhängigkeit von der Familiensituation

Regelung ab 1994, Erwerb von Wohneigentum aus dem Bestand

Tabelle 9: Baukindergeld nach § 34f EStG in Abhängigkeit von der Anzahl der Kinder

Erwerb von Wohneigentum aus dem Bestand

Tabelle 10: Subventionswerte der Sonderaugabenabzüge nach $\S 10 \mathrm{e}$ EStG in Abhängigkeit von der Familiensituation

Regelung ab 1994, Erwerb von Wohneigentum aus dem Bestand, Berücksichtigung der Einkommensteuerzusatztabelle für Steuerpflichtige mit geringem Einkommen

Tabelle 11: Baukindergeld nach § 34f EStG in Abhängigkeit von der Anzahl der Kinder

Regelung ab 1994, Erwerb von Wohneigentum aus dem Bestand, Berücksichtigung der Einkommensteuerzusatztabelle für Steuerpflichtige mit geringem Einkommen 


\section{Verzeichnis der Grafiken}

Grafik 1: Charakteristischer Verlauf der Liquiditätsbelastung einer Wohnimmobilie; monatliche Mieteinnahmen und Ausgaben für Zinsen pro Quadratmeter Wohnraum

Grafik 2: Charakteristischer Verlauf der Liquiditätsbelastung einer Wohnimmobilie; monatliche Mieteinnahmen und Ausgaben für den Kapitaldienst pro Quadratmeter Wohnraum

Grafik 3: Der Einfluß der synthetischen Einkommensbesteuerung; maximale steuerliche Ent- und Belastungen (monatlich) einer Investition in Wohnimmobilien im Zeitablauf pro Quadratmeter

Finanzierung über Annuitätendarlehen, anfänglicher Tilgungssatz 1 v.H.

Grafik 4: Der Einfluß der synthetischen Einkommensbesteuerung; maximale steuerliche Ent- und Belastungen (monatlich) einer Investition in Wohnimmobilien im Zeitablauf pro Quadratmeter

Finanzierung über tilgungsfreie Hypothek bzw. Kapitallebensversicherung mit Tilgungsaussetzung

Grafik 5: Schematisierter Verlauf der Zeitwerte und Buchwerte einer Immobilieninvestition

Grafik 6: Der Verlauf des Steuerkredits (kumulierte Zeitwerte) und der Zinsbelastung des Staates (Jahreswerte) aus der degressiven Abschreibung nach $\S 7$ Abs. 5 EStG

Grafik 7: Subventionswerte der degressiven Abschreibung nach $\S 7$ Abs. 5 EStG in Abhängigkeit vom Einkommen des Investors in Prozent des investierten Kapitals (schematisiert)

Grafik 8: Subventionswerte (Barwerte) der degressiven Abschreibung nach $\& 7 \mathrm{Abs}$. $5 \mathrm{EStG}$, in Abhängigkeit von der Haltedauer des Objekts und vom Grenzsteuersatz 
Grafik 9: Maximale fiskalische Effekte (monatlich) der Erstellung eines Quadratmeter Wohnraums im frei finanzierten Wohnungsbau

Förderung über degressive Abschreibung nach § 7 Abs. 5 EStG, Finanzierung mittels Annuitätendarlehen, anfänglicher Tilgungssatz 1 v.H.

Grafik 10: Maximale fiskalische Effekte (monatlich) der Erstellung eines Quadratmeter Wohnraums im frei finanzierten Wohnungsbau

Förderung über degressive Abschreibung nach $\S 7$ Abs. 5 EStG, Finanzierung über tilgungsfreie Hypothek bzw. über Kapitallebensversicherung mit Tilgungsaussetzung

Grafik 11: "Isar-Residenz-München" Anschaffungs/Herstellungskosten 560.000 DM, Wohnfläche $80 \mathrm{~m}^{2}$, Anfangsmiete $20 \mathrm{DM}$

Grafik 12: Kumulierte Entlastungseffekte der Sonderausgabenabzüge nach $\S 10$ e EStG, Erwerb neu erstellten Wohneigentums (Zeitwerte)

Grafik 13: Subventionswerte der Sonderausgabenabzüge nach § 10e EStG in Abhängigkeit von der Familiensituation

Grafik 14: Kumulierte Entlastungseffekte der Sonderausgabenabzüge nach § 10e EStG einschließlich Baukindergeld (§ 34f EStG) für eine Familie mit zwei Kindern nach der alten und neuen Regelung, beim Erwerb von Wohneigentum aus dem Bestand (Zeitwerte) 


\section{Problemstellung}

Die Nachfrage nach Wohnraum ist in den letzten Jahren erheblich gestiegen. Zur Erweiterung des Wohnungsangebotes und zur Sicherung des Wohnungsbestandes hat der Gesetzgeber auf die dadurch bedingte Verknappung, außer mit ordnungspolitischen Maßnahmen ${ }^{1}$, mit der Ausweitung bestehender bzw. Schaffung neuer finanzwirtschaftlicher Fördermaßnahmen innerhalb der Einkommensteuer reagiert. ${ }^{2}$ Außerdem wird der Erwerb selbstgenutzten Wohneigentums zusätzlich aus wohnungsbaupolitischen Gründen verstärkt gefördert. Die Wohnungsbaupolitik scheint erfolgreich zu sein. Im Jahr 1989, in dem die meisten Fördermaßnahmen beschlossen wurden, sind nur 238.617 Wohnungen fertiggestellt worden. ${ }^{3}$ Im Jahr 1993 waren es bereits 455.000 Wohnungen und für das Jahr 1994 wird mit einer weiteren Steigerung der fertiggestellten Wohnungen $^{4}$ gerechnet. $^{5}$

Die meisten Maßnahmen zur Förderung des privaten Wohnungsbaus und zur Förderung des Erwerbs selbstgenutzten Wohneigentums werden im Rahmen der Einkommensteuer eingesetzt. Der Subventionsbericht beziffert das Subventionsvolumen allein der Einkommensteuervergünstigungen 1991 auf ca. 7 Mrd. DM. ${ }^{6}$

1 Beispielsweise Mietrechtsänderungen und Baulandpolitik.

2 Daneben gibt es die Fördermaßnahmen im sogenannten Sozialen Wohnungsbau. Im Gegensatz zu den Maßnahmen in der Einkommensteuer besteht auf diese Fördermittel kein Rechtsanspruch. Die Vergabe der Mittel erfolgt in den einzelnen Bundesländern jährlich variierend nach eigenen Kriterien für relativ eng abgegrenzte Zielgruppen. Zu den Maßnahmen vgl. Die Finanzierungshilfen des Bundes, der Länder und der internationalen Institutionen, in: Zeitschrift für das gesamte Kreditwesen, Sonderausgabe, Heft 2, 1993/94.

3 Vgl. Statistisches Bundesamt, Statistisches Jahrbuch 1993, Wiesbaden 1993.

4 Vgl. Gewos, Institut für Stadt-, Regional- und Wohnforschung, zitiert nach: FAZ vom 11. Februar 1994, S. 43.

5 Diese Steigerung dürfte allerdings nicht nur den Fördermaßnahmen zuzuschreiben sein, sondern beruht auch auf endogenen Marktfaktoren.

6 Für die gesamte Wohnungswirtschaft werden im gleichen Jahr Subventionen von insgesamt 23,053 Mrd. DM ausgewiesen. Vgl. Bericht der Bundesregierung über die Entwicklung der Finanzhilfen des Bundes und der Steuervergünstigungen für die Jahre 1989 bis 1992 (Dreizehnter Subventionsbericht), Bonn 1991. Diese Zahl dürfte bei weitem nicht den tatsächlichen Verhältnissen entsprechen, da quantitativ 
Die vorliegende Untersuchung möchte sich mit diesen einkommensteuerlichen Maßnahmen unter folgenden Aspekten beschäftigen:

- Es wird untersucht, wie die Einordnung der gezielten Fördermaßnahmen im System der Einkommensteuer zu beurteilen ist und wie diese Maßnahmen in Verbindung mit der allgemeinen Besteuerung der Aufwendungen und Erträge von Wohnimmobilien wirken.

- Bei der Wohnungsbau- und der Wohneigentumspolitik handelt es sich vornehmlich um Sozial- und Verteilungspolitik. Insbesondere bei der Wohneigentumspolitik wird deshalb betrachtet, ob die gezielten Fördermaßnahmen den an sie gestellten Anforderungen, aber auch allgemeinen verteilungspolitischen Erfordernissen genügen. ${ }^{1}$

- Die Förderung bedeutet für den Staat einen vorübergehenden oder endgültigen Verzicht auf Steuern. Es wird untersucht inwieweit die gesetzten Ziele mit einem effizienten Mitteleinsatz verfolgt werden.

- Außerdem ist der Wohnungsmarkt fiskalisch ein äußerst unergiebiger Markt. Das eigentliche Anliegen der Besteuerung von Einkünften ist fiskalischer Natur. Die letzte verfügbare Einkommensteuerstatistik $(1986)^{2}$ weist als veranlagte Summe der Einkünfte aus Vermietung und Verpachtung aber einen negativen Saldo (steuerliche Verluste) von insgesamt 32,62 $\mathrm{Mrd} . \mathrm{DM}^{3}$ aus. Das bedeutet, daß die Aufwendungen, die die Steuerpflichtigen geltend machen, die steuerlichen Bruttoeinkünfte in diesem Wirtschaftssektor übersteigen und daß der Staat durch die Zusammenfassung der Einkünfte aus Vermietung und Verpachtung mit den sonstigen Einkünften der Steuerpflichtigen mehr Steuern erstattet, als er einnimmt. Demgegenüber weist die Volkswirtschaftliche Gesamtrechnung für das gleiche Jahr eine positive Wertschöp-

bedeutende Teile der Subventionen wie die Befreiung der Mieten von der Umsatzsteuer, das zu geringe Aufkommen aus den einheitswertabhängigen Steuern, aber auch die Steuerbefreiung der Wertsteigerungen, verschiedene Abschreibungsvergünstigungen sowie die Befreiung der Nutzwerte selbstgenutzten Wohneigentums von der Einkommensteuer (umstritten) nicht erfaßt werden.

1 Die normativen Grundlagen der Wohnungsbau und der Wohneigentumspolitik können dabei außer acht gelassen werden. Die Ziele werden als vorgegeben akzeptiert.

2 Das ist gleichzeitig auch das letzte Jahr, in dem der Nutzwert des selbstgenutzten Wohneigentums bei allen Wohnungseigentümern erfaßt wurde.

3 Vgl. Statistisches Bundesamt, Finanzen und Steuern, Fachserie 14, Reihe 7.1, Einkommensteuer 1986, Wiesbaden 1991. 
fung im Bereich Vermietung und Verpachtung von 170,27 Mrd. DM aus. ${ }^{1}$ Die Untersuchung beschäftigt sich außer mit den oben genannten Aspekten auch mit diesem Phänomen.

\section{Abgrenzung des Untersuchungsgegenstandes und Aufbau der Arbeit}

Bei der Analyse der Wirkungen von Subventionen wird zwischen der formalen und der effektiven Inzidenz unterschieden. Bei der formalen Inzidenz betrachtet man die direkten Wirkungen von Subventionen beim Subventionsempfänger. Demgegenüber geht man bei der effektiven Inzidenz einen Schritt weiter und bezieht die Einflüsse der Subventionsgewährung auf die Märkte mit in die Betrachtung ein. Die Untersuchung beschränkt sich hauptsächlich auf die formalen Inzidenzwirkungen.

Bei der Wohnungspolitik muß zwischen der Wohnungsbau- und der Wohneigentumspolitik unterschieden werden. Ziel der Wohnungsbaupolitik ist die Sicherung und Erweiterung des Wohnraumangebotes. Die Marktmieten sollen dadurch unter dem Niveau gehalten werden, das sich ohne Förderung einstellen würde, was letztendlich den Mietern zugute kommt. Der Gesetzgeber wählt hierzu die Objektförderung, indem die Vermieter subventioniert werden. Die Untersuchung beschränkt sich bei der Analyse der wohnungsbaupolitischen Maßnahmen auf diese direkten Vergünstigungen, die bei den Vermietern wirksam werden.

Bei Immobilieninvestitionen handelt es sich um komplementäre Investitionen in die Bebauung und in Grund und Boden. Von der staatlichen Wohnungsbauförderung sind deshalb neben den Mietern und den Investoren vor allem die Bodenbesitzer betroffen. ${ }^{2}$ Die Menge des bebaubaren Bodens ist im wesentlichen von politischen Entscheidungen abhängig. Eine verstärkte Wohnungs-

1 Nach Abzug der Vorleistungen, der Abschreibungen zu Wiederbeschaffungspreisen und der Kapitalkosten verbleibt eine Nettowertschöpfung ca. $30 \mathrm{Mrd}$. DM. Eigene Berechnung auf der Grundlage der VGR und den Statistiken der Deutschen Bundesbank.

2 Außerdem kommt eine Ausweitung der Bautätigkeit den Anbietern von Bauleistungen zugute. Dabei handelt es sich allerdings weitgehend um Konkurrenzmärkte, so daß Verteilungswirkungen über die auslastungsgradabhängigen sektorenspezifischen Gewinne nicht anfallen. 
bauförderung bedeutet zugleich auch eine Erhöhung der Nachfrage nach bebaubarem Boden. In Abhängigkeit von der Angebotselastizität des Bodens ${ }^{1}$ muß damit gerechnet werden, daß ein entsprechender Teil der Fördermittel in Baulandpreissteigerungen versickert, ohne im gewollten Umfang zur Vergrößerung des Wohnraumangebotes beizutragen. Mit anderen Worten heißt dies, daß ein Teil der Fördermittel auf die Bodenpreise überwälzt wird. Von diesen Verteilungswirkungen wird weitgehend abgesehen.

Die Wohneigentumspolitik verfolgt eigene Ziele. Hier geht es darum, breiten Schichten der Bevölkerung zu selbstgenutztem Wohneigentum zu verhelfen. Gefördert wurde deshalb bis vor kurzem der Erwerb von Wohnungen aus dem Bestand gleichermaßen wie die Neuerstellung selbstgenutzten Wohneigentums. Seit ein paar Jahren steht die Wohneigentumspolitik wieder verstärkt im Dienst der Wohnungsbaupolitik. Die Untersuchung beschränkt sich auch hier auf die direkten Subventionswirkungen. ${ }^{2}$

Im Umfang der Förderung ändert sich zunächst die Einkommensverteilung bzw. das persönlich verfügbare Einkommen der Geförderten. Wohnungsbaupolitik und Wohneigentumspolitik sind aber auch Vermögenspolitik. Wenn vor allem die Wohnungsbaupolitik nicht explizit so verstanden wird, hat sie doch auch immer Wirkungen auf die Verteilung des Neuvermögenszugangs. Die Wirkungen auf die Vermögensverteilung gehen weit über den Umfang der Fördermittel bzw. der direkten Subventionen hinaus. Sie unterscheiden sich von diesen zum einen durch induzierte Verhaltensänderungen der Geförderten, im wesentlichen durch Änderungen des Sparverhaltens, zum anderen durch zu erwartende Wertsteigerungen des geschaffenen Vermögens. Da Vermögen meist wiederum

1 Der Baulandbericht der Bundesregierung kommt zu dem Ergebnis, daß mit den derzeitig vorhandenen baureifen Grundstücken insgesamt nur ca. 2/3 des Wohnraumbedarfs gedeckt werden könnten. Vgl. Bundesministerium für Raumordnung, Bauwesen und Städtebau: Baulandbericht 1993, Bonn 1993, S. 47. Es kann allerdings nicht davon ausgegangen werden, daß dieses baureife Land tatsächlich den Wohnungsmärkten aktuell zur Verfügung steht, da sich das Halten von Bauland in den letzten Jahrzehnten als lukrative Kapitalanlage erwiesen hat, so daß das faktische Baulandangebot hinter dem theoretisch verfügbaren zurückbleibt.

2 Hier sind ebenfalls Teilüberwälzungen denkbar. So stellt die Förderung des Erwerbs gebrauchten Wohneigentums sicherlich in gewissem Umfang eine Preisstütze auf den Märkten für Gebrauchtimmobilien dar. 
Einkommen abwirft, bestehen Rückwirkungen aus der Vermögensverteilung auf die Einkommensverteilung. Von diesen Sekundärwirkungen wird abgesehen.

Steuerliche Wohnungsbauförderung und Wohneigentumspolitik finden im Rahmen des bestehenden Steuersystems statt. Als Förderung werden vom Gesetzgeber i.d.R. nur solche Maßnahmen verstanden, die von der allgemeinen Praxis der Besteuerung abweichen. Diese Besteuerungspraxis soll im folgenden als Normalbesteuerung bezeichnet werden. Das ursprüngliche Anliegen des Verfassers bestand darin, die Subventionen ebenfalls nur in diesem Sinne zu untersuchen. Wie sich aber herausstellte, kann das bestehende Steuersystem nicht als Nullinie der Subvention aufgefaßt werden, denn es enthält bereits Vergünstigungselemente, die mit in die Betrachtung aufgenommen werden müssen. Nur auf diese Weise können die vom Gesetzgeber gezielt eingesetzten Fördermaßnahmen abschließend beurteilt werden.

Die Besteuerung erfolgt originär aus fiskalischen Zielsetzungen. Die Praxis der Einkommensbesteuerung soll bestimmten in der Finanzwissenschaft entwickelten Grundsätzen entsprechen. Um eine steuersystematische Analyse vornehmen zu können, muß deshalb von den Grundsätzen der Einkommensbesteuerung ausgegangen werden. Abzüge von der Bemessungsgrundlage des zu versteuernden Einkommens, die auf den ersten Blick scheinbar die gleiche Wirkung haben, wie beispielsweise Aufwendungen für Schuldzinsen, können in einem Fall steuersystematisch berechtigt sein, in einem anderen Fall nicht. Das bestehende Steuersystem fußt zwar in der Finanzwissenschaft, erfährt aber seine konkrete Ausgestaltung durch politische Entscheidungen und durch die steuerjuristische Wissenschaft. Abweichend von den in der Finanzwissenschaft entwikkelten Grundsätzen werden ökonomische Tatbestände, wie beispielsweise die Erfassung des Nutzwerts selbstgenutzten Wohneigentums, in der steuerjuristischen Wissenschaft anders interpretiert. Deshalb soll auf unterschiedliche Ansichten kurz eingegangen werden.

Immobilien sind private Investitionen, bei denen die Aufwendungen und Erträge sich auf mittlere Sicht mindestens entsprechen müssen. Sie weisen aber einige Besonderheiten auf, die es schwierig machen, Aussagen über den Förderbedarf bzw. über die steuerlich relevanten Ertrags- und Aufwandskomponenten zu treffen. Gründe sind vor allem die Langfristigkeit der Kapitalbindung und das empirische Phänomen, daß sich Investoren zunächst einmal scheinbar mit einer niedrigeren Rendite zufrieden geben (müssen), als sie auf dem Kapitalmarkt 
erzielen können. Zur Beurteilung der Notwendigkeit und der Wirkungen staatlicher Subventionen ist es deshalb zunächst sinnvoll, die charakteristischen Eigenschaften von Investitionen in Wohnimmobilien unabhängig von der $\mathrm{Be}-$ steuerung kurz zu betrachten, um anschließend die Subventionen bzw. die Praxis der Besteuerung der Aufwendungen und Erträge einer kritischen Würdigung unterziehen zu können.

Entsprechend diesen Problemen gliedert sich die Untersuchung in vier Teile. Im ersten Teil werden die Grundlagen der Einkommensbesteuerung sowie die Charakteristika der Investitionen in Wohnimmobilien dargelegt. Außerdem wird in diesem Teil gezeigt, daß die Erträge von Wohnimmobilien innerhalb der Einkommensteuer höchst unterschiedlich behandelt werden. Darauf aufbauend werden im zweiten und dritten Teil der Untersuchung die Maßnahmen zur Förderung der Erstellung von Wohnraum und des Erwerbs selbstgenutzten Wohneigentums analysiert, wobei zugleich der jeweilige steuersystematische Hintergrund einer kritischen Würdigung unterzogen wird. Im vierten Teil werden die Ergebnisse zusammengefaßt. 


\section{Teil 1: Grundlagen}

\section{A. Charakteristischer Liquiditäts- und Renditeverlauf einer Immobilieninvestition}

Die Investition in Wohnimmobilien unterscheidet sich von sonstigen privaten Investitionen besonders durch die Länge der Kapitalbindung. Die Bebauung erbringt oft Erträge über mehrere Generationen. Der komplementäre Bodenanteil der Investition unterliegt keinem nutzungsbedingten Werteverzehr. Die einmalige Investition in den Grund- und Bodenteil kann Erträge erwirtschaften, die weit über die Nutzungsdauer des Gebäude hinausgehen. Aufgrund dieser langen Kapitalbindung unterliegen Immobilieninvestitionen besonders nominalen und realen Wachstumseinflüssen, was einen nicht unerheblichen Einfluß bei der Beurteilung ihrer Vorteilhaftigkeit hat.

Bei Investitionen wird zwischen dem Liquiditäts- und dem Rentabilitätsaspekt unterschieden. Bei der Liquiditätsbetrachtung wird auf den zeitlichen Anfall von Einnahmen- und Ausgabenströmen abgestellt. Demgegenüber stellt die Rentabilitätsbetrachtung die Rendite des eingesetzten bzw. gebundenen Kapitals in den Vordergrund.

\section{Liquiditätsverlauf}

Die Liquiditätszu- und -abflüsse, die ein Vermieter zu berücksichtigen hat, sind auf der einen Seite die Mieteinnahmen. Üblicherweise wird in privatrechtlichen Mietverträgen zwischen einer sogenannten Kalt- und einer Warmmiete unterschieden. D.h. der Vermieter enthält ein fixes Entgelt für die Überlassung der Wohnungsnutzung und zusätzlich ein verbrauchsabhängiges Entgelt für die Nebenkosten (Heizung, Wasser e.c.t.). Die verbrauchsabhängigen Nebenkosten stellen für den Vermieter aus ökonomischer Sicht nur einen durchlaufenden Posten dar. Sie sind für das Untersuchungsziel der Arbeit nicht relevant. ${ }^{1}$

1 Gleichwohl werden diese Kosten innerhalb der Besteuerung beim Vermieter als zu versteuernde Einnahmen erfaßt ( $8 \mathrm{EStG})$ Die Ausgaben, die der Vermieter damit bestreitet, werden im Gegenzug als Werbungskosten ( $9 \mathrm{EStG}$ ) berücksichtigt. Da sich die Beträge entsprechen, tangieren sie das steuerpflichtige Einkommen per saldo im Regelfall nicht. 
Außer diesen verbrauchsabhängigen Nebenkosten kann der Vermieter aber auch verschiedene Fixkosten, wie beispielsweise die Grundsteuer formal auf den Mieter überwälzen, so daß er auch diese bei seiner Liquiditäts- und Renditebetrachtung nicht zu berücksichtigen braucht, da den Zahlungsverpflichtungen ebenfalls Einnahmen in gleicher Höhe gegenüberstehen.

Weiter hat der Wohnungseigentümer zur Erhaltung der Ertragsquelle in gewissen Zeitabständen Instandhaltungsmaßnahmen durchzuführen. Sofern diese durch eine eigene Instandhaltungsrücklage angespart werden, wie es zumindest bei Wohneigentumsanlagen üblich ist, belastet die Rücklagenbildung die Liquidität im Zeitablauf relativ gleichmäßig. Die Rücklagenbildung bleibt, abgesehen von der Steuerpflicht der Zinsen, von der Einkommensteuer unberührt. Sie muß aus Nettoeinkommen vorgenommen werden und stellt zunächst Geldvermögensbildung dar. Sie bleibt deshalb in diesem Abschnitt außer acht. Die relevante Miete ist somit die sogenannte Kaltmiete, die im folgenden als Marktmiete bezeichnet wird. Für den Eigentümer selbstgenutzten Wohneigentums stellt diese Miete die Opportunitätsausgaben dar, die er als Mieter bestreiten müßte.

Empirisch kann ein Investor bzw. Selbstnutzer von Wohneigentum davon ausgehen, daß die zum Investitionszeitpunkt erzielbare Marktmiete (gesparte Mietaufwendungen) nicht für den gesamten Investitionszeitraum gilt, sondern daß er im Zeitablauf mit steigenden Marktmieten rechnen kann. So stiegen die Mieten in den letzten 20 Jahren pro Jahr durchschnittlich um 4,14 v.H. ${ }^{1}$ Weiterhin zeichnen sich Immobilieninvestitionen in Abhängigkeit von der Eigenkapitalquote (Eigenkapital/investiertes Kapital) dadurch aus, daß es in den ersten Jahren nicht zu einer vollen Deckung der Fremdkapitalkosten kommt. Die Kapitalverzinsung des gesamten investierten Kapitals, ermittelt als Relation der Mieteinnahmen im Verhältnis zum investierten Kapital, liegt bei einer Anfangsrendite von ca. 4 bis 5 Prozent. Der durchschnittliche Kapitalmarktzins für langfristige Kredite $^{2}$ lag ebenfalls in den letzten 20 Jahren bei 7,83 v.H. ${ }^{3}$ Bei einem hohem Fremdkapitalanteil übersteigen also die Ausgaben für den Kapital-

1 Eigene Berechnung, Daten entnommen aus: Sachverständigenrat zur Begutachtung der gesamtwirtschaftlichen Entwicklung, Jahresgutachten 1992/1993, Tabelle 83.

2 Da Immobilien langfristige Anlagen sind, stellt der langfristige Kapitalmarktzins aufgrund von Substitutionalitäten einen Vergleichsmaßstab dar.

${ }^{3}$ Eigene Berechnung, Daten entnommen aus: Sachverständigenrat zur Begutachtung der gesamtwirtschaftlichen Entwicklung, Jahresgutachten 1992/1993, Tabelle 6. 
dienst die Mieteinnahmen für einen längeren Anfangszeitraum. Dieser Sachverhalt ist mit Hilfe der dargestellten empirischen Daten ${ }^{1}$ in Grafik 1 abgebildet.

In der Grafik 1 sind den Mieteinnahmen pro Quadratmeter Wohnraum die Aufwendungen für den Kapitaldienst gegenübergestellt. Es wurden Gestehungskosten von 3.500 DM pro Quadratmeter zugrundegelegt. Ausgehend von einer Anfangsmiete von $13 \mathrm{DM}$ verdoppeln sich die Mieteinnahmen im Zeitraum von ca. 17 Jahren. Diesen Einnahmen sind die Ausgaben für die Fremdkapitalkosten bei einer 100-prozentigen Fremdfinanzierung gegenübergestellt. Wird das Darlehen nicht getilgt, so entsteht ca. in den ersten 15 Jahren, bis zum Zeitpunkt $\mathrm{T} 1$, eine liquiditätsmäßige Unterdeckung. Wie sich bei der anschließenden Renditebetrachtung ergibt, sollte nicht von einem Verlust gesprochen werden. Mit zunehmendem Eigenkapitalanteil verliert der Sachverhalt der liquiditätsmäßigen Unterdeckung an Bedeutung. Wird die Immobilie nur mit Eigenkapital finanziert, besteht keine Liquiditätsbelastung, und der Investor gibt sich zunächst mit einer gegenüber dem Kapitalmarktzins niederigeren Verzinsung zufrieden.

Für den Selbstnutzer von Wohneigentum stellen diese ersten Jahre, in Abhängigkeit vom vorhandenen Eigenkapital und vom Einkommen, die zentrale, oft unüberwindbare Hürde dar. Die Mieteinnahmen, die in Grafik 1 dargestellt werden, entsprechen seinen alternativen Belastungen, die er als Mieter für ein gleichartiges Objekt zu tragen hätte. Die Differenz zu dem Kapitaldienst kann der Durchschnittsverdiener bei geringem Eigenkapital oft nur schwer aufbringen.

Sowohl bei der Förderung der Erstellung neuen Wohnraums als auch bei den wohneigentumspolitischen Fördermaßnahmen setzt der Staat an den anfangs hohen Liquiditätsbelastungen an. Ziel ist es, mit Hilfe einer im Zeitablauf im Regelfall degressiv ausgestalteten Förderung die liquiditätsmäßige Unterdeckung in den ersten Jahren zu verringern.

1 Es erscheint vielleicht nicht unmittelbar plausibel, die historischen Daten für die zukünftige Entwicklung im Sinne einer Trendextrapolation zugrundezulegen. Doch soll damit keine Prognose erstellt werden, es sollen vielmehr langfristige Zusammenhänge aufgezeigt werden. 


\section{Grafik 1}

Charakteristischer Verlauf der Liquiditätsbelastung einer Wohnimmobilie; monatliche Mieteinnahmen und Ausgaben für Zinsen pro Quadratmeter Wohnraum

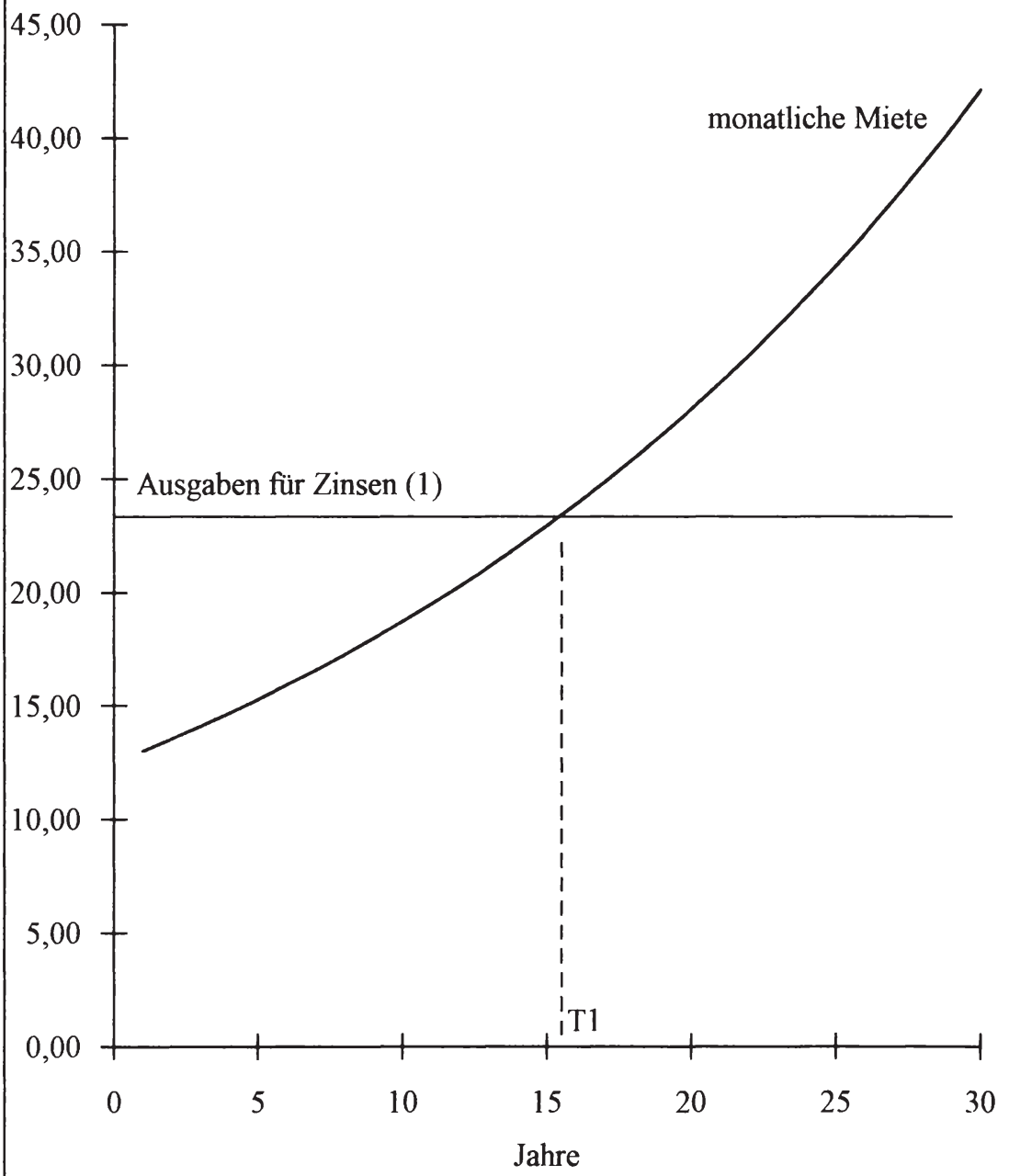

(1) Tilgungsfreie Hypothek in Höhe des ursprünglich eingesetzten Kapitals 
Wohnimmobilien können sehr unterschiedlich finanziert werden. Die Besteuerung wirkt sich, wie sich noch zeigen wird, auf die Wahl der Finanzierung keineswegs neutral aus. Ein tilgungsfreies Hypothekendarlehen, wie dies in Grafik 1 zugrundegelegt wurde, ist in Deutschland nicht üblich. ${ }^{1}$ Ein Finanzierungsinstrument, das in der Praxis breite Anwendung findet, ist das sogenannten Annuitätendarlehen. Es zeichnet sich dadurch aus, daß bei im Zeitablauf konstanter nominaler Liquiditätsbelastung in zunehmendem Maße Tilgungsleistungen erbracht werden. Zum Zeitpunkt der Investition wird ein Kapitaldienst, bestehend aus den Kapitalkosten in Höhe der Zinsen, zuzüglich einer Anfangstilgung (zusammen die Annuität) festgelegt. In Abhängigkeit vom Tilgungssatz liegt nun die Liquiditätsbelastung über der vergleichbaren Belastung der reinen Kapitalkosten. Dadurch, daß die Tilgungsleistungen periodisch auf die sich jeweils ergebende Restschuld angerechnet werden, sinkt der Zinsanteil der Annuität und der Tilgungsanteil nimmt bei konstanter Annuität im Zeitablauf zu. Dieser Sachverhalt ist in Grafik 2 abgebildet. Bei einem Zinssatz von 8 v.H. und einem Anfangstilgungssatz von 1 v.H. ist das Darlehen im 28. Jahr getilgt (Tilgungsverrechnung zum Quartalsende). Im Gegensatz zum tilgungsfreien Hypothekendarlehen liegt die Liquiditätsbelastung zwar höher, doch kommt es im Umfang der Tilgung bei wenigstens nominal konstanten Immobilienwerten zur Vermögensbildung.

Dies ist ein Aspekt, der besonders bei der Wohneigentumsförderung als Instrument der Vermögenspolitik von Interesse ist. In der Darstellung in Grafik 2 wird sichtbar, daß die Liquiditätsbelastung des Wohneigentümers zwar bis zum Zeitpunkt T2 über der vergleichbaren Belastung der Marktmiete bleibt, daß es aber von Anfang an zur Vermögensbildung kommt. Diese gewinnt im Zeitablauf zunehmend an Bedeutung. Ab dem Zeitpunkt T1 übersteigt der Tilgungsanteil der Annuität die Mehrbelastung, die der Wohneigentümer gegenüber dem Mieter bzw. gegenüber der Situation als Mieter hat. Ab dem Zeitpunkt T2 liegt die Liquiditätsbelastung des Wohneigentümers sogar unter der vergleichbaren Belastung des Mieters, bei im Zeitablauf weiter zunehmendem vermögensbildenden Anteil an den Ausgaben. T1 und T2 hängen von der Höhe des Fremdkapitalanteils, vom Zinssatz und von der Entwicklung der Mieten ab.

1 Die meisten Banken bestehen aus Gläubigerschutzgründen auf eine mindestens einprozentige Anfangstilgung für den Teil des Darlehens, der den sogenannten Realkredit (60 v.H. des Marktwertes) übersteigt. 


\section{Grafik 2}

Charakteristischer Verlauf der Liquiditätsbelastung einer Wohnimmobilie; monatliche Mieteinnahmen und Ausgaben für den Kapitaldienst pro Quadratmeter Wohnraum (1)
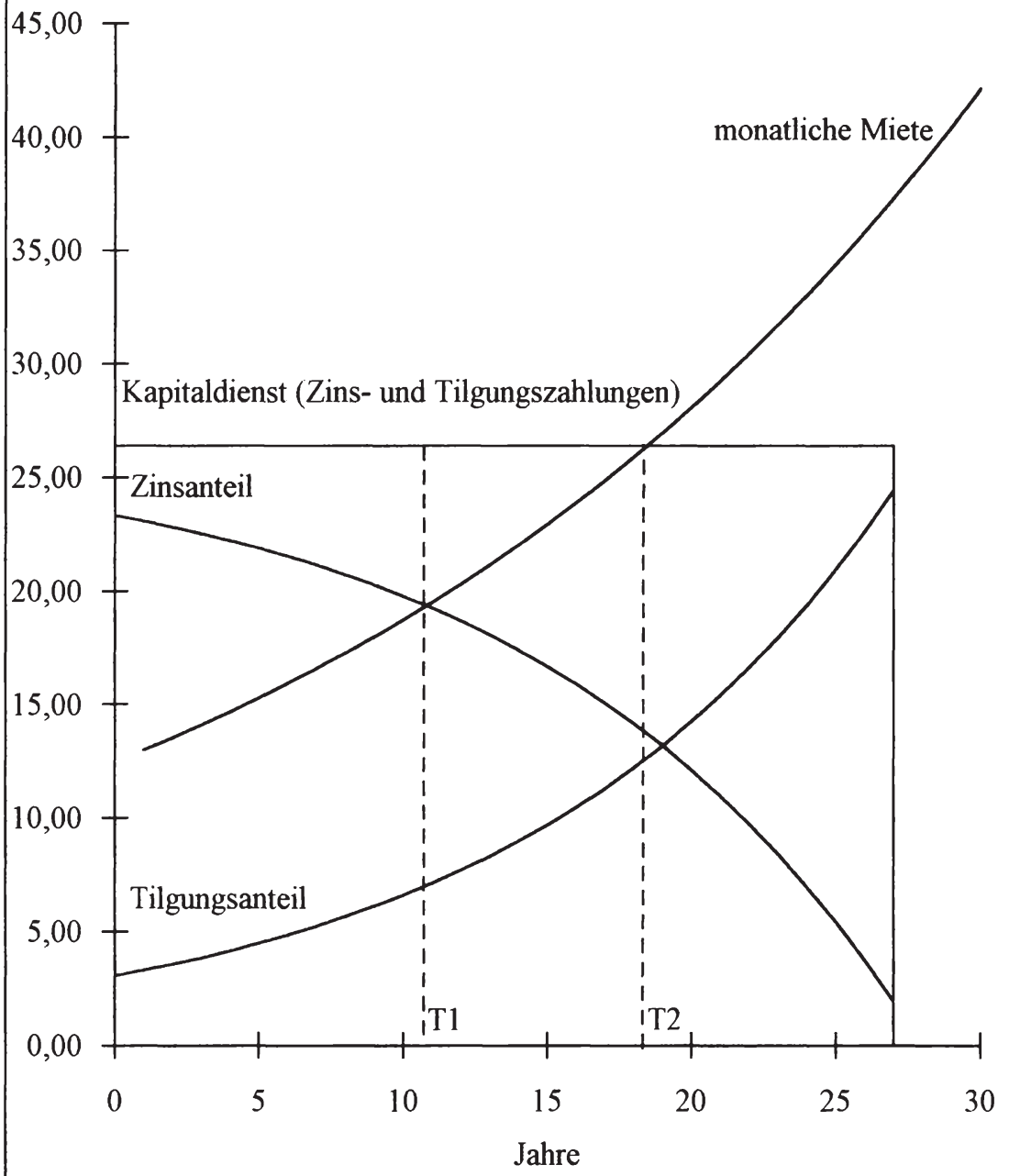

(1) Finanzierung über Annuitätendarlehen 
Je geringer die Verschuldung und der Zinssatz ist und je schneller die Mieten steigen, desto früher treten diese Zeitpunkte ein. Die Wohnungsbaupolitik und vor allem die Wohneigentumspolitik sind umso wirksamer, je mehr sie die Liquiditätsbelastung in den ersten Jahren senken, da dadurch der Kreis der potentiell Geförderten vergrößert wird.

\section{Renditeverlauf}

Eine Liquiditätsbetrachtung kann keinen Aufschluß über die Vorteilhaftigkeit von Investitionen geben. Dazu ist eine Renditebetrachtung notwendig. Bei dieser stehen nicht die Einnahmen und Ausgaben, sondern die Kosten und Erträge im Vordergrund der Betrachtung. Diese Kategorien unterscheiden sich dadurch, daß nicht allen Erträgen Liquiditätszuflüsse entsprechen, wie dies z.B. bei Wertsteigerungen der Fall ist, und nicht allen Aufwendungen Ausgaben entsprechen, wie dies bei den Abschreibungen aber auch kalkulatorischen Eigenkapitalzinsen gegeben ist.

Bei einer Renditebetrachtung muß der Nettoertrag einer Periode ins Verhältnis zum in der jeweiligen Periode gebundenen Kapital gesetzt werden. Der Nettoertrag ergibt sich als Saldo zwischen den Mieteinahmen und etwaigen Wertsteigerungen einerseits und den Zinsausgaben, der kalkulatorischen Verzinsung des gebundenen Eigenkapitals und vorzunehmender Abschreibungen andererseits. Das gebundene Kapital unterscheidet sich vom historisch investierten Kapital um die bis zur Betrachtungsperiode vorgenommenen $\mathrm{Zu}$ - und Abschreibungen.

An dieser Stelle stößt man bei Wohnimmobilien auf ein empirisch sonst selten anzutreffendes Phänomen. Einerseits ist die Nutzungsdauer der Bebauung endlich, so daß die historischen Gestehungskosten der Bebauung über einen bestimmten Zeitraum abgeschrieben werden müssen. Andererseits zeichnen sich Immobilien empirisch häufig dadurch aus, daß die komplementäre Investition in die Bebauung und in den Grund und Boden zum Teil bedeutende Wertsteigerungen erfährt, die als Teil der Rendite betrachtet werden müssen. Diese Wertsteigerungen sind zum Teil nominaler, zum Teil aber auch realer Natur. Ebenso wie die zukünftige Entwicklung der Mieten sind sie für den Investor zum Investitionszeitpunkt schwer abschätzbar. Kurzfristig besteht keine Garantie, daß sie überhaupt eintreten. 
Allerdings gibt es einige Anhaltspunkte für die relative Zuverlässigkeit von mittel- bis langfristig auftretenden Wertsteigerungen. Die Gründe für diese Wertsteigerungen sind für das Untersuchungsziel weniger von Bedeutung, doch soll deren Plausibilität kurz aufgezeigt werden.

Im Kapitalmarktzins kommen die Opportunitätskosten alternativer Vermögensanlagen zum Ausdruck. Da diese in nominalen Größen gemessen werden, ist es zweckmäßig, die Rendite von Immobilieninvestitionen ebenso nominal zu betrachten, zumal die Besteuerung an nominalen Größen ansetzt. ${ }^{1}$

Wertsteigerungen können auftreten, wenn ein Kosten- und/oder Nachfragedruck vorhanden ist. Ein Kostendruck kann nur durch Kostensteigerungen auf den Märkten für Bauleistungen auftreten und nur den Gebäudeteil der Investition betreffen. Ausgehend von einem ausgeglichenen Wohnungsmarkt, d.h. einem Wohnungsmarkt, auf dem Angebot und Nachfrage nach Wohnraum bei stabilen Preisen im Gleichgewicht sind, kann dieses Gleichgewicht nur dann gehalten werden, wenn die Abschreibungen, die in einer Periode anfallen, reinvestiert werden, da ansonsten das Wohnungsangebot abnimmt. Die Reinvestition kann laufend an bestehenden Gebäuden vorgenommen werden oder auch durch einmaligen Ersatz erfolgen. Dazu muß auf den Markt für Bauleistungen zurückgegriffen werden. Sofern der Produktivitätsfortschritt in der Baubranche nicht über den Produktivitätsfortschritten in den anderen Wirtschaftssektoren liegen, müssen die Preise für Bauleistungen ebenfalls mit der allgemeinen Inflationrate steigen, wenn die Reallöhne der Beschäftigten in der Baubranche nach unten unelastisch sind. Empirisch stiegen die Kosten in der Baubranche in der Nachkriegszeit allerdings durchschnittlich um ca. 2 v.H. schneller als die sonstigen privaten Lebenshaltungskosten, ${ }^{2}$ so $\mathrm{da} ß$ in der Vergangenheit von realen Baukostensteigerungen auszugehen war. Dies lag daran, daß der Produktivitätsfortschritt in dieser Branche unterhalb des durchschnittlichen volkswirtschaftlichen Produktivitätsfortschritts lag. ${ }^{3}$

1 Das Nominalwertprinzip und seine Auswirkungen auf die Besteuerung sind allerdings in der späteren Betrachtung der Abschreibungen bzw. der Abschreibungsvergünstigungen mit zu berücksichtigen.

2 Vgl. Eekhoff, J., Wohnungs- und Bodenmarkt, Tübingen 1987, S. 78. Eekhoff hat seiner Analyse den Zeitraum von 1945 bis 1986 zugrundegelegt. Er kam für einzelne Dekaden zu stark unterschiedlichen realen Preissteigerungen.

3 Vgl. Eekhoff, J., Wohnungs- und Bodenmarkt, a.a.O., S. 78. 
Steigen die Mieten nicht mindestens um diese Raten, würde das Wohnraumangebot abnehmen, da es nicht mehr rentabel wäre, die anfallenden Abschreibungen auf dem Wohnungsmarkt zu reinvestieren. ${ }^{1}$ Für die Bewertung des vorhandenen Wohnraumbestandes heißt dies, daß er als Substitut neu zu erstellenden Wohnraums, unter Berücksichtigung der jeweils kürzeren Restnutzungszeiten entsprechend der Entwicklung seiner Reproduktionskosten bewertet wird, so daß der Gebäudeteil der Investition wenigstens nominale, u.U. auch reale Wertsteigerungen erfährt.

Für die Entwicklung des Bodenwertes gelten weniger angebotsseitige als nachfrageseitige Argumente. Dem Grund und Boden stehen volkswirtschaftlich keine Kosten gegenüber. Von dieser Seite sind Wertsteigerungen nicht erklärbar. Trotzdem haben sich die Preise für unbebauten Boden in den letzten 30 Jahren verzehnfacht. ${ }^{2}$ Die Ursachen sind in einer (zum Teil künstlichen) Knappheit zu suchen. Bebaubarer Boden ist regional nicht in beliebigem Umfang vermehrbar bzw. wird durch die Baulandpolitik knapp gehalten. Sofern die Wirtschaftssubjekte bei nominalen Einkommenserhöhungen nicht einer Geldillusion unterliegen und bereit sind, wenigstens den gleichen Anteil des inflationär aufgeblähten Einkommens für Mieten auszugeben, wächst der Bodenpreis mindestens mit der Inflationsrate. Je mehr die Wirtschaftssubjekte darüber hinaus bereit sind, reale Einkommenszuwächse zugunsten von Wohnraum auszugeben, umso mehr fallen zusätzlich reale Wertsteigerungen beim Bodenanteil an. ${ }^{3}$

Insgesamt ergibt sich also, daß eine Betrachtung, bei der nur die Mieteinnahmen ins Verhältnis zum Investitionsvolumen gesetzt werden, die effektive Rendite der Investition nicht wiedergeben kann. Wertsteigerungen sind ex ante

1 Es gibt viele Volkswirtschaften, in denen der Staat aus "sozialen Motiven" die Mietpreise oft über Jahrzehnte eingefroren hat. Dies hat bei ansonsten steigenden Preisen zu Konsequenz, daß die Abschreibungen von privaten Besitzern nicht mehr reinvestiert werden. Da der Wohnungsbestand bis zur offensichtlichen Verrottung aber noch über Jahrzehnte nutzbar ist, treten die Konsequenzen dieser populistischen Politik ebenfalls erst nach Jahrzehnten in aller Deutlichkeit zu Tage.

2 Vgl. Statistisches Bundesamt, Fachserie 17, Reihe 5, 4. Quartal 1992. Die Preise für baureifes Bauland stiegen in Zeitraum von 1962 bis 1991 von 14,83 DM auf 125,41 DM pro Quadratmeter.

${ }^{3}$ Das heißt, daß die Einkommenselastizität der realen Wohnraumnachfrage größer als eins ist. 
mit einiger Plausibilität in das Investitionskalkül mit einzubeziehen. ${ }^{1}$ Allerdings sind diese sogenannten Marktlagengewinne kaum prognostizierbar, d.h. mit viel Unsicherheit behaftet. Wächst der Wert des Immobilienvermögens aber mindestens mit der Inflationsrate, so heißt dies, daß es für eine ausreichende Rendite genügen würde, wenn die Mieteinnahmen dem realen Zinssatz entsprechen würden. ${ }^{2}$ Faktisch würde dies bedeuten, daß im langfristigen Durchschnitt eine Nominalrendite (Mieteinnahmen/gebundenes Eigenkapital) von 3 bis 4 v.H. genügt.

Der Investor, der mit Eigenkapital finanziert, erzielt dann die gleiche Rendite wie der Anleger auf dem Kapitalmarkt. Für den Investor, der mit Fremdkapital finanziert, stellt sich allerdings in Abhängigkeit von der Fremdfinanzierungsquote das Problem der Liquiditätsbelastung, das im vorhergehenden Kapitel behandelt wurde. Allerdings kann er den Schuldnergewinn der Inflation verbuchen, da bei real konstantem Vermögenswert der reale Wert der Verschuldung abnimmt. Je mehr die Investoren zukünftige nominale und reale Wachstumsraten antizipieren und je mehr sie bereit sind, einen negativen Liquiditätssaldo in den ersten Jahren hinzunehmen, umso eher werden sie auch ohne Berücksichtigung der Besteuerung bereit sein, bei geringer Anfangsverzinsung des investierten Kapitals (Marktmieten/investiertes Kapital) zu investieren. ${ }^{3}$

\section{B. Grundlagen der Einkommensbesteuerung}

Der Staat bedient sich bei vielen Fördermaßnahmen des Steuerrechts. Daher ist es zunächst angebracht, sich über die wesentlichen, in der Finanzwissenschaft entwickelten und der deutschen Einkommensteuer zugrundeliegenden Steuerkriterien im klaren zu sein. Die Einkommensbesteuerung weicht allerdings aus

1 Außer Änderungen dieser endogenen Faktoren sind Änderungen exogener Nachfragefaktoren ebenfalls von Relevanz, wie etwa Bevölkerungsbewegungen oder Änderungen im Altersaufbau der Bevölkerung. Diese können die hier aufgezeigten Effekte verstärken, sie aber auch entgegengerichtet überlagern.

2 Vgl. Eekhoff, J., Wohnungs- und Bodenmarkt, a.a.O., S. 74ff.

3 Umgekehrt heißt dies für die Bewertung des Immobilienvermögens (besonders aber auch für die Bewertung des Baulandes als potentiellem Immobilienvermögen), daß die Immobilienpreise zu einem gegebenem Zeitpunkt um so höher sind, je mehr zukünftige Wertentwicklungen vom Markt erwartet und antizipiert werden. 
verschiedenen Gründen in manchen Punkten von diesen Kriterien ab, weshalb auf die Grundstrukturen der Praxis der deutschen Einkommensbesteuerung ebenfalls kurz eingegangen werden soll. Strittige Maßnahmen, die in der Untersuchung beleuchtet werden wie Abschreibungsvergünstigungen, die Steuerbefreiung der Nutzwerte selbstgenutzten Wohneigentums oder auch Sonderausgabenabzüge können sonst nicht gewürdigt werden.

Auf den ersten Blick erscheint es schwer möglich, in der gebotenen Kürze die theoretischen Grundlagen der Einkommensbesteuerung und die Struktur der deutschen Einkommensteuer darzulegen, ${ }^{1}$ doch gibt es einige zentrale Kriterien, deren Kenntnis für die Untersuchung genügt.

\section{Das Prinzip der Besteuerung nach der Leistungsfähigkeit}

Das originärste Anliegen der Besteuerung ist fiskalischer Natur. Der Staat benötigt Einnahmen zur Deckung der von ihm angebotenen Güter und Leistungen. Auf lange Sicht können diese nur durch die Erhebung von Steuern finanziert werden.

Jede Form der Besteuerung greift in die wirtschaftliche Dispositionsfreiheit der Besteuerten ein. Da die Besteuerung nicht ohne Rücksicht darauf erfolgen darf, welchen Beitrag der einzelne zur Finanzierung der Staatsleistungen erbringen kann, ist das Leistungsfähigkeitsprinzip ein zentraler Grundsatz der Besteuerung. Es besagt, daß die Besteuerung auf die Leistungsfähigkeit der Wirtschaftssubjekte Rücksicht nehmen muß. Dieses Grundprinzip der Besteuerung ist heute nicht nur in der finanzwissenschaftlichen Literatur von allgemeiner Gültigkeit, sondern hat auch in der aktuellen Steuerrechtsprechung der Bundesrepublik seinen Niederschlag gefunden. ${ }^{2}$

Das Leistungsfähigkeitsprinzip weist sowohl eine horizontale, als auch eine vertikale Komponente auf. Wirtschaftssubjekte mit gleicher Leistungsfähigkeit

1 Neumark arbeitet beispielsweise in seinem Werk "Grundsätze gerechter und okonomisch rationaler Steuerpolitik" 18 Grundsätze der Besteuerung aus. Vgl. Neumark, F., Grundsätze gerechter und ökonomisch rationaler Steuerpolitik, Tübingen 1970.

2 "Es ist ein grundsätzliches Gebot der Steuergerechtigkeit, daß die Besteuerung nach der wirtschaftlichen Leistungsfahigkeit ausgerichtet wird. "Vgl. Bundesverfassungsgericht, Urteil v. 22.2.1984, 1 BvL 10/80, in: BVerfGE 66, 214, 223. 
sollen in gleichem Umfang mit Steuern belastet werden (horizontale Komponente), und Wirtschaftssubjekte mit einer höheren Leistungsfähigkeit sollen höher belastet werden als Wirtschaftssubjekte mit geringerer Leistungsfähigkeit (vertikale Komponente).

Das Einkommen gilt heute als "das weitestgehend akzeptierte Maß der Leistungsfahigkeit". ${ }^{1}$ In modernen Volkswirtschaften ist es daher die zentrale Grundlage der staatlichen Mittelbeschaffung. Die Probleme liegen einmal in der Frage, was zum Einkommen zählt und somit in die Bemessungsgrundlage des zu versteuernden Einkommens eingehen soll. Auf dieser Ebene der Diskussion wird nach den Determinanten der objektiven Leistungsfähigkeit gefragt. Zum anderen stellt sich das Problem, inwieweit bei grundsätzlich gleicher objektiver steuerlicher Leistungsfähigkeit, persönliche Lebensumstände sowie spezifische Formen der Einkommensverwendung zu berücksichtigen sind. Auf dieser Ebene geht es um die Frage der Ermittlung einer persönlichen oder subjektiven Leistungsfähigkeit. ${ }^{2}$

1 Vgl. Musgrave, R.A. u.a., Die öffentlichen Finanzen in Theorie und Praxis, 2. Band, 4. Aufl., Tübingen 1988, S. 19. In der jüngeren finanzwissenschaftlichen Literatur wird in zunehmendem Maße auch die umstrittene Auffassung vertreten, daß die Konsumausgaben eines Wirtschafssubjektes das geeignete Maß für die Leistungsfähigkeit seien, da in ihnen zum Ausdruck komme, was sich ein Wirtschaftssubjekt leisten könne. Nach dieser Auffassung sollten nur der persönliche Konsum besteuert werden und die Ersparnisse steuerfrei bleiben. Diese Ansicht wird häufig im Zusammenhang mit dem ebenfalls umstrittenen Argument vertreten, $\mathrm{da} \beta$ dies für das Wirtschaftswachstum förderlich sei. Zur theoretischen Konzeption eines konsumorientierten Steuersystems vgl. Peffekoven, R., Persönliche allgemeine Ausgabensteuer, in H.d.F. Bd. II, 3. Aufl., Tübingen 1980, S. 418ff. Dieser Ansatz kann in der Untersuchung außer acht gelassen werden, da die Beurteilung der Maßnahmen innerhalb der Einkommensteuer aus deren systemimmanenten Logik heraus möglich ist, ohne daß die Wertgrundlagen der Einkommensteuer in Frage gestellt werden.

2 Vgl. Neumark, F., a.a.O., S. $121 \mathrm{ff}$. 


\section{Determinaten einer objektiven Bemessungsgrundlage der Einkommensteuer}

Die Definition des Einkommens ist eine Frage der Zweckmäßigkeit. ${ }^{1}$ Da das Einkommen bestimmt werden soll, das der Leistungsfähigkeit zum Zweck der Besteuerung entspricht, ist der Einkommensbegriff so weit $\mathrm{zu}$ fassen, daß alle Tatbestände, die der Bedürfnisbefriedigung dienen, eingeschlossen sind. ${ }^{2}$ Es ist jeder Zuwachs an "ökonomischer Dispositionskraft" ${ }^{\text {"3 }}$ zu erfassen - unabhängig davon, ob dieser Zuwachs periodisch wiederkehrend oder einmalig ist, ob er auf einem Marktvorgang beruht oder nichtpekuniär beispielsweise in Form der Selbstnutzung von Realvermögen anfällt. Neben dieser sogenannten "Reinvermögenszugangstheorie" ${ }^{4}$ wird in der "Quellentheorie" ${ }^{\text {s }}$ der Standpunkt vertreten, Einkommen stelle nur das dar, was regelmäßig wiederkehrend aus einer bestimmten Quelle fließe. ${ }^{6}$ Die Unterschiede zwischen diesen beiden Theorien beschränken sich zentral auf diesen Aspekt. Gemeinsam ist ihnen die Auffassung, daß nicht nur pekuniäre Erträge, sondern auch die Nutzung von eigenen oder von Fremden überlassenen Gütern die Leistungsfähigkeit erhöht. ${ }^{7}$ Ein Aspekt, der besonders bei der Diskussion um die Steuerbefreiung der Nutzwerte selbstgenutzten Wohneigentums zu diskutieren sein wird. Die Entscheidung für einen dieser Einkommensbegriffe hat über diesen Einzelfall hinaus für die konkrete Ausgestaltung einer Einkommensteuer große Tragweite.

1 Vgl. Andel, N., Einkommensteuer, in: H.d.F. Bd. II, 3. Aufl., Tübingen 1980, S. 334.

2 Vgl. Haller, H., Die Steuern, 2. Aufl., Tübingen 1974, S. 44.

3 Vgl. Neumark, F., a.a.O., S. $121 \mathrm{ff}$.

4 Die Reinvermögenszugangstheorie wird G.v. Schanz zugeschrieben. Vgl. Schanz, G.v., Der Einkommensbegriff und die Einkommensteuergesetze, in: Finanzarchiv 13. Jg., Tübingen 1896.

5 Die Quellentheorie wird B. Fuisting zugeschrieben. Vgl. Fuisting, B., Die Preußischen direkten Steuern, 4. Bd., Grundzüge der Steuerlehre, Berlin 1902, S. 110 u. $144 \mathrm{ff}$.

6 Zur Gegenüberstellung dieser Standpunkte vgl. Andel, N., Einkommensteuer, a.a.O., S. 335ff.

7 Schanz rechnet neben den heute gängigen Einkünften sowie der steuerlichen Erfassung unrealisierter Wertsteigerungen von Vermögensgegenständen insbesondere auch alle Nutzwerte zum steuerlichen Einkommen. Vgl. Schanz, G.v., a.a.O., S. 7 u. 24. Aber auch Fuisting erwähnt ausdrücklich die Notwendigkeit der steuerlichen Erfassung von Nutzwerten. Vgl. Fuisting, B. a.a.O., S. 112. 
Der quellentheoretische Besteuerungsansatz wird in der heutigen Finanzwissenschaft als veraltet angesehen. Da er aber auf die Ausgestaltung des aktuellen Steuerrechts noch Einfluß hat, kann über ihn nicht hinweggesehen werden. Entscheidet man sich für die Quellentheorie als adäquatem Maßstab für die Ermittlung des zu versteuernden Einkommens, so werden nur Stromgrößen (Löhne, Zinsen, Dividenden und Mieten) besteuert und dies auch nur dann, wenn es sich um regelmäßig wiederkehrende Erträge handelt. Insofern ist diese Theorie als Grundlage der Einkommensteuer nur schwer tauglich, da sie bei enger Auslegung beispielsweise keine Besteuerung von Gewinnen zuläßt (mangelnder kontinuierlicher Zufluß). ${ }^{1}$

Der Einkommensbegriff der Reinvermögenszugangstheorie ist demgegenüber weiter gefaßt. Er differiert von den oben beschriebenen Einkommensformen im wesentlichen bei der Erfassung von Vermögenswertänderungen. Da bei konsequenter Anwendung dieser Theorie gerade auch nicht realisierte Wertzuwächse in die Bemessungsgrundlage des zu versteuernden Einkommens eingehen, bezeichnet Musgrave den Einkommensbegriff auch als "Reinvermögenszuwachs". ${ }^{2}$

Aus historischen Gründen, ${ }^{3}$ aber auch aus Gründen der Praktikabilität hat sich der Gesetzgeber in Deutschland nicht konsequent für eine dieser beiden Theorien zur Bestimmung des Einkommens entschlossen. In der steuerjuristischen Literatur wird die Lehrmeinung vertreten, daß dem konkreten deutschen Einkommensteuerrecht ein "Markteinkommensbegriff"4 zugrundeliegt," welcher allerdings relativ eng an die Reinvermögenszugangstheorie angelehnt sei. Die Markteinkommenstheorie definiert als Einkommen den "erwirtschafteten und realisierten Reinvermogenszugang, d.h. alle Einkünfte aus einer Erwerbstätigkeit, die mit Gewinn-/Überschußabsicht erwirtschaftet worden sind". ${ }^{6}$

1 Vgl. Becker, H., Finanzwissenschaftliche Steuerlehre, München 1990, S. 349.

2 Vgl. Musgrave, R.A. u.a., a.a.O., S. 152ff.

3 Zur historischen Entwicklung vgl. Tipke, K./Lang, J., Steuerrecht, Ein systematischer Grundriß, 13. Auflage, Köln 1991 S. 199ff.

4 Dieser Begriff wird auf W. Roscher zurückgeführt. Vgl. Roscher, W., System der Volkswirtschaft, Bd. 1: Grundlagen der Nationalökonomie, 1883, § 144.

5 Vgl. Tipke, K./Lang, J., a.a.O., S. 200ff.

6 Vgl. Tipke, K./Lang, J., a.a.O., S. 202. 
Die Vorteile bestehen im wesentlichen darin, daß sich diese Einkommensteile relativ gut erfassen lassen. Aus finanzwissenschaftlicher Sicht ist diese Definition jedoch in zweierlei Hinsicht unbefriedigend. Zum einen werden nur Faktoren berücksichtigt, die auf einem Marktvorgang beruhen, ein Sachverhalt, der insbesondere wiederum bei der Frage um die Erfassung der Nutzwerte selbstgenutzten Wohneigentums von Bedeutung ist. Unbefriedigend ist an dieser Definition auch, daß Reinvermögenszugänge nur dann erfaßt werden sollen, wenn sie beabsichtigt sind, ein Argument, mit dem steuerjuristisch die Freistellung der Wertsteigerungen von der Einkommensteuer bei Immobilien des Privatvermögens begründet werden (vgl. Teil 1 C.1.). Der materielle Gehalt der deutschen Einkommensteuer ist aber insgesamt bei der Reinvermögenszugangstheorie angesiedelt, ${ }^{1}$ so laufen die Bestrebungen von Reformvorschlägen meist darauf hinaus, bestehende Diskrepanzen zum Ideal der Reinvermögenszugangstheorie abzubauen. ${ }^{2}$

Das Einkommensteuerrecht verzichtet allerdings auf eine allgemeine umfassende Einkommensdefinition und zählt statt dessen auf, was Einkünfte sind, und grenzt damit ab, was der Steuer unterliegt. Dabei wird zwischen sieben Einkunftsarten unterschieden ( $\S 2$ Abs. $1 \mathrm{EStG}$ ). Bei der Abgrenzung zwischen diesen Einkunftsarten blieb die Diskussion um die Reinvermögenszugangs- bzw. Quellentheorie aber nicht ohne Einfluß. Vereinfacht dargestellt ist die deutsche Einkommensteuerwelt in einen gewerblichen Bereich geteilt, in dem bei der Besteuerung in Anlehnung an die Reinvermögenszugangstheorie, und in einen Privatbereich, in dem in Anlehnung an die Quellentheorie vorgegangen wird.

Bei den gewerblichen bzw. Gewinneinkünften ( $\$ 2$ Abs. 2 Nr. 1 EStG) werden die zu versteuernden Einkünfte in enger Anlehnung an die handelsrechtliche Form der Gewinnermittlung erfaßt. Unter bestimmten Voraussetzungen werden die Erträge von Wohnimmobilien als Gewinne aus selbständiger Tätigkeit besteuert. Im wesentlichen geschieht dies durch einen Vergleich des Vermögensbestandes am Anfang und am Ende einer Rechnungsperiode. Die Differenz stellt die zu versteuernden Einkünfte dar. Wertzuwächse werden entsprechend der oben modifizierten Reinvermögenszugangstheorie (Markteinkommenstheorie), abweichend von der finanzwissenschaftlichen Reinvermögenszugangs-

1 Vgl. Musgrave, R.A. u.a., a.a.O., S. 139.

2 Vgl. Andel, N., Finanzwissenschaft, Tübingen 1983, S. 319. 
theorie, bei diesen Einkünften allerdings nur dann erfaßt, wenn sie realisiert werden, d.h. wenn der Vermögensgegenstand veräußert wird. Zusammen mit Bewertungsvorschriften, die u.a. aus Gläubigerschutzgründen im Zeitablauf zu einer systematischen Unterbewertung des Vermögens führen, bzw. der Möglichkeit, realisierte Wertsteigerungen (stille Reserven) auf andere Investitionsgüter zu übertragen ( $\S 6 \mathrm{~b} \mathrm{EStG}$ ), treten bei der Ermittlung der steuerpflichtigen Einkünfte, auch abweichend von der modifizierten Reinvermögenszugangstheorie, teilweise erhebliche Subventionselemente auf.

Die sogenannten Überschußeinkünfte ( $\$ 2$ Abs. 2 Nr. 2 EStG) werden in Anlehnung an die Quellentheorie erfaßt. Die Erträge von Wohnimmobilien werden als sogenannte Einkünfte aus Vermietung und Verpachtung im Regelfall dieser Einkunftsgattung zugerechnet. Hier wird zentral auf getätigte Ein- und Auszahlungen abgestellt. Die zu versteuernden Einkünfte errechnen sich hauptsächlich auf der Grundlage von Zahlungsströmen einer Periode, wobei auch hier seit dem 1.1.1986 nur auf Erträge abgestellt wird, die auf einem Marktvorgang beruhen. Insofern sind die Nutzwerte selbstgenutzten Wohneigentums seit diesem Zeitpunkt von der Einkommensteuer befreit. Wertsteigerungen bleiben bei den Einkünften aus Vermietung und Verpachtung sowohl in nicht realisierter als auch in realisierter Form steuerfrei.

Der gleiche ökonomische Sachverhalt kann bei den Erträgen von Wohnimmobilien, je nachdem zu welchen Einkünften sie gerechnet werden, zu höchst unterschiedlichen Steuerlasten führen. Dies verstößt auf den ersten Blick gegen das Prinzip der Gleichmäßigkeit der Besteuerung, ${ }^{1}$ das besagt, daß gleiche ökonomische Sachverhalte gleich besteuert werden sollen.

Das deutsche Steuerrecht beruht außerdem auf dem Prinzip der synthetischen Einkommensbesteuerung. Das bedeutet, daß die Summe aller Einkünfte eines Steuerpflichtigen Ausdruck der steuerlichen Leistungsfähigkeit ist und zur Bemessungsgrundlage des zu versteuernden Einkommens addiert wird. D.h. sie werden als Summe ohne Berücksichtigung ihrer theoretischen Zuordnung erfaßt und als Ganzes besteuert. Ergibt sich bei einer Einkunftsart ein negatives Einkommen, weil die Aufwendungen die Erträge (bei Gewinneinkünften) überschreiten bzw. die Einnahmen die Ausgaben (bei Überschußeinkünften),

${ }^{1}$ Zum Prinzip der Gleichmäßigkeit der Besteuerung, vgl. Neumark, F., a.a.O., S. $90 \mathrm{ff}$. 
wird dies als Minderung der steuerlichen Leistungsfähigkeit durch eine Minderung der Bemessungsgrundlage berücksichtigt. Der Saldo aus allen Einkunftsarten soll mithin die objektive Bemessungsgrundlage des zu versteuernden Einkommens darstellen. Dem Idealfall der Besteuerung, daß auf reale Größen abgestellt wird, ${ }^{1}$ da nur diese einen echten Vermögenszugang darstellen, genügt die bestehende Einkommensteuer nicht. Sofern Wertsteigerungen erfaßt werden, wird keine Rücksicht darauf genommen, inwieweit sie nominaler oder realer Natur sind. Das gleiche gilt für die Besteuerung der Stromgrößen (Mieten, Zinsen, Löhne, Gewinne), ein Umstand, der Bezieher von Vermögenseinkünften anders trifft als Bezieher von Nichtvermögenseinkünften (Löhne und Gewinne). Dieser Sachverhalt wird bei der Diskussion um die steuerliche Erfassung von Wertsteigerungen zu berücksichtigen sein.

Bei der folgenden kritischen Würdigung der steuerlichen Erfassung der Aufwendungen und Erträge von Wohnimmobilien sollte berücksichtigt werden, daß Minderungen der Bemessungsgrundlage, indem Einkommensteile steuerlich nicht bzw. nicht voll erfaßt werden, darauf hinauslaufen, daß andere Einkunftsarten bzw. Steuerpflichtige höher belastet werden müssen. Bei enger Anlehnung am theoretischen Idealkonzept der Einkommensteuer geht es also letztendlich nicht um eine Mehrung der Staatseinnahmen, sondern um Gleichheit in der Besteuerung.

\section{Die Berücksichtigung der persönlichen Lebensverhältnisse}

Der Leistungsfähigkeitsbegriff bezieht sich bei der Erfassung der Einkünfte nicht nur auf objektive Merkmale, welche unabhängig von den persönlichen Verhältnissen des Steuerpflichtigen sind. Bei der Einkommensbesteuerung wird auf die subjektive oder individuelle Leistungsfähigkeit abgestellt. Damit stellt sich das kontroverse Problem, inwieweit und in welchem Umfang Umstände aus dem persönlichen Bereich bzw. spezifische Formen der Einkommensverwendung berücksichtigt werden sollten. Allgemein herrscht heute die Auffassung vor, daß die Familiensituation bei der Besteuerung mit berücksichtigt werden soll. Die dafür eingesetzten Instrumente bestehen im wesentlichen aus dem Splittingverfahren und den Kinderfreibeträgen. Damit sollen Familien nicht

1 Aus stabilitätspolitischen - also aus nichtfiskalischen - Gründen kann dies anders zu beurteilen sein. 
subventioniert werden, vielmehr geht es um die Berücksichtigung der Anzahl von Personen, denen ein Markteinkommen zuzurechnen ist bzw. um die Berücksichtigung einer verminderten steuerlichen Leistungsfähigkeit von Familien. Wie sich bei der Analyse der wohneigentumspolitischen Maßnahmen zeigen wird, kollidieren diese zum Teil erheblich mit den Maßnahmen, die die Familiensituation bei der Besteuerung berücksichtigen sollen.

Inwieweit spezifische Formen der Einkommensverwendung zu berücksichtigen sind, wird bei der Analyse der wohneigentumspolitischen Maßnahmen ( $\S 10 \mathrm{e}$ EStG) näher diskutiert werden.

\section{Das Prinzip der progressiven Einkommensbesteuerung}

Wie schon erwähnt, weist die Besteuerung nach dem Leistungsfähigkeitsprinzip neben einer horizontalen Komponente auch eine vertikale auf. Diese vertikale Komponente sagt zunächst nur aus, daß Steuerpflichtige mit höherem Einkommen und damit höherer Leistungsfähigkeit auch eine höhere Steuerlast tragen sollen.

Als adäquates Mittel zur Berücksichtigung der vertikalen Leistungsfähigkeit wird die progressive Einkommensbesteuerung gesehen. Sie ist ebenso wie das Leistungsfähigkeitsprinzip ein nahezu unumstrittenes Postulat in der Literatur. Die progessive Einkommensbesteuerung leitet sich unmittelbar aus Grenznutzenüberlegungen $a b$. Es wird davon ausgegangen, daß der Grenznutzen des Einkommens, definiert als das subjektive Nutzenempfinden einer zusätzlichen Einkommenseinheit, mit zunehmendem Einkommen sinkt. Im allgemeinen wird daraus gefolgert, daß mit zunehmendem Einkommen die jeweils letzte Einkommenseinheit höher besteuert werden kann als die jeweils vorhergehende Einkommenseinheit, ohne daß die relative Nutzeneinbuße zunimmt.

Das deutsche Steuerrecht versucht diesem Sachverhalt zur Zeit mit dem Steuertarif T90 gerecht zu werden. ${ }^{1} \mathrm{Zu}$ versteuernde Einkommen bis zu einem Betrag von 5.616 DM sind bei diesem Tarif steuerfrei. Damit soll dem Existenzmini-

1 Seit 1993 wird in den unteren Einkommensgruppen ein von diesem Tarif abweichender Tarif angewendet. Dieser hat für das Untersuchungsziel keine grundsätzliche Bedeutung. Wie sich aber zeigen wird, kollidieren diese Maßnahmen wiederum zum Teil erheblich mit wohneigentumspolitischen Maßnahmen. 
mum Rechnung getragen werden. Zwischen einem zu versteuernden Einkommen von 5.616 DM und 8.104 DM betragen die Grenzsteuersätze ${ }^{1} 19$ v.H. Danach steigen sie linear progressiv bis zu einem Einkommen von 120.000 DM bis auf 53 v.H. an. Einkommen von über 120.000 DM werden marginal konstant mit 53 v.H. besteuert. Die Durchschnittssteuersätze, definiert als Relation von zu zahlender Gesamtsteuer und zu versteuernden Einkommen, bleiben hinter den Grenzbelastungen relativ weit zurück. Bei einem zu versteuernden Einkommen von 120.000 DM beträgt der Durchschnittsteuersatz beispielweise im Grundtarif 34 v.H., bei Verheirateten 24 v.H. (Splittingtarif).

\section{Der Subventionsbegriff}

Für die vorliegende Untersuchung soll eine zu geringe Erfassung des Reinvermögenszugangs als Vergünstigung bzw. Subvention bezeichnet werden. Wird der periodische Reinvermögenszugang nicht in der Periode, in der er anfällt, erfaßt, sondern erst in späteren Perioden, so führt dies zu Subventionen in Form der zwischenzeitlich anfallenden Zinsen bzw. der gesparten Zinsausgaben. Ebenso sollen Minderungen der Steuerschuld als Subvention bezeichnet werden.

Das Zusammenwirken von Änderungen der Bemessungsgrundlage des zu versteuernden Einkommens und den Wirkungen der Progression ist von elementarer Bedeutung. So führt die Nichterfassung von Einkunftsteilen (bzw. von Reinvermögenszugängen) sowie Minderungen der Bemessungsgrundlage, die nicht auf entsprechenden Minderungen der Leistungsfähigkeit beruhen, immer zu progressionsabhängigen Subventionen, d.h. die Subventionen nehmen mit steigendem Einkommen zu.

Soweit dies nicht auf technische Gründe, mangelnde Erfaßbarkeit oder zu hohe Kosten der Steuererhebung (im Verhältnis zum Ertrag) zurückzuführen ist, kann dies im Regelfall nicht gerechtfertigt werden und führt zu einem Verstoß gegen den Grundsatz horizontaler und vertikaler Gleichheit.

${ }^{1}$ Steuersätze, die auf die jeweils letzte Einkommenseinheit zur Anwendung kommen. 


\section{Steuerliche Erfassung der Aufwendungen und Erträge von Wohnimmobilien im Privatvermögen}

\section{Wohnimmobilien im steuerlichen Privatvermögen}

Im vorangegangenen Abschnitt wurde bereits darauf hingewiesen, daß Wohnimmobilien je nach Nutzung bzw. steuersystematischer Einordnung eine unterschiedliche steuerliche Behandlung der Aufwendungen und vor allem der Erträge erfahren.

Nach der Nutzung wird zwischen vermieteten und selbstgenutzten Objekten unterschieden. Selbstgenutzte Objekte werden seit dem 1.1.1987 im Normalfall von der Einkommensteuer nicht mehr tangiert. Sie gehören kraft Definition wie andere Konsumgüter in den Bereich der Einkommensverwendung. Bis zu diesem Zeitpunkt wurde die Selbstnutzung von Wohnungen - wenigstens prinzipiell - wie die Vermietung von Wohnungen behandelt, d.h. die Nettoerträge in Form der sogenannten Nutzwerte (vergleichbare Marktmiete) waren steuerpflichtig. Die Auseinandersetzung mit diesem Systemwechsel wird in Teil 3 A. gesondert Gegenstand der Untersuchung sein.

Das Vermieten von Wohnimmobilien wird normalerweise als sogenannte private Vermögensverwaltung aufgefaßt, was bedeutet, daß nur die Mieteinnahmen im Rahmen der Einkünfte aus Vermietung und Verpachtung ( $\S 2$ Abs. 1 Nr. 6 EStG), nicht aber die Wertsteigerungen der Besteuerung unterliegen. Die Ermittlung des steuerpflichtigen Ertrags erfolgt durch eine Überschußrechnung ( 2 Abs. 2 Nr. 2 EStG). Steuerpflichtig ist die Differenz zwischen den Mieteinnahmen und den Werbungskosten.

Werden Immobilien im Privatvermögen unabhängig vom quantitativen Umfang über einen längeren Zeitraum eigen- und/oder fremdgenutzt, stellen diese beiden geschilderten Fälle die Regel dar, sie liegen den Teilen B und C der Untersuchung zugrunde. Werden die Objekte allerdings nur für einen relativ kurzen Zeitraum genutzt, ergeben sich zwei Modifikationen, auf die aus Gründen der Vollständigkeit kurz einzugehen ist.

Liegen zwischen dem Zeitpunkt der Anschaffung und Veräußerung des Objektes weniger als zwei Jahre und ergeben sich in diesem Zeitraum Wertsteigerungen, sind diese als sogenannter Spekulationsgewinn ( $\$ 23$ Abs. 1 Nr. 1a EStG) steuerpflichtig. Diese Regelung betrifft eigen- und fremdgenutzte Objekte 
gleichermaßen. Liegt der Veräußerungspreis unterhalb der Anschaffungskosten, ergibt sich mithin ein Spekulationsverlust, kann dieser steuerlich nur insoweit geltend gemacht werden, als er mit anderen Spekulationsgewinnen des gleichen Kalenderjahres verrechnet werden kann ( $\$ 23$ Abs. 4 Satz 3 EStG).

Im Sinne eines rationalen Einkommensteuersystems ist diese Regelung aus zwei Gründen unbefriedigend. Die Erfassung eines realisierten Reinvermögenszugangs hängt weder von der zeitlichen Dauer ab, in der ein Vermögensobjekt gehalten wurde, noch ist es schlüssig, innerhalb des Zweijahreszeitraums auftretende Gewinne in die Bemessungsgrundlage der Einkommensteuer eingehen zu lassen, während dies für auftretende Verluste nur in eingeschränkter Form gilt. Umstände, die die steuerliche Leistungsfähigkeit tangieren und damit ohne Berücksichtigung außerfiskalischer Zielsetzungen in die Bemessungsgrundlage der Einkommensteuer eingehen sollten, tun dies unabhängig davon, ob es sich um einen Nettoertrag oder einen Nettoverlust handelt.

Die steuerlichen Erfassung des sogenannten Spekulationsgewinns als Ausnahme von der steuerlichen Nichterfassung von Wertsteigerungen, aber auch die Begrenzung des Abzugs von Spekulationsverlusten, sind wahrscheinlich nur historisch erklärbar und stoßen u.U. deshalb auf Akzeptanz, weil der Begriff der Spekulation mit einem negativen Wert behaftet ist. ${ }^{1}$ Die Regelung wird für die Praxis wenig Bedeutung haben, da die Besteuerung leicht umgangen werden kann. $^{2}$

Ein bedeutenderes Problem stellt die Abgrenzung der sogenannten privaten Vermögensverwaltung ${ }^{3}$ zum gewerblichen Grundbesitz dar. Abgesehen von

1 Aus nichtfiskalischen Erwägungen könnte diese Regelung u.U. dennoch gerechtfertigt werden, sofern bei häufigem kurzfristigem Eigentümerwechsel von negativen Auswirkungen auf den Grundstücks- und Wohnungsmarkt ausgegangen wird.

2 Sie dürfte nur bei Notverkäufen eine Rolle spielen bzw. schlecht beratene Veräußerer treffen. Es kommt allein darauf an, daß der schuldrechtliche Veräußerungsvertrag (auch Vorvertrag) frühestens am 1. Tag nach Ablauf von 2 Jahren nach dem Kaufvertrag, mit dem das Objekt erworben wurde, abgeschlossen wird. Vgl. Urteil des Finanzgerichts Köln vom 21.9.1988, in: EFG 1989, S. 114.

3 Es handelt sich hier um einen feststehenden Begriff aus der steuerjuristischen Literatur, der nicht sehr glücklich gewählt ist. Auch das Betriebsvermögen stellt in Abgrenzung zum Staatsvermögen im Regelfall Privatvermögen dar. Der Begriff der privaten Vermögensverwaltung ist wertbehaftet und suggeriert eine Sphäre steuerlicher Unantastbarkeit. 
gewerblichen Wohnungsbauunternehmen können auch Privatpersonen, die Wohnimmobilien als Vermögensanlage halten, unter bestimmten Umständen als Gewerbebetreibende besteuert werden. Die Erfassung der Aufwendungen und Erträge erfolgt dann auf der Basis einer Gewinnermittlung ( 2 Abs. 2 Nr. 1 EStG), d.h. durch einen Betriebsvermögensvergleich in Anlehnung an die modifizierte Reinvermögenszugangstheorie (nur realisierte Wertzuwächse werden erfaßt). Der zentrale Unterschied zur steuerlichen Behandlung von Wohnimmobilien im Privatvermögen besteht darin, daß realisierte Wertsteigerungen versteuert werden müssen. ${ }^{1}$

Mit dieser unterschiedlichen Erfassung der Wertsteigerungen ist ein Grundstein für Auseinandersetzungen zwischen Steuerpflichtigen und Finanzverwaltung im Steuerrecht gelegt worden:"Die Abgrenzung des gewerblichen Grundstückhandels von der privaten Vermögensverwaltung ist eine der vielleicht altesten Fragen einkommensteuerrechtlicher Dogmatik, und die Kette einschlägiger Entscheidungen und Veröffentlichungen ist niemals abgerissen. "2

Bei genauer Betrachtung geht es bei diesem Abgrenzungsproblem nicht um die Erfassung von Wertsteigerungen im Sinne der windfall profits, sondern um die Frage, was erfüllt den Tatbestand der Verwaltung von Vermögen mit der eher "zufälligen" Erwirtschaftung vor Wertsteigerungen und was den Tatbestand der beruflichen bzw. selbstständigen Unternehmertätigkeit als Immobilienmakler oder Bauunternehmer.

Steuerpflichtige, die ihr Vermögen in Wohnimmobilien anlegen und nach langjähriger Vermietung veräußern, können Wertsteigerungen unabhängig von der Anzahl der Objekte und unabhängig von der Höhe der erzielten Wertsteigerungen steuerfrei realisieren. Eine Unternehmertätigkeit wird bei ihnen nicht angenommen.

In den letzten Jahrzehnten traten die Wertsteigerungen in verschiedenen Phasen gegenüber den Mieteinnahmen quantitativ in den Vordergrund. Dies führte, wie

1 Außerdem unterliegen der Grundbesitz und seine Erträge dann der Gewerbesteuerpflicht, was die Steuerlast über die auf die Wertsteigerung abzuführende Einkommensteuer hinaus vergrößert.

2 Vgl. Beater, A., Die Abgrenzung des gewerblichen Grundstückhandels von der privaten Vermögensverwaltung anhand des Quellengedankens, in: StuW 1/1991, S. 33 . 
die umfangreiche Rechtsprechung zu diesem Thema belegt, ${ }^{1}$ bei zahlreichen Steuerpflichtigen zu einer regen Anschaffungs- und Veräußerungstätigkeit. Durch Veränderungen am Objekt kann außerdem der Objektwert zusätzlich erhöht werden. Beispiele hierfür sind:

- Die Anschaffung, grundlegende Sanierung und anschließende Veräußerung von älteren Objekten nach kurzfristiger bzw. ohne Vermietung.

- Die Anschaffung von unbebauten Grundstücken, Bebauung und anschließende Veräußerung nach kurzfristiger bzw. ohne Vermietung.

- Der Erwerb von Mietwohnungen, die Aufteilung in Eigentumswohnungen und anschließende Veräußerung. ${ }^{2}$

Bei diesen Maßnahmen steht im Regelfall nicht die Vermietung und die Erzielung von Mieterträgen im Vordergrund. Es handelt sich nach steuerjuristischer Interpretation vielmehr um eine "selbständige", ${ }^{3}$ "nachhaltige Tätigkeit", ${ }^{4}$ bei der der Steuerpflichtige unter "Beteiligung am allgemeinen wirtschaftlichen Verkehr"s mit "Gewinnerzielungsabsicht" und u.U. durch "Verwertungsmaßnahmen "7 Erträge erwirtschaftet. ${ }^{8}$ Zur Feststellung des Umfangs der Steuerpflicht wird somit nicht der Reinvermögenszugang zugrundegelegt, sondern es wird bewußt eine Diskriminierung zwischen gleichen ökonomischen Sachverhalten vorgenommen. Zentral kommt es hier auf die "Gesinnung" des Steuerpflichtigen an, ein Sachverhalt, der in einem rationalen Steuersystem keinen Platz hat. Die Ursachen für Wertsteigerungen sind ohne Bedeutung. Ob sie als

1 Vgl. Ehlers, E., Gewerblicher Grundstückshandel - Versuch einer Systematisierung unter Berücksichtigung der neuesten höchstrichterlichen Rechtssprechung - Teil 1, in: DStR, 1989, S. 687ff und Teil 2, S. 729ff.

2 Mietwohnungen sind im Gegensatz zu Eigentumswohnungen innerhalb eines einheitlichen Objektes nicht einzeln veräußerbar. Alle Wohnungen eines Mietwohnhauses stellen eine Einheit dar, an der nur gesamthaft Eigentum erworben werden kann. Sind bestimmte Voraussetzungen erfüllt (sogenannte Abgeschlossenheitsbescheinigung), so können sie als Einzeleigentum im Grundbuch eingetragen und an verschieden Erwerber veräußert werden.

3 Ehlers, E., a.a.O., S. 687.

4 Ebenda, S. 687.

5 Ebenda, S. 688.

6 Ebenda, S. 688.

7 Ebenda, S. 730.

8 Vgl. auch Abschnitt 134 EStR. 
windfall profits anfallen oder mit Gewinnerzielungsabsicht erwirtschaftet werden, spielt deshalb keine Rolle. Sie sind gemeinsam mit den Mieteinnahmen Teil der erzielten Rendite und sollten deshalb in die Bemessungsgrundlage des zu versteuernden Einkommens eingehen (vgl. Teil 1 C.3. ). Außerdem spekuliert jeder Vermieter, der eine Nominalrendite (Miete/investiertes Kapital) unterhalb der Kapitalmarktrendite hinnimmt, auch auf Wertsteigerungen.

Wertsteigerungen können im Rahmen der privaten Vermögensverwaltung steuerfrei realisiert werden, "solange sich die zu beurteilende Tatigkeit noch als Nutzung von Grundbesitz durch Fruchtziehung aus zu erhaltender Substanz darstellt und die Ausnutzung substantieller Vermögenswerte nicht entscheidend in den Vordergrund tritt. "I

Diese Definitionen sind mehr oder weniger interpretationsfähig, so daß die Rechtsprechnnung bis heute zu keiner generellen, für alle Fälle verbindlichen Lösung gekommen ist, sondern jeweils die Umstände des Einzelfalls gewürdigt werden. Dabei spielt die Anzahl der veräußerten Objekte und die Länge des Zeitraums der Vermietung eine entscheidende Rolle. ${ }^{2}$

Die erwähnten Kriterien entstammen der juristischen Nomenklatur und entziehen sich im einzelnen einer Beurteilung durch den Ökonomen. Anzumerken ist aber, daß auch jeder Vermieter, der seine Tätigkeit allein auf das Vermieten beschränkt, am "wirtschaftlichen Verkehr" teilnimmt, indem er auf dem Vermietungsmarkt tätig wird. Er tut dies "nachhaltig", da dies über einen längeren Zeitraum geschieht und hat natürlich eine "Gewinnerzielungsabsicht", da er diese Vermögensanlageform kaum aus altruistischen Gründen wählt. Da er nicht in fremdem Namen handelt, sondern in eigenem und außerdem auf eigene Rechnung, tut er dies "selbständig".

Vielleicht aus diesen Gründen, aber auch um Rechtssicherheit zu schaffen, hat das Bundesministerium der Finanzen 1990 unter Berücksichtigung der Rechtssprechung zur Vereinheitlichung Stellung bezogen. ${ }^{3}$ Danach können Objekte, die mindestens 10 Jahre vermietet waren, ohne steuerliche Konsequenzen

1 Vgl. Bundesfinanzhof, Urteil v. 18.1.89 X R 108/88.

2 Vgl. Ehlers, E., a.a.O., Beispiele, S. 689ff.

3 Vgl. Bundesminister der Finanzen, IV B 2 - S 2240 - 61/91, Abgrenzung zwischen privater Vermögensverwaltung und gewerblichem Grundstückshandel, Bundessteuerblatt 1990, Teil 1, S. 884ff. 
veräußert werden. Die Veräußerung gilt als private Vermögensverwaltung. ${ }^{1}$ Dies gilt auch dann, wenn es sich um umfangreichen Grundbesitz handelt ${ }^{2}$ und sämtliche Objekte in einem relativ kurzen Zeitraum an verschiedene Erwerber veräußert werden. ${ }^{3}$

Die Veräußerung von Objekten, die kürzer als 10 Jahre vermietet waren, führt aber noch nicht zur Steuerpflicht. Vielmehr kommt es hier u.a. auf die Anzahl der Objekte an. Werden maximal 3 Objekte, die jeweils kürzer als 5 Jahre vermietet waren ${ }^{4}$ innerhalb eines Zeitraum von 5 Jahren veräußert, so erfüllt dies ebenfalls noch den Tatbestand der privaten Vermögensverwaltung, ${ }^{5}$ auch wenn die Objekte selbst erstellt, ${ }^{6}$ bzw. umfangreich modernisiert wurden. Bei Ehegatten kann jeder Ehegatte bis zu 3 Objekte im Bereich der privaten Vermögensverwaltung veräußern. ${ }^{7}$ Kommen im darauf folgenden Zeitraum bis zu zeitlichen Obergrenze von 10 Jahren weitere Veräußerungen von kurzfristig vermieteten Objekten (unter 5 Jahren) hinzu, kann dies unter Würdigung der Umstände zur Gewerblichkeit führen. ${ }^{8}$ Insofern bleibt hier ein gewisser Unsicherheitsbereich bestehen, der Interpretationen notwendig macht.

Eigengenutzte Objekte, die ansonsten von der Einkommensteuer überhaupt nicht mehr berührt werden, sind bei der Frage, ob es sich um private Vermögensverwaltung oder gewerblichen Grundbesitz handelt, mit zu berücksichtigen. Sie werden in diesem Fall bei der Zählung von veräußerten Objekten vermieteten Objekten gleichgestellt. ${ }^{9}$ Das kann im Einzelfall zu dem Paradox führen, daß Wertsteigerungen eines definitorischen Konsumgutes der Besteuerung unter-

1 Vgl. Bundesminister der Finanzen, IV B 2 - S 2240 - 61/91, Abgrenzung zwischen privater Vermögensverwaltung und gewerblichem Grundstückshandel, Bundessteuerblatt 1990, Teil 1, S. 884, Tz. 2.

2 Vgl. ebenda, S. 884, Tz. 2.

3 Vgl. ebenda, S. 884, Tz. 2.

$4 \mathrm{Vgl}$. ebenda, Definition, Tz. 18, 21, 20, 23.

5 Vgl. ebenda, S. 885, Tz. 10.

6 Vgl. ebenda, S. 887, Tz. 17.

7 Vgl. ebenda, S. 885, Tz. 11.

8 Vgl. ebenda, S. 885, Tz. 10.

9 Vgl. ebenda, S. 884, Tz. 4. 
liegen, während die Wertsteigerungen von vermieteten Wohnungen (Investitionsgüter) im Regelfall steuerfrei bleiben.

Zusammenfassend heißt dies, daß Investoren Wohnimmobilien nach einem Vermietungszeitraum von jeweils mindestens 10 Jahren unabhängig von der Anzahl der Objekte und vom Umfang der realisierten Wertsteigerungen jederzeit veräußern können, ohne den Veräußerungsgewinn versteuern zu müssen. Objekte, die kürzer als 5 Jahre vermietet werden, können in einem Umfang veräußert werden, der es im Normalfall gestattet, daß ebenfalls unberührt von der Steuer über das Vermögen relativ frei disponiert werden kann. Diese Regelung gestattet es aber umgekehrt, wenn auch nur in beschränktem Ausmaß, steuerfrei als Unternehmer tätig zu sein, da allein die Zahl der Objekte gezählt wird und es nicht auf ergriffene werterhöhende Maßnahmen ankommt. Unter Einhaltung dieser Grenzen kann ein Steuerpflichtiger Immobilienvermögen nahezu in beliebiger Höhe veräußern bzw. Wertzuwächse steuerfrei realisieren. Für die weiteren Untersuchung ist deshalb nur noch der Fall der Immobilien im Privatvermögen von Interesse.

\section{Der Einfluß der synthetischen Einkommensbesteuerung auf die Immobilieninvestition}

Für den Investor auf dem Mietwohnungsmarkt sind auf der Ertragsseite die Mieteinnahmen, ihre Entwicklung und die Entwicklung des Objektwertes von Bedeutung. Auf der Aufwandseite sind zum einen die Kapitalkosten bzw. die Opportunitätskosten zu berücksichtigen. Zum anderen unterliegt der Gebäudeteil der Investition einem nutzungsbedingten Werteverzehr. D.h. nach einer bestimmten Anzahl von Jahren hat der Gebäudeteil keinen ökonomischen Wert mehr. Insofern müssen auf der Aufwandsseite zusätzlich Abschreibungen berücksichtigt werden. ${ }^{1}$ Dabei kann das Paradox auftreten, daß der Gesamtwert der Investition steigt, obwohl sich die Restnutzungsdauer des Gebäudes verkürzt. (vgl. auch Teil 1 A.2.)

1 Zusätzlich fallen von Zeit zu Zeit Renovierungen und Reparaturen an, sogenannte Instandhaltungs- und Instandsetzungsmaßnahmen. Sie werden an dieser Stelle vernachlässigt. In Teil 2 der Untersuchung sind sie Gegenstand einer eigenen Betrachtung. 
Die Besteuerung der Einkünfte aus Vermietung und Verpachtung erfaßt auf der Ertragsseite nur die Mieteinnahmen. Auf der anderen Seite kann der Investor die Fremdkapitalkosten und die Abschreibungen geltend machen. Das Gebäude wird über fünfzig Jahren linear abgeschrieben, d.h. es wird pro Jahr eine Abschreibung von 2 v.H. der urprünglichen Gebäudeanschaffungs- bzw. Herstellungskosten vorgenommen ( $\$ 7$ Abs. 4 EStG). Der Saldo aus Mieteinnahmen, Ausgaben für den Fremdkapitaldienst und der steuerlichen Abschreibung ist dabei in Abhängigkeit von der Höhe des Fremdkapitalanteils in den ersten Jahren im Regelfall negativ, d.h. es ergibt sich ein steuerlicher Verlust aus Vermietung und Verpachtung.

Es ist das Wesen der synthetischen Einkommensbesteuerung, daß alle Einkünfte eines Steuerpflichtigen zu einer einheitlichen Bemessungsgrundlage zusammengefaßt werden. In dem Umfang, in dem nun bei den Einkünften aus Vermietung und Verpachtung ein steuerlicher Verlust entsteht, mindert sich die Steuerlast, die sich aufgrund anderer Einkünfte ergeben würde. Durch den progressiven Steuertarif ist die steuerliche Entlastung absolut umso größer, je höher die sonstigen Einkünfte sind, d.h. der Teil des Verlustes, den der Staat trägt, nimmt absolut mit steigendem Einkommen des Investors zu. Sofern diese steuerlichen Verluste den tatsächlichen ökonomischen Gegebenheiten entsprechen, handelt es sich nicht um eine Subvention, sondern um die Rückwirkungen der Progression.

In Anlehnung an die Annahmen, die der Grafik 2 zugrundeliegen, wurde dieser Sachverhalt in Grafik 3 abgebildet. Es wurde von den gleichen empirischen Daten ausgegangen. Die dünne gestrichelte, fallende Linie gibt die Fremdkapitalkosten bei einem Annuitätendarlehen wieder, (8 v.H. Zinsen, 1 v.H. Anfangstilgung). Entsprechend der Tilgungsleistung nehmen diese im Zeitablauf ab. Zu diesen Kapitalkosten wurde die steuerliche Normalabschreibung addiert. Ausgegangen wurde von einem abschreibungsfähigen Gebäudeanteil an der Investition von 75 v.H. Dem steuerlichen Kostenverlauf sind die zu versteuernden Mieteinnahmen gegenübergestellt. Bis zum Zeitpunkt T3 ergibt sich ein steuerlicher Verlust. Um die maximalen Effekte aufzuzeigen, wurde ein Investor unterstellt, dessen sonstigen Einkünfte mit dem Spitzengrenzsteuersatz von 53 v.H. besteuert werden. Bei niedrigeren Grenzsteuersätzen sind die Effekte entsprechend geringer. Die schraffierte Fläche der Grafik (links von T3) gibt die Steuer"ersparnis" wieder, die aus der Zusammenfassung mit den anderen Einkunftsarten resultiert. Je schneller der Investor auf dem Objekt 


\section{Grafik 3}

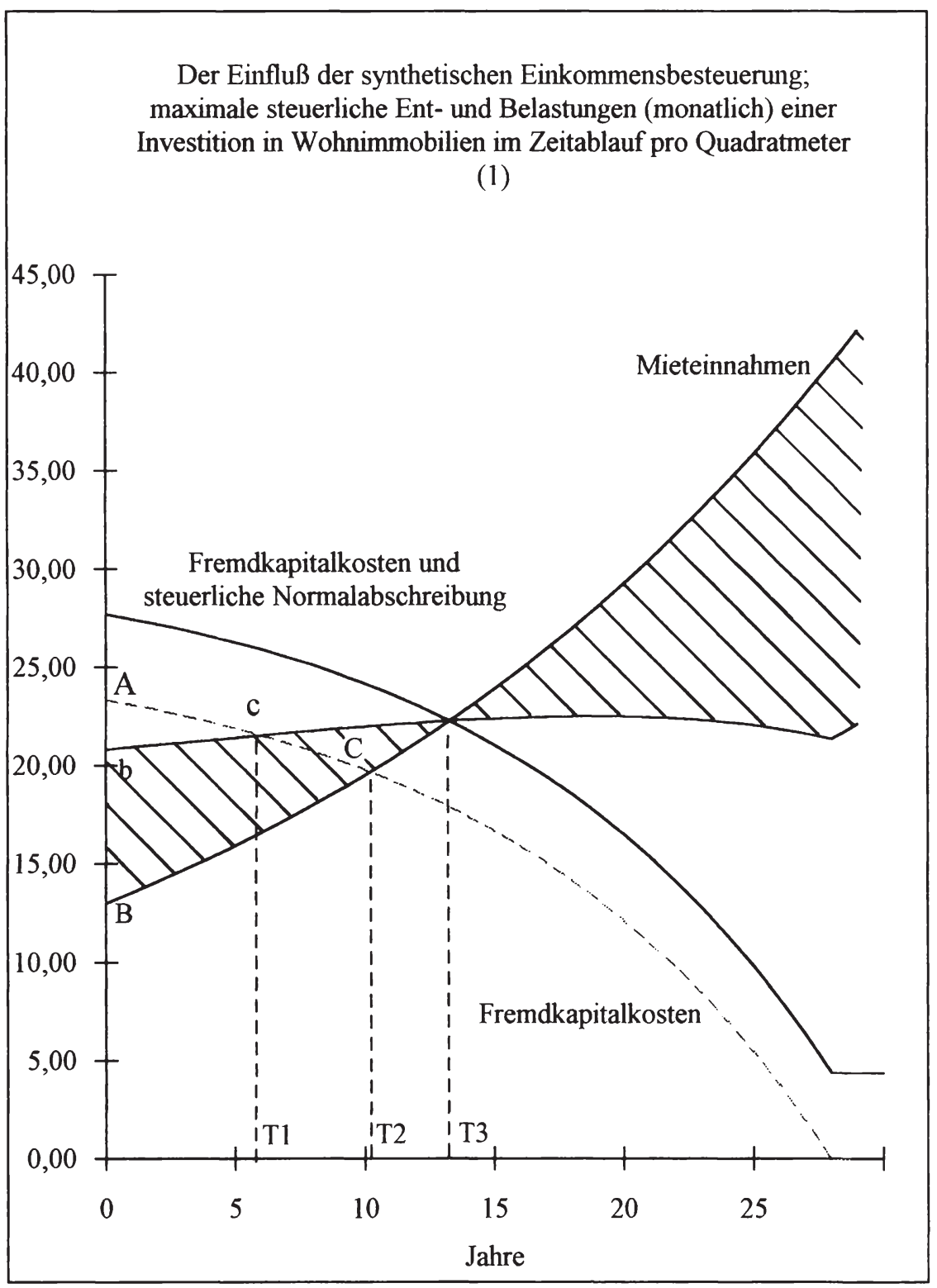

(1) Finanzierung über Annuitätendarlehen, anfänglicher Tilgungssatz 1 v.H. 
lastende Verschuldungen tilgt, und je schneller die Mieten steigen, desto kürzer ist die fiskalische Defizitphase, bzw. desto früher tritt T3 ein, und umgekehrt. D.h. mit zunehmender Tilgung tritt die Eigenkapitalverzinsung in den Vordergrund. Nach dem Zeitpunkt T3 verkehren sich die Verhältnisse zugunsten des Staates. Die straffierte Fläche gibt dann die Steuerbelastung wieder.

Es wurde ein im Zeitablauf konstanter Grenzsteuersatz unterstellt. Die Investition auf dem Mietwohnungsmarkt stellt für viele Investoren, vor allem für Selbständige und Angehörige freier Berufe, ein Mittel der Altersvorsorge dar, so daß durch den Eintritt der Investoren in den Altersruhestand der fiskalische Ertragsverlauf in diesen Fällen auch deutlich darunter liegen kann.

Würden die Mieten überhaupt nicht steigen, bliebe ein dauerhafter Verlust bzw. würden Erträge anfallen, die unter dem Kapitalmarktzinssatz bleiben. In diesem Fall ist es steuersystematisch konsequent und verteilungspolitisch neutral, wenn sich der Staat an diesem Verlust in Abhängigkeit vom individuellen Grenzsteuersatz beteiligt ${ }^{1}$ bzw. wenn sich im Falle der Eigenkapitalfinanzierung geringere fiskalische Erträge ergeben.

Sofern die Mieten aber steigen, wird sichtbar, daß sich zwei Effekte gegenseitig verstärken. Die Steuerminderungen in den ersten Jahren stellen Liquiditätshilfen dar, die es dem Investor erleichtern, den charakteristischen Liquiditätsengpaß zu überbrücken. Dieser Sachverhalt wird ebenfalls in Grafik 3 sichtbar. Die Abschreibungen fallen nicht liquiditätswirksam an, insofern können sie an dieser Stelle außer acht gelassen werden. Ohne Berücksichtigung der Besteuerung würden die Ausgaben für den Kapitaldienst bis zum Zeitpunkt T2 unter den Mieteinnahmen liegen. Durch die Besteuerung verkürzt sich dieser Zeitraum auf $\mathrm{T} 1$, wodurch sich die liquiditätsmäßige Unterdeckung von Dreieck $\mathrm{ABC}$ auf das Dreieck Abc verkleinert. Das Dreieck Abc ist umso kleiner, je höher das sonstige Einkommen des Investors ist. Da es dem Investor aber mit zunehmendem Einkommen naturgemäß leichter fällt, diese Phase zu überbrükken, kumulieren sich durch die synthetische Einkommensbesteuerung individuelle Sparfähigkeit und steuerliche Entlastungen.

${ }^{1}$ Mit zunehmendem Einkommen wird das individuelle Investitionsrisiko absolut kleiner, was aufgrund der progressiven Besteuerung systemimmanent hingenommen werden muß. 
Die Kapitalmärkte wären aber ineffizient, wenn sich steigende Mieten im Zeitablauf nicht ebenfalls in steigenden Objektwerte widerspiegeln würden. ${ }^{1}$ Das würde aber auf der anderen Seite bedeuten, daß bei steigenden Mieten der steuerliche Verlust auf Dauer nicht die tatsächlichen Gegebenheiten wiedergibt, sondern unter Berücksichtigung der Wertentwicklung des Objektes in den einzelnen Perioden einen Scheinverlust ausweist. Diesem Problem wäre auch nicht mit einer Besteuerung im Sinne der modifizierten Reinvermögenszugangstheorie beizukommen, da bei dieser die Wertzuwächse nur im Veräußerungsfall der Besteuerung unterliegen. Da das deutsche Steuerrecht auch im Unternehmensbereich aus vielfältigen Gründen keine Besteuerung im Sinne der Reinvermögenszuwachstheorie vornimmt, ist dieses Problem innerhalb des bestehenden Steuerrechts nur schwer lösbar. Somit treten außerhalb der Liquiditätshilfen, die aufgrund der synthetischen Einkommensbesteuerung anfallen und subventionsneutral wirken, Subventionselemente hinzu, da die Ertragsseite systematisch untererfaßt wird. Diese Problem macht sichtbar, daß die Diskussion um die steuerliche Erfassung von Wertsteigerungen nicht isoliert geführt, sondern nur im Kontext mit der Erfassung der Aufwendungen und Erträge der Einkünfte aus Vermietung und Verpachtung beurteilt werden kann, was in Teil 1 C.3. diskutiert wird.

Die bisherigen Überlegungen befaßten sich mit dem Einfluß der Besteuerung unter Normalbedingungen, d.h es wurde unterstellt, daß mit Fremdkapital finanziert und getilgt wird. Der Zeitraum des fiskalischen Verlustes ist zum einen von der Höhe des Fremdkapitalanteils abhängig, zum anderen davon, ob getilgt wird oder nicht. Es bleibt dem Investor freigestellt, auf eine Tilgung zu verzichten bzw. die Vermögensbildung entsprechend seiner individuellen marginalen Sparneigung geringer ausfallen zu lassen, wodurch sich die fiskalische Verlustphase entsprechend verlängert. Dieser Sachverhalt ist in Graphik 4 unter den gleichen Annahmen wie bisher dargestellt. Sichtbar wird, daß sich der Zeitpunkt der fiskalischen Belastung deutlich verlängert und sich die fiskalischen Erträge in der Zukunft entsprechend vermindern. Unter steuersystematischen und verteilungspolitischen Aspekten unterscheidet sich dieser Fall qualitativ nicht vom vorhergehenden Fall der Finanzierung mit Tilgung.

1 Der Wert eines Vermögensgegenstandes entspricht unter rationalen Gesichtspunkten der Summe aller zukünftig erwarteten Mieteinnahmen, abdiskontiert auf den Betrachtungszeitpunkt. Steigen die zukünftigen Mieteinnahmen, muß der Objektwert demnach ebenfalls zunehmen. 


\section{Grafik 4}

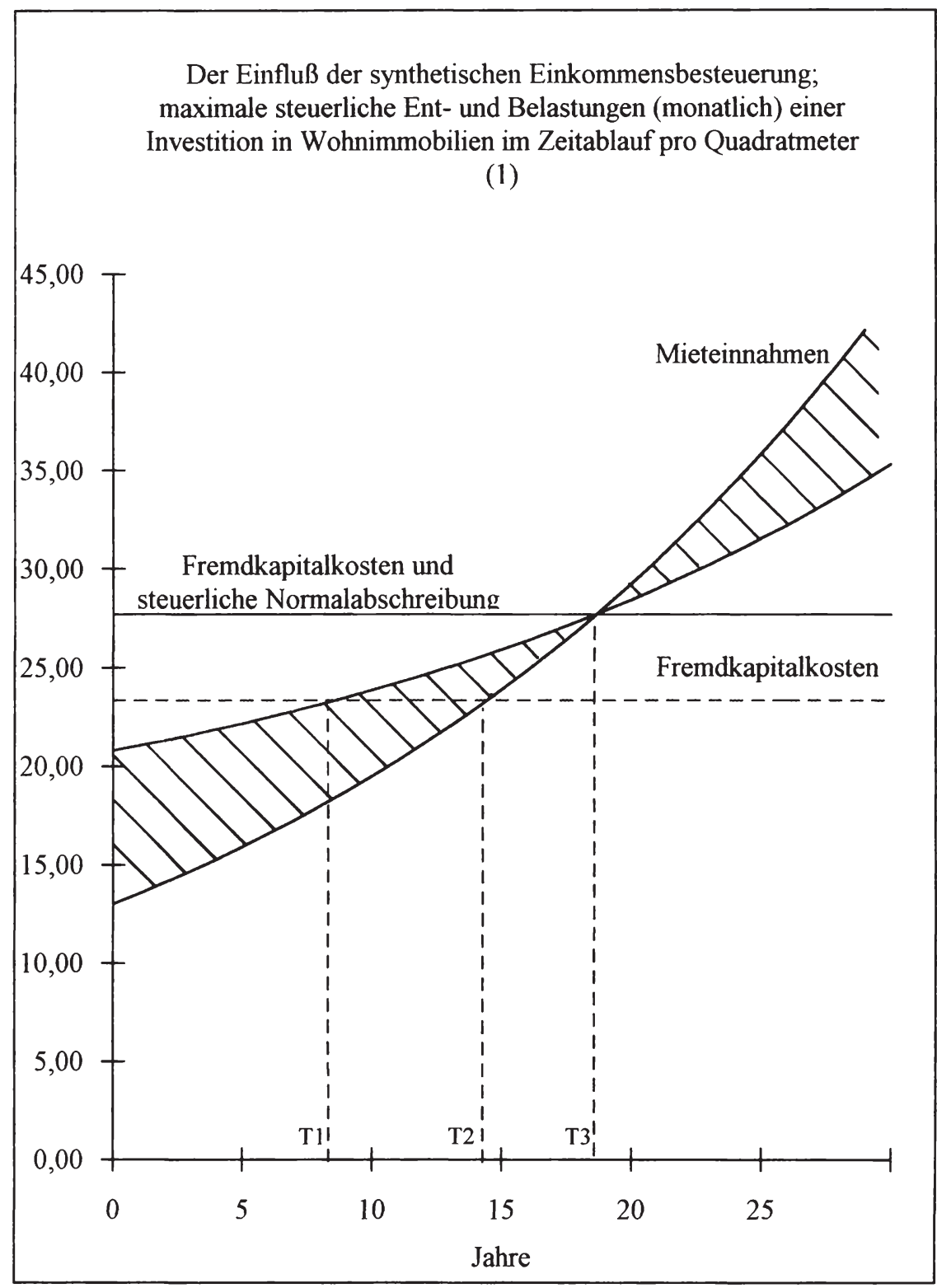

(1) Finanzierung über tilgungsfreie Hypothek bzw. Kapital LV mit Tilgungsaussetzung 
Sofern der Investor aus seinem Einkommen aufgrund seiner individuellen Sparneigung Vermögen bildet, wäre es ohne Berücksichtigung der Besteuerung rational, diese Ersparnisse zur Tilgung zu verwenden. Ein Anlage auf dem Kapitalmarkt wäre irrational, da bei gleichen Risikostrukturen die Sollzinsen, die der Investor für das im Wohnraum gebundene Fremdkapital aufbringen muß, über den auf dem Kapitalmarkt erzielbaren Habenzinsen liegen. Die Besteuerung verhält sich aber nicht neutral auf die Finanzierungsentscheidung bzw. das Tilgungsverhalten, so daß sich in Abhängigkeit von der gewählten Finanzierungsform, wie sich zeigen wird, zusätzliche Subventionselemente ergeben können.

Wie in Teil 1 C.2. der Untersuchung angesprochen, sind Finanzierungen ohne Tilgung nicht üblich. Um möglichst lange die steuerliche Vorteile eines Verlustes aus Vermietung und Verpachtung nutzen zu können und gleichzeitig der Erfordernis bzw. auch dem Wunsch einer Tilgung nachzukommen, hat sich speziell aus steuerlichen Gründen in der Praxis eine Finanzierungskonstruktion entwickelt, die in mehrfacher Hinsicht unbefriedigend ist. Breite Anwendung findet die Finanzierung über ein Hypothekendarlehen mit sogenannter Tilgungsaussetzung (d.h. es wird nicht getilgt) bei gleichzeitigem Ansparen einer Kapitallebensversicherung. Der Erstattungsanspruch auf das Endkapital der Lebensversicherung wird an den Versicherer abgetreten. ${ }^{1}$

Die steuerlichen Behandlung von Kapitallebensversicherungen berührt das Untersuchungsziel im engeren Sinne nicht, doch hat sie als Instrument zur Finanzierung von Wohnimmobilien große empirische Relevanz. An ihr wird sichtbar, welche Konsequenzen sich daraus ergeben, daß Erträge unterschiedlicher Anlageformen nicht gleichmäßig in die Bemessungsgrundlage des zu versteuernden Einkommens eingehen. Diese Finanzierungsform zielt systematisch darauf $a b$, die steuerliche Verlustphase zu verlängern bzw. die Steuerlast zu senken. Die Kapitallebensversicherung besteht aus einem Sparvertrag mit Todesfallschutz, d.h. über einen längeren Zeitraum werden regelmäßig Sparleistungen erbracht. Die jeweils anfallenden Zinsen verbleiben zur Wiederanlage beim Versicherer. Die Zinserträge sind variabel, was bedeutet, daß vertraglich

1 Durch die dadurch verminderten Risiken und der geringen garantierten Rendite sind die Versicherer in der Lage, im Vergleich zu anderen Finanzintermediären günstigere Zinssätze für Hypothekendarlehen anzubieten. 
eine geringe Mindestverzinsung (teilweise unter 1 v.H.) ${ }^{1}$ garantiert wird, mit der Aussicht auf zusätzliche Erträge, sogenannte Überschußanteile. ${ }^{2}$ Nach einer festgelegten Anzahl von Jahren wird der sich ergebende Endbetrag ausgezahlt, seine Höhe ist ex ante ungewiß. ${ }^{3}$ Bei vorzeitigem Ableben wird die gesamte Summe sofort fällig.

Steuerlich wird diese Anlageform auf zweierlei Weise subventioniert. Zum einen können die Sparleistungen des Steuerpflichtigen im Rahmen der Vorsorgeaufwendungen (teilweise) steuerlich geltend gemacht werden. ${ }^{4}$ Zum anderen sind die Kapitalerträge steuerfrei. Sie stehen jeweils in voller Höhe zur Wiederanlage beim Versicherer zur Verfügung. Ebenso ist die gesamte Ausschüttung im Erlebensfall steuerfrei, sofern die Versicherung mindestens 12 Jahre Laufzeit hatte. Im Todesfall ist die Vertragssumme auf jeden Fall steuerfrei. Diese Form der steuerlichen Subvention von Vorsorgeaufwendungen kann im Rahmen der Untersuchung nicht problematisiert werde, doch interessieren hier die Wirkungen, die sich im Zusammenhang mit Erfassung der Einkünfte aus Vermietung und Verpachtung ergeben.

Der Investor finanziert mit einem tilgungfreien Darlehen und schließt gleichzeitig eine Kapitallebensversicherung ab. Den zukünftigen Erstattungsanspruch aus der Lebensversicherung tritt er gleichzeitig an den Kreditgeber ab. Diese Konstruktion hat den steuerlichen Vorteil, daß die Schuldzinsen aus dem Darle-

1 Eigene Berechnung aufgrund der Prospekte gängiger Versicherungen.

2 Diese Überschußanteile sollen von den Bruttoerträgen abhängen, die die Lebensversicherungen auf dem Kapitalmarkt erwirtschaften, vermindert um die wirksam gewordenen Sterbefallsrisiken.

${ }^{3}$ Bei einer anderen Variante ist der Endbetrag festgelegt und die Laufzeit offen, d.h. je höher die von den Lebensversicherungen ausgeschüttete Rendite ist, umso kürzer ist die Laufzeit.

4 Bei Selbständigen und Angehörigen freier Berufe stellt diese Anlageform oft einen Ersatz für die Vorsorgeaufwendungen Unselbständiger zur gesetzlichen Rentenversicherung dar. Unselbständige haben die maximal berücksichtigungsfähigen Vorsorgeaufwendungen in mittleren Einkommenslagen durch ihre Rentenversicherungsbeiträge im Regelfall ausgenutzt, so daß sie den Abzug der Sparbeiträge zu Kapitallebensversicherungen nicht mehr nutzen können. Diese Regelung kommt daher vor allem Beamten zugute, die keine eigene Altersvorsorge betreiben müssen und die Vorsorgeaufwendungen innerhalb der (verminderten) Höchstgrenzen geltend machen können. 
hen während der gesamten Laufzeit in voller Höhe steuerlich geltend gemacht werden können, während sich die Lebensversicherungsbeiträge als Alternative zur Tilgung steuerfrei verzinsen. Nach 20 bis 30 Jahren wird die Vertragssumme ausgeschüttet und kann zur Tilgung des Darlehens verwendet werden. Ohne die steuerliche Privilegierung der Kapitallebensversicherung wäre es aus den oben erwähnten Gründen nicht rational, statt sukzessive zu tilgen, den Verschuldungsbetrag parallel anzusparen. Der Todesfallschutz ließe sich auch isoliert mit einer Risikolebensversicherung erreichen.

Die Nettovermögensposition eines Investors besteht in einer Besteuerungsperiode c.p. aus dem Guthaben auf dem Lebensversicherungskonto (sogenannter Rückkaufswert) und der Verschuldung in Höhe der Hypothek. Ökonomisch stellen diese beiden Sachverhalte eine Einheit dar. Es wäre unter dem Aspekt der Begrenzung des Gestaltungsmißbrauchs angebracht, Schuldzinsen auf das Hypothekendarlehen nur in dem Umfang steuerlich anzuerkennen, in dem die Verschuldung auf einer effektiven Verschuldungsposition beruht. Dies entspräche dem Saldo aus der Hypothek und dem Rückkaufswert der Lebensversicherung. ${ }^{1}$

Bis vor kurzem ging der Mißbrauch dieser Finanzierungsform noch weiter, da Zinsen aus der Hypothek steuerlich geltend gemacht werden konnten, auch wenn sie faktisch nicht (voll) gezahlt wurden. Der Investor schloß eine entsprechend höhere Kapitallebensversicherung ab. Die Zinsen wurden kreditfinanziert (sogenanntes Zinsaufblähungsmodell). Der Vorteil bestand auch hier darin, daß die Zinsen auf die Zinsen (Zinseszinsen) ebenfalls steuerlich geltend gemacht werden konnten, während die Guthabenzinsen auf die parallel angesparte Lebensversicherung steuerfrei waren.

Dieser offensichtliche Mißbrauch wurde durch das Steueränderungsgesetz 1992 beseitigt. ${ }^{2}$ Sofern die Höhe der Lebensversicherung die Anschaffungskosten des Objektes übersteigt, somit also der Absicherung und Tilgung von Kreditzinsen dient, verlieren die Beiträge und die Erträge der Kapitallebensversicherung die

1 Diese Rückkaufswerte liegen in den ersten Jahren weit unter den erbrachten Sparleistungen, so daß sich erst im Zeitablauf fiskalisch bedeutsame Erträge einstellen würden.

2 Vgl. Steueränderungsgesetz 1992 v. 25.2.1992, in: BGBl. 1992, S. 297 und in: BStBl I 1992, S. 146. 
Steuerbegünstigung. ${ }^{1}$ Interessanterweise wird nicht der Schuldzinsabzug bei den Einkünften aus Vermietung und Verpachtung verwehrt, sondern die Begünstigung der Kapitallebensversicherung.

Aus steuersystematischer, verteilungspolitischer und fiskalischer Sicht wäre es angebracht, Schuldzinsen aus steuerlich relevante Verschuldungen nur in dem Umfang anzuerkennen, in dem sie auf einer effektiven Nettoverschuldungsposition des Steuerpflichtigen beruhen. ${ }^{2}$ Würden die Erträge aller verzinslichen Forderungen eines Steuerpflichtigen vollständig erfaßt werden, wäre dies indirekt erfüllt. ${ }^{3} \mathrm{Da}$ dies heute aber nicht der Fall ist, bedeutet das, daß die fiskalischen Ausfälle, die in der Einkommensteuerstatistik bei den Einkünften aus Vermietung und Verpachtung ausgewiesen werden, weniger auf schlechte Erträge im Wohnungsbau zurückzuführen sind, sondern auf die mangelnde steuerliche Erfassung anderer (Kapital-)Einkünfte. Aus steuerlichen Gründen ist es mit zunehmendem Grenzsteuersatz nicht rational im Wohnungsbau Eigenkapital einzusetzen, solange andere Anlageformen existieren, bei denen die Kapitalerträge (teilweise) steuerfrei sind, während die Fremdkapitalzinsen bei den Einkünften aus Vermietung und Verpachtung in vollem Umfang steuerlich geltend gemacht werden können. Diese asymmetrische steuerliche Behandlung von Soll- und Habenzinsen führt bei privaten Wirtschaftssubjekten dazu, daß sie aus steuerlichen Gründen über den Kapitalmarkt gleichzeitig ihre eigenen

1 Zu Zweifelsfragen vgl. BMF, Schreiben v. 19.5.1993, in: BStBI I 1993, S. 406.

2 Es würde nicht genügen, dieses Abzugsverbot nur auf Lebensversicherungen zu beschränken, deren Auszahlungsanspruch zur Sicherung eines Darlehens abgetreten wurde. Um auch weiteren steuerlichen Einschränkungen in der Zukunft vorzubauen, verzichten heute bereits die ersten Versicherer auf die Abtrittserklärung der Auszahlungsansprüche zur Sicherung von Hypotheken (allerdings nur bis zur Höhe des Realkredites), so daß die Lebensversicherung nicht mehr einer Einkunftsart direkt zurechenbar ist.

3 Seit der Einführung des Zinsabschlagsteuergesetzes werden Kapitalerträge bis 6.000 DM bzw. 12.000 DM von der Besteuerung freigestellt, so daß es unter steuerlichen Gesichtspunkten rational ist, Geldvermögen bis zu ca. 100.000 DM /200.000 DM (ledig/verh.) zu bilden, anstatt zu tilgen. Vielleicht nur bedingt rational, weil strafbar, aber empirisch sicherlich relevant ist es aber auch, sein Geldvermögen in Luxemburg zu halten anstatt als Eigenkapital in Wohnraum zu binden und Schuldzinsen steuerlich geltend zu machen. 
Gläubiger und Schuldner sind, was nicht zuletzt allokative Verzerrungen mit sich bringt. ${ }^{1}$

Zusammenfassend läßt sich sagen, daß sich der Staat durch die normale steuerliche Erfassung der Aufwendungen und Erträge von vermieteten Wohnimmobilien an der Verlustphase der ersten Jahre - bedingt durch den progressiven Steuertarif - mit zunehmendem Einkommen zunehmend beteiligt. Sofern Wertsteigerungen eintreten, sind die Verluste der ersten Jahre zumindest zum Teil Scheinverluste, die in entsprechendem Umfang ungerechtfertigt zur Verkürzung der Bemessungsgrundlage führen, was zu grenzsteuersatzabhängigen Vergünstigungen führt. Sofern sich kein negativer Saldo bei den Einkünften aus Vermietung und Verpachtung ergibt, handelt es sich bei der Nichterfassung von Wertsteigerungen dennoch um Subventionen, da der Betrag, der positiv in die Bemessungsgrundlage des zu versteuernden Einkommens eingeht, nicht die tatsächlichen Erträge der Investition wiedergibt. In Abhängigkeit von der Finanzierungsform werden die Steuervorteile von negativen Einkünfte aus Vermietung und Verpachtung jenseits der tatsächlichen ökonomischen Verhältnisse darüber hinaus systematisch ausgenutzt, so daß sich unter Berücksichtigung der in Teil 2 zu diskutierenden Abschreibungsregelungen erklären läßt, warum der Staat aus diesem Wirtschaftssektor keine Erträge bei der Besteuerung erzielt.

Dem Selbstnutzer von Wohneigentum bleiben die steuerlichen Entlastungen aus negativen Einkünften aus Vermietung und Verpachtung und die Gestaltungsmöglichkeiten bei der Finanzierung verwehrt. Durch die Einstufung seiner Wohneigentumsinvestition als Konsumgut braucht er zwar keine Einkünfte zu versteuern, im Gegenzug hat er aber nicht die Möglichkeit, steuerliche Verluste in diesem Bereich geltend zu machen.

\section{Die Problematik der Nichterfassung von Wertsteigerungen}

Wertsteigerungen sollen als Erhöhung der Marktwerte von Immobilien über die historischen Anschaffungskosten hinaus definiert werden. In Grafik 5 wurde die Wertentwicklung einer Immobilie im Zeitablauf schematisiert dargestellt. Der

1 Diese Problematik tritt auch bei allen Selbstständigen auf, die im Zusammenhang mit der Einkunftserzielung Schuldzinsen steuerlich geltend machen können. 


\section{Grafik 5}

\section{Schematisierter Verlauf der Zeitwerte und Buchwerte einer Immobilieninvestition}

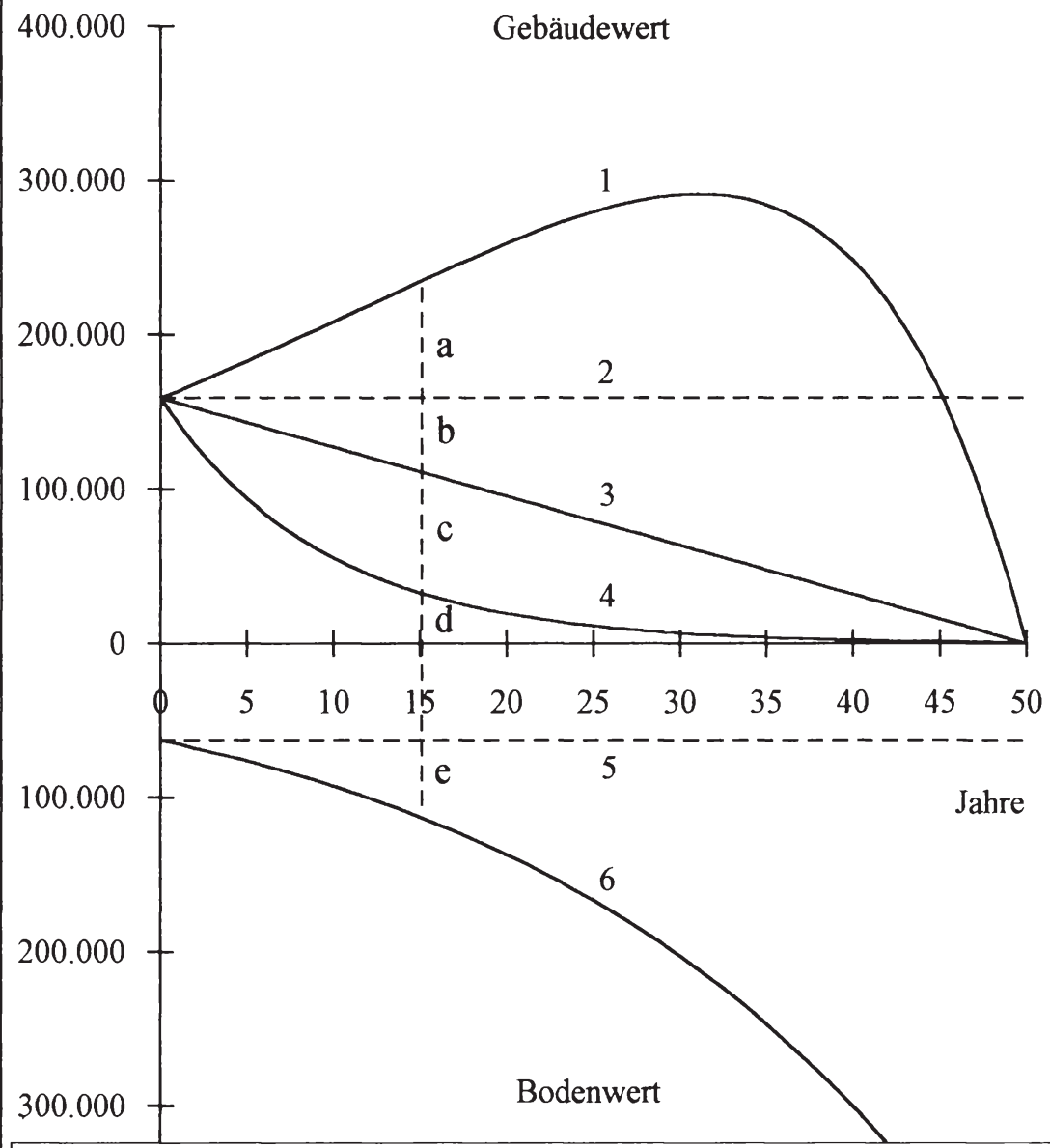

1 Zeitwert Gebäude, 2 historische Anschaffungskosten, 3 Buchwert bei linearer Abschreibung, 4 Buchwert bei degressiver Abschreibung, 5 historische Anschaffungskosten Boden, 6 Zeitwert Boden. 
obere Teil der Grafik gibt den Verlauf des Gebäudewertes wieder, der untere Teil die Entwicklung des Bodenwertes. Die Wertsteigerungen setzen sich aus den Beträgen a und e zusammen. Sie können real und nominal sein. Der Gebäudeteil der Investition wird als reproduzierbares Vermögen hauptsächlich nominale Wertsteigerungen, z.T. aber auch reale Wertsteigerungen erfahren (vgl. Teil 1. A.2.). Der überwiegende Teil der realen Wertsteigerungen, die die gesamte Investition erfährt, wird aber auf den Bodenteil entfallen. Entsprechend dem Untersuchungsziel sollen hier nur die Wertsteigerungen des bebauten Bodens betrachtet werden. ${ }^{1}$ Die Frage, wie Wertsteigerungen von Wohnimmobilien in der Einkommensteuer zu erfassen sind, ist nicht nur fiskalisch bzw. steuersystematisch, sondern auch bodenpolitisch von Bedeutung. Sie kann deshalb im Rahmen dieser Untersuchung nicht erschöpfend behandelt werden. Der Wissenschaftliche Beirat hat sich mit dieser Problematik auseinandergesetzt und kam in seinem Gutachten zur steuerlichen Erfassung von Bodenwertzuwächsen zu keinem abschließenden Ergebnis. ${ }^{2}$ Die Probleme scheinen jedoch nicht unüberwindbar zu sein.

Wertsteigerungen berühren in gleicher Weise wie Einkommen die steuerliche Leistungsfähigkeit. ${ }^{3}$ Sie sollten deshalb eigentlich in die Bemessungsgrundlage des zu versteuernden Einkommens eingehen. ${ }^{4}$ Der überwiegende Teil der

1 Bei der Problematik der Besteuerung von Wertsteigerungen des unbebauten Bodens ist zwischen den Wertsteigerungen im Sinne von windfall profits und Planungswertgewinnen zu differenzieren. Die Problematik sogenannter Sperreffekte, die nur bei der Besteuerung der realisierten Wertsteigerungen eintreten können, kommt hier größere Bedeutung zu, als bei der Besteuerung der Wertzuwächse des bebauten Bodens.

2 Vgl. Wissenschaftliche Beirat beim Bundesministerium der Finanzen, Gutachten über Probleme und Lösungsmöglichkeiten einer Bodenwertzuwachsbesteuerung, Nr. 22 vom 5. Dezember 1975, abgedruckt in: Der Wissenschaftliche Beirat beim Bundesministerium der Finanzen, Gutachten und Stellungnahmen 1974 - 1987, hrsg. vom Bundesministerium der Finanzen, Tübingen 1988, S. $31 \mathrm{ff}$.

3 Vgl. Oberhauser, A., Wertzuwachssteuer, in: Handwörterbuch der Wirtschaftswissenschaften, Band 8, Tübingen 1980, S. $667 \mathrm{ff}$.

4 Vgl. Wissenschaftliche Beirat beim Bundesministerium der Finanzen, Gutachten zur Reform der direkten Steuern (Einkommensteuer, Körperschaftsteuer, Vermögensteuer und Erbschaftsteuer) in der Bundesrepublik Deutschland, Nr. 27 vom 11. Februar 1967, abgedruckt in: Der Wissenschaftliche Beirat beim Bundesministerium der Finanzen, Entschließungen, Stellungnahmen und Gutachten 1949 - 1973, hrsg. vom Bundesministerium der Finanzen, Tübingen 1974, S. $339 \mathrm{ff}$. 
Wertsteigerungen, die bei vermietetem Wohnraum anfallen, ist, wie in Teil 1. C.1. dargelegt wurde, steuerfrei. Die Trennung in einen gewerblichen Grundbesitz, bei dem die Wertsteigerungen der Besteuerung unterworfen werden, und in eine private Vermögensverwaltung ist nicht begründbar (vgl. C.1.). Für die Erfassung des Reinvermögenszugangs spielt es keine Rolle, ob Wertsteigerungen beabsichtigt sind oder eher zufällig anfallen.

Die Diskussion beschränkt sich hier auf die steuerliche Erfassung der Wertsteigerungen von vermietetem Wohnraum. Da selbstgenutztes Wohneigentum seit 1986 durch Definition steuerlich wie ein Konsumgut behandelt wird, können diese Wertsteigerungen im Rahmen der Einkünfte aus Vermietung und Verpachtung nicht mehr erfaßt werden, da es dem Steuerpflichtigen verwehrt ist, Werbungskosten geltend zu machen. Der Reinvermögenszugang läßt sich aber nur als Saldo von Aufwendungen und Erträgen erfassen. Eine eigenständige Wertzuwachssteuer, außerhalb der Einkünfte aus Vermietung und Verpachtung, würde innerhalb der Einkommensteuer eine neue Einkunftsart erfordern und wäre nur schwer auszugestalten. Eine singuläre Sondersteuer außerhalb der Einkommensteuer, die nur die Wertsteigerungen selbstgenutztes Wohneigentum erfaßt, wäre ebenfalls nur schwer auszugestalten und gehört nicht mehr in den Untersuchungsbereich. Mit dem Übergang zur Konsumgutlösung werden damit nicht nur die Mieterträge steuerfrei belassen, es wurde auch die steuerliche Erfassung der Wertsteigerungen selbstgenutzten Wohneigentums innerhalb der Einkommensteuer fast unmöglich gemacht.

Beim vermietetem Wohnraum sind Wertsteigerungen Teil des erzielten Ertrages. Bei rationalem Verhalten der Wirtschaftssubjekte bei der Anlage ihrer Vermögen müssen sich unter Berücksichtigung der unterschiedlichen Risiken die Erträge tendenziell ausgleichen. ${ }^{1}$ Bei Vermögensanlagen, die trotz niedriger Verzinsung gehalten werden, sind Wertzuwächse zum Teil Ausdruck entgangener Zinsen. ${ }^{2} \mathrm{Daß}$ dabei Zufälle ein Rolle spielen und daher erwartete und effektive Wertzuwächse voneinander abweichen, spielt keine Rolle. ${ }^{3}$ Sie sind Teil der erzielten Rendite.

1 Vgl. Oberhauser, A., Wertzuwachssteuer, a.a.O., S. 668.

2 Vgl. ebenda, S. 668.

3 Vgl. ebenda, S. 668. 
Außer diesen grundsätzlichen Erwägungen kommt beim bebauten Boden das Problem hinzu, daß sich die Einkünfte aus Vermietung und Verpachtung im Mietwohnungsbau ohne Berücksichtigung der Wertänderungen des Objektes überhaupt nicht ermitteln lassen. Bei der Erfassung der Einkünfte aus Vermietung und Verpachtung ist es nicht konsequent, die Aufwendungen des Investors in Form der Zinsen und Abschreibungen in voller Höhe zu berücksichtigen, auf der Ertragseite aber nur die Mieteinnahmen. Erst bei Berücksichtigung der Wertsteigerungen läßt sich der Periodenertrag abschließend ermitteln - ein Problem, das vor allem auch unter Berücksichtigung der in Teil 2 A.2. noch zu behandelnden Abschreibungen an Bedeutung gewinnt. Daher wäre es konsequent, gerade auch die nicht realisierten Wertsteigerungen einer Periode steuerlich zu erfassen. Dies soll an einem Beispiel verdeutlicht werden. Angenommen ein Investor finanziert zu hundert Prozent mit Fremdkapital, bei 8 v.H. Kapitalkosten. Die Mieteinnahmen entsprechen einer Verzinsung von 5 v.H., der Objektwert wächst mit 3.v.H. Für den Investor handelt es sich unter diesen Bedingungen um eine Investition, bei der weder Erträge noch Verluste entstehen. Steuerlich macht er aber Verluste in Höhe von -3 v.H. geltend zuzüglich der Normalabschreibung von beispielsweise 1,5 v.H. ${ }^{1}$ Insgesamt wird somit ein steuerlicher Verlust von 4,5 v.H. des investierten Kapitals ausgewiesen.

Die steuerliche Erfassung nicht realisierter Wertsteigerungen wird aber an technisch kaum lösbaren Erfassungs- bzw. Bewertungsproblemen scheitern. Außerdem fußt das deutsche Steuerrecht entsprechend der modifizierten Reinvermögenszugangstheorie (vgl. Teil 1 B.2.) auf dem Realisationsprinzip, das besagt, daß nur realisierte Größen erfaßt werden. Das bedeutet, daß ein Übergang zur steuerlichen Erfassung auch der nicht realisierten Wertsteigerungen eine grundlegende Reform des Einkommensteuersystems einschließlich der Besteuerung der Unternehmen voraussetzen würde.

Aus bodenpolitischen Gründen hätte eine Besteuerung der nicht realisierten Wertsteigerungen allerdings positive Effekte. So ist ein großer Teil der extremen Preissteigerungen, die sich bei Nachfrageerhöhungen auf den Märkten für unbebauten Boden ergeben, darauf zurückzuführen, daß der bebaute Boden

1 Die Normalabschreibung beträgt 2 v.H. vom Gebäudewert. Bei einem Anteil des Gebäudes an der Investition von 75 v.H. ergeben sich Abschreibungen bezogen auf das gesamte Kapital von 1,5 v.H. 
nicht zur Reallokation (dichtere Bebauung) zur Verfügung steht. Durch eine Besteuerung der nicht realisierten Wertsteigerungen würde der Effizienzdruck auf die Nutzung gerade auch des bebauten Bodens steigen. Das Bodenangebot würde sich wesentlich elastischer gestalten, wodurch die unerwünschten starken Preissteigerungen auf den Bodenmärkten gedämpft würden.

Mißt man den steuertechnischen (Erfaßbarkeit) und steuersystematischen (Realisationsprinzip) Bedenken jedoch größere Bedeutung zu, lassen sich nur die realisierten Wertsteigerungen erfassen. Dann muß allerdings auf die Vorteile, die sich bei der Besteuerung der nicht realisierten Wertsteigerungen aus bodenpolitischer Sicht ergeben, verzichtet werden. Außerdem führt ein Abweichen von der Besteuerung der nicht realisierten Wertzuwächse zu Subventionen in Form der zwischenzeitlichen Zinsen, die durch die Steuerstundung bis zur Realisation anfallen. ${ }^{1}$

Gegen eine Besteuerung der realisierten Wertsteigerungen werden vor allem negative Auswirkungen auf die Allokation angeführt. Um Steuern zu vermeiden, würden die Steuerpflichtigen die Veräußerung unterlassen, so daß sogenannte Sperreffekte auftreten. ${ }^{2}$ Dieses Argument trifft jedoch hauptsächlich den unbebauten Grund und Boden und bedarf bei diesem einer eigenen Betrachtung. Bei bereits erstellten Wohnungen dürfen diese negativen Wirkungen nicht überbewertet werden. Bei einer Wohnung, die dem Mietwohnungsmarkt zur Verfügung steht, ist es von untergeordnete Rolle, wer ihr Eigentümer ist. Das heißt, sofern durch die steuerliche Erfassung der Wertsteigerungen Sperreffekte auftreten, tangiert dies den Mietwohnungsmarkt nicht, da das Angebot der Nutzung der Wohnung auf dem Mietwohnungsmarkt c.p. unberührt bleibt. Probleme können vor allem bei älteren Wohnungen auftauchen, da eine Reallokation des Gebäudes (Sanierung) bzw. des Bodens (dichtere Bebauung) u.U. verhindert wird, sofern der Eigentümer selbst kein Interesse hat, diese Investitionen durchzuführen.

Mißt man diesem Problem größere Bedeutung bei, so wäre eine Regelung ähnlich dem $\S 6 \mathrm{~b}$ EStG zu erwägen. Dieser Paragraph wurde vor allem ge-

1 Vgl. Wissenschaftliche Beirat beim Bundesministerium der Finanzen, Gutachten über Probleme und Lösungsmöglichkeiten einer Bodenwertzuwachsbesteuerung, a.a.O., S. 44.

${ }^{2}$ Vgl. ebenda, S. 45. 
schaffen, um Sperreffekte im Unternehmensbereich zu vermeiden. ${ }^{1}$ Er gestattet es, realisierte Wertsteigerungen (stille Reserven) steuerfrei auf andere Anlagegüter zu übertragen. Für den Wohnungsmarkt könnte eine ähnliche Regelung dem Investor gestatten, stille Reserven steuerfrei auf andere Investitionen zu übertragen. Sinnvoll wäre eine Regelung, die einen steuerfreien Übertrag auf die Wiederanlage auf dem Wohnungsmarkt gestattet. Der Übertrag sollte allerdings nur auf Gebäudeinvestitionen möglich sein, nicht auf den Erwerb des Bodenteils, da es ansonsten nicht zu Nachholwirkungen in der Besteuerung kommt. ${ }^{2}$ Durch die zinsfreie Steuerstundung würden zwar die Vergünstigungen weiter zunehmen, auf der anderen Seite würde man Sperreffekten entgegentreten und die Kapitalbindung im Wohnungsbau (mit progressionsabhängigen Subventionen) begünstigen.

Sofern aus wohnungs- oder bodenpolitischen Gründen Vergünstigungen durch Regelungen in Anlehnung an $\S 6 \mathrm{~b}$ EStG geschaffen werden, müßten sich diese auf ein Steuersubjekt beschränken. Es wäre deshalb zu erwägen, zum Zeitpunkt der Vererbung bzw. im Schenkungsfall diese stillen Reserven nachzuversteuern. Die heutige Erbanfallsteuer könnte um eine Besteuerung des Erbnachlasses erweitert werden. Dies wäre keine eigene Steuer, die auf einer gesonderten Rechtfertigung fußt, sondern es würden im Rahmen der Einkommensteuer Steuerstundungen, die aus nichtfiskalischen Gründen gewährt werden, spätestens mit dem Ableben der Steuerpflichtigen nachgeholt werden. Eine solche Maßnahmen würde unerwünschten Vermögenskonzentrationsprozessen entgegenwirken.

Zusätzlich muß der Progression Rechnung getragen werden. Sofern die realisierten Wertsteigerungen im Verhältnis zur Bemessungsgrundlage der Einkommensteuer einen relativ großen Betrag ausmachen, würde die progressive Einkommensteuer zu einer Steuerlast führen, die nicht der Intention der Einkommensteuer entspricht. Allein aus diesem Grund würde sich allerdings kein verminderter Steuersatz rechtfertigen lassen. Realisierte Wertsteigerungen sollten gegenüber anderen Einkünften nicht über die Vergünstigungen der Steuerstundung hinaus begünstigt werden. Es würde sich deshalb anbieten, den

1 Vgl. ebenda, S. 38.

2 Durch den Übertrag vermindern sich die abschreibungsfähigen Anschaffungskosten, weshalb in den späteren Jahren weniger abgeschrieben werden kann. Insofern kommt es zu Nachholwirkungen in der Besteuerung. 
durchschnittlichen Grenzsteuersatz, den der Steuerpflichtige in den Jahren vor der Veräußerung hatte, anzuwenden. Dies würde dem Gedanken der progressiven Einkommensbesteuerung Rechnung tragen.

Bei der Erfassung von Wertsteigerungen sollte man sich auf reale Wertsteigerungen beschränken, ${ }^{1}$ ein Sachverhalt, der ein Abweichen vom Nominalwertprinzip in der Einkommensteuer mit sich bringen würde und ebenso wie die Durchbrechung des Realisationsprinzips singulär auf dem Wohnungsmarkt nicht möglich sein dürfte. Besitzer von Vermögenseinkünften werden vom allgemeinen Preisniveauanstieg anders getroffen als Bezieher von Lohn- und Gewinneinkünften. Wird beispielsweise unterstellt, daß sich die Vermögenswerte entsprechend dem allgemeinen Preisniveauanstieg nominal im Wert erhöhen, behalten sie gerade ihren realen Wert. Die Scheinerträge, die dadurch entstehen, tangieren die steuerliche Leistungsfähigkeit im eigentlichen Sinne nicht. Während die steigende Steuerlast, die aus der progressiven Einkommensbesteuerung resultiert (kalte Progression) durch eine Reform des Steuertarifs von Zeit zu Zeit korrigiert werden kann, ${ }^{2}$ wäre das Problem der Besteuerung der Vermögenssubstanz bei der Erfassung nominaler Wertsteigerungen durch Korrekturen des Steuertarifs nicht gelöst.

Dieses Argument trifft bei der steuerlichen Erfassung von Wertsteigerungen innerhalb der Einkünfte aus Vermietung und Verpachtung allerdings nur zum Teil zu. Es sollte berücksichtigt werden, daß dieses Problem im gesamten Unternehmensbereich und ebenfalls beim Geldvermögensbesitzer existiert. Der Geldvermögensbesitzer muß die nominalen Zinsen versteuern, während nur die realen Zinsen einen echten Reinvermögenszugang darstellen. Um sein Kapital real zu erhalten, müßte er es nominal um die Preissteigerungsrate erhöhen. Nur der darüber hinausgehende Zinsanteil dürfte nach der Intention der Einkommensteuer versteuert werden. Ein singuläres Abweichen bei Immobilien des Privatvermögens wäre deshalb nicht zu rechtfertigen. D.h. mit dem Verweis auf die ungelösten Probleme des Nominalwertprinzips im Rahmen der Einkommensteuer kann die Durchführung einer Wertzuwachssteuer nicht blockiert werden.

1 Vgl. Oberhauser, A., Wertzuwachssteuer, a.a.O., S. 668.

2 Vgl. ebenda, S. 668. 
Dieser Sachverhalt betrifft auch das Betriebsvermögen und bedarf einer einheitlichen Lösung für alle Vermögensarten. ${ }^{1}$

Die Probleme des Nominalwertprinzips relativieren sich aber mit zunehmendem Fremdkapitalanteil an der Investition. Es kann nicht außer acht gelassen werden, daß der Investor durch die allgemeine Preissteigerung nicht nur Scheinerträge erzielt, sondern durch die Entwertung der Verschuldung eine Verbesserung seiner Nettovermögensposition erfährt. Das kann am Beispiel einer Investition mit 100prozentigem Fremdkapitalanteil veranschaulicht werden, da hier am deutlichsten wird, wie sich diese Effekte überlagern. Der Investor erfährt in einem Jahr eine nominale Erhöhung des Immobilienvermögens entsprechend dem allgemeinen Preisniveauanstieg von beispielweise 5 v.H. Der Vermögenswert ist also gerade real erhalten geblieben. Die Verschuldung hat sich zwar nominal nicht verändert, hat aber real um 5 v.H. abgenommen, wodurch sich die Nettovermögensposition des Investors um 5 v.H. verbessert hat. Für die Besteuerung bedeutet dies, daß die Wertsteigerungen nominal erfaßt und besteuert werden könnten, ohne daß dies unter Berücksichtigung des Schuldnergewinns zu Diskriminierungen führt. ${ }^{2}$ Soweit im Gebäude aber Eigenkapital gebunden ist, wird dieses absolut betrachtet diskriminiert, da es einer Scheinbesteuerung unterworfen wird. Es würde aber zu einer Gleichstellung mit dem Geld- und Betriebsvermögen führen.

Es könnte nun erwogen werden, ob die Steuerbefreiung der Wertsteigerungen vielleicht aus wohnungsbaupolitischen Gründen notwendig ist. Es fragt sich, ob der Anreiz, steuerfreie Wertsteigerungen realisieren zu können, eine Vermö-

1 Die Akzeptanz des Nominalwertprinzips bei der Besteuerung in der gewerblichen Wirtschaft dürfte darauf zurückzuführen sein, daß der Gesetzgeber bei der steuerlichen Erfassung der Auflösung stiller Reserven die Möglichkeit des § 6b EStG und Freibeträge geschaffen hat. Außerdem werden zum Teil geringere Steuersätze angewandt.

2 Dies gilt nur, sofern der Nominalzins nicht aufgrund von Preissteigerungen entsprechend höher liegt. Dann geht es allerdings nicht mehr um die Frage, wie sich die Inflation auf die Bewertung der Aktiv- und der Passivseite der privaten Vermögensbilanz verhält, sondern um die Wirkungen der Inflation auf die Stromgrößen Mieten und Zinsen. Empirisch schwanken die realen Zinssätze im Zeitablauf stark. Es gab Perioden mit negativen realen Zinsen, so daß nicht davon auszugehen ist, daß Preissteigerungen sich in vollem Umfang stets in einer Erhöhung des Zinsniveaus niederschlagen. 
gensanlage in Wohnimmobilien für Private erst attraktiv macht. Dieses Argument trifft nur zum Teil zu. Bei rationalem Verhalten wird ein Vermögensgegenstand in Abhängigkeit von seinen zukünftig zu erwartenden Erträgen bewertet. Sinken die Nettoerträge durch eine steuerliche Belastung der Wertsteigerungen, so bedeutet dies, daß die Wirtschaftssubjekte nur bei entsprechend verminderten Anschaffungskosten investieren würden. Da dem Bodenanteil der Investition nahezu keine Kosten gegenüberstehen, werden sich für den Boden als variablem Kostenfaktor entsprechend geringere Marktpreise einstellen, wodurch die Mietrendite (Mieteinnahmen/investiertes Kapital) zunimmt. Ob eine Besteuerung von Wertzuwächsen somit zu einer Verminderung des Wohnraumangebotes führt, kann nicht ohne weiteres abgeleitet werden. Allerdings wird hier ein anderes Problem sichtbar. Die Besteuerung von Wertzuwächsen würde bei ihrer Einführung wahrscheinlich zu einem "Crash" auf dem Markt für bestehenden Wohnraum führen. Bei langjährigen Wohnungseigentümern ist dieses Problem nicht so gravierend, da diese noch zu günstigen Preisen angeschafft haben und dadurch nur um Buchgewinne gebracht werden. Allerdings könnten Eigentümer, die Wohnraum erst in den letzten Jahren erworben haben, stärker betroffen sein, da ihre Immobilienwerte unter die historischen Anschaffungskosten fallen könnten. $\mathrm{Ob}$ es genügen würde, daß sie diese Verluste mit der Einführung einer Wertzuwachssteuer (im Realisationsfall) steuerlich geltend machen können, bedarf einer eigenen Erörterung.

Da ein Übergang zur Besteuerung von Wertzuwächsen vorübergehend negative Auswirkungen auf die zusätzliche Erstellung von Wohnraum hat, sollte ein solcher Übergang nur in Zeiten ausgeglichener Wohnungsmärkte vorgenommen werden.

Insgesamt heißt dies, daß die Probleme der steuerlichen Erfassung der Wertzuwächse des bebauten Bodens im Rahmen der Einkünfte aus Vermietung und Verpachtung lösbar erscheinen, ohne vom Nominalwert- und vom Realisationsprinzip abzuweichen. ${ }^{1}$ Sucht man eine Lösung, die in das heutige System der Einkommensteuer integrierbar ist, müsste man sich auf die Erfassung der nominalen realisierten Wertsteigerungen beschränken, wie dies im Betriebsvermögen üblich ist. Es käme dadurch einerseits zu Diskriminierungen durch das

1 Davon unberührt bleibt die Tatsache, daß auch Wertsteigerungen anderer Vermögensarten des steuerlichen Privatvermögens in die Besteuerung einbezogen werden sollten. 
Nominalwertprinzip, die mit den Zinsvorteilen gegenüber der korrekten Erfassung von nicht realisierten Wertsteigerungen abzuwiegen sind. Andererseits ist zu berücksichtigen, daß den nominalen Wertsteigerungen Schuldnergewinne gegenüberstehen, die ein Übermaß an Besteuerung relativieren. Ebenso wie beim Betriebsvermögen könnte unter nicht fiskalischen (allokativen) Aspekten eine Regelung ähnlich dem § $6 \mathrm{~b}$ EStG erwogen werden. Allerdings sollte ein Übertrag auf Investitionen im Wohnungsbau beschränkt und nur auf Gebäudeinvestitionen zugelassen werden, nicht aber für den Erwerb von Grund und Boden. Faktisch würde dies dazu führen, daß der überwiegende Teil der Wertsteigerungen erst im Erbnachlaß zur Veranlagung herangezogen werden könnte. $\mathrm{Ob}$ dieses starke Abweichen von den Zielen der Einkommensteuer noch vertretbar ist, hängt von der Wertentscheidung zwischen allokativen und distributiven Erfordernissen ab. Allerdings wäre diese Vorgehensweise immer noch befriedigender als die heutige Lösung, bei der nahezu alle Wertsteigerungen bei Wohnimmobilien steuerfrei bleiben. Betrachtet man den skizzierten Lösungsweg, entspricht das Vorgehen weitgehend der heutigen Besteuerung der Gewinneinkünfte. Das würde letztendlich nahelegen, die Einkünfte aus Vermietung und Verpachtung aus den Überschußeinkunftsarten herauszunehmen und steuersystematisch als Gewinneinkünfte zu behandeln. ${ }^{1}$

1 Dieses Vorgehen wurde auch vom Wissenschaftlichen Beirat trotz Bedenken als ein Lösungsansatz befürwortet. Vgl. Wissenschaftliche Beirat beim Bundesministerium der Finanzen, Gutachten über Probleme und Lösungsmöglichkeiten einer Bodenwertzuwachsbesteuerung, a.a.O. S. 46. Unbenommen von dieser Vorgehensweise bliebe eine grundlegende Reform der Einkommensteuer, die die allgemeinen Probleme des Realisationsprinzips und des Nominalwertprinzips für alle Einkunftsarten löst. Ob dieses Vorgehen zur Gewerbesteuerpflicht führen sollte, bedarf einer gesonderten Erörterung. Die Einbeziehung in die heutige Gewerbesteuer wäre wahrscheinlich unbefriedigend, so daß eine solche Umstellung im Einkommensteuersystem mit einem Übergang zu einer "Kommunalen Wertschöpfungsteuer" leichter wäre. Zum Konzept einer kommunalen Wertschöpfungsteuer vgl. Oberhauser, A., Die Eignung der Wertschöpfungsteuer als Gemeindesteuer, in: Kommunale Finanzen und Finanzausgleich, Schriften des Vereins für Socialpolitik, NF 32, Berlin 1964, S. $241 \mathrm{ff}$. 


\section{Teil 2: Maßnahmen zur Förderung des Mietwohnungsbaus}

Wie der erste Teil der Untersuchung zeigte, weisen Immobilieninvestitionen in Abhängigkeit von der Fremdkapitalquote in den ersten 10 bis 15 Jahren charakteristischerweise eine liquiditätsmäßige Unterdeckung auf. Das heißt, daß der Saldo zwischen den Mieteinnahmen und den Ausgaben, im wesentlichen der Ausgaben für die Fremdkapitalkosten, negativ ist. Die Mieteinnahmen übersteigen erst im Zuge des allgemeinen Anstiegs des Mietniveaus die Ausgaben. Von Verlusten in der Anfangssphase sollte in diesem Zusammenhang nicht gesprochen werden, da die Rentabilität der Investition nur unter Berücksichtigung der Abschreibungen, der Wertentwicklung des Objekts und etwaigen Schuldnergewinns durch den allgemeinen Anstieg des Preisniveaus beurteilt werden kann.

Ebenso kann in den späteren Phasen der liquiditätsmäßigen Überdeckung, wenn also die Mieteinnahmen die historisch bedingten Kapitalkosten übersteigen, noch nicht unbedingt von Gewinnen gesprochen werden, da zum einen in späteren Phasen wiederum das gebundene Kapital (ursprünglich eingesetztes Kapital zuzüglich der Wertänderungen) bzw. dessen Opportunitätskosten für die Ertragsermittlung von Bedeutung sind. Läßt man die Wertsteigerungen außer acht, so müssen mit diesen Überschüssen die Defizite der ersten Jahre, zuzüglich der zwischenzeitlichen Kapitalverzinsung, gedeckt werden. Der Zeitpunkt des Eintritts in die liquiditätsmäßige Überdeckung ist somit nicht mit dem Eintritt in die Ertragsphase gleichzusetzen.

Außerdem erfahren Investoren durch die steuerliche Erfassung der Immobilienerträge bei hohem Fremdkapitalanteil bereits progressionsabhängige Liquiditätsentlastungen, im Regelfall aber bereits progressionsabhängige Vergünstigungen, da der steuerlich Verlust aus Vermietung und Verpachtung unter berücksichtigung der Wertzuwächse auf längere Sicht einen Scheinverlust darstellt. Das heißt, damit sich eine Investition in Wohnimmobilien rentiert, muß der Bruttoertrag des gebundenen Kapitals (Miete zuzüglich Wertsteigerungen) nicht unbedingt dem Bruttoertrag alternativer Anlageformen entsprechen, da ein Teil des Ertrags steuerfrei bleibt.

Trotzdem "entsteht immer wieder der Eindruck, die Vermieter von Neubauwohnungen müßten subventioniert werden, damit sie auf ihre Kosten kommen, und 
die Vermieter von Altbauwohnungen müssten daran gehindert werden, hohe Mieten zu verlangen, denen keine entsprechende Kosten gegenüberstehen. " ${ }^{1}$

Diese beiden Vorstellungen haben ihren Niederschlag neuerdings auch wieder in der Gesetzgebung gefunden. Der Gesetzgeber hat in Reaktion auf die gestiegene Wohnungsnachfrage zur Subventionierung von Investoren auf den Wohnungsmärkten eine Reihe bestehender Maßnahmen im Rahmen der Einkommensbesteuerung ausgeweitet bzw. neu geschaffen. Außerdem wurden Maßnahmen ergriffen, um die Mietsteigerungsmöglichkeiten für bestehenden Wohnraum zu begrenzen. ${ }^{2}$ Entsprechend dem Untersuchungsziel werden nur die finanzwirksamen Maßnahmen bzw. Subventionen betrachtet, die ihren Niederschlag im Einkommensteuerrecht gefunden haben.

Die Maßnahmen setzen ausschließlich an den Abschreibungen an und sind in $\S 7$ EStG angesiedelt bzw. für die neuen Bundesländer in § 4 FördergebietsG. Abschreibungen sind zum Synonym für Steuervergünstigungen geworden. Etwas abschreiben zu können, gilt als erstrebenswert, weil damit (u.U. vermeintlich) Steuern gespart werden können. Da sich Abschreibungen außerdem zu einem intensiven Förderinstrument entwickelt haben, erscheint es sinnvoll, zunächst Klarheit über das Wesen und den Inhalt von Abschreibungen zu schaffen, um danach die steuerliche Normalabschreibung und darauf aufbauend die Abschreibungsvergünstigungen würdigen zu können. Ein nicht unerheblicher Teil der Fördermaßnahmen bezieht sich auf Abschreibungen von sogenannten Instandsetzungs-, Herstellungs- und Sanierungsaufwendungen. Daher muß deren steuerliche Berücksichtigung ebenfalls kurz kritisch beleuchtet werden, um die Subventionselemente ermitteln zu können.

1 Eekhoff, J., Wohnungs- und Bodenmarkt, a.a.O., S. 73, Ziffer 73. Eekhoff bezog seine Aussage auf die mangelnde Berücksichtigung der Bedeutung von im Zeitablauf steigenden Mieten.

2 Vgl. 4. Mietrechtsänderungsgesetz, in: BGBI. I, S. 1257. Mit diesem Gesetz wird der Spielraum für Mieterhöhungen in bestehenden Mietverträgen eingeschränkt. 


\section{A. Kritische Würdigung der linearen Abschreibung}

\section{Der Sinn von Abschreibungen}

Abschreibungen sind ein Phänomen, das aus der Periodizität der Wirtschaftsrechnung und aus der Tatsache resultiert, daß die Lebensdauer der meisten Investitionsgüter eine Rechnungsperiode überschreitet. Ein Investor steht vor dem Problem, daß ein Investitionsobjekt nach einer bestimmten Anzahl von Jahren keine Erträge mehr erbringt und somit ökonomisch oder auch technisch verbraucht ist. Um den Periodenertrag zu ermitteln, ist es deshalb nötig, diesen Werteverzehr den einzelnen Jahren der Nutzung zuzuordnen. Abschreibungen werden in den jeweiligen Perioden nicht liquiditätswirksam, d.h. ihnen entspricht keine jährliche Auszahlung, was ihre quantitative Erfassung so schwierig macht. Ihr zeitlicher Anfall und ihre Höhe können damit nur kalkulatorisch ermittelt werden.

In der Regel wird davon ausgegangen, daß sich das Objekt in der jeweiligen Periode gleichmäßig abnutzt, es kann linear abgeschrieben werden. Die kalkulatorische jährliche Wertminderung, die Abschreibung, ergibt sich somit aus den Anschaffungskosten dividiert durch die Anzahl der voraussichtlichen Nutzungsjahre.

Diese relativ transparente Betrachtung ist aber nur für Wirtschaftsgüter tauglich, die eine geringe Anzahl von Jahren genutzt werden. Bei langfristigen Investitionsgütern, vor allem bei Immobilien, sind zwei Modifikationen notwendig, welche die Betrachtung erschweren. Zum einen ist es das Phänomen, daß die Bewertung von Vermögensteilen durch den Markt im Zeitablauf schwankt und der Marktwert zu einem Betrachtungszeitpunkt vom Buchwert abweicht, der sich als Differenz zwischen den Anschaffungskosten und den bis zum Betrachtungszeitpunkt vorgenommenen Abschreibungen ergibt. Zum anderen unterliegen gerade Immobilieninvestitionen, wie im ersten Teil der Untersuchung dargestellt wurde, nominalen und realen Wachstumseinflüssen. Der Marktwert der Betrachtungsperiode stellt aber als Vergleichswert den realistischen Wert des Investitionsgutes bzw. des Vermögensgegenstandes dar. Der Investor müßte also, um den korrekten Vermögenswert am Ende einer jeden Wirtschaftsperiode zu ermitteln und um damit eine Basis für die Feststellung der angefallenen Wertminderungen (Abschreibungen) zu erhalten, den Marktwert bzw. den 
Wiederbeschaffungswert am Ende der Rechnungsperiode als Vergleichswert heranziehen.

Die Konsequenzen, die sich daraus ergeben, können sein, daß einerseits außerplanmäßige Abschreibungen vorzunehmen sind, wenn die geplanten kalkulatorischen Abschreibungen geringer waren als der effektive Vermögensverzehr, der sich aufgrund geänderter Marktbewertung tatsächlich ergeben hat. Es müßten also Abschreibungen nachgeholt werden. Damit verbunden hätte dies aber andererseits zur Konsequenz, was bei Immobilien häufiger der Fall ist, daß Zuschreibungen notwendig wären, sofern der Marktwert den kalkulatorischen Buchwert überschreitet. Das heißt, der Buchwert müßte am Ende der Rechnungsperiode u.U. über den Buchwert des Periodenanfangs erhöht werden. In diesem letzten Fall handelt es sich somit nicht um einen Vermögensverzehr, sondern um eine Vermögensvermehrung mit entsprechender Erhöhung des auszuweisenden Periodenertrags.

Das hätte außerdem zur Konsequenz, daß sich durch diese Neubewertungen die Abschreibungsgrundlage für zukünftige Perioden ändern würde. D.h. der auf diese Weise neu ermittelte Buchwert würde dividiert durch die wiederum angenommene Restnutzungsdauer den zukünftig jährlich vorzunehmenden kalkulatorischen Abschreibungsbetrag darstellen. Wird also vom jeweiligen Zeitwert abgeschrieben, so ergibt sich der Werteverzehr in der Betrachtungsperiode nicht als Bruchteil der Anschaffungs-/Herstellungskosten über die gesamte Lebensdauer der Investition, sondern als Bruchteil in Abhängigkeit von der Restlaufzeit. Gerade bei Immobilien zeigt die Erfahrung immer wieder, daß dieser Buchwert über einen längeren Zeitraum steigen kann, da die Wiederbeschaffungskosten bzw. der Marktwert, sofern er diesen entspricht, im Zeitablauf zunimmt. ${ }^{1}$

Es könnte deshalb argumentiert werden, daß die korrekte Form der Abschreibung die Abschreibung zu Wiederbeschaffungskosten ist. Das heißt, daß die Abschreibungsbeträge entsprechend den gestiegenen Wiederbeschaffungskosten

1 Wiederbeschaffungskosten und Marktwert können kurzfristig voneinander abweichen. Sind die Kosten der Bebauung (Wiederbeschaffungskosten) höher als der Marktwert, kommt es zu keinem zusätzlichen Immobilienangebot bzw. werden die abgeschriebenen Gebäude nicht mehr reinvestiert. Der Marktwert für gebrauchte Immobilien muß somit c.p. mittelfristig auf die Kosten der Wiederbeschaffung ansteigen. Vgl. auch Teil $1 \mathrm{~A}$. 
bzw. dem erhöhten Marktwert erhöht werden müßten, da diese als Bruchteil der Wiederbeschaffungskosten dem tatsächlichen Vermögensverzehr der betrachteten Periode entsprechen. Eine Abschreibung zu Wiederbeschaffungskosten kommt aber nur dann in Frage, wenn konsequenterweise auch Zuschreibungen vorgenommen werden, sofern die Wiederbeschaffungswerte steigen. Sofern der prozentuale Wertzuwachs einer Periode, ermittelt als Verhältnis von Wertsteigerung der Periode und dem Vermögenswert am Periodenanfang, größer ist als die prozentuale Abschreibung (Vermögenswert am Anfang der Periode/Restlaufzeit in Jahren), ergibt sich insgesamt netto eine Zuschreibung, welche den effektiven Periodenertrag erhöht.

Mit der Frage nach dem Werteverzehr einer Periode ist als weiters Problem verbunden, daß die Wirtschaftsrechnung ebenso wie die Besteuerung auf dem Nominalwertprinzip beruht. Das heißt, es wird nicht berücksichtigt, inwieweit ein Ertrag u.U. nur auf eine Geldentwertung zurückzuführen ist. In dem Umfang, in dem sich in gestiegenen Marktwerten Preisniveausteigerungen widerspiegeln, handelt es sich bei diesen Wertsteigerungen um Scheinerträge. Eine Zuschreibung würde also in diesen Fällen nur einen Scheingewinn ausweisen. Andererseits stellt sich das Problem, daß der Investor in zukünftigen Perioden von diesem (nominal) gestiegenen Marktpreis seine kalkulatorischen Abschreibungen vornehmen muß, um den jeweiligen Periodenertrag korrekt ermitteln zu können. Diese höhere Abschreibung kann aber nur vorgenommen werden, wenn zuvor der Buchwert entsprechend erhöht wurde. Der Investor käme also nicht umhin, zunächst eine Zuschreibung vorzunehmen - mit entsprechender Ausweisung eines Scheinertrags.

$\mathrm{Zu}$ diesen Problemen kommen Bewertungsprobleme hinzu. Investitionen, gerade auch Immobilieninvestitionen, sind in aller Regel keine homogenen Güter, sondern individueller Natur. Ein konkreter Marktwert ließe sich in aller Regel erst durch Realisation, d.h. Veräußerung, ermitteln.

Darüber hinaus unterliegen Immobilienwerte Konjunkturschwankungen um ihren langfristigen Trend. Periodisch schwankende $\mathrm{Zu}$ - und Abschreibungen könnten notwendig sein, damit die Buchwerte den Zeitwerten entsprechen, was entsprechende periodische Schwankungen der ermittelten Erträge zur Folge hätte. 
Um diesen Problemen zu entgehen, hat die kaufmännische Form der Ertragsermittlung, in deren Anlehnung die steuerliche Ertragsermittlung erfolgt, pragmatische Lösungen geschaffen. Zum Zeitpunkt der Anschaffung bzw. Herstellung eines Wirtschaftsgutes wird die voraussichtliche Nutzungsdauer festgelegt. Es wird von einem linearen Werteverzehr ausgegangen, d.h. die Kosten werden gleichmäßig über die erwartete Nutzungsdauer verteilt. Sofern die Entwicklung des Marktwertes von den auf diese Weise ermittelten Buchwerten abweicht, werden keine Zuschreibungen vorgenommen, ${ }^{1}$ wohl aber Sonderabschreibungen (nur im Unternehmensbereich), sofern der Marktwert unter dem Buchwert liegt. $^{2}$

Wird das Investitionsobjekt bis zum vollständigen Werteverzehr gehalten und nicht vorzeitig veräußert, erleidet der Investor einen Werteverzehr gerade in Höhe der historischen Anschaffungskosten. Wertsteigerungen während der Dauer der Investition werden nicht zugeschrieben, insofern wird der Buchwert des Vermögensgegenstand nicht entsprechend erhöht. Kompensiert wird dieser Mangel dadurch, daß in anderen Perioden im Umfang der unterlassenen $\mathrm{Zu}$ schreibungen keine höheren Abschreibungen notwendig sind, damit der Buchwert zum Zeitpunkt des totalen Werteverzehrs dem Wert null entspricht. Die Folge dieser Vorgehensweise ist, daß in Phasen der Nettowertsteigerung, in denen der Marktwert über dem Buchwert liegt, ein zu geringer Ertrag ausgewiesen wird und in anderen Phasen ein entsprechend zu hoher Ertrag.

Wird der Vermögensgegenstand hingegen nicht bis zum vollständigen Werteverzehr genutzt, sondern vorzeitig veräußert, so entspricht der Veräußerungserlös in den seltensten Fällen dem Buchwert. Die Veräußerung wirkt im Regelfall somit nicht neutral auf den Periodenerfolg. Wird ein Veräußerungserlös erzielt, der über dem Buchwert liegt, entsteht ein außerordentlicher Ertrag in der Periode der Veräußerung in Höhe der Differenz zwischen beiden Werten. Der außerordentliche Ertrag ist im engeren Sinne nicht der Veräußerungsperiode, sondern den vergangenen Perioden der Nutzung zuzurechnen. Liegt der Veräußerungserlös unter dem Buchwert, gilt entsprechend die Umkehrung.

1 Dieses weitgehende Zuschreibungsverbot dient vor allem dem Gläubigerschutz.

2 Das weitgehende Zuschreibungsverbot und die Vornahme von Sonderabschreibungen, auch bei temporären Markteinflüssen, führt im Unternehmensbereich dazu, daß die Buchwerte oft weit unter den Marktwerten liegen. Die Differenz zwischen diesen beiden Werten wird als "stille Reserve" bezeichnet. 
Allerdings bleibt das Nominalwertproblem, das bedeutet, daß nicht differenziert wird, inwieweit der Ertrag nominaler bzw. realer Natur ist. Dieser Sachverhalt trifft die meisten Investitionen, so daß das Problem bei der Ermittlung der relativen Vorteilhaftigkeit von Investitionen, auch im Vergleich zu anderen Anlageformen, an Gewicht verliert.

Als Ergebnis kann festgehalten werden, daß die lineare Abschreibung kalkulatorischer Natur ist. Dieser Umstand ist aber von untergeordneter Bedeutung, sofern das Investitionsobjekt bis zum Ende der Nutzungsdauer gehalten wird, da unterlassene ertragserhöhende Zuschreibungen durch im gleichen Umfang mithin unnötige und damit ebenfalls zu unterlassende höhere Abschreibungen kompensiert werden. Es handelt sich also letztendlich um ein zeitliches Synchronisationsproblem. Wird das Investitionsobjekt dagegen vorzeitig veräußert, stellt die Differenz zwischen dem Veräußerungserlös und dem Buchwert zum Veräußerungszeitpunkt einen außerordentlichen Ertrag/Aufwand dar, der ausweist, in welchem Umfang zu hoch bzw. zu niedrig abgeschrieben wurde.

$\mathrm{Da}$ die unterlassenen $\mathrm{Zu}$ - und Abschreibungen zu unterschiedlichen Zeitpunkten angefallen wären, die gerade bei Immobilien sehr weit auseinanderliegen können, stellt sich das Problem der zwischenzeitlichen Kapitalverzinsung, ein Sachverhalt, dem bei der steuerlichen Betrachtung eine Bedeutung zukommt.

\section{Die lineare Abschreibung nach $\S 7$ Abs. 4 EStG}

Die Immobilieninvestition ist eine komplementäre Investition in die Bebauung und in den Grund und Boden. Der Boden unterliegt keinem nutzungsbedingten Werteverzehr, insofern gestattet es das Steuerrecht nur für den Gebäudeteil der Investition, Abschreibungen geltend zu machen. Im Regelfall wird von einem linearen Werteverzehr über einen Nutzungszeitraum von 50 Jahren ausgegangen. Das Alter des Objekts ist dabei nahezu ohne Bedeutung. D.h. wechselt das Gebäude während seiner Nutzungsdauer den Eigentümer mehrmals, wird jedesmal von neuem eine Nutzungsdauer von 50 Jahren zugrundegelegt. Als Abschreibungsbeträge gelten somit jeweils 2 v.H. der Anschaffungskosten bzw. Herstellungskosten ${ }^{1}$ ( $\$ 7$ Abs. 4 EStG), die der Erwerber für den Gebäudeteil

1 Wurde das Gebäude vor 1925 erstellt, geht der Gesetzgeber abweichend von einer 40-jährigen Nutzungsdauer aus und gestattet so, daß ein Abschreibungssatz von 
aufgewendet hat. In den Fällen, in denen der Erwerber nicht der Bauherr ist, teilen die Finanzbehörden die Anschaffungskosten in einem pauschalierenden Verfahren in einen Boden- und in einen Gebäudeteil auf, um die Abschreibungsgrundlagen zu erhalten (Abschnitt 43 Abs. 1 EStR, März 1993).

Bei dieser Abschreibungsregelung ist einmal zu analysieren, wie sie vor dem Hintergrund der Ergebnisse des vorigen Abschnitts zu beurteilen ist. Zum anderen fragt sich, wie Abschreibungen bei den quellentheoretisch erfaßten Einkunftsarten gerechtfertigt sind bzw. wie ihre Wirkung in Verbindung mit der generellen Ertragserfassung dieser Einkunftsarten zu sehen ist.

Zunächst fällt die widersprüchliche Behandlung von Aufwendungen und Erträgen bei der Ermittlung der Einkünfte aus Vermietung und Verpachtung auf. Diese Einkünfte gehören zu den sogenannten Überschußeinkunftsarten. Die Ermittlung des steuerpflichtigen Überschusses geschieht nach dem Prinzip der Vereinnahmung und Verausgabung ${ }^{1}$ ( $\left.\$ 11 \mathrm{EStG}\right)$. Einnahmen werden nach dem Zuflußprinzip in dem Jahr zur Versteuerung herangezogen, in dem sie zufließen, also liquiditätswirksam werden. Es wird im Regelfall nicht berücksichtigt, welchem Jahr sie wirtschaftlich zuzurechnen sind. Sinngemäß müßten bei den Überschußeinkunftsarten die Ausgaben, bzw. Anschaffungskosten im Jahr der Anschaffung in vollem Umfang berücksichtigt werden. Dieser Standpunkt wird teilweise in der steuerjuristischen Literatur vertreten. ${ }^{2}$ Der Saldo zwischen Einnahmen und Ausgaben entspräche dem steuerpflichtigen Überschuß einer Periode.

Bei der Ermittlung der Bemessungsgrundlage für das zu versteuernde Einkommen soll aber die Änderung der Nettovermögensposition einer Periode erfaßt werden. Bei der Anschaffung einer Immobilie handelt es sich zunächst nur um

2,5 v.H. geltend gemacht wird ( $\$ 7$ Abs. 4 EStG). Darüber hinaus bleibt es dem Steuerpflichtigen vorbehalten, bei alten Gebäuden eine kürzere zu erwartende Lebensdauer nachzuweisen und geltend zu machen.

1 Vgl. Tipke, K./Lang, J., a.a.O., S. 205.

2 Zur Argumentation sowie entsprechenden Literaturhinweisen vgl. Tipke, K./Lang. J., a.a.O., S. 327. Die Verpflichtung zur Abschreibung anstatt der Berechtigung des Sofortabzugs sei nur deshalb möglich, weil der Gesetzgeber bei der Aufzählung der Werbungskosten in § 9 EStG mit der expliziten Erwähnung des Abschreibungsbegriffs ( $\$ 9$ I Nr. 7 EStG) dies abweichend von den sonstigen Regelungen bei den Überschußeinkunftsarten vorschreibt. 
eine Umschichtung im Portfolio des Steuerpflichtigen, die Nettovermögensposition wird davon nicht tangiert. ${ }^{1}$ Ein Sofortabzug der Anschaffungskosten würde bedeuten, daß der Steuerpflichtige im Jahr der Anschaffung in Abhängigkeit vom Grenzsteuersatz bis zu maximal 53 v.H. der Anschaffungskosten vom Staat in Form von Steuerminderungen erstattet bekäme, ohne daß dies auf eine entsprechende Änderung der Nettovermögensposition zurückzuführen wäre. Insofern kommt eine volle Absetzung im Jahr der Anschaffung aus steuersystematischen Überlegungen und den damit verbundenen verteilungspolitischen Konsequenzen nicht in Frage. ${ }^{2}$

An dieser Stelle wird nochmals deutlich, daß der quellentheoretische Ansatz, der der Besteuerung der Überschußeinkunftsarten zugrunde liegt, bei der Erfassung der Aufwendungen und Erträge von Immobilien, zumindest was den Gebäudeteil betrifft, an seine Grenzen stößt. Bei diesem Ansatz sollen die Komponenten berücksichtigt werden, die auf einem periodisch regelmäßigen Vermögenszufluß beruhen. Auf der Ertragsseite folgt die Praxis der Einkommensbesteuerung konsequent diesem Besteuerungsansatz. Mieteinnahmen erfüllen diese Bedingungen, insofern unterliegen sie der Besteuerung. Wertzuwächse bleiben sowohl in realisierter als auch nicht realisierter Form von der Besteuerung befreit, da sie die "Quelle", nicht aber ihre regelmäßigen periodischen Erträge berühren.

Die Anschaffungskosten stellen im Jahr der Anschaffung keinen Werteverzehr dar. Der Werteverzehr findet im Zuge der Nutzung erst im Zeitablauf statt. Er kann in einer Besteuerungsperiode nur in seiner effektiven Höhe bestimmt werden, sofern er mit den Wertsteigerungen der Periode saldiert wird. Erst die Summe beider Effekte gibt den tatsächlichen wirtschaftlichen Verschleiß wie-

1 An diesem Sachverhalt ändert sich nichts, wenn die Immobilie teilweise oder ganz mit Fremdmitteln finanziert wird. Das Nettovermögen des Steuerpflichtigen als Saldo zwischen Bruttovermögenswert und Fremdkapital entspricht der Vermögensumschichtung.

2 Auch unter Ökonomen wird teilweise die Auffassung vertreten, daß unter allokativen Gesichtspunkten eine Vollabschreibung im Jahr der Anschaffung wünschenswert wäre. Vgl. Nachtkamp, H.H., Grundsätze der Besteuerung - Steuerlicher Einkommensbegriff - Konsequenzen, in: Wohnungspolitik an der Wende, XIX. Königsteiner Gespräche - Referate und Diskussionen, Bonn 1984. Unabhängig davon, wie dieses Argument unter allokativen Gesichtspunkten zu beurteilen ist, scheidet diese Vorgehensweise unter steuersystematischen und verteilungspolitischen Aspekten aus. 
der. ${ }^{1}$ Hier versagt der quellentheoretische Besteuerungsansatz. Anschaffungskosten können bei diesem Besteuerungsansatz, im Sinne einer spiegelbildlichen Erfassung von Aufwendungen und Erträgen, nicht berücksichtigt werden. "Der Aufwand zum Erwerb und ein Wertverlust durch Abnutzung müßten ... ebenso gleichgültig sein wie ein Wertzuwachs, den der Eigentümer mit stiller Freude als nicht steuerbar vermerkt. Zum Beweis dafür, wie wohltuend Inkonsequenz sein kann, sagt das Gesetz, daß es auch hier Absetzungen gibt, und zwar als Werbungskosten." 2

Im vorangegangenen Kapitel wurde herausgearbeitet, daß Abschreibungen eine kalkulatorische Verteilung der Anschaffungs- und Herstellungskosten auf die vermutete Nutzungsdauer darstellen. Das steuerlich pauschalierte Abschreibungsverfahren entspricht dieser Form der Ertragsermittlung. Insofern wird nicht berücksichtigt, wie sich der Werteverzehr in den einzelnen Perioden tatsächlich gestaltet, sondern nur, daß das Gebäude nach einer gewissen Anzahl von Jahren keine Erträge mehr erwirtschaftet. Bei den Regelungen im Steuerrecht geht es auch der Formulierung nach weniger um die Absetzung für Abnutzung im Sinne der Berücksichtigung eines Vermögensverzehrs, sondern letztendlich um die Verteilung der Anschaffungs- und Herstellungskosten. ${ }^{3}$ Der Periodenertrag wird somit bei der Besteuerung bewußt nicht korrekt als Änderung der Nettovermögensposition in der Betrachtungsperiode ermittelt. Diese Abweichung vom Idealtyp der Ermittlung des Periodenertrages könnte als Notwendigkeit zur Vereinfachung der Steuererhebung erklärt werden.

Bei genauerer Betrachtung zeigt sich, daß es anscheinend aber nicht die Intention der Einkommensbesteuerung ist, den Werteverzehr als Änderung der Nettovermögensposition zu berücksichtigen. Ein Eigentümer, der keine oder verminderte Anschaffungskosten hat, weil er beispielsweise ein Objekt erbt,

1 So ist es möglich, daß nach Abzug der Abschreibungen, die wegen einer Verkürzung der Restnutzungsdauer vorzunehmen sind, der gesamte Vermögenswert steigt, da das "Restvermögen" vom Markt höher bewertet wird.

2 Costede, J., Grundfragen der Absetzungsbefugnis wegen Abnutzung, in: StuW, $1 / 1986$, S. 45. Interessant ist in diesem Zusammenhang die Einordnung der Abschreibungen in die Systematik der Einkommensteuer. Sie sind ein Instrument, das bei den Gewinneinkunftsarten (Teil II., Abschnitt 3 EStG) und nicht bei den Überschußeinkunftsarten (Teil II., Abschnitt $4 \mathrm{EStG}$ ) angesiedelt ist.

3 Vgl. Tipke, K./Lang, J., a.a.O., S. 305. 
kann nur in dem Umfang Abschreibungen vornehmen, in dem sie vom vorherigen Eigentümer, bezogen auf dessen historischen Anschaffungs-/Herstellungskosten noch nicht vorgenommen wurden ( $\S 11 \mathrm{~d}$ EStDV). Das heißt, der Erbe muß den Buchwert des Erblassers übernehmen und dessen Abschreibungen fortführen. Dies entspricht aber nicht dem Gedanken der Erfassung der Nettovermögensposition eines Wirtschaftssubjektes. Unabhängig davon, wie ein Steuerpflichtiger zu seinem Objekt gekommen ist, ${ }^{1}$ erfährt er in den jeweiligen Perioden der Nutzung bzw. der Vermietung einen Vermögensverzehr in Abhängigkeit vom Marktwert zum Zeitpunkt des Vermögenszugangs.

Abgesehen von diesem Sonderfall fragt es sich, inwieweit mit der linearen Abschreibungsregelung im Regelfall Subventionen bzw. Diskriminierungen verbunden sind. Zu differenzieren ist zwischen den Fällen, in denen die steuerliche Nutzungsdauer mit der effektiven Nutzungsdauer übereinstimmt, das Ziel der korrekten periodischen Ertragserfassung der Vereinfachung dieser Regelung aber untergeordnet ist. $\mathrm{Zu}$ berücksichtigen ist auch, wie sich Abweichungen in der tatsächlichen von der steuerlichen Nutzungsdauer auswirken. Außerdem kommt es bei der Würdigung der linearen Abschreibungsregelungen in Verbindung mit der Ertragserfassung entscheidend darauf an, ob das Objekt bis zum Ende der Nutzungsdauer gehalten oder vorzeitig veräußert wird.

Wird in einem ersten Schritt davon ausgegangen, daß die steuerliche Nutzungsdauer der tatsächlichen Nutzungsdauer entspricht, so erleidet der Steuerpflichtige bei der Einkunftserzielung bis zur Beendigung der Investition einen Werteverzehr in Höhe des eingesetzten Kapitals. Ändert sich der Marktwert während der Nutzungsdauer, ändert sich nichts an dem Ergebnis, daß das ursprünglich eingesetzte Kapital gerade in seiner ursprünglichen Höhe verbraucht wird. Das bedeutet, daß in den Phasen, in denen das Objekt seinen Wert erhält bzw.

1 Dieser Effekt kann nicht als Ergänzung zu einer eventuell als ungenügend empfundenen Erbschafts- und Schenkungsteuer gesehen werden, die gerade bei Immobilien aufgrund der Einheitsbewertung zu einer erheblich unterbewerteten Bemessungsgrundlage führt. Die steuerliche Behandlung des Vermögenszugangs in der Periode des Erbanfalls bzw. der Schenkung, ist unabhängig von der steuerlichen Berücksichtigung des Werteverzehrs in den zukünftigen Nutzungsperioden zu sehen. Es wäre allerdings, wie in Teil 1 C.3. dargelegt wurde, konsequent, beim Erblasser die Differenz zwischen dem steuerlichen Restbuchwert und dem Marktwert in der Periode des Erbnachlasses zu versteuern. Damit wäre die Abschreibungsgrundlage für den Erben geschaffen. 
Wertsteigerungen erfährt, der Steuerpflichtige einen Werteverzehr geltend macht, obwohl effektiv keiner eintritt bzw. sich sogar der Objektwert erhöht. Nominal wird dies in anderen, meist späteren Phasen dadurch kompensiert, daß ein Werteverzehr eintritt, der über dem liegt, der steuerlich geltend gemacht werden kann. Es kommt somit im Zeitablauf einerseits zu Vergünstigungen und andererseits zu Diskriminierungen. Die Höhe der Steuerersparnis ist abhängig vom individuellen Grenzsteuersatz.

Im Regelfall kann der Steuerpflichtige aber Abschreibungen früher vornehmen, als sie tatsächlich eintreten, vgl. Graphik 5. Insofern erfährt er eine Subvention in Höhe der bis zum tatsächlichen Abschreibungszeitpunkt anfallenden Zinsen. Sofern die tatsächliche Nutzungsdauer mit der steuerlichen Nutzungsdauer übereinstimmt, beschränkt sich die Subvention auf diesen Effekt. Es handelt sich bei der Verteilung der Anschaffungs- und Herstellungskosten auf den Nutzungszeitraum daher um einen Sachverhalt, der unter dem Aspekt der Vereinfachnung der Steuererhebung als Approximation an die Erfassung der steuerlichen Leistungsfähigkeit gerechtfertigt zu sein scheint.

Diese Feststellung ist jedoch zu modifizieren. Zum einen fällt auf, daß auch bei neuen Gebäuden ein nicht unerheblicher Teil des Gebäudes, im wesentlichen die Ausbauten, keine fünfzigjährige Nutzungsdauer aufweisen. Wand-, Boden- und Deckenbeläge, sanitäre Einrichtungen ect. sind in den Anschaffungs- und Herstellungskosten enthalten und werden ebenfalls über 50 Jahre abgeschrieben, obwohl ihre mögliche Nutzungsdauer sicherlich darunter liegt. Auf der anderen Seite werden die elementare Gebäudekonstruktion, Gemäuer, Gebälk ect. eine Nutzungsdauer aufweisen, die wesentlich über fünfzig Jahre hinausgeht.

Auch hier muß die Bemühung um die korrekte steuerliche Erfassung des Vermögensverzehrs wohl einer Notwendigkeit der Vereinfachung der Steuererhebung zum Opfer fallen. Es stellt sich allerdings die Frage, ob aus dem Sachverhalt, daß ein Teil des Gebäudes eine kürzere Nutzungsdauer aufweist, eine degressive Abschreibung zu rechtfertigen ist. Das würde bedeuten, daß ein Teil der Anschaffungs-/Herstellungskosten in früheren Perioden geltend gemacht werden kann. Doch sollen Abschreibungen nicht dem technischen sondern dem ökonomischen Werteverschleiß Rechnung tragen. "So hat ... der technische Verschleiß bei Gebäuden nicht in gleichem Umfang ein Absinken der wirtschaft- 
lichen Leistung zur Folge wie bei einem beweglichen Anlagegut ". ${ }^{1}$ Insofern ist der zeitliche Anfall des technischen Verschleißes für die steuerlichen Abschreibungen von untergeordneter Bedeutung.

Es scheint aber auch nicht das Ziel der Abschreibungsregelung nach $\& 7$ Abs. 4 EStG zu sein, die Anschaffungs-/Herstellungskosten über den effektiven Zeitraum der Nutzung zu verteilen. Dies wird daran sichtbar, daß nahezu ohne Berücksichtigung des Alters des Objektes grundsätzlich von einer 50-jährigen Nutzungsdauer ausgegangen wird. Ein Objekt, das z.B. im Jahr 1925 gebaut wurde und heute seinen Besitzer wechselt, für das also die zweiprozentige Normalabschreibung gilt, müßte mithin eine gesamte Lebensdauer von nahezu 125 Jahren aufweisen. Auch gehen die Finanzbehörden in anderem Zusammenhang $^{2}$ bei der steuerlichen Ertragserfassung davon aus, daß die tatsächiche Nutzungsdauer 100 Jahre beträgt. $^{3}$ Dieser Nutzungszeitraum wurde bis 1964 als Abschreibungszeitraum zugrundegelegt. Bis zu diesem Jahr war eine Abschreibung von nur 1 v.H. zulässig. Die Verkürzung des Abschreibungszeitraums auf 50 Jahre wurde damit begründet, daß massive Wohngebäude zwar im Regelfall eine Lebensdauer von 100 Jahren aufweisen, die Wohngewohnheiten sich aber wesentlich schneller wandeln, so daß Wohngebäude erhebliche Zeit vor Ablauf ihrer technischen Nutzungsdauer abgerissen würden. ${ }^{4}$

Je länger die tatsächliche Nutzungsdauer im Verhältnis zur steuerlichen Nutzungsdauer ist, umso stärker treten Subventionselemente in Form der zwischenzeitlichen Verzinsung der zusätzlichen Abschreibungsbeträge auf. Bei einer einhundertjährigen Nutzungsdauer des Gebäudes erhält der Steuerpflichtige bei einer 2 v.H. Abschreibung im ersten Jahr einen steuerfreien Kredit in Höhe von 1 v.H. multipliziert mit dem individuellen Grenzsteuersatz. Es handelt sich um

1 BMF - Gutachten der Steuerreformkommission 1971, Schriftenreihe des Bundesministeriums der Finanzen, Heft 17, Bonn 1971, S. 487, Tz. 228.

2 Es geht darum, inwieweit Verluste aus Vermietung und Verpachtung in Abgrenzung zur sogenannten Liebhaberei von den Steuerbehörden anerkannt werden.

3 Vgl. Einkommensteuerkartei der OFD München, Karte 4.1. § 21 Abs. 2. Zitiert nach Schönhofer/Reinisch, HuG 15/1/S. 10, Sep. 1992. Danach kommt es bei der Beurteilung der Frage, inwieweit negative Einkünfte aus Vermietung und Verpachtung anerkannt werden, darauf an, ob innerhalb eines 100-jährigen Zeitraums realistischerweise ein Nettoertrag zu erwarten ist.

4 Vgl. Entwurf eines Gesetzes zur Neuregelung der Absetzung für Abnutzung bei Gebäuden, Bundesratsdrucksache, 61/64, S. 5. 
einen Kredit in Höhe der zu hoch in Anspruch genommenen Abschreibungen. Da jedes Objekt nur zu 100 v.H. abgeschrieben werden kann, können diese Abschreibungsbeträge in späteren Perioden nicht mehr in Anspruch genommen werden. Die Nachholwirkungen dieser in den ersten 50 Jahren zu hoch in Anspruch genommenen Abschreibungen setzen im 51. Jahr ein und reichen bis zum 100. Jahr. Vor dem Hintergrund der menschlichen Lebensdauer spielen sie für den Steuerpflichtigen keine Rolle. Insofern stellt dieser zinsfreie Kredit im Regelfall eine endgültige Subvention dar. ${ }^{1}$

Bricht der Steuerpflichtige das Gebäude innerhalb des steuerlichen Abschreibungszeitraums ab, etwa um das Grundstück neu zu bebauen, so erweist sich die steuerliche Nutzungsdauer offensichtlich als zu lang und der Steuerpflichtige kann den steuerlichen Restbuchwert im Jahr des Abbruchs als außergewöhnliche Abschreibung für Abnutzung (AfaA) steuermindernd geltend machen (Abschnitt 44a 14, EStR 1990).

Hält der Investor das Objekt hingegen nicht bis zum Ende der Nutzungsdauer, sondern veräußert es, so kommt es im Regelfall zu Differenzen zwischen dem steuerlichen Restbuchwert zum Veräußerungszeitpunkt - historische Anschaffungskosten abzüglich der bis dahin vorgenommenen Abschreibungen - und dem Veräußerungserlös. Der Veräußerungerlös setzt sich zwar aus dem Gesamterlös für den Grund und Boden und für das Gebäude zusammen, doch kommt es hier nur auf den Teil des Veräußerungserlöses an, der den Gebäudeteil der Investition betrifft. ${ }^{2}$

1 Allerdings ist zu berücksichtigen, daß die Erben nur Abschreibungen geltend machen können, sofern sie vom Erblasser noch nicht vorgenommen wurden (§ 11d EStDV). Die Nachholwirkungen trifft somit die Erben, soweit sie das Objekt nicht veräußern. Die korrekte Besteuerung nach der Leistungsfähigkeit würde es aber in diesem Fall gebieten, daß beim Erblasser die Differenz zwischen dem Marktwert und dem steuerlichen Restbuchwert nachversteuert wird, während der Erbe vom Marktwert zum Zeitpunkt des Erbanfalls seine Abschreibungen zukünftig vornehmen kann.

2 In der Steuerpraxis dürfte dies keine allzu großen Schwierigkeiten bereiten. Beim Erwerber dividieren die Finanzbehörden die Anschaffungskosten in einen Gebäudeund in einen Bodenteil, um die Abschreibungsgrundlage zu erhalten (Abschnitt 43 Abs. 1 EStR, März 1993). Die gleichen Verhältnisse könnten beim Veräußerer ebenfalls für die Nachversteuerung zu hoch vorgenommener Abschreibungsbeträge zugrundegelegt werden. 
Diese Differenz setzt sich am Beispiel der Grafik 5 aus zwei Beträgen zusammen, einmal aus der Differenz zwischen dem historischen Gebäudeanschaffungswert und dem steuerlichen Restbuchwert. Dieser Betrag gibt an, in welchem Umfang der Steuerpflichtige Abschreibungen geltend gemacht hat, die über einen ökonomischen Werteverzehr hinausgehen, in welchem Umfang also zu hoch abgeschrieben wurde (Betrag b). Der darüber hinausgehende Teil gibt die eigentlichen Wertsteigerungen an (Betrag a). Entsprechend dem quellentheoretischen Gedanken ist der gesamte Veräußerungserlös steuerfrei, da er nur einmalig und nicht regelmäßig wiederkehrt und anfällt.

Bei der linearen Abschreibung handelt es sich aber, wie dargestellt wurde, zunächst einmal um einen zugunsten des Steuerpflichtigen vermuteten Werteverzehr, der bis zum Ende der Nutzungsdauer auch tatsächlich eintreten würde. Veräußert nun der Investor das Objekt vorzeitig, so müßten die zu hoch in Anspruch genommenen Abschreibungen konsequenterweise nachversteuert werden. Der Vorteil, der sich aus dieser Inkonsequenz ergibt, ist wiederum abhängig vom individuellen Grenzsteuersatz, den der Investor in der Nutzungsphase hatte.

Diese Überlegungen sind von der Frage der steuerlichen Erfassung von Wertsteigerungen zu trennen. Bei der Nachversteuerung zu hoch vorgenommener Abschreibungen geht es darum, Kosten, die der Steuerpflichtige zu hoch geltend gemacht hat, den tatsächlichen Verhältnissen anzupassen. Bei der Erfassung von Wertsteigerungen geht es dagegen um die Erfassung der Erhöhung des Nettovermögens. Liegt der Veräußerungserlös unter dem steuerlichen Restbuchwert, was selten der Fall sein dürfte, ist es dem Steuerpflichtigen verwehrt, die Differenz als Verlust geltend zu machen. Als Pendant zum umgekehrten Fall ist dies zwar konsequent, es ist aber nur eine Konsequenz in der Inkonsequenz.

Daher ist es für Eigentümer von Immobilien rational, bei steigenden Immobilienpreisen ihr Immobilienvermögen nach einer entsprechenden Anzahl von Jahren zu veräußern und die stillen Reserven steuerfrei zu realisieren. Durch Wiederanlage des Veräußerungserlöses in gleichartige Objekte kann die Abschreibungsgrundlage somit auf die Wiederbeschaffungskosten erhöht werden, ohne die den gestiegenen Wiederbeschaffungskosten zugrundeliegenden Wertsteigerungen zu versteuern. Dieser Sachverhalt ist auch fiskalisch von Bedeutung. Er kann nicht aus wohnungsbaupolitischen Gründen gerechtfertigt werden. So könnte die Abschreibungsgrundlage eines gegebenen Wohnraumbestand 
permanent auf die Wiederbeschaffungskosten erhöht werden, ohne daß dies zusätzlichen Wohnraumbestand schafft.

Daher würde es aus fiskalischer Sicht nicht genügen, nur die zu hoch in Anspruch genommenen Abschreibungen nachzuversteuern. Wechselt ein Objekt während seiner Nutzungsdauer mehrmals den Eigentümer, so könnten die Erwerber, bei gleichen Grenzsteuersätzen, fiskalisch neutral nur dann vom Anschaffungspreis abschreiben, wenn der Veräußerer den Veräußerungserlös versteuert hat. D.h. auch die Wertsteigerungen im engeren Sinne müßten versteuert werden (Beträge $a$ und $b$ in Grafik 5). Sofern der Gesetzgeber nicht zu einer Versteuerung der Veräußerungserlöse in voller Höhe übergeht, wäre zu erwägen, ob der Erwerber den steuerlichen Restbuchwert des Veräußerers übernehmen sollte. D.h. daß das Gebäude bezogen auf seine historischen Anschaffungskosten insgesamt, unabhängig von der Anzahl der Eigentümer und vom Werteverlauf, nur einmal abgeschrieben wird. ${ }^{1}$ Diese Vorgehen würde sich als second best Lösung anbieten. Es hätte den Vorteil, daß die fiskalischen Belastungen nicht permanent dadurch ansteigen, daß immer wieder von den Wiederbeschaffungskosten abgeschrieben wird. Gegenüber einer Lösung, bei der der Veräußerungserlös nachversteuert wird, hätte man den Vorteil, daß sogenannte Sperreffekte vermieden werden. Allerdings entfernt man sich mit einer solchen Lösung von der Intention der Einkommensteuer. Ziel ist die Erfassung von Änderungen des Reinvermögenszugangs eines Steuer"subjektes". Darf der Erwerber nur vom Buchwert des Veräußerers abschreiben, knüpft man bei der Besteuerung nicht mehr an subjektiven, sondern an objektiven Kriterien an. ${ }^{2}$ D.h. eigentlicher Gegenstand der Besteuerung wird die Investition.

Zusammenfassend kann zur Normalabschreibung nach § 7 Abs. 4 EStG festgehalten werden: Sie ist ein pauschaliertes Verfahren, welches zunächst zugunsten des Steuerpflichtigen die Geltendmachung eines vermuteten Werteverzehrs gestattet. Hält der Investor das Objekt bis zum Nutzungsende, ergeben sich aus

1 Vgl. Naust,H./Werth, G., Marktwirtschaftliche Reformen in der Wohnungspolitik, Institut für empirische Wirtschaftsforschung der Universität des Saarlandes, Forschungsberichte, Heft 52, Saarbrücken 1984, S. 25.

2 Es ist allerdings fraglich, ob der Erwerber dadurch tatsächlich diskriminiert wird. Bei effizienten Märkten wird der Erwerbspreis um die geringeren Abschreibungsmöglichkeiten vermindert sein, so daß er c.p. um so niedriger ist, je geringer der steuerliche Restbuchwert ist. Es käme somit zu einer indirekten Besteuerung des Veräußerungserlöses. 
dem Kriterium der Erfassung des Reinvermögenszugangs keine gravierenden Bedenken. Wird die Investition aber durch Veräußerung vorzeitig beendet, ist die Nachversteuerung zu hoch vorgenommener Abschreibungen unumgänglich. Eine Besteuerung von Wertsteigerungen im eigentlichen Sinne wäre mit dieser Form der Besteuerung noch nicht verbunden, es wäre nur gewährleistet, daß vorübergehende Steuervergünstigungen, die im wesentlichen aus Vereinfachungsgründen bei der Steuererhebung gewährt werden, nicht zu endgültigen Subventionen werden. ${ }^{1}$ Durch diese Vorgehensweise würden die Abschreibungen für Abnutzung ihrem eigentliche Wortsinne näher kommen. Sie wären, entgegen der heutigen Praxis, keine Verteilung der Anschaffungs- und Herstellungskosten auf die vermutete Nutzungsdauer, sondern entsprechen dann eher der Berücksichtigung des wirtschaftlichen Werteverzehrs. Damit sich die Veräußerung auch fiskalisch neutral verhält, müssen die Wertsteigerungen im engeren Sinne mit versteuert werden. Entschließt sich der Gesetzgeber nicht, den Veräußerungserlös mit in die Besteuerung aufzunehmen, wäre als Hilfslösung ein Übertrag des steuerlichen Restbuchwertes vom Veräußerer auf den Erwerber denkbar.

\section{Die Berücksichtigung von Instandsetzungsmaßnahmen}

Um den Wert einer Immobilie zu erhalten, ist ein Investor darauf angewiesen, in gewissen Zeitabständen Aufwendungen für die Instandhaltung bzw. Instandsetzung zu tätigen. Diese sogenannten Erhaltungsaufwendungen sind von den Herstellungsaufwendungen abzugrenzen (Abschnitt 157 Abs. 1 EStR, Okt. 1990). Herstellungsaufwand ist dadurch gekennzeichnet, daß etwas Neues, bisher noch nicht vorhandenes geschaffen wird (Abschnitt 157 Abs. 3 EStR, Okt. 1990). Er wird deshalb konsequenterweise aktiviert, d.h. der jeweilige steuerliche Restbuchwert wird um diese Aufwendungen erhöht und gemeinsam mit dem Gebäude abgeschrieben. ${ }^{2}$

1 Im Erbschaftsfall wäre die Nachversteuerung beim Erblasser ebenfalls unumgänglich. Damit könnte die Grundlage dafür geschaffen werden, daß der Erbe die korrekten Abschreibungen in Abhängigkeit des Objektwertes beim Vermögenszugang in Zukunft vornehmen kann.

2 Allerdings sind auch Herstellungskosten bis 4.000 DM im Einzelfall aus Vereinfachungsgründen im jeweiligen Jahr wie Instandsetzungsaufwendungen voll abzugsfähig (Abschnitt 157 Abs. 4 EStR Jan. 1991). 
Erhaltungsaufwendungen dienen hingegen dazu, das Gebäude in seiner bestimmungsmäßigen Nutzungsmöglichkeit zu erhalten (Abschnitt 157 Abs. 3 EStR, Jan. 1991). Sie sind in dem Jahr, in dem sie vorgenommen werden bzw. im Jahr der Verausgabung voll abzusetzen (Abschnitt 157 Abs. 2 EStR, Okt. 1990). Die laufenden Instandhaltungskosten (Reparaturen im engeren Sinne) dürften quantitativ von untergeordneter Bedeutung sein. Dies ist darauf zurückzuführen, daß wohl die wenigsten Abnutzungserscheinungen einer Periode zuzurechnen sind und somit die wenigsten Teile im Sinne von Instandhaltungsaufwendungen periodisch ersetzt werden.

Demgegenüber kommt den Instandsetzungsaufwendungen eine weit größere Bedeutung zu. Sie stellen eine Nachholung zurückgestellter Instandhaltungsaufwendungen dar. Bei Instandsetzungsaufwendungen handelt sich um Aufwendungen für die Erneuerung bzw. den Ersatz von bereits vorhandenen Teilen. Dabei ist es unerheblich, ob die alten Teile technisch verbraucht sind. Ein Ersatz durch technisch modernere Teile kommt ebenso als Instandsetzungsaufwand in Betracht (vgl. Beispiele in Abschnitt 157 Abs. 1 EStR, Okt. 1990).

Ökonomisch gesehen stellen Instandsetzungsaufwendungen Reinvestitionen dar. Im getätigten Umfang wird der Werteverschleiß der vergangenen Perioden reinvestiert. Das bedeutet, daß der gleiche ökonomische Sachverhalt, der wirtschaftliche Werteverzehr, in doppelter Hinsicht bei der Besteuerung berücksichtigt wird. Einmal konnte der Steuerpflichtige die Abschreibungen in der Vergangenheit als Werbungskosten geltend machen. Werden sie nun in Form von Erhaltungsaufwendungen bzw. in Form von Instandsetzungsausgaben reinvestiert, müßten sie konsequenterweise aktiviert werden, d.h. der steuerliche Buchwert des Gebäudes müßte um den Betrag der Erhaltungsaufwendungen erhöht werden. Der Werteverzehr der erneuerten Teile fällt nutzungsbedingt wie die Anschaffungs- und Herstellungkosten erst in zukünftigen Perioden an. Ihre Abschreibung würde sich dann nach der Restnutzungsdauer des Gebäudes richten. Exakter, aber aufwendiger, wäre eine Abschreibung über gesonderte Afa-Tabellen. Theoretisch könnte ein Steuerpflichtiger durch laufende Reinvestition (mit technisch verbesserten Materialien) ${ }^{1}$ das Gebäude in seinem Neu-

1 "Eine deutliche Verbesserung (mit der Annahme von Herstellungsaufwand, Anm. d.Verf.) ist nicht schon deshalb anzunehmen, weil mit notwendigen Erhaltungsmaßnahmen eine dem technischen Fortschritt entsprechende übliche Modernisierung verbunden ist." Abschnitt 175 Abs. 3, S. 5, EStR, Okt. 1991. 
wert erhalten und zusätzlich die normalen Abschreibungen in Anspruch nehmen. Dies liefe faktisch auf eine Abschreibung zu Wiederbeschaffungspreisen hinaus, wobei der steuerlichen Normalabschreibung nach $\S 7$ Abs. 4 EStG zusätzlich ein Freibetragscharakter zukäme.

Die sofortige Abschreibung von Reinvestitionen bedeutet zunächst nur einen Zinsvorteil. Bereits in der zweiten Periode nach der Reinvestition setzen Nachholwirkungen ein, da jedes Wirtschaftsgut nur einmal abgeschrieben werden kann. Die Subvention ist umso höher, je länger die tatsächliche Nutzungsdauer der ersetzten Teile und je höher der individuelle Grenzsteuersatz ist.

Es könnte argumentiert werden, daß diese Regelung aus dem Zwang zur Vereinfachung der Steuererhebung zu erklären ist. Dazu wäre es aber notwendig, daß sie in ihrer Höhe begrenzt ist. Eine völlige Renovierung und Modernisierung eines Gebäudes wird aber nur in wenigen Ausnahmen zur Annahme von Herstellungsaufwand (mit entsprechender Aktivierungspflicht) führen. ${ }^{1}$ Dies käme nur in Betracht, wenn auch erhebliche Teile des Mauerwerks erneuert würden und das Gebäude gleichzeitig umgebaut wird. ${ }^{2}$ Beträge von 100.000 DM scheinen durchaus im Bereich des Möglichen zu liegen. ${ }^{3}$

Allerdings treffen diese Regelungen nur für Investoren zu, die nach längerer Vermietertätigkeit Instandsetzungsmaßnahmen vornehmen. Wird ein Objekt neu erworben und werden Aufwendungen getätigt, die im Normalfall Instandsetzungsaufwendungen darstellen, müssen diese als sogenannte anschaffungsnahe Aufwendungen aktiviert werden (Abschnitt 157 Abs. 5 EStR, Jan. 1991), sofern sie in den ersten 3 Jahren nach dem Erwerb insgesamt 20 v.H. der Anschaffungskosten des Gebäudes überschreiten (Abschnitt 157 Abs. 5 Satz 7 EStR, Jan. 1991). Insoweit bestehen auch hier Begünstigungen. Beim Erwerber, der höhere Aufwendungen tätigt, wird implizit davon ausgegangen, daß sein eingesetztes Kapital der Summe der Anschaffungskosten und der Instandsetzungsmaßnahmen entspricht und als Einheit abzuschreiben ist.

1 Vgl. Jaser, G., Werbungskosten beim Haus und Grundbesitz, in: Schönhofer/ Reinisch, HuG, Loseblattsammlung Gruppe 15 I S. 70/1987.

2 Vgl. ebenda, S. 70.

${ }^{3}$ Vgl. ebenda, Beispiel S. 75. 
Überschreiten die Instandsetzungsaufwendungen im Verhältnis zur steuerlichen Bemessungsgrundlage bestimmte Grenzen, so kann der Sofortabzug allerdings zum Nachteil werden. Dies kann zum einen dadurch der Fall sein, daß die steuerliche Bemessungsgrundlage nicht ausreicht, um die vollen Kosten in einem Jahr geltend zu machen. Zum anderen wird bei großen Abzügen innerhalb der Progressionszone der durchschnittliche Grenzsteuersatz, der auf den Abzugsbetrag angewandt wird, unter dem liegen, der bei einer Verteilung über mehrere Jahre zur Anwendung käme. Damit der Steuerpflichtige die relativen Nachteile der Sofortabschreibung nicht hinnehmen muß, kann er bei größeren Instandsetzungsaufwendungen auch eine gleichmäßige Verteilung auf bis zu fünf Jahr vornehmen ( 8 82d EStDV). Die Entscheidung über die Verteilung auf mehrere Jahre ist ein Optimierungskalkül unter Abwägung der Progressionswirkungen einerseits und der zwischenzeitlichen Kapitalverzinsung andererseits. Für Investoren, deren Einkommen in der oberen Proportionalzone des Steuertarifs besteuert wird, ist ein Sofortabzug in jedem Fall von Vorteil.

Die Nachholwirkungen der Sofortabschreibung der Instandsetzungsmaßnahmen können ebenso wie zu hoch vorgenommene Abschreibungen im allgemeinen durch Veräußerung umgangen werden. Die Problematik der steuerlichen Nichterfassung von Veräußerungserlösen wird an dieser Stelle besonders deutlich. So kann es interessant sein, den Marktwert eines Objektes vor der Veräußerung durch umfangreiche Instandsetzungsmaßnahmen zu erhöhen. Diese Werterhöhung wird in dem Jahr, in dem sie geltend gemacht wird, in Abhängigkeit vom individuellen Grenzsteuersatz vom Staat begünstigt. In dem Umfang, in dem diese Aufwendungen im anschließenden Veräußerungserlös werterhöhend ihren Niederschlag finden, können sie ebenso wie der gesamte Veräußerungserlös steuerfrei realisiert werden. Fiskalisch läuft das darauf hinaus, daß der gleiche Tatbestand einmal beim Veräußerer als Instandsetzungsaufwendungen steuerlich geltend gemacht wird und einmal beim Erwerber im Rahmen der Abschreibungen aufgrund der erhöhten Anschaffungskosten. Sofern der Investor den gesamten Werteverschleiß, der in seine Vermieterzeit fällt, vor der Veräußerung reinvestiert, heißt dies, daß der bis zum Veräußerungszeitpunkt vorgenommenen steuerlichen Normalabschreibung ex post ein Freibetragscharakter zukommt. Am Beispiel der oben erwähnten 100.000 DM kann somit der Vorteil, Instandsetzungsmaßnahmen vor Veräußerung noch durchzuführen, gegenüber einer Veräußerung im unrenovierten Zustand im Extremfall zu einem Nettovermögensvorteil von 53.000 DM führen. Insgesamt würde in diesem Beispiel der 
tatsächliche Werteverzehr aus fiskalischer Sicht dreimal abgeschrieben werden, zweimal im Form von Abschreibungen und einmal in Form von Instandsetzungsaufwendungen.

Wurde eine Verteilung der Instandsetzungskosten auf bis zu fünf Jahre vorgenommen und wird das Objekt innerhalb dieses Zeitraums veräußert, können die noch nicht vorgenommenen Abzugsbeträge trotzdem geltend gemacht werden, jedoch besteht die Verpflichtung, dies vorzeitig im Jahr der Veräußerung zu tun ( $\$ 82 \mathrm{~b}$ Abs. 2 EStDV).

Instandsetzungsaufwendungen stellen mithin eine doppelte Berücksichtigung des gleichen ökonomischen Sachverhaltes dar, einmal durch die Vornahme der allgemeinen Abschreibungen und einmal durch die sofortige Berücksichtigung im Jahr der Verausgabung. Konsequent wäre eine Verteilung der Instandsetzungsaufwendungen auf die zukünftigen Perioden der Nutzung. Da die Abschreibungsregelung des $\S 7$ Abs. 4 EStG bei den Überschußeinkunftsarten wegen der Möglichkeit der steuerfreien Auflösung stiller Reserven ohnehin problematisch ist, wäre zu erwägen, die Normalabschreibung bei Gebäuden des Privatvermögens abzuschaffen. Damit wäre das Problem der Nachversteuerung des Teiles der stillen Reserven, der allein auf einer Überabschreibung beruht, gelöst.

An der Trennung zwischen Herstellungs- und Instandsetzungsaufwand müßte jedoch festgehalten werden. Praktisch würde dies bedeuten, daß die Steuerpflichtigen den Werteverzehr in Form von Instandhaltungsaufwendungen geltend machen können, sofern sie ihn reinvestieren. Wird das Gebäude veräußert, legt der Markt den angefallenen Werteverzehr durch die Bewertung fest. Die Differenz zu den historischen Anschaffungskosten kann der Investor als offensichtlichen Werteverzehr ex post geltend machen, ${ }^{1}$ sofern der Veräußerungserlös unter den historischen Anschaffungskosten liegt. Die Problematik der

1 Allerdings würde dies dazu führen, daß der tatsächliche bzw. reale Werteverzehr in den späteren Veräußerungsperioden steuerlich nicht mehr hinreichend zur Geltung käme, da er inflationär entwertet wurde - ein Problem, das auf das Nominalwertprinzip zurückzuführen ist. Es handelt sich dabei zwar um einen absoluten Nachteil, nicht aber um einen relativen, verglichen mit anderen Vermögensbesitzern. Deren Vermögen wird ebenfalls inflationär entwertet, ohne daß sie dies geltend machen können. Dieses Problem bedarf daher einer einheitlichen Lösung für alle Formen der Vermögensanlage. 
Erfassung von Wertsteigerungen im engeren Sinne bliebe davon jedoch unberührt. Es handelt sich daher um eine wenig befriedigende Lösung.

Befriedigender wäre ein Versteuerung des Veräußerungserlöses unter Beibehaltung der linearen Abschreibung. Sofern die Instandsetzungsmaßnahmen dann weiterhin sofort abzugsfähig bleiben, reduziert sich dieser Vorteil zunächst auf einen Zinsvorteil. Schlagen sich die Instandsetzungsmaßnahmen in einer Werterhöhung des Objektes nieder und veräußert der Investor das Objekt, würde sich der steuerpflichtige Veräußerungsgewinn entsprechend erhöhen. Insofern könnten die Nachholwirkungen nicht mehr umgangen werden. Würde man Instandsetzungsmaßnahmen aktivierungspflichtig machen, was dem Gedanken der Einkommensteuer am ehesten entspricht, mindert sich der steuerpflichtige Teil des Veräußerungserlöses gegenüber dem Fall des Sofortabzuges, da dem Veräußerungserlös ein höherer steuerlicher Restbuchwert gegenüberstünde.

Entschließt sich der Gesetzgeber nicht, den Veräußerungsgewinn zu versteuern und an der linearen Abschreibung festzuhalten, müßte man in jedem Fall dazu übergehen, Instandsetzungsaufwendungen zu aktivieren, da es nicht sinnvoll sein kann, daß der gleiche Tatbestand bis zu dreimal abgeschrieben wird.

Im Rahmen der second best Lösung, einer Fortführung der Abschreibungen durch den Erwerber, wie dies bei der Analyse der linearen Abschreibung vorgeschlagen wurde, könnte man an einem Sofortabzug von Instandsetzungsmaßnahmen festhalten. Dadurch wäre aus wohnungspolitischer Sicht gewährleistet, daß Instandsetzungsaufwendungen nicht unterlassen werden. Veräußert der Investor das Objekt anschließend, verhält sich die Veräußerung fiskalisch neutral, da der Erwerber nicht von den dadurch erhöhten Anschaffungskosten abschreiben kann. Bei effizienten Märkten würde dies dazu führen, daß sich der Veräußerungserlös nicht um die Bruttoinstandsetzungsaufwendungen erhöht, sondern um die Nettoinstandsetzungsaufwendungen. Für Veräußerer mit einem überdurchschnittlichen Grenzsteuersatz wäre es dann allerdings immer noch rational, Instandsetzungsaufwendungen vor der Veräußerung durchzuführen.

\section{B. Kritische Würdigung der speziellen Fördermaßnahmen}

Wie im Teil A gezeigt wurde, beinhaltet die steuerliche Normalerfassung der Aufwendungen und Erträge von Wohnimmobilien zum Teil bereits erhebliche 
Subventionselemente, die nicht als explizite Förderung des Wohnungsbaus aufgefaßt werden. Zur Förderung der Erstellung und Erhaltung von Wohnraum werden verschiedene Maßnahmen eingesetzt, die im folgenden analysiert werden.

\section{Die Fördermaßnahmen}

Die zentralen Instrumente der Wohnungsbaupolitik sind die Abschreibungsregelungen des $\S 7 \mathrm{EStG}$. Insbesondere die degressive Abschreibung nach $\S 7$ Abs. 5 EStG hat mit wechselnder Förderintensität eine lange Tradition. ${ }^{1}$ Für die neuen Bundesländer wurden zusätzlich gesonderte Abschreibungsregelungen in $\S 4$ FördergebietsG geschaffen. Alle Maßnahmen lassen sich unter dem globalen Ziel der Förderung der Erstellung und der Erhaltung bzw. Sanierung von bestehendem Wohnraum einordnen. Die zur Zeit geltenden Regelungen sind in Übersicht 1 zusammengestellt.

- Die wichtigsten und fiskalisch bedeutsamsten Instrumente zur Förderung des Wohnungsneubaus sind die sogenannte degressive Abschreibung nach $\S 7$ Abs. 5 EStG und für die neuen Bundesländer die Sonderabschreibung nach $\S$ 4 Abs. 1 FördergebietsG. Im Vergleich dazu dürften die $\S \S 7 \mathrm{k}$ und 7c EStG von untergeordneter Bedeutung sein. Entschließt sich der Investor, einkommensschwachen Personen eine Wohnung für mindestens zehn Jahre zu einer verminderten Miete zur Verfügung zu stellen, kommt für die Anschaffungs/Herstellungskosten die Abschreibungsregelung nach $\S 7 \mathrm{k}$ EStG in Betracht. Werden in bestehenden Gebäuden zusätzlich neue Wohnungen geschaffen (z.B. ein Dachgeschoß ausgebaut), kann für die Herstellungskosten die Abschreibungsregelung nach $\S 7 \mathrm{c} \mathrm{EStG}$ in Anspruch genommen werden.

- Zur Sicherung des Wohnraumbestandes können die Sanierungsaufwendungen an bestehenden Gebäuden nach § 7h EStG abgesetzt werden, sofern die Wohnung in einem sogenannten festgesetzten Sanierungsgebiet ${ }^{2}$ liegen. Für die neuen Bundesländer kann entsprechend die Sonderabschreibung nach $\S 4$

1 Zur Entwicklung vgl. Anlage 4 zu Abschnitt 44 Abs. 6 EStR, Oktober 1990, 1/4, Übersicht über die degressiven Absetzungen für Gebäude nach $\S 7$ Abs. 5 EStG.

2 Die Festsetzung erfolgt durch die regionalen Gebietskörperschaften aufgrund städtebaulicher Zielsetzungen. 
Übersicht 1

\begin{tabular}{|c|c|c|c|c|}
\hline \multicolumn{5}{|c|}{ Steuerliche Förderung der Erstellung und Erhaltung von vermieteten Wohnungen } \\
\hline & Abschreibungsregelungen & primäre Ziele & $\begin{array}{l}\text { gesetzliche } \\
\text { Grundlagen }\end{array}$ & Abschreibungssätze \\
\hline 1. & Normalabschreibung & $\begin{array}{l}\text { Berücksichtigung des } \\
\text { wirtschaftlichen Werteverschleisses }\end{array}$ & $\S 7$ Abs. 4 EStG & 50 Jahre $\times 2$ v.H. \\
\hline 2. & Degressive Abschreibung & Förderung des Mietwohnungsbaus & $\S 7$ Abs. 5 EStG & $\begin{array}{l}4 \text { J. } x 7 \text { v.H., } 6 \text { J. x } 5 \text { v.H., } \\
6 \text { J. } \times 2 \text { v.H., } 24 \text { J. x 1,25 v.H. }\end{array}$ \\
\hline 3. & $\begin{array}{l}\text { Erhöhte AfA bei Gebäuden in } \\
\text { Sanierungsgebieten }\end{array}$ & Sanierung des Wohnungsbestandes & $\S 7 \mathrm{~h} \mathrm{EStG}$ & $10 \mathrm{~J} . \times 10$ v.H. \\
\hline 4. & $\begin{array}{l}\text { Erhöhte AfA für Wohnungen mit } \\
\text { Sozialbindung }\end{array}$ & Sozialer Wohnungsbau & $\S 7 \mathrm{k} \mathrm{EStG}$ & $\begin{array}{l}5 \text { J. x } 10 \text { v.H., } 5 \text { J. x } 7 \text { v.H., } \\
\text { danach } 3,33 \text { v.H. vom Restwert }\end{array}$ \\
\hline 5. & $\begin{array}{l}\text { Schaffung von Wohnungen in } \\
\text { bestehenden Gebäuden }\end{array}$ & Erhöhung des Wohnungsbestandes & $\S 7 \mathrm{c} \mathrm{EStG}$ & 5 J. x 20 v.H. , max. $60.000,-$ \\
\hline 6. & $\begin{array}{l}\text { Erhöhte Absetzung bei } \\
\text { Baudenkmälern }\end{array}$ & Denkmalschutz & $\S 7 \mathrm{i} \mathrm{EStG}$ & $10 \mathrm{~J} . \times 10 \mathrm{v} . \mathrm{H}$ \\
\hline \multicolumn{5}{|c|}{ Neue Bundesländer } \\
\hline 7. & Neubauten & $\begin{array}{l}\text { Förderung des Mietwohnungbaus, } \\
\text { Beschäftigungspolitik }\end{array}$ & $\S 4$ FördergebietsG & $\begin{array}{l}50 \mathrm{v} . \mathrm{H} \text {. in den ersten } 5 \text { Jahren } \\
\text { zusätzlich zur Normalabschreibung }\end{array}$ \\
\hline 8. & $\begin{array}{l}\text { Sanierungsaufwand an bestehenden } \\
\text { Gebäuden }\end{array}$ & Sanierung des Wohnungsbestandes & $\S 4$ FördergebietsG & $\begin{array}{l}50 \text { v.H. in den ersten } 5 \text { Jahren } \\
\text { Restwertabschreibung bis zum } \\
\text { 10. Jahr }\end{array}$ \\
\hline
\end{tabular}


Abs. 1 FördergebietsG in Anspruch genommen werden. Der § 7 i EStG dürfte empirisch wenig relevant sein, er dient der Subventionierung von Herstellungsaufwendungen an Baudenkmälern.

Die Inanspruchnahme der Maßnahmen ist zeitlich teils begrenzt, d.h. an bestimmte Termine der Baugenehmigung bzw. der Fertigstellung gebunden, teils unbegrenzt. Die detaillierten Voraussetzungen sind für das Untersuchungsziel von untergeordneter Bedeutung, sie sind an den entsprechenden Stellen im Einkommensteuergesetz aufgeführt.

\section{Steuersystematische und verteilungspolitische Beurteilung}

Wie der Abschnitt A. 2. zeigte, wird mit Hilfe der linearen Abschreibung eine Verteilung der historischen Anschaffungs- und Herstellungskosten auf die vermutete Nutzungsdauer eines Objektes vorgenommen. Somit wird bei der Besteuerung keine Rücksicht auf den tatsächlichen Verlauf des effektiven Werteverzehrs genommen. Es wurde ebenfalls gezeigt, daß die lineare Abschreibung im Regelfall vor allem dann Subventionselemente enthält, wenn der Investor das Gebäude nicht bis zum Ende des Nutzungszeitraums hält.

Allen Abschreibungsvergünstigungen ist es gemeinsam, daß die Abschreibungen zeitlich vorgezogen werden. D.h. in den ersten Jahren nach der Investition können Abschreibungen geltend gemacht werden, die über denen der linearen Abschreibung liegen. Die Notwendigkeit eines degressiven Verlaufs der Abschreibungssätze läßt sich bei Gebäuden aber weder aus technischen noch wirtschaftlichen Überlegungen begründen. ${ }^{1}$ Abschreibungen mindern als Werbungskosten die Bemessungsgrundlage des zu versteuernden Einkommens. Insofern kommt es zu Minderungen der Steuerschuld. Die absolute Höhe der Steuerminderung ist deshalb von der Höhe des sonstigen Einkommens bzw. vom Grenzsteuersatz abhängig.

Jedes Objekt kann bezogen auf seine historischen Anschaffungs- bzw. Herstellungskosten insgesamt nur zu 100 v.H. abgeschrieben werden. Insofern können in dem Maße, in dem zeitlich vorgezogene Abschreibungen gewährt

Vgl. Gutachten der Steuerreformkommission 1971, a.a.O., S. 487. Vgl. auch Teil 2 A. 2. der vorliegenden Untersuchung. 
werden, in späteren Perioden nur noch Abschreibungen geltend gemacht werden, die unter denen der linearen Abschreibung liegen. In späteren Phasen liegt damit das zu versteuernde Einkommen über dem Einkommen, das der Besteuerung bei Vornahme von linearen Abschreibungen zugrundeläge. Insofern kommt es zu Nachholwirkungen. Die absolute Höhe der Nachholwirkungen ist wiederum von den Grenzsteuersätzen abhängig. Ändern sich die Grenzsteuersätze während des gesamten Investitionszeitraums nicht, was bei einer langfristigen Investition unrealistisch erscheint, heben sich die Steuervergünstigungen und die Nachholwirkungen nominal, d.h. dem Betrage nach, gerade auf. Abschreibungsvergünstigungen stellen in diesem Fall lediglich die Gewährung eines zinslosen Steuerkredites dar. Die Subvention besteht aus den zwischenzeitlichen Zinsersparnissen. Da diese proportional mit der Höhe des Steuerkredites zunehmen und die Höhe des Steuerkredites vom Einkommen abhängt, nimmt die absolute Höhe des Zinsvorteils ebenfalls mit zunehmendem Einkommen zu.

Die Nachholwirkungen können durch Veräußerung umgangen werden. Der Veräußerungserlös bleibt, abgesehen von den wenigen in Teil 1 C. 1. der Untersuchung beschriebenen Fällen, von der Besteuerung unberührt. In dem Umfang, in dem über die lineare Abschreibung hinaus abgeschrieben wurde, kommen die Nachholwirkungen nicht mehr zum Tragen. Die nominale Höhe der umgangenen Nachholwirkungen besteht zum Zeitpunkt der Veräußerung aus der Differenz des steuerlichen Buchwertes bei Normalabschreibung und dem Buchwert bei degressiver Abschreibung multipliziert mit dem Grenzsteuersatz. Diese Differenz entspricht in der schematisierten Grafik 5 dem Betrag c multipliziert mit dem individuellen Grenzsteuersatz.

Steuersystematisch sind Abschreibungsvergünstigungen ein Fremdkörper. Sie sind den Werbungskosten zugeordnet. Werbungskosten sollen dazu dienen, die Aufwendungen, die der Steuerpflichtige in Verbindung mit der Erzielung der jeweiligen Einkunftsart tätigt, den Erträgen gegenüber zu stellen, um den effektiven Reinertrag für die Ermittlung der Bemessungsgrundlage des zu versteuernden Einkommens zu erhalten. Gestattet der Gesetzgeber, in einer Periode höhere Aufwendungen geltend $\mathrm{zu}$ machen als tatsächlich anfallen, hat dies nichts mehr mit dem Ziel der Ermittlung der steuerlichen Leistungsfähigkeit zu tun. Damit wird die objektive Bemessungsgrundlage der Einkommensteuer verzerrt, sie spiegelt nicht mehr die tatsächlichen Verhältnisse wider. Sofern aus sozialpolitischen oder anderen Gründen Subventionen gewährt werden, sollten Maßnahmen ergriffen werden, die die Besteuerung nach der 
Leistungsfähigkeit möglichst wenig stören. ${ }^{1}$ Eine Verfolgung außerfiskalischer Zielsetzungen mit solchen steuerlichen Mitteln, die an der Bemessungsgrundlage ansetzen, ist deshalb grundsätzlich abzulehnen. ${ }^{2}$ Der mit den einzusetzenden Mitteln angestrebte Erfolg ist unabhängig davon, wer bzw. aus welchem Einkommen die Investitionen finanziert werden. ${ }^{3}$ Es ist deshalb nicht einzusehen, warum der gleiche Sachverhalt unterschiedlich "steuerlich honoriert" ${ }^{\text {"4 }}$ wird. Abschreibungsvergünstigungen sind somit ein Verstoß gegen die Subventionsgerechtigkeit, da der gleiche Beitrag zur Zielerreichung unterschiedlich subventioniert wird. Die progressionsabhängigen Vergünstigungswirkungen, die aus solchen Maßnahmen resultieren, sind deshalb "eine Pervertierung der Progression". 5

Unmittelbar verbunden mit den Verteilungswirkungen stellt sich auch die Frage nach der Effizienz des staatlichen Mitteleinsatzes. Das Effizienzkriterium gibt vor, daß ein bestimmtes Ziel, die Erstellung einer zusätzlichen Wohneinheit, mit einem Minimum an staatlichem Mitteleinsatz verfolgt werden sollte. Es ist unbestreitbar, daß der Staat kaum die exakte Höhe der notwendigen Subvention kennen kann, aufgrund derer die Investition in Wohnimmobilien den Privaten als Alternative zu anderen Anlageformen als rentabel erscheint. Doch rechtfertigt dies nicht, ausgehend von einer bestimmten Ausgangs- bzw. Mindestsubvention (beispielsweise $1 \mathrm{DM}$ bei einem Grenzsteuersatz von 19 v.H.) entsprechend dem heutigen Progressionstarif bis zum knapp Dreifachen (2,78 DM, Grenzsteuersatz 53 v.H.) dieser Ausgangssubvention zu gewähren. Wird auf-

1 Vgl. Wissenschaftliche Beirat beim Bundesministerium der Finanzen, Gutachten zur Reform der direkten Steuern (Einkommensteuer, Körperschaftsteuer, Vermögensteuer und Erbschaftsteuer) in der Bundesrepublik Deutschland, a.a.O., S. 337.

2 Vgl. Gutachten der Steuerreformkommission 1971, a.a.O., S. 488.

3 Vgl. Peffekoven, R., Freibetrag oder Steuerkredit?, in: Finanzarchiv, Bd.30, 1971, S. 415.

4 Vgl. Andel, N., Einkommensteuer, a.a.O., S. 377.

5 Vgl. Wissenschaftliche Beirat beim Bundesministerium der Finanzen, Gutachten zur Reform der direkten Steuern (Einkommensteuer, Körperschaftsteuer, Vermögensteuer und Erbschaftsteuer) in der Bundesrepublik Deutschland, a.a.O., S. 327. Mit solchen Maßnahmen bleibt zwar die Progression bei der Einkommensteuer erhalten, doch wird ihre Wirkung abgeschwächt. Insofern bezieht sich diese Formulierung auf die Wirkungen der Progression und nicht auf den absoluten Grad der Progression. Zur Kritik an dieser harten Formulierung vgl. Peffekoven, R., Freibetrag oder Steuerkredit?, a.a.O., S. 415. 
grund der geltenden Abschreibungsvergünstigungen das Wohnraumangebot vergrößert, scheint es innerhalb der Progressionszone des Steuertarifs eine Stelle zu geben, bei der der Subventionswert gerade ausreicht, damit den Investoren die Rendite einer Wohnungsbauinvestition alternativ zur Rendite anderer Anlageformen genügt. ${ }^{1}$

Dies hat zur Konsequenz, daß unterhalb dieser Einkommensgrenze die potentiellen Investoren mangels Rentabilität von diesen Maßnahmen ausgeschlossen sind. Die Subventionswerte reichen bei diesen Grenzsteuersätzen nicht aus, damit die Rendite von Wohnimmobilien mit denen alternativer Anlageformen mithalten kann. Somit wird die Verteilung des Neuvermögenszugangs in Form von Wohnimmobilien aufgrund des staatlichen Einflusses auf die Rendite zu einer Funktion des Grenzsteuersatzes. ${ }^{2}$ Weiter hat dies zur Konsequenz, daß der Staat oberhalb dieser Grenze mehr Subventionen aufwendet, als zur Erreichung des Subventionsziels nötig wären. Außer dem Einfluß auf die Verteilung des Immobilienvermögens wird damit auch über das Subventionsziel hinausgeschossen, was einen ineffizienten Einsatz von Fördermitteln bedeutet.

Im ersten Teil der Untersuchung wurde dargelegt, daß sich durch die synthetische Einkommensbesteuerung individuelle Sparfähigkeit und Liquiditätsentlastungen durch Steuerminderungen kumulieren. Außerdem führt die unzulängliche periodische Erfassung von Wertsteigerungen zu Scheinverlusten, die progressionsabhängige Subventionen mit sich bringen.

Die Abschreibungsvergünstigungen wirken sich zusätzlich auf die Liquidität aus. Dieser Effekt spiegelt sich in den weiter unten ermittelten Subventionswerten, die im wesentlichen zeitpunktbezogen ermittelt werden, eher unzulänglich wider. In den Finanzierungsrechnungen der privaten Investoren bzw. der finanzierenden Bank werden die Abschreibungsvergünstigungen üblicherweise auch nicht mit ihrem tatsächlichen ökonomischen Wert berücksichtigt. Die

1 Theoretisch könnte diese Grenze auch am Übergang zur oberen Proportionalzone liegen.

2 Da die Brutto- bzw. auch Nettorenditen in Abhängigkeit vom Einkommen asymmetrisch beeinflußte werden, sind darüber hinaus Rückwirkungen auf die Bewertung des Immobilienvermögens zu erwarten. Mit zunehmendem Einkommen kann unter Berücksichtigung der steuerlichen Förderung ein höherer Immobilienpreis bezahlt werden, so daß sich das Rendite/Preisverhältnis der unteren Einkommensgruppen verschlechtern kann. 
Subventionswerte, die aus ihnen resultieren, werden vielmehr wie ein verlorener staatlicher Investitionszuschuß behandelt. Dies liegt einmal an der unvollkommenen Information über den tatsächlichen Gehalt von Abschreibungsvergünstigungen, vielleicht aber auch daran, daß die Nachholwirkungen spät angesetzt sind bzw. durch Veräußerung umgangen werden können. Im Fall der vorzeitigen Veräußerung werden die Abschreibungsvergünstigungen ex post zu Freibeträgen mit einkommensabhängigen endgültigen Subventionen. Auch setzen die Nachholwirkungen relativ spät ein und die Tilgung des Steuerkredites zieht sich über einen sehr langen Zeitraum hin. Im Regelfall werden die Abschreibungsvergünstigungen in den ersten 10 Jahren gewährt, während die Tilgung danach bis zum 50. Jahr stattfindet. Für die extremen Abschreibungsvergünstigungen des § 4 FördergebietsG heißt dies, daß der Investor im ersten Jahr einen Finanzierungszuschuß von bis zu 26,5 v.H. (52 Abschreibung * 53 v.H. Grenzsteuersatz) des im Gebäude investierten Kapitals erhält. Dieser Zuschuß wird danach zinslos im Zeitraum vom 6. bis zum 50. Jahr zurückbezahlt. In Anbetracht menschlicher Planungs- und Finanzierungshorizonte kommt dem Sachverhalt der Tilgung, zumindest der Beträge in den letzten Jahrzehnten, nahezu keine Bedeutung zu.

Zusammenfassend kann festgehalten werden: Abschreibungvergünstigungen setzen an der Bemessungsgrundlage des zu versteuernden Einkommens der Investoren an. Da das Subventionsziel unabhängig von den Einkommensverhältnissen des Investors ist, wird damit gegen das Postulat der Besteuerung nach der Leistungsfähigkeit verstoßen. Außerdem ist dies ein Verstoß gegen die Subventionsgerechtigkeit, da der gleiche Beitrag zur Erreichung eines Subventionsziels auch gleich bezuschußt werden sollte. Rentiert sich eine Investition in Wohnimmobilien ohne staatlichen Zuschuß nicht, beeinflußt der Staat mit den Abschreibungsvergünstigungen aufgrund des Einflusses auf Liquidität und Rentabilität außerdem die Verteilung des neugebildeten Immobilienvermögens. 


\section{Quantitative Ermittlung der Subventionswirkungen}

\subsection{Erfassung der Subventionswirkungen am Beispiel der degressiven Abschreibung nach $\$ 7$ Abs. 5 EStG}

Abschreibungsvergünstigungen bewirken in den ersten Jahren eine Liquiditätsentlastung beim Investor. Sie führen beim Staat im gleichen Umfang zu Steuerausfällen. ${ }^{1}$ Bleiben die Grenzsteuersätze im Zeitablauf konstant, werden die Steuerausfälle in späteren Jahren nominal durch höhere Steuereinnahmen kompensiert. Somit wächst im Umfang der Abschreibungsvergünstigung zunächst ein "Kredit" an, der in späteren Jahren "getilgt" wird. In einer steuerund inflationsfreien Welt beliefe sich der Saldo der ermittelbaren Subventionswerte mithin auf Null.

Dieser Sachverhalt ist am Beispiel der degressiven Abschreibung nach $₹ 7$ Abs. 5 EStG in Grafik 6 abgebildet. Die lineare Abschreibung wird als Nullinie der Subvention zugrundgelegt. In den ersten 10 Jahren liegen die Abschreibungsbeträge über denen der linearen Abschreibung, ${ }^{2}$ wodurch sich die Steuerausfälle in Abhängigkeit vom Grenzsteuersatz bis auf maximal 20,1 v.H. des im Gebäude investierten Kapitals kumulieren. Vom 11. bis zum 16. Jahr entsprechen die Abschreibungsbeträge der degressiven Abschreibung denen der linearen, wodurch der angewachsene Steuerkredit in diesem Zeitraum unberührt bleibt. Ab dem 17. Jahr setzen die Nachholwirkungen ein. Im folgenden Zeitraum liegen die Abschreibungsbeträge der degressiven Abschreibung leicht unter denen der linearen Abschreibung, wodurch allmählich eine Tilgung stattfindet. Im 40. Jahr ist das Gebäude bei der degressiven Abschreibung zu 100 v.H. abgeschrieben, wodurch sich die Tilgung bis zum 50. Jahr beschleunigt.

Der entsprechende Verlauf ist für den Eingangssteuersatz von 19 v.H. ebenfalls in der Grafik abgebildet. Der maximale Kredit beträgt hier 7,22 v.H. des

1 Von Änderungen der Höhe des Sozialproduktes, die in Zeiten der Unterbeschäftigung durch staatliche Subventionen hervorgerufen werden können, wird abstrahiert. Sie spielen allerdings für die Finanzpolitik eine bedeutende Rolle. Die Rückwirkungen auf die Steuereinnahmen können bei entsprechender Gestaltung den ursprünglichen fiskalischen Aufwand übersteigen. Vgl. Oberhauser, A., Das Schuldenparadox, in: Jahrbücher für Nationalökonomie und Statistik, Band 200, 1985, S. $333 \mathrm{ff}$.

$2 \mathrm{Zu}$ den Abschreibungssätzen vgl. Übersicht 1. 


\section{Grafik 6}

Der Verlauf des Steuerkredits (kumulierte Zeitwerte) und der Zinsbelastung des Staates (Jahreswerte) aus der degressiven Abschreibung nach $\S 7 \mathrm{Abs} .5 \mathrm{EStG}$

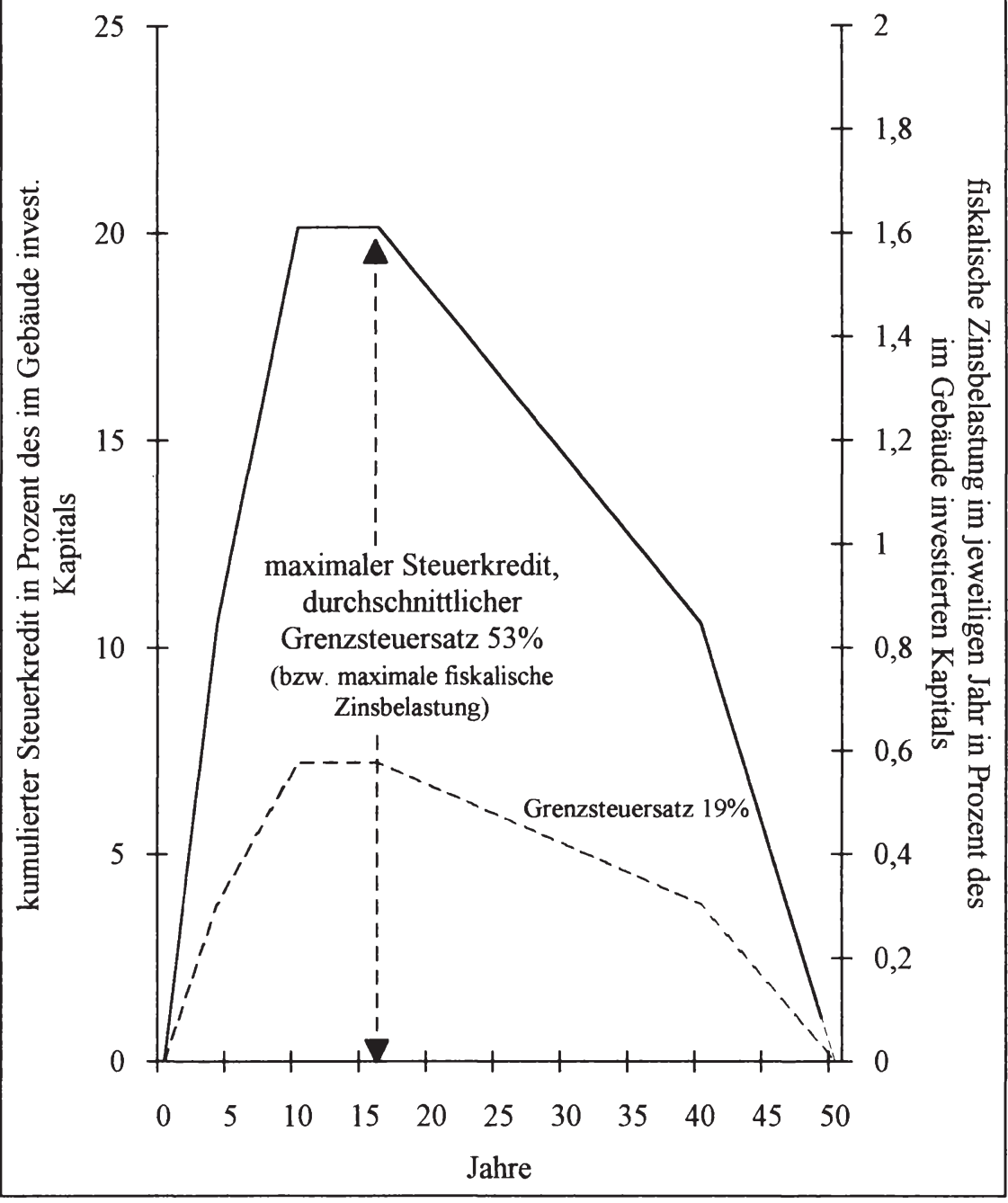


investierten Kapitals, mithin knapp ein Drittel des maximal gewährten Kreditvolumens. Die Abzugsbeträge der Abschreibungsvergünstigungen entsprechen einem bestimmten Teil der Bemessungsgrundlage, so daß darauf ein durchschnittlicher und nicht ein einheitlicher Grenzsteuersatz zur Anwendung kommt. Deshalb sollte eigentlich vom durchschnittlichen Grenzsteuersatz gesprochen werden.

Ändern sich die Grenzsteuersätze im Zeitablauf, was wohl der Realität entspricht, können bei im Zeitablauf steigenden Grenzsteuersätzen die Nachholwirkungen nominal größer sein, als der im Förderjahr gewährte Kredit und umgekehrt. Der letzte Fall spielt vor allem für Selbständige und Angehörige freier Berufe eine Rolle, für die die Wohnungsbauinvestition Teil der Alterssicherung ist.

Der Fall der vorzeitigen Veräußerung ist jedoch von größerer Bedeutung. Wird das Objekt während des fünfzigjährigen Zeitraum veräußert, werden die noch ausstehenden Nachholwirkungen umgangen, da der Veräußerungserlös von der Steuer unberührt bleibt. Der noch ausstehende Teil des Steuerkredits wird nicht mehr getilgt. Der Liquiditätszuschuß, der in den ersten Förderjahren gewährt wurde, nimmt durch die Veräußerung ex post den Charakter eines Investitionsfreibetrages bzw. einer einkommensabhängigen Investitionsprämie an.

Dies ist nicht zu rechtfertigen. Unabhängig von der Erfassung von Wertsteigerungen sollte der Teil des Steuerkredites nachversteuert werden, der bis zum Veräußerungszeitpunkt noch nicht getilgt wurde. Bei der Analyse der linearen Abschreibung wurde festgestellt, $d a ß$ es für den Investor rational ist, seine Objekte von Zeit zu Zeit zu wechseln, da er dadurch die Abschreibungsgrundlage auf die Wiederbeschaffungskosten erhöhen kann, ohne die den gestiegenen Wiederbeschaffungskosten zugrundeliegenden Wertsteigerungen versteuern zu müssen. Dieser Anreiz wird durch die Gewährung der degressiven Abschreibung erhöht.

Technisch wäre der nachzuversteuernde Betrag relativ einfach zu ermitteln. Er entspricht der Differenz des steuerlichen Restbuchwertes bei linearer und bei degressiver Abschreibung (Betrag c in Grafik 5). Man könnte diesen Betrag voll in die Bemessungsgrundlage des zu versteuernden Einkommens eingehen lassen oder aber mit einem konstanten Grenzsteuersatz besteuern, um die Progressionswirkungen zu begrenzen. Angebracht wäre im letzten Fall wiederum eine 
Proportionalbesteuerung mit dem durchschnittlichen individuellen Grenzsteuersatz der letzten Jahre, der beim Investor zur Anwendung kam.

Die bisherigen Ausführungen erfolgten ohne Berücksichtigung der zwischenzeitlichen Zinsersparnisse. Diese Darstellung liefert nicht nur einen Überblick über die Liquiditätsentlastungen des Investors, sondern bringt auch die Verminderungen des Steueraufkommens in den Förderjahren zu Ausdruck. Die Gewährung und Tilgung des Steuerkredites zieht sich über einen sehr langen Zeitraum hin, wodurch dem Sachverhalt der zwischenzeitlichen Zinsersparnissen große Bedeutung zukommt. Zur Erfassung der Subventionswirkungen, die auf der zwischenzeitlichen Kapitalverzinsung beruhen, bieten sich zwei Verfahren an, die Zeitwertmethode und die Barwertmethode. Die Eignung dieser Methoden ist von der Fragestellung abhängig.

Die Zeitwertmethode wird dem nicht finanzwissenschaftlich geschulten Ökonomen auf den ersten Blick ungewöhnlich vorkommen, doch wird sie fiskalischen Überlegungen gerecht, die auf Zahlungsströmen (Einnahme- und Ausgaberechnung) und nicht auf einer Aufwands- und Ertragsrechnung beruhen. Es wird davon ausgegangen, daß sich der Staat in Höhe der Mindereinnahmen, die durch die Steuerausfälle der Abschreibungsvergünstigungen resultieren, verschulden muß, da die Höhe der Ausgaben als exogen vorgegeben angesehen wird. Die Zeitwertmethode erfaßt die Zinsen, die auf diese Staatsverschuldung zu zahlen sind. Die Methode gibt dem Finanzpolitiker einen Anhaltspunkt, in welchem Umfang in den zukünftigen Perioden auf den Staat Zinsbelastungen zukommen. ${ }^{1}$ Während die Steuermindereinnahmen selbst nicht direkt im Staatshaushalt sichtbar werden, zeigen sich die fiskalischen Ausfälle in der sich kumulierenden Staatsverschuldung und den daraus resultierenden Zinsbelastungen. Die Staatsverschuldung und ihre Tilgung entspricht wiederum dem Verlauf des Steuerkredites in Grafik 6. Bei der Zeitwertmethode steht der zeitliche Verlauf der Zinszahlungen im Vordergrund. Den über den gesamten Zeitraum saldierten Zinsausgaben kommt weniger Aussagekraft zu. ${ }^{2}$

${ }^{1}$ Vgl. Oberhauser, A., u.a., Eigentumsbildung im Wohnungsbau, Lübeck 1982, S. $15 \mathrm{f}$.

2 Die Überlegungen bewegen sich auf einem relativ hohen Abstraktionsniveau. Der Staatshaushalt beruht auf dem Nonaffektationsprinzip, was bedeutet, daß die Staatsverschuldung bzw. Tilgung einer Periode nicht disaggregiert nach ihren Ursachen aufgegliedert ist. Vielmehr geht die Kreditgewährung und Tilgung von Abschreibungsvergünstigungen in der allgemeinen Verschuldung unter. 
Am Beispiel der degressiven Abschreibung nach § 7 Abs. 5 heißt das, daß sich die Zinsausgaben proportional zum sich kumulierenden Steuerkredit verhalten, d.h. in der Phase, in der die Abschreibungsbeträge über denen der linearen Abschreibung liegen, wachsen bzw. im umgekehrten Fall abnehmen. Dieser Sachverhalt ist ebenfalls in Grafik 6 dargestellt. Der zeitliche Verlauf der Zinsbelastung ist auch hier als Prozentsatz des investierten Kapitals mit Hilfe der gleichen Linie dargestellt und als jährlich notwendige fiskalische Ausgabe an der zweiten Achse ablesbar (Zinssatz 8 v.H.). ${ }^{1}$

Die Zinsen, die der Investor spart, stellen im Gegensatz zum zugrundliegenden Steuerkredit endgültige Subventionen dar. Da sie von der Höhe des Steuerkredites abhängen und dieser wiederum von der Höhe der Grenzsteuersätze der einzelnen Investoren, ist die Höhe der endgültigen Subvention ebenfalls von der Höhe der Einkommen der Investoren abhängig. Die über den gesamten Zeitraum saldierten Zinsaufwendungen sind in Grafik 7 in Abhängigkeit von der Höhe des Einkommens des Investors dargestellt. Sie belaufen sich ausgehend von 18,8 v.H. des investierten Kapitals bei einem durchschnittlichen Grenzsteuersatz von 19 v.H. bis auf 52,5 v.H. des investierten Kapitals beim Grenzsteuersatz von 53 v.H. ${ }^{2}$

Die Zeitwerte liefern zwar einen Anhaltspunkt über die fiskalische Liquiditätsbelastung aus der Verzinsung des Steuerkredites, lassen aber nur begrenzt eine Aussage über die effektiven Kosten im ökonomischen Sinne zu. Hierzu ist die Barwertmethode geeigneter. Sie entspricht der in der Betriebswirtschaft vorherrschenden Art der Ermittlung der Vorteilhaftigkeit von Investitionen und von Subventionen.

Bei der Barwertmethode werden alle zukünftigen Steuerminder- und Steuermehreinnahmen auf einen bestimmten Zeitpunkt, meist die Gegenwart, ab-

1 Es wurde eine vorschüssige Auszahlung der Beträge unterstellt, d.h, daß der volle Steuerkredit im Jahr der Gewährung zu verzinsen ist. Wird er erst am Ende der Periode fällig, so verläuft die Kurve der Zinsbelastung um eine Periode versetzt hinter der Entwicklung des Steuerkredites.

2 Es handelt sich um eine schematisierte Grafik, da ihr eine Marginalinvestition von $1 \mathrm{DM}$ zugrundeliegt. Die tatsächlichen Subventionen liegen in Abhängigkeit von der Höhe des Abschreibungsbetrages darunter, da mit zunehmenden Abschreibungsbeträgen ein durchschnittlich geringerer Grenzsteuersatz auf die Abzugsbeträge angewandt wird. 


\section{Grafik 7}

Subventionswerte der degressiven Abschreibung nach $\S 7 \mathrm{Abs}$. $5 \mathrm{EStG}$ in Abhängigkeit vom Einkommen des Investors

(1) in Prozent des investierten Kapitals (schematisiert)

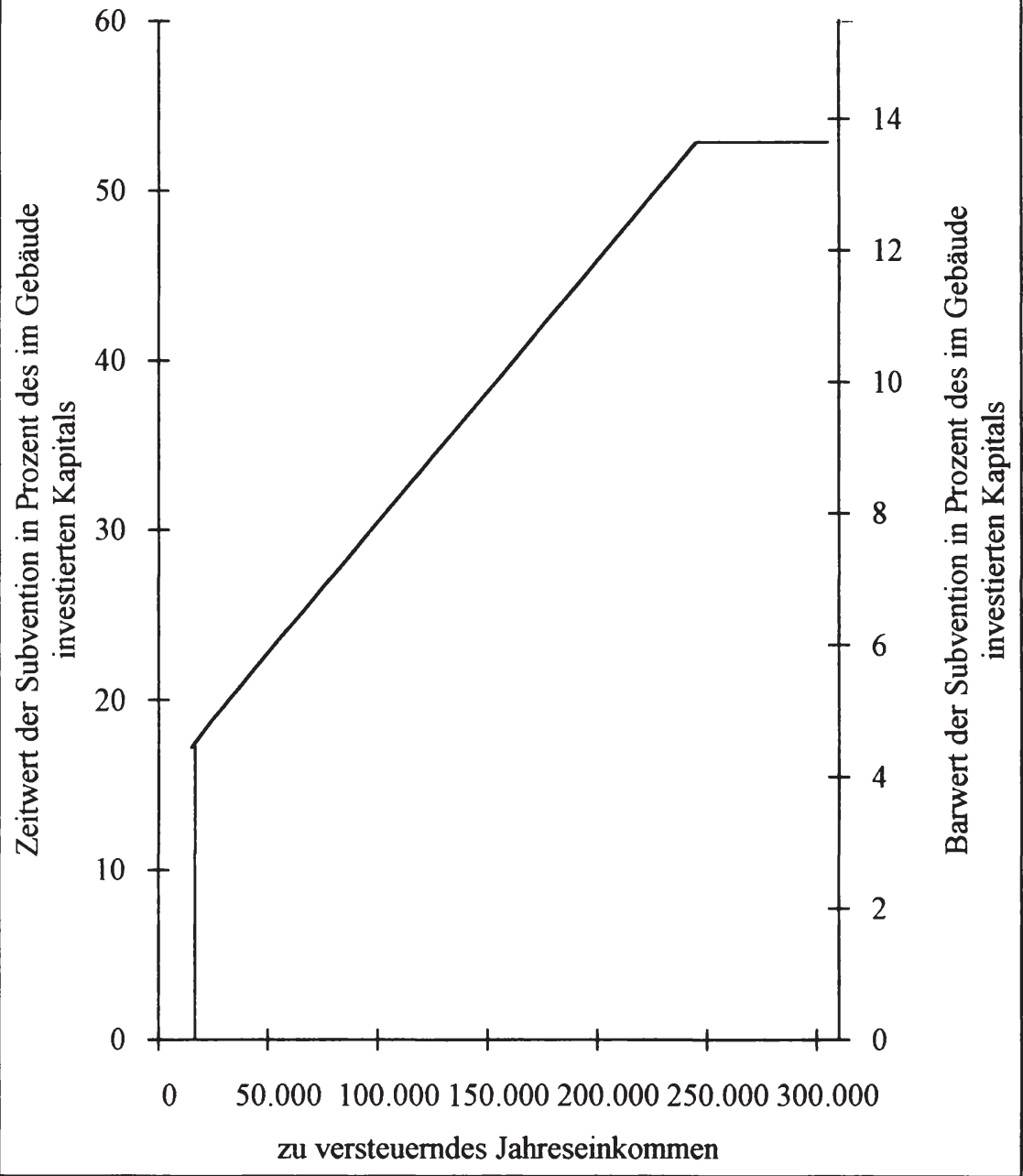

(1) Splittingtarif 
diskontiert. Als Diskontierungsfaktor wird ein einheitlicher Kapitalmarktzins zugrundegelegt. Je höher dieser Zinssatz ist, desto höher ist der Barwert der Subvention, da zu späten Zeitpunkten anfallende Beträge ( hier die "Tilgungen") entsprechend geringer in den Barwert eingehen. Aus fiskalischer Sicht gibt der Barwert eine Vorstellung über die Höhe einer notwendigen verzinslichen Rückstellung, die heute gebildet werden müßte, damit mit den Mitteln der Rückstellung und deren Verzinsung der Steuerkredit abgewickelt werden kann. Die Rückstellung wäre am Ende des 50. Jahres gerade aufgebraucht. Anders formuliert entspricht der Barwert dem Betrag, den der Staat heute einer privaten Bank geben müßte, damit diese die Subventionsgewährung und Tilgung für ihn bis zum Ende des 50. Jahres vornimmt.

Die Barwerte der Subvention der degressiven Abschreibung belaufen sich wiederum in Abhängigkeit vom Einkommen zwischen 4,9 v.H. des investierten Kapitals bei einem durchschnittlichen Grenzsteuersatz von 19 v.H. bis zu maximal 13,6 v.H. beim Spitzengrenzsteuersatz. Die Barwerte sind ebenfalls in Grafik 7 in Abhängigkeit vom zu versteuernden Jahreseinkommen entsprechend der rechten Skala abgebildet.

Die Nachholwirkungen finden bei der degressiven Abschreibung erst in einem relativ späten Zeitraum zwischen dem 17. und dem 50. Jahr statt. Die Barwerte der Nachholwirkungen fallen deshalb relativ zum Barwert der Steuerausfälle in den ersten Förderjahren gering aus. Untersucht man den Barwert in Abhängigkeit von der Haltedauer des Objektes, so erscheint zumindest nach dieser Methode die Umgehung der Nachholwirkung für die fiskalische Gesamtbelastung von geringerer Bedeutung zu sein. Veräußert der Investor das Objekt zum Zeitpunkt des Einsetzens der Nachholwirkungen, somit am Ende des 16. Jahres, beträgt der Barwert der Subvention maximal 15,3 v.H. Der Barwert der umgangenen Nachholwirkungen, abdiskontiert auf die Gegenwart, beträgt demgegenüber nur 1,7 v.H. beim Spitzensteuersatz.

In Grafik 8 ist der Barwert der degressiven Abschreibung in Abhängigkeit von der Haltedauer des Objektes zur Veranschaulichung abgebildet. Der geringe Barwert der umgangenen Nachholwirkungen erklärt sich daraus, daß die zwischenzeitliche Kapitalverzinsung gegenüber den nominalen Tilgungsleistungen in den Vordergrund tritt. Schwankungen des Grenzsteuersatzes im Zeitablauf, vor allem aber ein starkes Absinken in der Tilgungsphase, spielen für die fiskalische Belastung bei dieser Betrachtung ebenfalls ein untergeordnete Rolle. 


\section{Grafik 8}

Subventionswerte (Barwerte) der degressiven Abschreibung nach $\S 7 \mathrm{Abs}$. $5 \mathrm{EStG}$, in Abhängigkeit von der Haltedauer des Objekts und vom Grenzsteuersatz

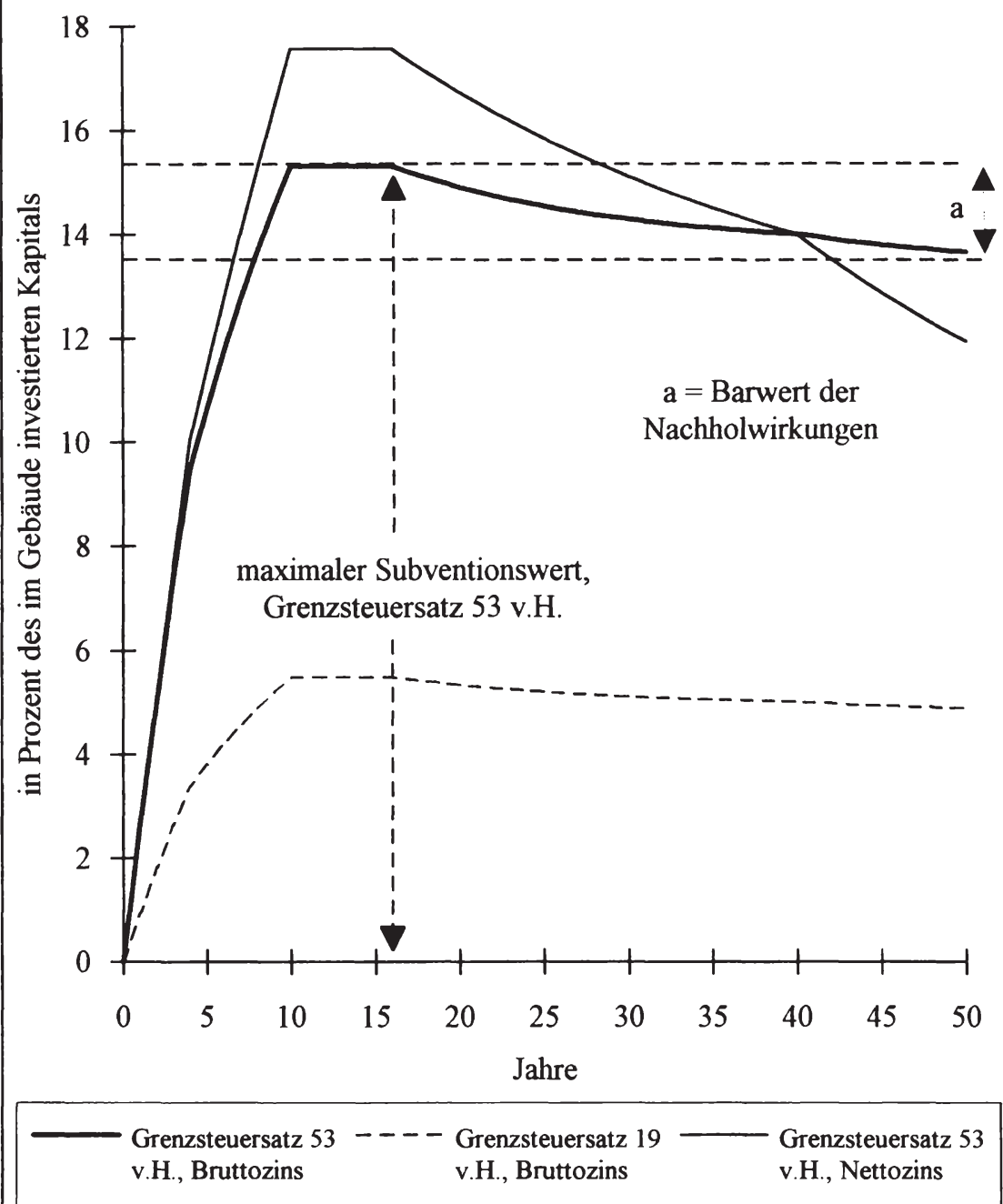


Die hier ermittelten Subventionswerte sind zur besseren Übersicht und zum Vergleich mit den weiter unten skizzierten sonstigen Abschreibungsvergünstigungen in Tabelle 1 zusammengestellt. Die ausgewiesenen Werte geben jeweils die maximalen Subventionen beim Spitzengrenzsteuersatz wieder, die darunterliegenden Subventionswerte beziehen sich auf den Eingangssteuersatz. Dazwischen steigen die Subventionswerte bedingt durch den linear progressiven Steuertarif linear progressiv an (entsprechend den Verläufen in Grafik 7). Spalte 2 gibt den Barwert der Subvention wieder, Spalte 3 den Zeitwert, sofern das Objekt bis zum Ende der Nutzungsdauer gehalten wird. Spalte 4 enthält den Zeitpunkt (Jahr) des Einsetzens der Nachholwirkungen. Spalte 5 gibt den Barwert der Nachholwirkung wieder, sofern das Gebäude bis zum Ende des 50jährigen Zeitraums genutzt wird. Je geringer dieser Wert ist, umso stärker sind die Abschreibungsbeträge durch die Abschreibungsvergünstigungen zeitlich vorgezogen worden bzw. umso später setzen die Nachholwirkungen ein.

Unter dem Blickwinkel der Barwertmethode kommt dem Aspekt der Nachversteuerung umgangener Nachholwirkungen eine andere Bedeutung zu. In Tabelle 1 wird der Sachverhalt der umgangenen Nachholwirkungen in den Spalten 6 bis 9 getrennt ausgewiesen. Ausgangspunkt der Überlegung ist wiederum der Betrag c in Grafik 5. Der Zeitpunkt, in dem die Nachholwirkungen einsetzen, ist gleichzeitig der Zeitpunkt der maximalen Überabschreibung. Das kommt dadurch zum Ausdruck, daß die Differenz zwischen dem steuerlichen Restbuchwert bei Normalabschreibung und dem Buchwert bei degressiver Abschreibung zu diesem Zeitpunkt das Maximum erreicht (Spalte 6). In der Übersicht ist der Zeitpunkt des Einsetzens der Nachholwirkungen als ein fiktiver Veräußerungszeitpunkt zugrundegelegt. Insofern handelt es sich wiederum um die maximalen Effekte. Wird die Differenz zum Veräußerungszeitpunkt nachversteuert, würde die Steuerschuld beim Spitzensteuersatz 20,1 v.H. betragen, was gerade dem aufgelaufenen Kredit entspricht (bei im Zeitablauf konstanten Grenzsteuersätzen). Dieser Betrag wäre beispielsweise im Unternehmensbereich an Steuern im Jahr der Veräußerung zu entrichten, ${ }^{1}$ da hier die Differenz zwischen steuerlichem Restbuchwert und Veräußerungserlös steuerpflichtig ist. Liegt der Veräußerungserlös über dem Buchwert bei linearer Abschreibung, so vergrößert sich der fiskalische Ausfall entsprechend, da der Erwerber von den Anschaf-

1 Sofern der Veräußerungerlös gerade dem Buchwert bei linearer Abschreibung entspricht. 


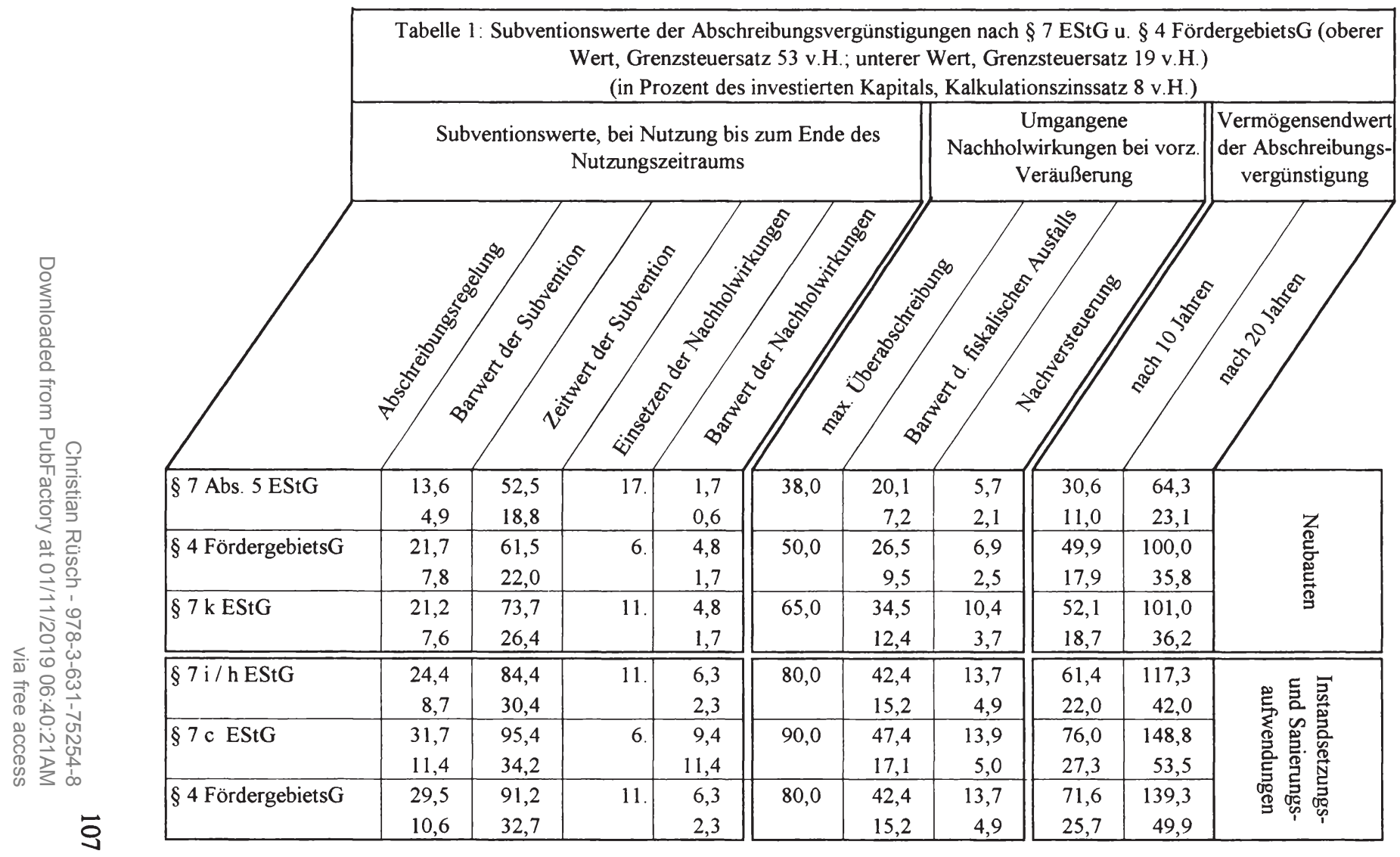


fungskosten erneut abschreibt (vgl. auch A.2.) Dieser Verlust ist hier nicht ausgewiesen.

Der in Spalte 7 ausgewiesene Betrag entspricht aber nicht dem effektiven fiskalischen Ausfall, der durch die vorzeitige Veräußerung eintritt. Er entspricht ihm zwar nominal, d.h. ohne Berücksichtigung der zwischenzeitlich anfallenden Zinsen, liegt aber unter Berücksichtigung der zeitlichen Komponente bzw. der zwischenzeitlich anfallenden Zinsen erheblich darunter. Er entspricht dem Barwert der Nachholwirkungen, abdiskontiert auf den Veräußerungszeitpunkt, also hier auf das 17. Jahr. In diesem Fall beträgt er 5,7 v.H. des investierten Kapitals.

Die Frage, in welcher Höhe bei vorzeitiger Veräußerung Steuern zu erheben wären, in diesem Fall 5,7 v.H. oder 20,1 v.H. hängt von der Zielsetzung ab. Geht man davon aus, daß das Subventionsziel des Staates, eine Wohnung zu erstellen, darin bestand, vorgezogene Abschreibungen zu gewähren, und daß der Staat bereit war, dafür einen bestimmten Aufwand hinzunehmen, so sollte durch die vorzeitige Veräußerung der Subventionsbetrag zumindest nicht vergrößert werden. Unter diesem Aspekt würde es genügen 5,7 v.H. an Steuern zum Veräußerungszeitpunkt nachzuerheben.

Stellt man jedoch grundsätzlichere Erwägungen an, die am eigentlichen Sinn von Abschreibungen anknüpfen, dann gilt die gleiche Argumentation wie bei der Analyse der linearen Abschreibung. Steuersystematisch sollten Abschreibungen mit dem Werteverzehr eines Gutes in Zusammenhang stehen. Erweist sich bei der Veräußerung, daß der tatsächliche Werteverzehr geringer war, muß dies zum Zeitpunkt der Realisierung korrigiert werden, spätestens also zu dem Zeitpunkt, an dem die Diskrepanz zwischen steuerlichem und tatsächlichem Werteverschleiß offensichtlich wird. Zu Diskriminierungen würde dies keineswegs führen. Dem Steuerpflichtigen blieben nach wie vor die Liquiditätsvorteile bzw. die Vorteile der zwischenzeitlich anfallenden Zinsen.

In Tabelle 1 ist nachrichtlich der Vermögensenswert ermittelt, der sich aus den jeweiligen Abschreibungsvergünstigungen ergibt. Er entspricht dem Endbetrag, den der Investor aus der Anlage der Subventionen aus den Abschreibungsvergünstigungen am Kapitalmarkt nach 10 bzw. 20 Jahren erzielt. Das Kapitalkonto wurde um die Nachholwirkungen der Abschreibungsvergünstigungen, die bis zum Betrachtungszeitpunkt eingetreten sind, gemindert. 


\subsection{Subventionswirkungen der sonstigen Abschreibungsvergünstigungen}

Außer der exemplarisch beschriebenen degressiven Abschreibung nach $\S 7$ Abs. 5 EStG hat der Gesetzgeber mit einer Reihe weiterer Abschreibungsregelungen auf die Wohnraumknappheit reagiert. Sie lassen sich in zwei Gruppen einteilen.

- Die Sonderabschreibung nach § 4 FördergebietsG und die erhöhte Abschreibung für Wohnungen mit Sozialbindung nach $\S 7 \mathrm{k}$ EStG werden ebenfalls wie die oben beschriebene degressive Abschreibung nach $\S 7$ Abs. 5 EStG für die Schaffung neuen Wohnraums gewährt. Sie stellen für den Investor unter bestimmten Voraussetzungen eine Alternative zur degressiven Abschreibung dar.

- Die Abschreibungsvergünstigungen nach § 7c, 7h und 7i EStG beziehen sich demgegenüber auf Herstellungs- und Sanierungsaufwendungen an bestehenden Gebäuden. Sie werden für die Modernisierung von vorhandenen Wohnungen bzw. Schaffung von neuen Wohnungen in bestehenden Gebäuden gewährt. Das gleiche gilt für $\S 4$ FördergebietsG. Er kann ebenfalls für Sanierungsaufwendungen in Anspruch genommen werden. Die Höhe der Subventionen dieser Abschreibungsvergünstigungen hängt $\mathrm{u}$.U. von der Restnutzungsdauer des Gebäudes ab.

\section{a. Die Vergünstigungen zur Erweiterung des Wohnungsangebotes ( $\$ 7 \mathrm{k}$ EStG und $\& 4$ FördergebietsG)}

- Die quantitativ höchste Abschreibungsvergünstigung, die derzeitig im deutschen Steuerrecht gewährt wird, ist die Sonderabschreibung nach § 4 FördergebietsG. "Sie eröffne(t) dem Geldanleger Steuersparmöglichkeiten, wie sie einer Generation nur selten zu Teil werden ${ }^{.1}$ Diese Maßnahme wurde nicht gezielt für den Wohnungsbau geschaffen, sondern ursprünglich für nahezu alle Arten von Investitionen in den neuen Bundesländern gewährt. Trotz erheblicher Einschränkungen der begünstigungsfähigen Investitionen durch das Standortsicherungsgeset $\mathrm{z}^{2}$ (1993) blieb die Begünstigung von Wohnungsbauinvestitionen unberührt, woran der hohe Stellenwert der Wohnungspolitik sichtbar wird. In

1 Fleischmann, G., zitiert nach: "Ein Generationsgeschenk für steuergeplagte Anleger", in: FAZ vom 29.10.1993, S. 41.

2 Vgl. Standortsicherungsgesetz in: BGBl. I, 1993, S. 1569. 
diesem Abschnitt wird nur der Teil des § 4 FördergebietsG betrachtet, der sich auf Neubauten bezieht.

Die Abschreibungsvergünstigung des $\S 4$ FördergebietsG hat gegenüber den anderen Abschreibungsvergünstigungen neben der außerordentlichen Höhe der Abschreibungssätze zwei Besonderheiten. Zum einen handelt es sich bei dieser Abschreibungsregelung um eine sogenannte Sonderabschreibung, was bedeutet, daß die Abschreibungssätze zusätzlich zur linearen Abschreibung gewährt werden. Dem Investor steht es frei, in den ersten 5 Jahren bis zu 50 v.H. der Anschaffungskosten nach freiem Ermessen zusätzlich zur Normalabschreibung in Anspruch zu nehmen. Es können mithin im ersten Jahr bis zu maximal 52 v.H. der Anschaffungskosten abgeschrieben werden, bzw. in den ersten fünf Jahren bis zu 60 v.H. Nach dem Ende des 5. Jahres wird der steuerliche Restbuchwert linear über die restlichen 45 Jahre abgeschrieben. ${ }^{1}$ Der Beginn der Nachholwirkungen liegt ab dem 6. Jahr zwar relativ früh, doch sind die Abschreibungssätze in den ersten Jahren außergewöhnlich hoch, so daß ein Barwert der Subvention von 21,7 v.H. bzw. Zeitwert von 61,5 v.H. verbleibt (vgl. Tabelle 1).

Der § 4 FördergebietsG weist noch eine weitere Besonderheit auf. Alle anderen Abschreibungsvergünstigungen sind zunächst an den Subventionserfolg gebunden. Sie können erstmals im Jahr der Anschaffung bzw. Fertigstellung eines Gebäudes in Anspruch genommen werden. Demgegenüber kann die Sonderabschreibung nach $\S 4$ Fördergebiets $G$ auch schon auf den vorausgezahlten Kaufpreis bzw. Anzahlungen geltend gemacht werden ( $\$ 4$ Abs. 2 FördergebietsG). ${ }^{2}$ Daher ist damit zu rechnen, daß diese Abschreibungsvergünstigung bis weit über die vorgesehene zeitliche Begrenzung Ende 1996 hinaus zum Tragen kommt, da eine "Welle von Steuersparobjekten ${ }^{m 3}$ bis zu diesem Zeitpunkt erst einmal bezahlt werden, ohne daß faktisch eine Bauleistung getätigt wurde. ${ }^{4}$ Das heißt, daß vor Baubeginn die nötige Eigenkapitalausstattung vom

1 Vgl. Der Bundesminister der Finanzen, AfA bei Gebäuden nach Ablauf eines Begünstigungszeitraums, IV B 3 - S 2181 - 3/92, in: BStBl. 1992, Teil 1, S. 415. Insofern wird hier von den Regelungen des § 7a Abs. 9 EStG abgewichen.

2 Ausführlicher hierzu vgl. Fleischmann, G., a.a.O., S. 41.

3 Ebenda, S. 41.

4 Der Verfasser hält es für bedenklich, wenn der Staat Investoren aus steuerlichen Gründen zu einer solchermaßen fraglichen Vorgehensweise verleitet. Unseriösen 
Staat in Abhängigkeit vom Grenzsteuersatz in Höhe von bis zu 26,5 v.H. des noch zu investierenden Kapitals bereitgestellt wird.

Neben den allgemeinen Kritikpunkten an Abschreibungsvergünstigungen hat der § 4 FördergebietsG noch einen besonderen Verteilungsaspekt. Wegen der Progressionsabhängigkeit kommt er wohl hauptsächlich für Investoren bzw. "Eigenkapitalgeber" aus den alten Bundesländern in Frage. Der größte Teil der Bevölkerung aus den neuen Bundesländern wird weder über das nötige Eigenkapital verfügen, um die allgemeinen Investitionsrisiken bzw. die Liquiditätsanforderungen von Wohnungsbauinvestitionen zu tragen, noch über das nötige Einkommen, um in größerem Umfang an den Subventionen der Abschreibungsvergünstigungen des $\S 4$ FördergebietsG teilzuhaben. Es wird vor allem die Vermögensbildung in Form von Immobilien bei den Steuerpflichtigen aus den alten Bundesländern bzw. den wenigen Neureichen im Osten gefördert.

- Der § 7k EStG dient ebenfalls der Erweiterung des Wohnraumangebotes. Die Abschreibungsvergünstigung kann für Wohnungsbauinvestitionen im gesamten Bundesgebiet in Anspruch genommen werden. In den ersten 10 Jahren können insgesamt bis zu 85 v.H. der Investitionsausgaben abgeschrieben werden. Die restlichen 15 v.H. verteilen sich gleichmäßig auf die folgenden 30 Jahre. Im Gegensatz zur degressiven Abschreibung nach $\S 7$ Abs. 5 EStG sind die Abschreibungssätze nicht fest vorgegeben, sondern stellen Obergrenzen dar. Abschreibungssätze, die in einzelnen Förderjahren nicht geltend gemacht werden, erhöhen den steuerlichen Restbuchwert des Objektes und können nach Ablauf des 10. Jahres wiederum nur linear über die folgenden 30 Jahre verteilt geltend gemacht werden. ${ }^{1}$ Die maximale Überabschreibung als Differenz zur

Absichten von Erstellern von Bauleistungen (Bauträgern), die in der Immobilienbranche immer wieder beklagt werden, wird dadurch Vorschub geleistet, daß der volle Kaufpreis gezahlt wird, ohne daß bereits eine Bauleistung erbracht wurde.

1 Es fragt sich, warum der Gesetzgeber, neben der beabsichtigten Differenzierung der Abschreibungssätze der einzelnen Vergünstigungen, das Steuerrecht derart intransparent gestaltet. Während die Abschreibungssätze des § 7 Abs. 5 EStG feste Sätze sind, und in einzelnen Jahren nicht vorgenommene Abschreibungsbeträge für immer verloren sind, können diese beim § $7 \mathrm{k}$ EStG ab dem 10. Jahr in den folgenden 30 Jahren nachgeholt werden, wobei aber im Förderzeitraum Höchstsätze für die einzelnen Jahre vorgegeben sind. Demgegenüber ist der Investor beim § 4 Fördergebiets $\mathrm{G}$ frei, die Abschreibungsbeträge innerhalb des Vergünstigungszeitraums von 5 Jahren nach Belieben selbst zu bestimmen. 
Normalabschreibung beträgt somit nach Ablauf des 10. Jahres 65 v.H. (vgl. Tabelle 1). Der steuerliche Restbuchwert beträgt am Ende des 10. Jahres nur noch 15 v.H. der Anschaffungskosten.

Ein Investor steht beim Bau einer neuen Wohnung vor der Option, die degressive Abschreibung nach $\S 7$ Abs. 5 EStG in Anspruch zu nehmen und die Wohnung auf dem freien Wohnungsmarkt zu vermieten, oder aber die erhöhte Absetzung nach $\S 7 \mathrm{k}$ EStG zu beanspruchen. Er ist allerdings für den Zeitraum von 10 Jahren daran gebunden, die Wohnung zu einer verminderten Miete zur Verfügung zu stellen. ${ }^{1}$ Eine zusätzliche Förderung mit Mitteln des Sozialen Wohnungsbaus ist ausgeschlossen. Aufgrund der allgemeinen mietrechtlichen Regelungen im Bürgerlichen Gesetzbuch dürfte der Zeitraum, in dem nur eine verminderte, unter dem Marktmietniveau liegende Miete zu erzielen ist, aber noch einige Jahre darüber hinaus dauern. ${ }^{2}$ Veräußert der Investor das Objekt innerhalb des 10-jährigen Vergünstigungszeitraumes, verliert er rückwirkend die gesamten erhaltenen Subventionen, auch wenn der Erwerber es weiterhin bis zum Ende des 10-jährigen Zeitraums an die Zielgruppe zu den verminderten Mietsätzen vermietet, das Subventionsziel also erreicht wurde ( $\S 7 \mathrm{k}$ Abs. 2 EStG). Dieser Sachverhalt sollte aber nicht mit einer Nachversteuerung umgangener Nachholwirkungen verwechselt werden, da es dem Investor ja weiterhin vorbehalten bleibt, das Objekt nach Ablauf von 10 Jahren steuerfrei zu veräußern.

Die Barwerte der Subvention reichen fast an die Werte des § 4 FördergebietsG heran (vgl. Tabelle 1). Der Zeitwert der Subvention übersteigt sogar die Zeitwerte des § 4 FördergebietsG. Dieses Paradox kommt dadurch zustande, daß beim $\S 7 \mathrm{k}$ EStG zwar ein höherer Steuerkredit aufläuft, die Subventionen aber zu späteren Zeitpunkten gewährt werden. Dennoch dürfte diese Abschreibungsvergünstigung von untergeordneter Bedeutung sein, da es für potentielle Investoren kaum rentiert, sie zu beanspruchen. Wird die Wohnung auf dem freien

1 Die Höhe der Miete ist in Anlehnung an die Mieten im Sozialen Wohnungsbau länderspezifisch geregelt ( $\$ 7 \mathrm{k}$ Abs. $3 \mathrm{EStG}$ ).

2 Nach Ablauf der 10-jährigen Bindung ist eine Anhebung der Miete nur im Rahmen der nach Bürgerlichem Recht vorgegebenen Höchstgrenzen zulässig. Danach kann die Miete innerhalb von 3 Jahren nur maximal 30 v.H. angehoben werden. Je weiter die Ausgangsmiete am Ende des 10. Jahres unter der vergleichbaren Marktmiete liegt, umso länger wird der Zeitraum, den der Investor benötigt, um die Miete auf Marktniveau anzuheben. 
Markt vermietet, kann der Investor die degressive Abschreibung nach \& 7 Abs. 5 EStG mit einer Überabschreibung von insgesamt 38 v.H. innerhalb von 10 Jahren in Anspruch nehmen. Demgegenüber beträgt die Überabschreibung beim § 7k EStG im gleichen Zeitraum 65 v.H., die Differenz mithin 27 v.H. Die maximale Steuerersparnis, die ohne Berücksichtigung der zwischenzeitlichen Verzinsung während des Förderzeitraums aus dieser Differenz resultiert, beträgt bis zu 14,3 v.H. des investierten Kapitals (Grenzsteuersatz 53 v.H), mithin pro Jahr durchschnittlich 1,4 v.H. Der Steuerersparnis stehen die verminderten Mieteinnahmen gegenüber, die u.U. nur gut die Hälfte der ortsüblichen Miete betragen. ${ }^{1}$ Je niedriger der Grenzsteuersatz des Investors und je größer die Differenz zwischen der vereinbarten Sozialmiete und der Marktmiete sind, desto weniger wird diese Abschreibungsregelung als Alternative zur degressiven Abschreibung nach $\S 7$ Abs. 5 EStG in Frage kommen.

\section{b. Die Vergünstigungen zur Erhaltung des Wohnungsbestandes ( 8 7c, h, i EStG)}

Die Maßnahmen zur Begünstigung der Sanierung des Wohnungsbestandes kommen hauptsächlich Erwerbern von Sanierungsobjekten zugute. Altbesitzer, die nach langjähriger Vermietertätigkeit ihre Objekte sanieren, können diese Investitionen u.U. als Instandsetzungsmaßnahmen im Jahr der Verausgabung geltend machen (vgl. Teil 2 A. 3).

Der $\$ 7$ 7c EStG dient dazu, die Schaffung von neuem Wohnraum in bestehenden Gebäuden zu begünstigen, etwa wenn ein Dachgeschoß ausgebaut wird. Der Investor kann Aufwendungen bis zu maximal 60.000 DM über einen Zeitraum von 5 Jahren gleichmäßig verteilen. Voraussetzung für die Inanspruchnahme ist lediglich, daß der Wohnraum mindestens fünf Jahre auf dem Mietwohnungsmarkt zur Verfügung gestellt wird. Eine eigene Nutzung nach Ablauf dieses Zeitraum ist unschädlich. Veräußert der Investor das Objekt im 5-jährigen Förderzeitraum und wird es vom Erwerber weiterhin für den Rest des Förderzeitraums vermietet, bleibt dies für die bereits in Anspruch genommenen Abschreibungsvergünstigungen ohne Konsequenz ( $§ 7 \mathrm{c} \mathrm{Abs.} 4 \mathrm{EStG}$ ), sofern der Erwerber die Wohnung weiterhin vermietet. Insofern besteht ein

1 Vgl. hierzu die Beispielsrechnung bei Jaser, G., Erhöhte Absetzung für Wohnungen mit Sozialbindung (§ 7k EStG), in: Schönhofer/Reinisch, HuG 15/I/150i, Jan. 1991. 
Gegensatz zur Regelung des $\S 7 \mathrm{k}$ EStG, bei dem die Abschreibungsvergünstigungen rückwirkend von Beginn an versagt werden.

Die Höhe der Subvention dieser Abschreibungsregelung ist von der Restnutzungsdauer des Gebäudes abhängig. Bei den begünstigten Aufwendungen handelt es sich um Herstellungsaufwand, der üblicherweise den steuerlichen Restbuchwert des Gebäudes, in dem die Wohnung liegt, erhöht, da er aktiviert werden muß. Somit könnten diese Aufwendungen nur mit dem jeweiligen Abschreibungssatz, der auf das restliche Gebäude zur Anwendung kommt (im Regelfall 2 v.H.), abgeschrieben werden (Abschnitt 44. Abs. 11 EStR Okt. 1990). Dadurch verlängert sich der Abschreibungszeitraum für das gesamte Gebäude normalerweise über den fünfzigjährigen ursprünglichen Gesamtabschreibungszeitraum hinaus. ${ }^{1}$ Vom verbleibenden steuerlichen Restwert, der sich am Ende des 50-jährigen Abschreibungszeitraums ergibt, kann bis zur vollen Absetzung nur eine Absetzung von 2 v.H. bis zur Vollabschreibung vorgenommen werden. ${ }^{2}$ Faktisch heißt dies, daß nachträgliche Herstellungsaufwendungen nahezu unabhängig vom tatsächlichen Alter des Gebäudes im Regelfall über einen Zeitraum von 50 Jahren abgeschrieben werden müssen. ${ }^{3}$ Die Subvention des $\& 7 \mathrm{c}$ EStG besteht somit in der Verkürzung des Abschreibungszeitraums für die begünstigten Maßnahmen von 50 auf 5 Jahre.

Der Zeitwert dieser Subvention liegt mit bis zu 95,4 v.H. außerordentlich hoch. Er übersteigt ebenfalls wie der Barwert mit 31,7 v.H. die Werte aller anderen Abschreibungsvergünstigungen (vgl. Tabelle 1), doch sollte der Effekt der

1 Die Finanzbehörden gehen davon aus, daß die gesamte Lebensdauer des Gebäudes nicht mit dem fünfzigjährigen steuerlichen Abschreibungszeitraum übereinstimmt, sondern diesen übersteigt. Insofern kann nicht argumentiert werden, daß der Herstellungsaufwand an bestehenden Gebäuden auf den restlichen Nutzungszeitraum bis zum Ende des fünfzigsten Jahres verteilt werden muß, da dieser Zeitraum der Lebensdauer des Gebäudes entspräche. Vgl. Bundesfinanzhof, Entscheidung 122, 300, in: BStBl. II 1977, 606.

2 Vgl. ebenda, S. 606.

${ }^{3}$ Dem Steuerpflichtigen bleibt es im Einzelfall vorbehalten nachzuweisen, daß die Restnutzungsdauer des Gebäudes zum Zeitpunkt, zu dem die Herstellungsaufwendungen getätigt werden, keine 50 Jahre mehr beträgt. Er müßte dann eine "Erhöhte Absetzung fur außergewöhnliche technische und wirtschaftiche Abnutzung "geltend machen. Vgl. Bundesfinanzhof - Urteil vom 20. Januar 1987 IX R 103/83 in: BStBL II 1987, S. 491ff, insbesondere S. 492, Abschnitt b. 
Gesamtsubvention nicht überschätzt werden. Berücksichtigungsfähig sind nämlich nur Herstellungskosten bis zu 60.000 DM. Insofern wird das Subventionsziel, eine neue Wohnung zu erstellen, mit einem recht geringen fiskalischen Gesamtaufwand von maximal 19.020 DM $(31,7$ v.H. * 60.000 DM) erreicht. Veräußert der Investor die Wohnung im 6. Jahr und umgeht sämtliche Nachholwirkungen, steigt der Barwert der Subvention auf maximal 41,4 v.H. bzw. 24.660 DM. Das entspricht dem Barwert der Subvention in Spalte 2 zuzüglich dem Barwert der umgangenen Nachholwirkungen in Spalte 5. Da die Subvention nur an die Bedingung geknüpft ist, die Wohnung für mindestens 5 Jahre dem Mietwohnungsmarkt zur Verfügung zu stellen, bedeutet dies, daß die Wohnung für jedes tatsächliche Nutzungsjahr mit bis zu maximal ca. 3.800 DM bezuschußt wird. Je länger die Wohnung über diesen Zeitraum hinaus vermietet wird, desto mehr verringern sich der durchschnittliche fiskalische Aufwand pro Vermietungsjahr.

- Eine für die Praxis weitaus relevantere, auch fiskalisch bedeutendere Regelung stellt der \& 7h EStG dar. Diese Regelung subventioniert die Instandsetzungsmaßnahmen an vorhandenem Wohnraum. Voraussetzung für die Inanspruchnahme ist, daß das Gebäude in einem sogenannten "förmlich festgelegten Sanierungsgebiet" bzw. "städtebaulichen Entwicklungsbereich" ( $87 \mathrm{~h} \mathrm{EStG)}$ liegt. Insofern dient diese Vergünstigung auch städtebaulichen Zielsetzungen. Erfüllt der Investor verschiedene Voraussetzungen, die im Gesetz näher geregelt sind, kann er für Instandsetzungsmaßnahmen und Herstellungsaufwendungen in den ersten 10 Jahren jährlich bis zu 10 v.H. abschreiben. Das bedeutet, daß die gesamten Instandsetzungs- und Herstellungsaufwendungen innerhalb von 10 Jahren geltend gemacht werden können. Diese Abschreibungsvergünstigung kann wie die erhöhte Absetzung nach § 7k EStG nur in Anspruch genommen werden, wenn keine direkten öffentlichen Zuschüsse bzw. öffentliche zinsverbilligte Darlehen gewährt wurden.

Die Subventionswerte dieser Abschreibungsvergünstigung hängen zum einen von der Restnutzungsdauer des Gebäudes ab, zum anderen von der alternativen steuerlichen Normalbehandlung dieser Kosten. Zu unterscheiden ist weiter, ob es sich bei den Aufwendungen um Instandsetzungsmaßnahmen oder Herstellungsaufwand handelt, für die der $\S 7 \mathrm{~h} \mathrm{EStG}$ eine einheitliche Regelung trifft. Weiter ist der Subventionswert als Abweichung zur Normalbesteuerung davon abhängig, ob der Investor die Maßnahmen nach langjähriger Vermietungs- 
tätigkeit vornimmt oder aber das Objekt erwirbt, um die Investitionen vorzunehmen, seine Vermietungstätigkeit also erst beginnt. ${ }^{1}$

Herstellungskosten sind normalerweise zu aktivieren, d.h. der steuerliche Restbuchwert des Gebäudes ist um den Betrag der Investition zu erhöhen und in den folgenden Jahren mit dem für den ursprünglichen Restwert des Gebäudes anzuwendenden Abschreibungssatz abzuschreiben (Abschnitt 44 Abs.11 EStR, Okt. 1990).

Die Regelung ist unabhängig davon, ob der Investor das Objekt schon besaß oder erst erworben hat. Durch die Erhöhung des steuerlichen Restbuchwertes zum Investitionszeitpunkt nimmt die gesamte Abschreibungsdauer des Gebäudes über den ursprünglichen Abschreibungszeitraum von 50 Jahren hinaus zu. Da der steuerliche Restbuchwert nach Ablauf von 50 Jahren weiterhin mit 2 v.H. abgeschrieben werden muß, heißt dies, daß Herstellungsaufwendungen üblicherweise über 50 Jahre abgeschrieben werden müssen. Die Subventionswirkungen bestehen wie bei den begünstigten Maßnahmen nach § 7c EStG in einer Verkürzung des Abschreibungszeitraums von 50 Jahren auf 10 Jahre.

Etwas unterschiedlich, im Ergebnis aber nicht anders, ist diese Regelung, wenn es sich bei den begünstigten Aufwendungen um Instandsetzungsmaßnahmen handelt. Diese sind Teil des sogenannten Erhaltungsaufwandes (Abschnitt 157 Abs.1 EStR Okt. 1990). Erhaltungsaufwand liegt vor, wenn bereits vorhandene Teile erneuert werden, auch wenn die Teile sich dadurch technisch verbessern. ${ }^{2}$ Erhaltungsaufwendungen können im Jahr der Entstehung grundsätzlich in voller Höhe als Werbungskosten geltend gemacht werden ${ }^{3}$ und mindern in voller Höhe das zu versteuernde Einkommen. ${ }^{4}$ Erwirbt der Investor das Objekt und nimmt in den ersten Jahren umfangreiche Erhaltungsaufwendungen vor, ist er üblicherweise von dem Sofortabzug ausgeschlossen. Es wird davon ausge-

1 Vgl. hierzu auch Teil 2 A.3.

2 Vgl. Abschnitt 157 Abs. 1 EStR Okt. 1990 bzw. Teil 2 A.3.

3 Zur Kritik an dieser Regelung vgl. Teil 2 A.3.

4 Dem Investor ist es freigestellt, diese Aufwendungen über einen Zeitraum von maximal 5 Jahren gleichmäßig zu verteilen (§ 82b EStDV). Diese Regelung wird dann in Anspruch genommen werden, wenn die Instandhaltungskosten einen relativ großen Teil der Bemessungsgrundlage des zu versteuernden Einkommens ausmachen und somit der durchschnittliche Progressionssatz, der auf den Abzugsbetrag zur Anwendung kommt, weit unter dem Spitzengrenzsteuersatz liegt. 
gangen, daß es sich um anschaffungsnahen Erhaltungsaufwand handelt, in dessen Umfang die Anschaffungskosten ${ }^{1}$ zu erhöhen sind, so daß diese Kosten gemeinsam mit dem Gebäude über einen Zeitraum von 50 Jahren abgeschrieben werden müssen (Abschnitt 157 Abs. 5 EStR Jan. 1991). ${ }^{2}$ In diesem Fall handelt es sich, soweit es um Erhaltungsaufwendungen geht, bei den Subventionswirkungen ebenfalls um eine Verkürzung der Abschreibungsdauer von 50 auf 10 Jahre.

Was bleibt, ist zunächst eine Diskriminierung der Altbesitzer, da diese ihre Aufwendungen, sofern es sich um Erhaltungsaufwendungen handelt, über 10 Jahre verteilen müssen und nicht sofort absetzen können. Doch ist diese Diskriminierung nur scheinbar. Üblicherweise müssen auch Erhaltungsaufwendungen, sofern sie gleichzeitig mit Herstellungsaufwendungen vorgenommen werden und von diesen nur schwer zu trennen sind, gemeinsam mit diesen aktiviert werden (Abschnitt 157 Abs. 4 Jan. 1991). Das wird bei den begünstigten Sanierungsaufwendungen im Sinne des $\S 7 \mathrm{~h}$ EStG meistens der Fall sein, so daß für die Normalbesteuerung bei den nunmehr begünstigten Maßnahmen auch beim Altbesitzer im Regelfall ein 50-jähriger Abschreibungszeitraum zugrundegelegt wird.

Bei den Maßnahmen im Sinne des $\S 7 \mathrm{~h}$ EStG handelt es sich um grundlegende Sanierungsmaßnahmen, so daß der Investor zum Zeitpunkt der Investition unabhängig vom Alter des Objektes normalerweise keine verkürzte Restlebensdauer des Gebäudes geltendmachen kann. Da die Aufwendungen, die mit diesen Maßnahmen im Zusammenhang stehen, wie sich gezeigt hat, meist aktiviert und über einen Zeitraum von 50 Jahren abgeschrieben werden müssen, bestehen die Subventionen aus der Verkürzung des Abschreibungszeitraums von 50 Jahren auf 10 Jahre. $^{3}$

1 Dahinter steht die Vorstellung, daß das Gebäude um einen um die nachträglich vorgenommenen Instandsetzungskosten verminderten Preis erworben wurde und der eigentliche Anschaffungspreis der Summe aus Anschaffungs- und Instandsetzungskosten entspricht.

2 Die Regelung sieht vor, daß die gesamten geltend gemachten Kosten aktiviert werden müssen, sofern sie in den ersten 3 Jahren nach dem Erwerb 20 v.H. der Anschaffungskosten übersteigen.

3 Wurde das Gebäude vor 1925 errichtet, wird ein Gesamtabschreibungszeitraum von 40 Jahren zugrundegelegt, so daß auf die Sanierungsaufwendungen bis zur Vollabschreibung des ursprünglichen Gebäudes ein Abschreibungssatz von 2,5 v.H. 
Der Barwert der Subvention beträgt 24,5 v.H. Der Zeitwert ist mit 84,4 v.H. außerordentlich hoch. Obwohl bei § $7 \mathrm{~h}$ EStG die Subventionen im Förderzeitraum die Werte andere Maßnahmen zum Teil deutlich übersteigen, kommt dies im Barwert nicht anschaulich zum Ausdruck, da die Nachholwirkungen ab dem 11. Jahr bereits 2 v.H. der Anschaffungskosten betragen.

Im Fall der vorzeitigen Veräußerung steigt der Barwert der Subvention zum Ende des 10. Jahres bis auf 30,7 v.H. des investierten Kapitals. Dies entspricht dem Barwert der Subvention zuzüglich dem Barwert der umgangenen Nachholwirkungen, bezogen auf den Investitionszeitpunkt (Tabelle 1, Spalten 2 und 5). Am Ende des 10. Jahres beträgt die Überabschreibung als Differenz zur Normalabschreibung 80 v.H. Der Barwert des fiskalischen Ausfalls, der aus der Veräußerung zu diesem Zeitpunkt resultieren würde, beträgt bis zu 13,7 v.H. des investierten Kapitals bezogen auf den Veräußerungszeitpunkt. Bei einer Nachversteuerung der umgangenen Nachholwirkungen, wie dies im Unternehmensbereich üblich ist, wären beim Grenzsteuersatz von 53 v.H. 42,4 v.H. des ursprünglich investierten Kapitals an Steuern abzuführen (80 v.H. Überabschreibung * 53 v.H. Grenzsteuersatz). ${ }^{1}$

Im Gegensatz zu § 7c EStG, der sich ebenfalls auf Herstellungsaufwendungen an bestehenden Gebäuden bezieht, handelt es sich bei den Subventionen des $\S$ $7 \mathrm{~h}$ EStG nicht nur um erhebliche prozentuale Vergünstigungen sondern auch um enorm hohe Subventionsbeträge, gemessen am Ziel eine Wohnung zu erhalten. Städtische Sanierungsgebiete, in denen diese Abschreibungsbeträge ausschließlich gelten, sind dadurch gekennzeichnet, daß der bestehende Wohnraum technisch mehr oder weniger abgeschrieben ist. Dies ist die Motivation für die Gemeinden, ein Gebiet als Sanierungsgebiet zu deklarieren. Der Erwerber eines Sanierungsobjektes bezahlt den Kaufpreis hauptsächlich für den Grund und Boden. Die Aufwendungen (oftmals sog. Entkernung der Gebäude) können bei solchen Objekten die Kosten einer neuen Bebauung übersteigen, so daß der

angewandt wird. Nach Ablauf des 40. Jahres reduziert sich dieser Satz bis zur Vollabsetzung der nachträglichen Sanierungsaufwendungen auf 2 v.H. Von diesem Fall wurde bei der Berechnung der Subventionswerte abgesehen.

1 Unter der Annahme, daß der Veräußerungserlös zum Veräußerungszeitpunkt dem Buchwert bei linearer Abschreibung entspricht. Die Überabschreibung von 80 v.H. entspricht in Grafik 6 dem Betrag c. Würden Wertsteigerungen zusätzlich berücksichtigt, so wären die Beträge a,b, und e in Grafik 6 außerdem zu versteuern. 
spätere Gebäudewert hauptsächlich auf den begünstigten Herstellungs- und Instandsetzungsmaßnahmen beruht. Dies bedeutet, daß die Sanierung von Gebäuden durch diese hohen Abschreibungssätze fiskalisch meist teurer ist als die Erstellung von Neubauwohnungen, die durch die degressive Abschreibung nach $\S 7$ Abs. 5 EStG subventioniert werden.

- Die Vergünstigungen des § 4 FördergebietsG werden auf dem Gebiet der neuen Bundesländer für Herstellungs- und Instandsetzungsmaßnahmen bzw. Sanierungsaufwendungen an bestehenden Gebäuden gewährt. In den ersten 5 Jahren können bis zu 50 v.H. der begünstigten Aufwendungen bzw. auch der Anzahlungen $^{1}$ als Sonderabschreibung zusätzlich zur Normalabschreibung geltend gemacht werden. Im Unterschied zu den Regelungen bei Neubauten ist hier eine lineare Restwertabschreibung vom 6 . bis zum 10. Jahr vorgesehen ( $\S$ 4 Abs. 3 FördergebietsG). Für Investoren mit einer ausreichend hohen Bemessungsgrundlage für das zu versteuernde Einkommen ergibt sich dadurch ein etwas ungewöhnlicher Abschreibungsverlauf, im ersten Jahr 52 v.H., vom 2. bis zum 5. Jahr 2.v.H. und vom 6. bis zum 10. Jahr 8 v.H.

Der $\S 4$ FördergebietsG ist das Pendant zu $\S 7 \mathrm{~h} \mathrm{EStG.} \mathrm{Abgesehen} \mathrm{vom} \mathrm{quanti-}$ tativ untergeordneten $\S 7 \mathrm{c}$ EStG ist er die Regelung mit den höchsten Subventionswerten, 29,9 v.H. Barwert bzw. 91,2 v.H. Zeitwert. Da die Sanierungsaufwendungen ebenfalls wie bei den begünstigten Maßnahmen nach $\S 7 \mathrm{~h}$ EStG absolut eine bedeutende Höhe haben, ergibt sich aus dieser Regelung eine beträchtliche fiskalische Belastung.

- Der § 7i EStG dient der Subvention von Herstellungsaufwendungen an Baudenkmälern. Dies sind Gebäude, die aufgrund von landesrechtlichen Vorschriften als kulturell wertvoll eingestuft werden. Diese Abschreibungsvergünstigung hat im engeren Sinne nichts mit der Wohnungsbauförderung zu tun. Die Subventionswerte entsprechen denen des $\S 7 \mathrm{~h} \mathrm{EStG.}$

\subsection{Die Subventionswirkungen bei der Verwendung von Abschreibungs- vergünstigungen als Finanzierungsmittel}

In den vorangegangenen Abschnitten wurde ausgeführt, inwieweit Abschreibungsvergünstigungen einem zinslosen Kredit entsprechen bzw. inwiefern sie

${ }^{1}$ Vgl. Die Ausführungen zu $\S 4$ FördergebietsG für Neubauten in Teil 2 B.3.2.a. 
durch vorzeitige Beendigung der Investition einem Freibetrag gleichkommen. Für die Höhe der Subventionswerte, die auf dem zeitlichen Vorziehen der Abschreibungssätze beruhen, kommt es entscheidend auf die Höhe des zugrundegelegten Zinssatzes an. Je höher der Zinssatz ist, desto höher fallen die Subventionswerte, sowohl bei der Barwertmethode als auch bei der Zeitwertmethode aus. Bislang wurde von einem einheitlichen Bruttokapitalmarktzins von 8 v.H. ausgegangen. Dieser entspricht dem durchschnittlichen Zinsniveau für langfristige Staatsschuldtitel in den letzten Jahrzehnten. Bei den ermittelten Subventionswerten wurde unterstellt, daß diese dem effektiven fiskalischen Aufwand bzw. dem tatsächlichen Subventionswert entsprechen.

In der betriebswirtschaftlichen Literatur wurde ein Verfahren zur Ermittlung der Vorteilhaftigkeit von Investitionen bzw, von Subventionen entwickelt, dem der voranstehende Ansatz nicht genügt. Die Überlegungen führen dazu, daß den Berechnungen nicht der Bruttozinssatz in Höhe des Kapitalmarktzinses zugrundezulegen ist, sondern ein versteuerter Zinssatz. ${ }^{1}$ Im Ergebnis führt dies dazu, daß die Subventionswerte geringer als die zuvor ermittelten ausfallen, bzw. die Abschreibungsvergünstigungen nicht ganz so regressiv wirken. Die Übertragung auf die vorliegende Untersuchung ist allerdings nur in begrenztem Umfang möglich. Die Subventionswerte, die auf diesem Verfahren beruhen, werden deshalb in diesem Kapitel gesondert ausgewiesen.

Ausgangspunkt der Überlegung ist der Sachverhalt, daß die Mittel aus den Abschreibungsvergünstigungen dem Investor als Finanzierungsmittel bzw. alternativ zur Kapitalmarktanlage zur Verfügung stehen. Beide Verwendungsformen haben Rückwirkungen auf die Höhe der Besteuerung.

Im ersten Fall wird davon ausgegangen, daß die Mittel aus den Abschreibungsvergünstigungen zur Tilgung einer durch die Investition eingegangenen Verschuldung bzw. einer sonstigen steuerlich relevanten Verschuldung verwendet werden. Entsprechend mindern sich die Kapitalkosten des Investors in den folgenden Perioden. Die gesparten Kapitalkosten hätte der Investor aber steuerlich geltend machen können. Durch die Tilgung vermindern sich seine effektiven Ausgaben für Zinsen um die Bruttokapitalmarktzinsen multipliziert mit dem

1 Zum versteuerten Kalkulationszinssatz vgl. Volk, R., Vergleich der Vergünstigungseffekte der verschiedenen investitionsfördernden Maßnahmen, Frankfurt 1993, S. $32 \mathrm{ff}$. 
durchschnittlichen Grenzsteuersatz. Diese Nettosubvention entspricht der tatsächlichen fiskalischen Belastung, da sich im Umfang der vom Investor nun vermindert geltend gemachten Kapitalkosten die Steuereinnahmen erhöhen. Die fiskalische Gesamtbelastung in einer Besteuerungsperiode entspricht der Zinsbelastung des Staates auf den bis zum Betrachtungszeitpunkt kumulierten Steuerkredit und den Steuermehreinnahmen, bedingt durch die in gleichem Umfang beim Investor verminderte Verschuldung. Das führt dazu, daß der Staat nur eine Zinsbelastung in Höhe des Nettozinssatzes bzw. des "versteuerten" Zinssatzes trägt.

Im Fall der alternativen Kapitalmarktanlage bzw. im Fall der Eigenfinanzierung wird davon ausgegangen, daß ein rational handelnder Investor die aus den Abschreibungsvergünstigungen zufließenden Mittel auf dem Kapitalmarkt anlegt. Die Zinserträge sind steuerpflichtig, was bedeutet, daß dem Investor aus den gewährten Mitteln der Abschreibungsvergünstigung nur ein Ertrag in Abhängigkeit vom Nettozins bleibt. Für die Ermittlung der effektiven Subventionswerte muß deshalb auch in diesem Fall von einem "versteuerten" Zinssatz ausgegangen werden, da dieser für die tatsächliche fiskalische Belastung maßgeblich ist. Der fiskalischen Zinsbelastung aus den Abschreibungsvergünstigung sind somit die Mehreinnahmen aus der Versteuerung der Anlage dieser Erträge durch den Investor gegenzurechnen.

Die auf diese Art ermittelten Subventionswerte sind in Tabelle 2 zusammengestellt. Der Aufbau entspricht dem der Tabelle 1. Die Subventionbeträge liegen nun beim Spitzensteuersatz zum Teil deutlich unter den Subventionswerten, die sich bei Anwendung des Bruttozinssatzes ergeben. Der Barwert der Subvention aus der Sonderabschreibung des $§ 4$ FördergebietsG sinkt beispielsweise von 21,7 v.H. auf 16,2 v.H., der Zeitwert sogar von 61,5 v.H. auf 28,6 v.H. Die Annahme, daß ein versteuerter Zinssatz zugrundezulegen ist, hat demgegenüber auf die Höhe der Subventionswerte bei niedrigen Grenzsteuersätzen einen wesentlich geringeren Einfluß, die Barwerte reagieren zum Teil kaum.

Die regressiven Wirkungen der Abschreibungsvergünstigungen werden daher gemindert. Dies erklärt sich daraus, daß mit steigendem Grenzsteuersatz die direkten Vergünstigungswirkungen, die aus dem Abzug der Beträge der Überabschreibung resultieren, zwar unverändert zunehmen. Dieser Effekt wird aber dadurch gemindert, daß ebenfalls mit zunehmendem Einkommen die relative 


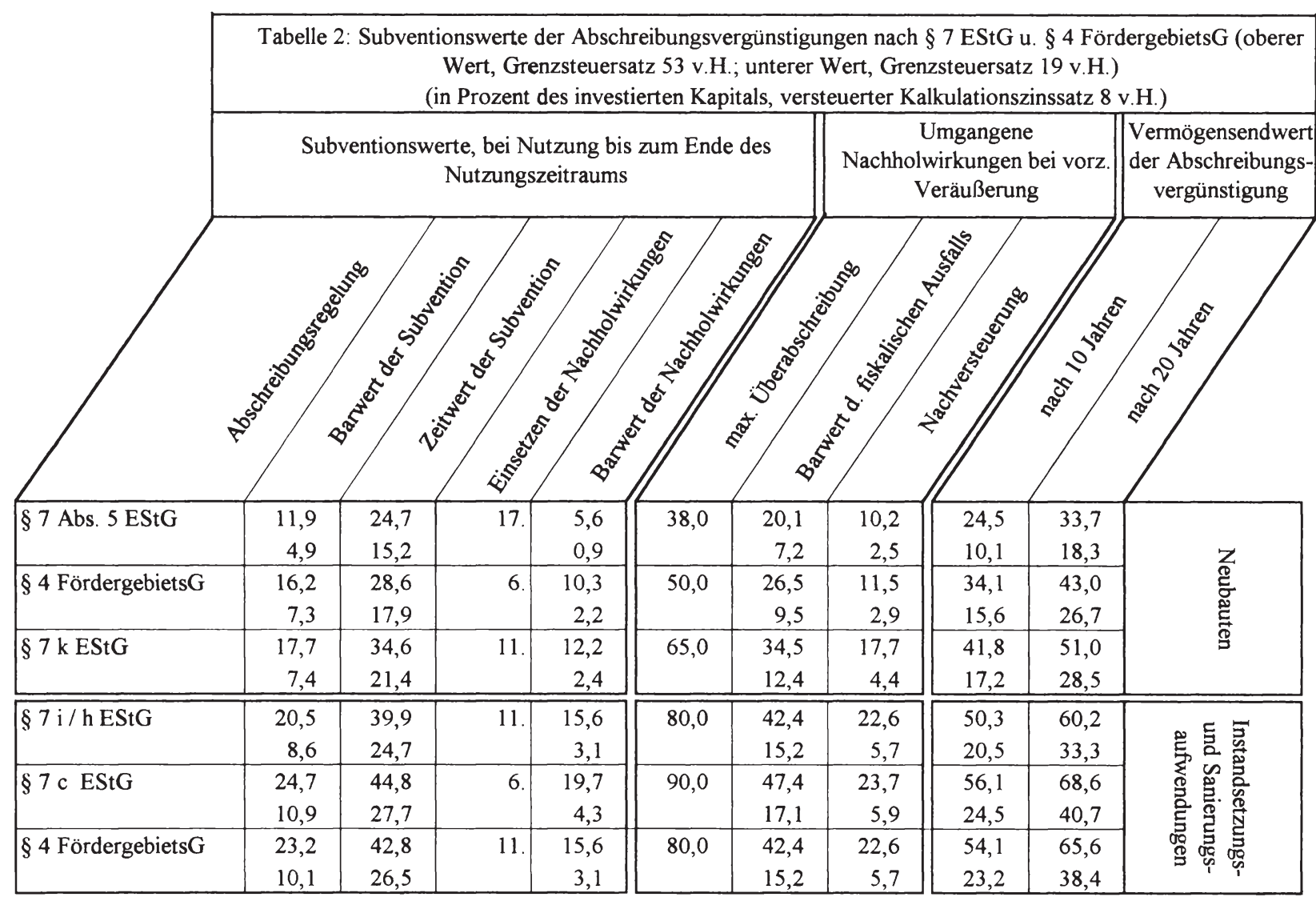


Zinsbelastung des Staates abnimmt (effektive Subvention). Dem Staat fließen entweder die Steuern aus den Kapitalerträgen des Investors zu. Oder der Investor verwendet die Mittel zur Tilgung, dadurch erhöhen sich die Einkünfte aus Vermietung und Verpachtung bzw. verringern sich die Verluste mit wiederum entsprechend höheren Steuereinnahmen.

Den Nachholwirkungen kommt durch die Annahme eines Nettozinssatzes eine größere Bedeutung zu. Dies veranschaulicht Grafik 8. Die Vergünstigungen aus den erhöhten Abschreibungssätzen steigen zwar im Vergünstigungszeitraum stärker an, die Nachholwirkungen spielen aber eine wesentlich größere Rolle, da sie durch den geringeren Zinssatz stärker in den Gegenwartswert eingehen. Im Fall der vorzeitigen Veräußerung steigt deshalb der fiskalische Verlust an. Der Barwert der umgangenen Nachholwirkungen verdoppelt bzw. verdreifacht sich zum Teil bezogen auf die Gegenwart bzw. verdoppelt sich knapp bezogen auf den fiktiven Veräußerungszeitpunkt (Tabelle 2, Spalten 5 und 8).

Diese für betriebswirtschaftliche Zwecke entwickelte Art der Subventionsermittlung ist auf Maßnahmen in der Einkommensteuer nur begrenzt übertragbar. Während alle Nettoerträge eines Betriebes als geschlossene Rechnungseinheit im Zeitablauf im wesentlichen lückenlos erfaßt werden und das Betriebsergebnis einheitlich besteuert wird, spiegelt sich dieses geschlossene Bild der Besteuerung bei der Einkommensbesteuerung aus verschiedenen Gründen nicht wider. Es kommen hier teilweise die gleichen Unzulänglichkeiten bei der Erfassung der Erträge privater Wirtschaftssubjekte zum Tragen, die in Teil 1 C.2. problematisiert wurden.

Einmal ist nicht gewährleistet, daß die Zuflüsse der Abschreibungsvergünstigungen beim Investor nachhaltig zu einer Nettovermögensänderung führen. Dazu wäre es notwendig, daß die Zuflüsse tatsächlich zur Tilgung von Verbindlichkeiten genutzt bzw. verzinslich auf dem Kapitalmarkt angelegt werden. Soweit die Vergünstigungen in einem geänderten Konsumverhalten des Investors zum Ausdruck kommen, ist dies nicht garantiert.

Entscheidender ist jedoch die unzulängliche Erfassung des Reinvermögenszugangs bzw. der Einkünfte eines privaten Wirtschaftssubjektes innerhalb der Einkommensteuer. Da es für Vermieter unter steuerlichen Gesichtspunkten nicht rational sein muß, Eigenkapital in Wohnimmobilien zu binden, ist für den Fall der Fremdfinanzierung nur bedingt gewährleistet, daß eine Verwendung der 
Mittel aus den Abschreibungsvergünstigungen zu Steuereinnahmen führt. Wird die Immobilie beispielsweise über eine Kapitallebensversicherung finanziert, findet eine Tilgung im eigentlichen Sinne nicht statt. Vielmehr besteht die Verwendung der Zuflüsse in einer steuerfreien Kapitalanlage. ${ }^{1}$ Verwendet der Investor die aus den Abschreibungsvergünstigungen zufließenden Mittel in diesem Sinne, erreicht er beim Spitzensteuersatz nach 20 Jahren bei fast allen Abschreibungsvergünstigungen einen Vermögensendwert, der über dem ursprünglich eingesetzten Kapital liegt (vgl. Spalte 10 in Tabelle 2). ${ }^{2}$ D.h. die Tilgung einer reinen Fremdfinanzierung wäre dadurch nach Ablauf von 20 Jahren mit den Mitteln einer fälligen Kapitallebensversicherung gewährleistet. ${ }^{3}$

Relevant ist auch der Fall, daß die Abschreibungsvergünstigungen zur Tilgung eines steuerlich irrelevanten Kredites bzw. eines Kredites, der nicht mit den Einkünften aus Vermietung und Verpachtung in Zusammenhang steht, verwendet werden. Dies wird dann gegeben sein, wenn der Investor über verschuldetes selbstgenutztes Wohneigentum verfügt, da er durch die Konsumgutlösung den Kapitaldienst aus diesen Verbindlichkeiten steuerlich nicht geltend machen kann.

Werden die Zuflüsse aus den Abschreibungsvergünstigungen nicht zur Tilgung von Darlehen im weitesten Sinne verwendet, sondern zur Kapitalmarktanlage, ist die Versteuerung der Erträge ebenfalls nicht gewährleistet. Auch ist der Sparerfreibetrag von 6.000 DM/12.000 DM zu berücksichtigen. Darüber hinausgehende Kapitalerträge sind zudem nicht bei allen Anlageformen steuer-

1 Vgl. Teil 1 C.2.

2 Um die Vergleichbarkeit zu gewährleisten, liegt den ausgewiesenen Endwerten ebenfalls ein Zinssatz von 8 v.H. zugrunde. Dies erscheint für die ausgeschüttete Rendite von Lebensversicherungen zu hoch gewählt, so daß bei niedrigeren Renditen die Ausschüttung um eine entsprechende Zahl von Jahren später stattfindet. Auf der anderen Seite sollte aber auch berücksichtigt werden, daß es sich um ein fiktives Kapitalkonto handelt, aus dem der Investor die Nachholwirkungen der Abschreibungsvergünstigungen bis zum Betrachtungszeitpunkt bereits bestritten hat. Sofern die gesamte Immobilie ihren Wert gerade nominal erhält, erhöhen sich außerdem die Vermögensendwerte der Abschreibungen insgesamt, da die Abschreibungsbeträge der linearen Abschreibung mit zu berücksichtigen sind.

3 Allerdings bliebe in diesem Fall eine liquiditätsmäßige Unterdeckung in den ersten Jahren entsprechend dem Verlauf in Grafik 4. Der Investor müßte die Fläche Abc als verlorenen Zuschuß aufbringen, um in diesem Beispiel nach Ablauf von 20 Jahren über eine lastenfreie Immobilie zu verfügen. 
pflichtig. Außer bei der oben beschriebenen Lebensversicherung sind bei vielen Arten von Fonds die Erträge nur teilweise steuerpflichtig, da diese darauf abzielen, einen möglichst hohen Ertrag steuerfrei auszuschütten. ${ }^{1}$ Erwähnenswert ist auch der Fall der Steuerhinterziehung. Wie die Erfahrungen mit der Zinsabschlagsteuer gezeigt haben, wird trotz der pauschalen Erhebung einer 30 prozentigen Abschlagsteuer (anrechenbare Quellensteuer bis zur endgültigen Einkommensteuerveranlagung) nur ein geringer Teil der Erträge des volkswirtschaftlichen Geldvermögens, u.a. auch wegen der Anlage in Steueroasen, der Besteuerung unterworfen.

Dennoch kann über diesen Effekt, daß ein Nettozinssatz für die Ermittlung der Subventionswerte relevant sein kann, nicht hinweggesehen werden. Je lückenloser die synthetische Einkommensbesteuerung und die Steuerpraxis die Reinvermögenszu- und -abgänge eines Wirtschaftssubjektes erfaßt, desto eher ist von einem versteuerten Zinsatz mit entsprechend geminderten Subventionwerten auszugehen.

\section{Gesamteffekte einer Förderung der Erstellung neuen Wohnraums im frei finanzierten Wohnungsbau}

Wie in Abschnitt B gezeigt wurde, beinhalten die Fördermaßnahmen zur Erstellung neuen Wohnraums zum Teil erhebliche Subventionen. Selbst unter Berücksichtigung der Nachholwirkungen erreichen die Barwerte einzelner Abschreibungsvergünstigungen bis zu ca. 30 v.H. des investierten Kapitals, die Zeitwerte in manchen Fällen bis zu 100 v.H. Als Subventionen wurden in Abschnitt B nur die ökonomischen Vorteile betrachtet, die der Investor durch eine von der Normalbesteuerung abweichende Besteuerungspraxis erhält. Die fiskalischen Gesamteffekte der Erstellung neuen Wohnraums gehen aber z.T. weit über diese Subventionswerte hinaus. Wie im ersten Teil der Untersuchung dargestellt wurde, kommt es auch ohne Berücksichtigung von Abschreibungsvergünstigungen in Abhängigkeit vom Fremdkapitalanteil zu negativen Einkünften aus Vermietung und Verpachtung.

1 Bei Immobilien-, Aktien- und sonstigen Fonds sind wie bei Wohnimmobilien die Ertragsanteile steuerfrei, die von der Fondsverwaltung in Form von Wertsteigerungen erwirtschaftet werden, sofern es sich um sogenanntes Privatvermögen handelt. 
Wohnungsbauinvestitionen werden heute vielfach nicht von den Investoren selbst vorgenommen, sondern von Bauträgern durchgeführt. Diese suchen geeignete Grundstücke, übernehmen die Planung, die Finanzierung und die gesamte Bauabwicklung. Außerdem übernehmen sie oftmals die Vermietung und eine Mietausfallgarantie für die ersten Jahre. Der Investor schließt neben dem eigentlichen Kaufvertrag daher noch mehrere anderer Verträge ab, die zusätzlich zu Werbungskosten führen. Diese können ohne Berücksichtigung eines Disagios bei der Finanzierung bis zu ca. 10 v.H. der Anschaffungskosten erreichen. Sie führen als Werbungskosten in der Bauphase bzw. im Jahr der Anschaffung zusätzlich zu Minderungen der steuerlichen Bemessungsgrundlage. Von diesen Kosten wird in der folgenden Gesamtbetrachtung aus Gründen der Transparenz abgesehen. ${ }^{1}$

Wie sich die gesamten fiskalischen Effekte der Erstellung von einem Quadratmeter Wohnraum im Zeitablauf entwickeln, ist wiederum am Beispiel der degressiven Abschreibung nach $\S 7$ Abs. 5 EStG in Grafik 9 dargestellt. Diese Abschreibungsvergünstigung weist zwar bezogen auf ein vorgegebenes Investitionsvolumen die geringsten relativen Subventionswerte auf (vgl. Tabellen 1 und 2). Sie hat aber neben dem $\S 4$ FördergebietsG wahrscheinlich die größte fiskalische Relevanz, da sie in den alten Bundesländern das zentrale Instrument zur Förderung der Erstellung neuen Wohnraums ist.

Der Grafik 9 liegen die Annahmen der Grafik 3 zugrunde. Betrachtet wird die Entwicklung der monatlichen fiskalischen Belastung der Erstellung eines Quadratmeters Wohnraum im frei finanzierten Wohnungsbau. Als Gesamtkosten liegen 3.500 DM zugrunde - bei einem Grundstücksanteil (nicht abschreibungsfähig) von 25 v.H. Der Zinssatz wurde wiederum mit 8 v.H. gewählt, die Anfangsmiete mit 13 DM, was einer Gesamtkapitalrendite vor Steuern (Miet-

1 Bis 1990 waren die Gestaltungsmöglichkeiten sogenannter Bauherrenmodelle weit größer. Sie bestanden darin, einen Teil der Anschaffungskosten als sofort abziehbare Werbungskosten in die Bauphase zu verlagern. Diese Möglichkeiten wurden mit dem Bauherrenerlaß vom 31. August 1990 stark eingeschränkt. Vgl. Bundesministerium der Finanzen, Schreiben betr. negative Einkünfte aus Vermietung und Verpachtung im Rahmen von sog. Bauherrenmodellen und vergleichbaren Modellen sowie geschlossenen Immobilienfonds, in: BStBl. I, 1990, S. 366ff. 


\section{Grafik 9}

Maximale fiskalische Effekte (monatlich) der Erstellung eines Quadratmeter Wohnraums im frei finanzierten Wohnungsbau

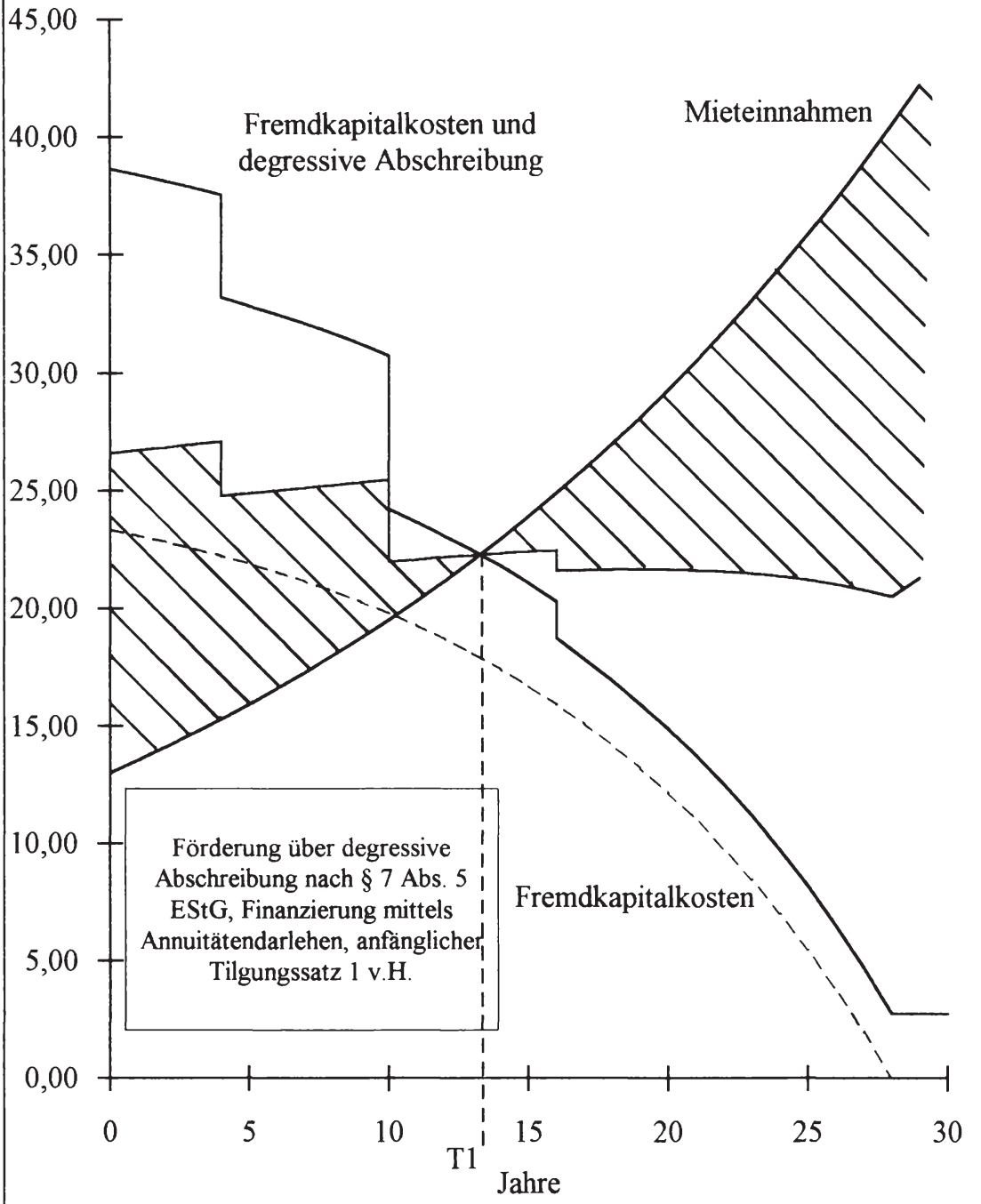


einnahmen/investiertes Kapital) von 4,5 v.H. entspricht. ${ }^{1}$ Die Miete wächst entsprechend den empirischen Werten der letzten Jahrzehnte jährlich um 4,14 v.H. Ausgegangen wurde von einer hundertprozentigen Fremdfinanzierung über ein Annuitätendarlehen mit einem Anfangstilgungssatz von 1 v.H. Dadurch ist das Darlehen nach 28 Jahren getilgt. Um die maximalen Effekte zu ermitteln, wurde wiederum der Spitzengrenzsteuersatz von 53 v.H. zugrundegelegt. Für niedrigere Grenzsteuersätze liegen die Effekte entsprechend den Verläufen in Grafik 7 proportional darunter.

Der steuerliche Aufwand, den der Investor geltend machen kann, besteht aus den Aufwendungen für die Fremdkapitalverzinsung und den Abschreibungen. Er beträgt im ersten Jahr monatlich knapp 39 DM. Durch die Tilgung des Annuitätendarlehens nehmen die Fremdkapitalkosten und damit der steuerliche Aufwand kontinuierlich ab. Die Degression der Abschreibung nach $\S 7$ Abs. 5 EStG läuft in drei Stufen, wodurch sich das Absinken der steuerlichen Aufwendungen im Zeitablauf entsprechend beschleunigt. Diesen steuerlichen Aufwendungen stehen die Mieteinnahmen gegenüber. Insgesamt ergeben sich bis zum Zeitpunkt T1 negative Einkünfte aus Vermietung und Verpachtung. Die Gesamtkapitalrendite nach Steuern ist von den Mieteinnahmen und den Steuererstattungen in der fiskalischen Defizitphase bzw. den Steuerzahlungen in der fiskalischen Überschußphase abhängig. Die fiskalischen Effekte, die sich auf diese Weise ergeben, sind durch die schraffierte Fläche kenntlich gemacht. Im ersten Jahr beträgt die Steuerminderung monatlich 13,60 DM pro Quadratmeter. Dem Investor stehen auf der Einnahmeseite die Mieteinnahmen und die Steuererstattungen, d.h. insgesamt 26,60 DM, zur Verfügung, was einer anfänglichen Gesamtkapitalrendite nach Steuern von gut 9 v.H. entspricht. Bei Fremdkapitalkosten in Höhe vom 8 v.H. ergibt sich somit ein Überschuß.

Die fiskalische Belastung nimmt entsprechend dem Mietanstieg, der Tilgung des Darlehens und der Degression in den Abschreibungssätzen bis ins 13. Jahr kontinuierlich ab. Der sich im Zeitablauf kumulierende fiskalische Aufwand kann wiederum mit Hilfe der Barwertmethode bzw. der Zeitwertmethode ermittelt werden. Der Barwert entspricht der Summe aller zukünftigen steuerlichen Minder- und Mehreinnahmen abdiskontiert auf den heutigen Zeitpunkt

1 Von den kalkulatorischen Abschreibungen (nicht den steuerlichen) wird an dieser Stelle abstrahiert. Es genügt, wenn das gesamte Objekt, Gebäude und Grund und Boden, seinen Wert nominal erhält, damit sie nicht berücksichtigt werden müssen. 
(Zinssatz 8 v.H.). In diesem Beispiel kumuliert er sich in den ersten 10 Jahren auf 920 DM bzw. auf 881 DM in den ersten 20 Jahren. Bezieht man alle fiskalischen Überschüsse, die nach $\mathrm{T} 1$ bis zum Ende des 50. Jahres anfallen, mit in die Betrachtung ein, sinkt der Barwert auf 246 DM. D.h. im gesamten 50-jährigen Betrachtungszeitraum verbleibt ein fiskalischer Verlust. Insgesamt scheint der fiskalische Ausfall gemessen am Ziel, einen Quadratmeter Wohnraum zu schaffen, in einem vertretbaren Rahmen zu liegen. Allerdings muß der Staat heute zu einer relativ hohen Liquiditätsbelastung bereit sein.

Diese Feststellung muß modifiziert werden. Zum einen wurde eine Finanzierung mit sukzessiver Tilgung unterstellt. Zum anderen ist es wahrscheinlich unrealistisch, über so lange Zeiträume von konstanten Bedingungen auszugehen. Vielmehr dürften spätestens nach 20 Jahren die ersten Instandsetzungsaufwendungen anfallen, so daß die fiskalischen Erträge entsprechend geringer ausfallen.

Unter steuerlichen Gesichtspunkten wäre es aus der Sicht des Investors auch nicht rational, das Objekt darüber hinaus zu halten. Nach Ablauf des 20. Jahres besitzt das Gebäude einen steuerlichen Restbuchwert von 25 v.H., bezogen auf die historischen Anschaffungskosten. Bei geringen nominalen Wertsteigerungen von beispielsweise 3 v.H. besitzt das Objekt aber einen Marktwert von 180 v.H., so daß es rational ist, es zu veräußern und ein gleichartiges Objekt zu erwerben. Damit kann die Abschreibungsgrundlage steuerfrei auf das zukünftige Marktniveau angehoben werden (vgl. Teil 2 A.2.).

Ebenso wie bei den Abschreibungsvergünstigungen lassen sich auch die Zeitwerte des fiskalischen Aufwands ermitteln. Es wird wiederum davon ausgegangen, daß sich der Staat in Höhe der Steuerausfälle verschuldet, um sein Bugdet auszugleichen. Mit den späteren Steuermehreinnahmen (nach T1) wird diese Verschuldung wieder abgebaut. Die Zeitwerte entsprechen der Summe der zwischenzeitlich anfallenden Zinsen. Diese belaufen sich in den ersten 10 Jahren auf etwa 606 DM, steigen aber bis zum Ablauf den 28. Jahres auf 2.445 DM. Danach ist die induzierte Staatsverschuldung getilgt. ${ }^{1}$

In der Bundesrepublik Deutschland schwanken die Preise für Wohnraum regional stark. Für eine Eigentumswohnung werden in den alten Bundesländern

1 Zur Ermittlung der Zeitwerte vgl. auch Teil 2 B. 3.1. 
Werte zwischen 1.500 DM und 10.000 DM pro Quadratmeter angegeben. ${ }^{1}$ In Tabelle 3 sind die Barwerte und Zeitwerte des fiskalischen Aufwands bzw. die steuerliche Entlastung für Anschaffungs-/Herstellungskosten zwischen 3.000 DM und 7.000 DM pro Quadratmeter Wohnraum ermittelt. Für die Anfangsmiete wurde angenommen, daß sie mit zunehmenden Anschaffungskosten zwischen von $12 \mathrm{DM}$ und $20 \mathrm{DM}$ pro Quadratmeter liegt. Der nicht abschreibungsfähige Grundstücksanteil der Investition wurde ausgehend von 23 v.H. bis auf knapp 40 v.H. erhöht. Damit soll der Tatsache Rechnung getragen werden, daß regional höhere Anschaffungskosten z.T. auf höheren Grundstückspreisen beruhen. $^{2}$

Ansonsten liegen die gleichen Annahmen wie im beschriebenen Beispiel zugrunde. Insofern handelt es sich wiederum um die maximal möglichen fiskalische Belastungen, da beim Investor vom Spitzensteuersatz und einer 100 prozentigen Fremdfinanzierung ausgegangen wird. Unterschieden wurde zwischen dem Fall der Fremdfinanzierung mit Tilgung (B) und dem Fall der Fremdfinanzierung über eine tilgungsfreie Hypothek bzw. der Tilgung über eine Kapitallebensversicherung (A). Die erste Zahlenreihe gibt die Barwerte (BW) des fiskalischen Aufwands wieder, die zweite Zahlenreihe die Zeitwerte (ZW). Sofern die Zeitwerte zweimal den gleichen Wert annehmen, heißt dies, daß die induzierte Staatsverschuldung durch die zwischenzeitlichen Mehreinnahmen getilgt wurde. Sichtbar wird, daß die fiskalischen Erträge zwischen dem 20. und 50. Jahr c.p. noch Bedeutung haben. Das kommt in der Übersicht dadurch zum Ausdruck, daß die Barwerte nach dem 20. Jahr sinken. Allerdings kommen diese fiskalischen Erträge erst einer späteren Generation von Steuerzahlern zugute.

Bei den Werten in Tabelle 3 handelt es sich um maximale Effekte, die tatsächlichen Verläufe der fiskalischen Belastung hängen aber vom (durchschnittlichen) Grenzsteuersatz des Investors ab. Die fiskalische Belastung verhält sich bei

1 Vgl. Verband Deutscher Makler VDM im Oktober 1992, zitiert nach: Bauherrenratgeber, Bauen \& Finanzieren, Fellbach Dezember 1992.

2 Bei vollkommener Konkurrenz unter den Anbietern von neuem Wohnraum dürften regionale Preisunterschiede nahezu ausschließlich auf unterschiedlichen Grundstückspreisen beruhen. 


\begin{tabular}{|c|c|c|c|c|c|c|c|c|c|c|c|c|}
\hline \multirow[t]{2}{*}{$\begin{array}{l}\text { Herstellungsk. } \\
\text { Anfangsmiete: }\end{array}$} & \multicolumn{2}{|c|}{$\begin{array}{c}\text { 3.000 DM } \\
12 \mathrm{DM} \\
\text { ohne Tilgung }\end{array}$} & \multicolumn{2}{|c|}{$\begin{array}{l}\text { Grundstück } \\
23 \text { v.H. } \\
\text { mit Tilgung }\end{array}$} & \multicolumn{2}{|c|}{$\begin{array}{c}\text { 4.500 DM } \\
15 \mathrm{DM} \\
\text { ohne Tilgung }\end{array}$} & \multicolumn{2}{|c|}{$\begin{array}{l}\text { Grundstück } \\
29 \text { v.H. } \\
\text { mit Tilgung }\end{array}$} & \multicolumn{2}{|c|}{$\begin{array}{c}\text { 6.000 DM } \\
18 \mathrm{DM} \\
\text { ohne Tilgung }\end{array}$} & \multicolumn{2}{|c|}{$\begin{array}{l}\text { Grundstück } \\
35 \text { v.H. } \\
\text { mit Tilgung }\end{array}$} \\
\hline & BW & ZW & BW & ZW & BW & ZW & BW & ZW & BW & ZW & BW & ZW \\
\hline nach 10 Jahren & 802 & 430 & 756 & 415 & 1.303 & 689 & 1.234 & 667 & 1.763 & 926 & 1.671 & 896 \\
\hline 20 Jahren & 848 & 1.358 & 692 & 1.182 & 1.478 & 2.305 & 1.243 & 2.041 & 2.061 & 3.179 & 1.747 & 2.827 \\
\hline 30 Jahren & 755 & 2.104 & 459 & 1.400 & 1.414 & 3.966 & 970 & 2.757 & 2.025 & 5.693 & 1.432 & 4.076 \\
\hline 40 Jahren & 639 & 2.207 & 251 & 1.400 & 1.294 & 4.814 & 712 & 2.757 & 1.898 & 7.439 & 1.123 & 4.085 \\
\hline 50 Jahren & 530 & 2.207 & 100 & 1.400 & 1.168 & 4.814 & 522 & 2.757 & 1.755 & 7.599 & 895 & 4.085 \\
\hline \multirow{3}{*}{$\begin{array}{l}\text { Herstellungsk. } \\
\text { Anfangsmiete: }\end{array}$} & \multirow{2}{*}{\multicolumn{2}{|c|}{$\begin{array}{c}\text { 3.500 DM } \\
13 \mathrm{DM} \\
\text { ohne Tilgung }\end{array}$}} & \multirow{2}{*}{\multicolumn{2}{|c|}{$\begin{array}{l}\text { Grundstück } \\
25 \text { v.H. } \\
\text { mit Tilgung }\end{array}$}} & \multirow{2}{*}{\multicolumn{2}{|c|}{$\begin{array}{c}5.000 \mathrm{DM} \\
16 \mathrm{DM} \\
\text { ohne Tilgung }\end{array}$}} & \multirow{2}{*}{\multicolumn{2}{|c|}{$\begin{array}{l}\text { Grundstück } \\
31 \text { v.H. } \\
\text { mit Tilgung }\end{array}$}} & \multirow{2}{*}{\multicolumn{2}{|c|}{$\begin{array}{c}\text { 6.500 DM } \\
19 \text { DM } \\
\text { ohne Tilgung }\end{array}$}} & \multirow{2}{*}{\multicolumn{2}{|c|}{$\begin{array}{l}\text { Grundstück } \\
37 \text { v.H. } \\
\text { mit Tilgung }\end{array}$}} \\
\hline & & & & & & & & & & & & \\
\hline & BW & $Z W$ & BW & ZW & BW & ZW & BW & ZW & BW & ZW & BW & ZW \\
\hline nach 10 Jahren & 973 & 518 & 920 & 501 & 1.461 & 770 & 1.385 & 746 & 1.907 & 1.000 & 1.808 & 968 \\
\hline 20 Jahren & 1.064 & 1.682 & 881 & 1.476 & 1.678 & 2.604 & 1.416 & 2.311 & 2.244 & 3.454 & 1.905 & 3.073 \\
\hline 30 Jahren & 981 & 2.740 & 635 & 1.846 & 1.623 & 4.557 & 1.129 & 3.209 & 2.217 & 6.240 & 1.575 & 4.488 \\
\hline 40 Jahren & 863 & 3.032 & 410 & 1.846 & 1.501 & 5.712 & 854 & 3.209 & 2.089 & 8.269 & 1.248 & 4.507 \\
\hline 50 Jahren & 748 & 3.032 & 246 & 1.846 & 1.369 & 5.738 & 652 & 3.209 & 1.940 & 8.523 & 1.008 & 4.507 \\
\hline \multirow{3}{*}{$\begin{array}{l}\text { Herstellungsk. } \\
\text { Anfangsmiete: }\end{array}$} & \multirow{2}{*}{\multicolumn{2}{|c|}{$\begin{array}{c}\text { 4.000 DM } \\
14 \text { DM } \\
\text { ohne Tilgung }\end{array}$}} & \multirow{2}{*}{\multicolumn{2}{|c|}{$\begin{array}{l}\text { Grundstück } \\
27 \text { v.H. } \\
\text { mit Tilgung }\end{array}$}} & \multirow{2}{*}{\multicolumn{2}{|c|}{$\begin{array}{c}\text { 5.500 DM } \\
17 \mathrm{DM} \\
\text { ohne Tilgung }\end{array}$}} & \multirow{2}{*}{\multicolumn{2}{|c|}{$\begin{array}{c}\text { Grundstück } \\
33 \text { v.H. } \\
\text { mit Tilgung }\end{array}$}} & \multirow{2}{*}{\multicolumn{2}{|c|}{$\begin{array}{c}\text { 7.000 DM } \\
20 \mathrm{DM} \\
\text { ohne Tilgung }\end{array}$}} & \multirow{2}{*}{\multicolumn{2}{|c|}{$\begin{array}{l}\text { Grundstück } \\
39 \text { v.H. } \\
\text { mit Tilgung }\end{array}$}} \\
\hline & & & & & & & & & & & & \\
\hline & BW & ZW & BW & ZW & BW & ZW & BW & ZW & BW & ZW & BW & ZW \\
\hline nach 10 Jahren & 1.141 & 605 & 1.079 & 585 & 1.614 & 849 & 1.530 & 822 & 2.047 & 1.072 & 1.940 & 1.038 \\
\hline 20 Jahren & 1.273 & 1.997 & 1.065 & 1.762 & 1.872 & 2.896 & 1.584 & 2.573 & 2.423 & 3.722 & 2.057 & 3.311 \\
\hline 30 Jahren & 1.200 & 3.360 & 805 & 2.301 & 1.827 & 5.132 & 1.283 & 3.650 & 2.404 & 6.771 & 1.713 & 4.884 \\
\hline 40 Jahren & 1.081 & 3.907 & 564 & 2.301 & 1.702 & 6.587 & 991 & 3.650 & 2.274 & 9.076 & 1.369 & 4.913 \\
\hline 50 Jahren & 961 & 3.907 & 387 & 2.301 & 1.565 & 6.668 & 776 & 3.650 & 2.120 & 9.432 & 1.116 & 4.913 \\
\hline
\end{tabular}


Objekten des $\S 7$ Abs. 5 EStG proportional zum Grenzsteuersatz. ${ }^{1}$ Sie ergibt sich bei niedrigeren Einkommen des Investors als 53ten Bruchteil der Werte der Tabelle 3 multipliziert mit dem individuellen Grenzsteuersatz des Investors.

Bei der Betrachtung der Werte wird der Einfluß der gewählten Finanzierungsform auf den fiskalischen Aufwand sichtbar. Im ersten Jahrzehnt weichen die Werte einer Finanzierung mit Tilgung von einer Finanzierung ohne Tilgung bzw. mit Tilgungsaussetzung (Kapitallebensversicherung) nicht nennenswert voneinander ab. Dies liegt daran, daß es innerhalb eines Annuitätendarlehens erst allmählich zu einem spürbaren Eigenkapitalanteil bzw. zu einem Rückgang der Fremdkapitalkosten kommt.

Die unterschiedlichen Entwicklungen der fiskalischen Be- und Entlastung sind in den Grafiken 9 und 10 in Abhängigkeit von der gewählten Finanzierungsform wiederum anhand des Ausgangsbeispiels einander gegenübergestellt. Tilgt der Investor nicht, steigt der Barwert der fiskalischen Belastung im 50-jährigen Zeitraum ausgehend vom knapp 2-fachen bei der teuersten Wohnung bis zum gut 5-fachen bei der günstigsten Wohnung (Tabelle 3). Die unterschiedliche Abhängigkeit der Barwerte von der Finanzierungsform hängt wiederum von den unterschiedlichen Gesamtkapitalrenditen vor Steuern ab. Je niedriger die Ausgangsrendite ist, desto mehr verlängert sich die fiskalische Belastungsphase, wodurch den späteren fiskalischen Erträgen innerhalb des Barwertes eine entsprechend geringere Bedeutung zukommt. Daher spielt es für den Barwert der fiskalischen Belastung eine geringere Rolle, wenn der Investor auf eine sukzessive Tilgung verzichtet.

Welche fiskalischen Gesamtwirkungen die Schaffung einer neuen Wohnung verursachen kann, wurde anhand der Daten der Tabelle 3 in Tabelle 4 exemplarisch für eine 80 Quadratmeterwohnung ermittelt. So kumulieren sich die Steuerausfälle des Grundmodelles mit 3.500 DM Anschaffungskosten pro Quadratmeter (280.000 DM) in 20 Jahren auf einen Barwert von bis zu 70.458 DM, im Fall mit Tilgung bzw. auf 85.084 DM für den Fall ohne Tilgung. Die

${ }^{1}$ Bei Objekten, die mit anderen Abschreibungsvergünstigungen gefördert werden, nimmt die fiskalische Belastung mit abnehmendem Grenzsteuersatz überproportional $a b$, da es bei geringeren Grenzsteuersätzen rational sein kann, die maximal möglichen Abschreibungen nicht im jeweiligen Jahr in Anspruch zu nehmen, sondern auf spätere Jahre zu verlagern. Beim $\S 7$ Abs. 5 EStG handelt es sich hingegen um feste Abschreibungssätze ohne Verlagerungsmöglichkeit. 


\section{Grafik 10}

Maximale fiskalische Effekte (monatlich) der Erstellung eines Quadratmeter Wohnraums im frei finanzierten Wohnungsbau

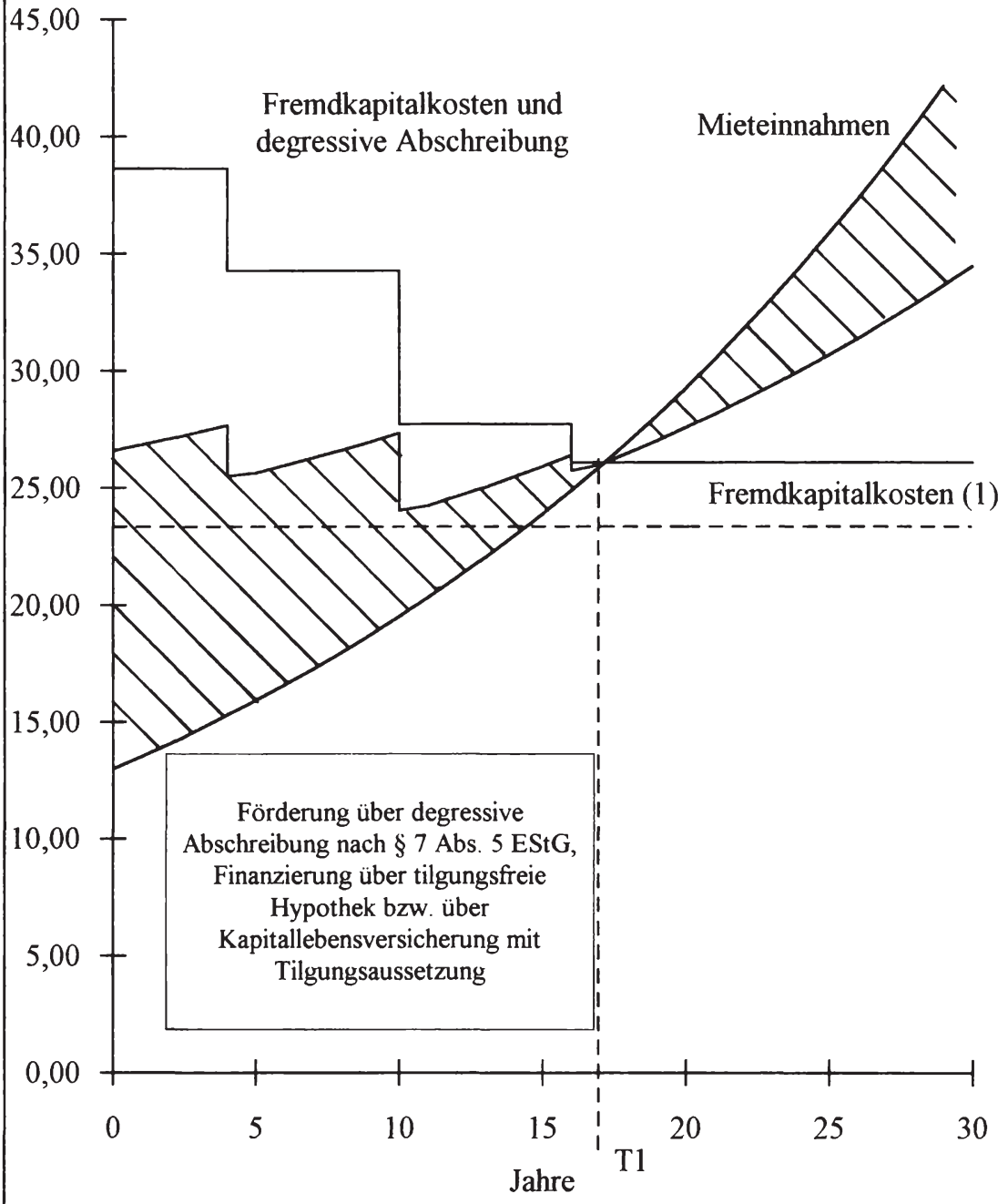

(1) bezogen auf das ursprünglich eingesetzte Kapital 
Tabelle 4: Maximale fiskalische Gesamtbelastung der Erstellung einer Wohnung mit 80 Quadratmetern im frei finanzierten Wohnungsbau, Förderung über degressive Abschreibung nach $\S 7$ Abs. 5 EStG

\begin{tabular}{|c|c|c|c|c|c|c|c|c|c|c|c|c|}
\hline \multirow[t]{2}{*}{$\begin{array}{l}\text { Herstellungsk. } \\
\text { Anfangsmiete: }\end{array}$} & \multicolumn{2}{|c|}{$\begin{array}{c}\text { 3.000 DM } \\
12 \mathrm{DM} \\
\text { ohne Tilgung }\end{array}$} & \multicolumn{2}{|c|}{$\begin{array}{l}\text { Grundstück } \\
23 \text { v.H. } \\
\text { mit Tilgung }\end{array}$} & \multicolumn{2}{|c|}{$\begin{array}{c}\text { 4.500 DM } \\
\text { 15 DM } \\
\text { ohne Tilgung }\end{array}$} & \multicolumn{2}{|c|}{$\begin{array}{l}\text { Grundstück } \\
29 \text { v.H. } \\
\text { mit Tilgung }\end{array}$} & \multicolumn{2}{|c|}{$\begin{array}{c}6.000 \mathrm{DM} \\
18 \mathrm{DM} \\
\text { ohne Tilgung }\end{array}$} & \multicolumn{2}{|c|}{$\begin{array}{l}\text { Grundstück } \\
35 \text { v.H. } \\
\text { mit Tilgung }\end{array}$} \\
\hline & BW & ZW & BW & ZW & BW & ZW & BW & ZW & BW & ZW & BW & ZW \\
\hline nach 10 Jahren & 64.125 & 34.373 & 60.452 & 33.190 & 04.249 & 55. & 98.7 & 53.323 & 141.062 & 74 & 6 & 71.7 \\
\hline 20 Jahren & 67.875 & 108.640 & 55.338 & 94.548 & 118.249 & 184.383 & 99. & 163.245 & 164.859 & 254 & 86 & 226.139 \\
\hline $30 \mathrm{~J}$ & 60.432 & 168.329 & 36.727 & 111.994 & 113. & 317 . & & 220 . & & & & 326.106 \\
\hline $40 \mathrm{Jz}$ & 51.152 & 176.566 & 20.119 & 4 & 103.504 & 385 & 4 & 220 & 876 & 595 & & 326.828 \\
\hline 50 Jahren & 42.393 & 176.566 & 7.964 & 111.994 & 93.404 & 385.118 & 41.761 & 220.555 & 140.433 & 607.920 & 71.577 & 326.828 \\
\hline \multirow[t]{2}{*}{$\begin{array}{l}\text { Herstellungsk. } \\
\text { Anfangsmiete: }\end{array}$} & \multicolumn{2}{|c|}{$\begin{array}{c}\text { 3.500 DM } \\
13 \mathrm{DM} \\
\text { ohne Tilgung }\end{array}$} & \multicolumn{2}{|c|}{$\begin{array}{l}\text { Grundstück } \\
25 \text { v.H. } \\
\text { mit Tilgung }\end{array}$} & \multicolumn{2}{|c|}{$\begin{array}{c}\text { 5.000 DM } \\
16 \text { DM } \\
\text { ohne Tilgung }\end{array}$} & \multicolumn{2}{|c|}{$\begin{array}{l}\text { Grundstück } \\
31 \text { v.H. } \\
\text { mit Tilgung }\end{array}$} & \multicolumn{2}{|c|}{$\begin{array}{c}\text { 6.500 DM } \\
19 \text { DM } \\
\text { ohne Tilgung }\end{array}$} & \multicolumn{2}{|c|}{$\begin{array}{l}\text { Grundstück } \\
37 \text { v.H. } \\
\text { mit Tilgung }\end{array}$} \\
\hline & BW & ZW & BW & $w$ & 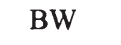 & ZW & $\mathrm{W}$ & ZW & W & Z & BW & $Z$ \\
\hline nach 10 Jahren & 77.868 & 41.475 & 73.5 & 40.095 & 116.8 & 61. & 11 & 59. & 152.597 & & & 77 . \\
\hline 20 Jahren & 85.084 & 134.532 & 70.458 & 118.092 & 134.204 & 208. & 10 & 184 & 179.560 & 276 & 97 & 245.814 \\
\hline 30 Jahren & 78.441 & 219.167 & 50.785 & 147.719 & 129.859 & 364.528 & 50 & 256.719 & 177.365 & 499.164 & 126 & 359.012 \\
\hline 40 Jahren & 69.045 & 242.543 & 32.839 & 147.719 & 120.070 & 456.9 & 68.3 & 256.719 & 167.115 & 661.5 & & 360.5 \\
\hline 50 Jahren & 59.839 & 242.543 & 19.672 & 147.719 & 109.522 & 459.022 & 52.142 & 256.719 & 155.225 & 681.861 & 80.631 & 360.577 \\
\hline \multirow[t]{2}{*}{$\begin{array}{l}\text { Herstellungsk. } \\
\text { Anfangsmiete: }\end{array}$} & \multicolumn{2}{|c|}{$\begin{array}{c}\text { 4.000 DM } \\
14 \mathrm{DM} \\
\text { ohne Tilgung }\end{array}$} & \multicolumn{2}{|c|}{$\begin{array}{l}\text { Grundstück } \\
27 \text { v.H. } \\
\text { mit Tilgung }\end{array}$} & \multicolumn{2}{|c|}{$\begin{array}{c}\text { 5.500 DM } \\
17 \mathrm{DM} \\
\text { ohne Tilgung }\end{array}$} & \multicolumn{2}{|c|}{$\begin{array}{l}\text { Grundstück } \\
33 \text { v.H. } \\
\text { mit Tilgung }\end{array}$} & \multicolumn{2}{|c|}{$\begin{array}{c}7.000 \mathrm{DM} \\
20 \mathrm{DM} \\
\text { ohne Tilgung }\end{array}$} & \multicolumn{2}{|c|}{$\begin{array}{l}\text { Grundstück } \\
39 \text { v.H. } \\
\text { mit Tilgung }\end{array}$} \\
\hline & BW & ZW & BW & ZW & BW & ZW & BW & ZW & BW & ZW & BW & ZW \\
\hline nach 10 Jahren & 91.242 & 48.383 & 86.345 & 46.806 & 129.159 & 67.947 & 122.425 & 65.779 & 163.764 & 85.771 & 155.194 & 83.0 \\
\hline 20 Jahren & 101.876 & 159.780 & 85.160 & 140.991 & 149.741 & 231.654 & 126.757 & 205.819 & 193.842 & 297.724 & 164.590 & 264.844 \\
\hline 30 Jahren & 96.015 & 268.812 & 64.408 & 184.083 & 146.129 & 410.599 & 102.670 & 292.008 & 192.331 & 541.659 & 137.019 & 390.726 \\
\hline 40 Jahren & 86.496 & 312.546 & 45.118 & 184.083 & 136.194 & 526.967 & 79.299 & 292.008 & 181.911 & 726.064 & 109.499 & 393.075 \\
\hline 50 Jahren & 76.842 & 312.546 & 30.938 & 184.083 & 125.199 & 533.476 & 62.081 & 292.008 & 169.575 & 754.586 & 89.242 & 393.075 \\
\hline
\end{tabular}


Zeitwerte erreichen ihr Maximum innerhalb von 30 Jahren mit 147.719 DM bzw. innerhalb von 40 Jahren mit 242.543 DM.

Bei der teuersten dargestellten Variante, der Wohnung mit Gesamtkosten in Höhe von 7.000 DM pro Quadratmeter, kumuliert sich der Barwert auf bis zu maximal 193.842 DM und sinkt wiederum unter Einbeziehung aller Erträge bis zum 50. Jahr auf immer noch 169.575 DM ab. Der Zeitwert des fiskalischen Aufwands, dem als zeitpunktbezogene Größe weniger ökonomische Aussagekraft zukommt, erreicht sein Maximum mit einer dreiviertel Million DM und übersteigt damit die historischen Gestehungskosten bei weitem. Faktisch heißt dies, daß diese Wohnung in den nächsten 50 Jahren den Staat c.p. pro Jahr durchschnittlich 15.000 DM Zinsen kostet bzw. gut 15 DM pro Quadratmeter und Monat.

Der Leser kann sich nun fragen, ob ein Preis von 7.000 DM pro Quadratmeter bei einer Ausgangsmiete von $20 \mathrm{DM}$ noch realistisch ist. Dies entspricht einer Gesamtkapitalrendite vor Steuern von 3,4 v.H. Es fragt sich mithin, ob sich die Investition nicht als Fehlinvestition erweist. Doch abgesehen davon, daß diese Preise in einigen Großstädten Deutschlands (Hamburg, München, Stuttgart) für (abschreibungsbegünstigte) Eigentumswohnungen übertroffen werden, ist es für die Ermittlung der fiskalischen Belastung uninteressant, ob sich der Investor "verspekuliert" hat. Durch das Steuersystem beteiligt sich der Staat an den Kosten der Fehlspekulation. Wichtiger ist, daß die Rechnung für den Investor durchaus noch aufgehen kann, sofern er über einen genügend hohen Grenzsteuersatz verfügt. Zur Illustration ist dieses Beispiel in Grafik 11 abgebildet. Bezugsgröße ist hier nicht der Quadratmeter Wohnraum, sondern die gesamte Wohnung, um die fiskalischen Dimensionen zu veranschaulichen.

Im ersten Jahr der Investition erzielt der Investor Mieteinnahmen in Höhe von 19.200 DM. Demgegenüber macht er Abschreibungen in Höhe von 23.912 DM und Fremdkapitalkosten in Höhe von 44.800 DM geltend. Die steuerlich berücksichtigungsfähigen Aufwendungen übersteigen mit $68.712 \mathrm{DM}$ die Mieteinnahmen somit um 49.512 DM. Die Steuerminderung, die daraus in der oberen Proportionalzone des Steuertarifs resultiert, beträgt 26.241 DM. Insgesamt stehen dem Investor an Einnahmen (Steuerminderung und Miete) 45.441 DM zur Verfügung. Dem stehen Zinsausgaben in Höhe von 44.800 DM gegenüber, woraus ein Überschuß von $641 \mathrm{DM}$ resultiert. Oder anders formuliert, die Gesamtkapitalrendite nach Steuern beträgt 8,11 v.H. Dem steht die Fremdkapi- 


\section{Grafik 11}

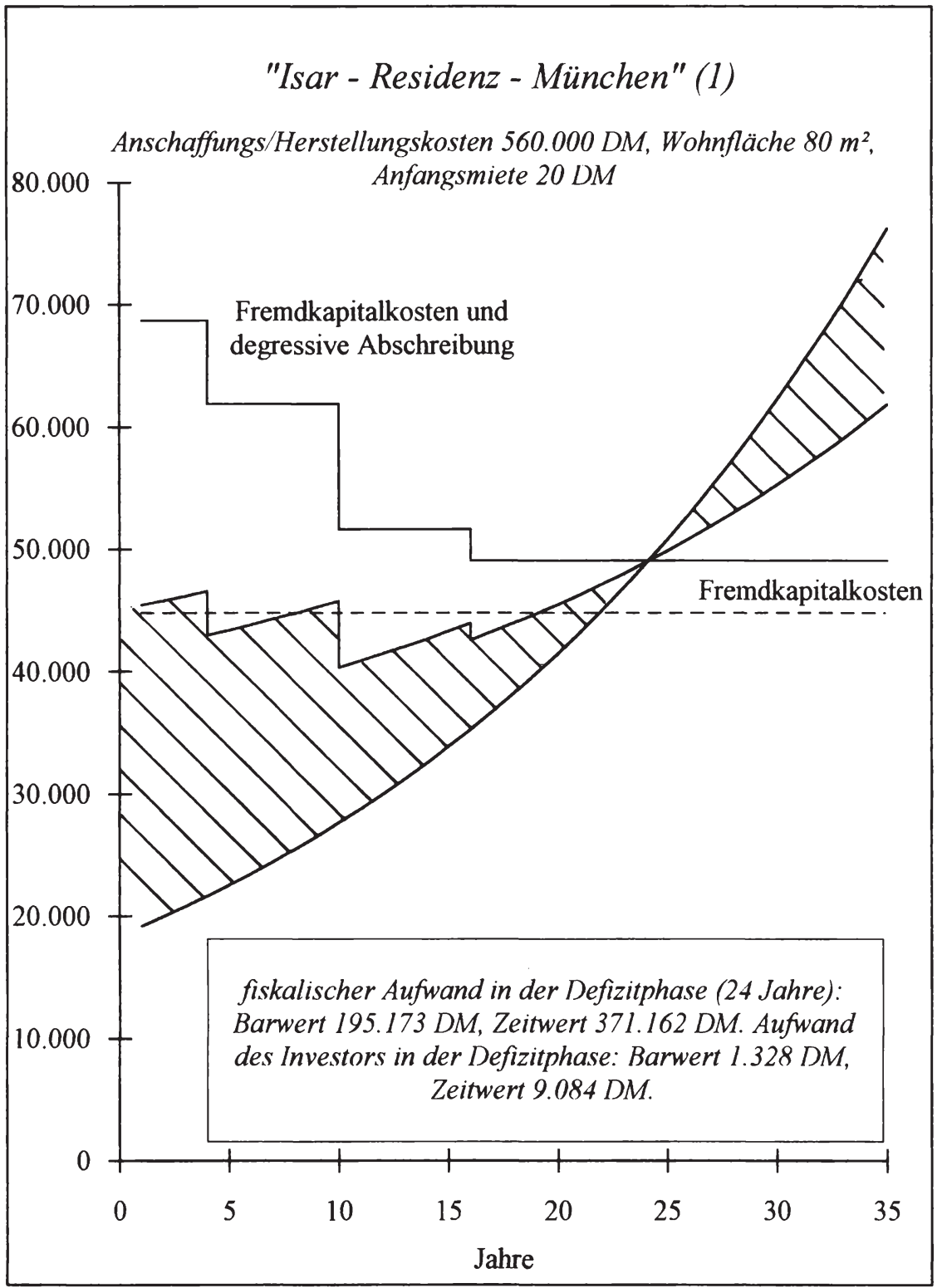

(I) Alternativ: "Alster - Residenz - Hamburg". 
talverzinsung von 8 v.H. gegenüber. Die fiskalische Defizitphase dauert 24 Jahre. Der Investor hat in dieser Zeit ungedeckte Kapitalkosten in Höhe von 9.084 DM. Diese haben einen Barwert von 1.328 DM. Dem steht ein fiskalischer Aufwand mit einem Barwert von 195.173 DM bzw. mit einem Zeitwert von 371.162 DM gegenüber. Für den Investor kann es also noch rational sein, in dieses Objekt zu investieren. Inwieweit er effektiv Erträge erzielt, hängt allerdings entscheidend von der Wertentwicklung des Objektes ab.

Die vorliegende Untersuchung beschäftigt sich hauptsächlich mit den formalen Inzidenzwirkungen der Wohnungsbauförderung. Das oben beschriebene Beispiel wirft aber die Frage auf, ob diese enormen fiskalischen "Zuschüsse", die aus negativen Einkünften aus Vermietung und Verpachtung resultieren, nicht auch Rückwirkungen auf die Preisbildung für Neubauwohnungen haben. Es wurde bereits darauf hingewiesen, daß die Investitionen normalerweise nicht von den Investoren selbst, sondern von Bauträgern durchgeführt werden. Diese offerieren in ihren Prospekten meistens keine Rentabilitätsrechnung, sondern nur eine Liquiditätsrechnung in Abhängigkeit vom Grenzsteuersatz des Investors. Sie endet im Regelfall nach Ablauf des 4. Jahres, spätestens nach Ablauf des 10. Jahres, zu Zeitpunkten also, ab denen die Abschreibungssätze vermindert werden (vgl. Abschreibungsregelung nach $\S 7$ Abs. 5 EStG in Tabelle 1). Unter dem Aspekt der Liquidität können sich aber auf Grund von Irrationalitäten bei den Investoren Immobilienpreise ergeben, die vollkommen von rationalen Renditeüberlegungen losgelöst sind.

Dies soll an einem extremen Beispiel verdeutlicht werden. Sofern der Kapitalmarktzins dem Abschreibungssatz entspricht, können die abschreibungsfähigen Baukosten bei einer hundertprozentigen Fremdfinanzierung und einem Grenzsteuersatz von $50 \mathrm{v} . \mathrm{H}$. in unendliche Höhe getrieben werden, ohne daß für den Investor eine Liquiditätsbelastung eintritt. Der Preis, den der Investor zahlen kann, wäre unter diesen Bedingungen nach oben offen. Liegt der Grenzsteuersatz über 50 v.H., ${ }^{1}$ stellt sich unter diesen Bedingungen das Paradox ein, daß der Investor nicht nur einen Liquiditätsüberschuß erzielt, sondern daß dieser mit steigenden Baukosten zunimmt. D.h., je teurer gebaut wird, desto größer ist der Überschuß, den der Investor in der Phase der Abschreibungsvergünstigung erzielt. Übersteigt der Abschreibungssatz den Zinssatz, kommt dieses Paradox

1 Der Spitzensteuersatz beträgt unter Berücksichtigung von Kirchensteuern und dem ab 1.1.1995 geltenden Solidaritätszuschlag nicht 53 v.H., sondern ca. 60.v.H. 
bereits bei Grenzsteuersätzen unter 50 v.H. zustande. ${ }^{1}$ Rational handelnde Investoren werden sich von diesen Liquiditätsrechnungen weniger beirren lassen und das Kapital, das sie bereit sind zu investieren, von den Preisen alternativer gebrauchter Immobilien abhängig machen.

Soweit aber Förder- bzw. Steuerüberwälzungen eintreten, führt dies beim Staat zu entsprechenden Belastungen. Dieses Problem legt die Frage nahe, ob die Bebauungskosten als Fördergrundlage geeignet sind. In der Marktwirtschaft sind Preise bzw. die Anschaffungs- und Kapitalkosten Knappheitsanzeiger. Die Stärke des marktwirtschaftlichen Systems liegt darin, daß die Marktkräfte endogen darauf hinwirken diese Kosten zu minimieren. Werden sie durch die Einkommensteuer und gezielte Fördermaßnahmen "bezuschußt", so wird der marktwirtschaftliche Prozeß der Kostenminimierung geschwächt bzw. unter Berücksichtigung von Irrationalitäten, wie oben beschrieben, außer Kraft gesetzt. Daher wäre zu überlegen, ob bei der Ausgestaltung der direkten Fördermaßnahmen nicht am Wohnraum selbst bzw. am Quadratmeter angeknüpft werden sollte. D.h., daß unabhängig von den Gestehungskosten ein fixer Subventionsbetrag gewährt wird. Zumindest sollte aber eine Regelung, die an Kosten anknüpft, mit Obergrenzen pro Quadratmeter versehen sein.

Bei der Analyse der Wirkungen der Abschreibungsvergünstigungen wurde herausgearbeitet, daß neben der Liquidität auch auf die Rendite in Abhängigkeit vom Grenzsteuersatz des Investors Einfluß genommen wird. Die Gesamtkapitalrendite nach Steuern ist absolut umso geringer, je geringer der Grenzsteuersatz ist, da sich die Abschreibungsvergünstigungen entsprechend geringer auswirken. Insofern wird durch die progressionsabhängige Förderung die übliche Wirkung der Progression auf den Kopf gestellt. Der Einfluß auf die Rendite wurde in Tabelle 5 anhand der Beispiele der Tabelle 4 ermittelt. Die Gesamtkapitalrendite vor Steuern gibt der Quotient aus Mieteinnahmen und Herstellungskosten wieder. Differenziert wurde zwischen dem Fall der reinen Fremd- und dem Fall der reinen Eigenkapitalfinanzierung. Dargestellt sind die Renditen beim durchschnittlichen Grenzsteuersatz von 19 v.H. und 53 v.H. Die Renditen steigen zwischen diesen Steuersätzen mit zunehmendem Grenzsteuer-

1 In den Finanzierungrechnungen wird daher oft mit einem Disagio operiert, um die Liquiditätsbelastung auch für niedrigere Grenzsteuersätze zu senken bzw. zu einem positiven Überschuß zu kommen. Das Disagio kann im Jahr der Anschaffung steuerlich in voller Höhe als Werbungskosten geltend gemacht werden. 
Tabelle 5: Renditen der ersten Jahre im freifinanzierten Wohnungsbau unter dem Einfluss der Besteuerung, Förderung über degressive Abschreibung nach $\S 7$ Abs. 5 EStG

(ohne Berücksichtigung von Wertänderungen des Objektes)

\begin{tabular}{|c|c|c|c|c|c|c|c|c|c|c|}
\hline Herstellungskosten & in $\mathrm{DM}$ & 3.000 & 3.500 & 4.000 & 4.500 & 5.000 & 5.500 & 6.000 & 6.500 & 7.000 \\
\hline Anfangsmiete & in $\mathrm{DM}$ & 12 & 13 & 14 & 15 & 16 & 17 & 18 & 19 & 20 \\
\hline Grundstücksanteil & in v.H. & 23 & 25 & 27 & 29 & 31 & 33 & 35 & 37 & 39 \\
\hline Gesamtkapitalrendite v. Steuern & in v.H. & 4,8 & 4,5 & 4,2 & 4,0 & 3,8 & 3,7 & 3,6 & 3,5 & 3,4 \\
\hline \multicolumn{11}{|l|}{ Gesamtkapitalrendite n. Steuern } \\
\hline Grenzsteuersatz & in v.H. & $19 \quad 53$ & $19 \quad 53$ & $19 \quad 53$ & $19 \quad 53$ & $19 \quad 53$ & $19 \quad 53$ & $19 \quad 53$ & $19 \quad 53$ & $19 \quad 53$ \\
\hline \multicolumn{11}{|l|}{ Fremdfinanzierung } \\
\hline Fiskalische Defizitphase & Jahre & 16 & 18 & 19 & 20 & 21 & 22 & 23 & 23 & 24 \\
\hline Anfangsrendite & in $\mathrm{v} . \mathrm{H}$. & $6,4 \quad 9,4$ & $6,1 \quad 9,2$ & $5,9 \quad 8,9$ & $5,7 \quad 8,8$ & $5,68,6$ & $5,4 \quad 8,5$ & $5,3 \quad 8,2$ & $5,2 \quad 8,2$ & $5,1 \quad 8,1$ \\
\hline Rendite in der Defizitphase & in $\mathrm{v} . \mathrm{H}$. & (a) 9,1 & (a) 8,9 & (a) 8,7 & (a) 8,5 & (a) 8,4 & (a) 8,3 & (a) 8,3 & (a) 8,1 & (a) 8,0 \\
\hline \multicolumn{11}{|l|}{ Eigenfinanzierung } \\
\hline Anfangsrendite & in $\mathrm{v} . \mathrm{H}$. & $4,9 \quad 5,1$ & $4,6 \quad 4,9$ & $4,4 \quad 4,7$ & $4,2 \quad 4,5$ & $4,0 \quad 4,4$ & $3,9 \quad 4,2$ & $3,8 \quad 4,1$ & $3,7 \quad 4,0$ & $3,6 \quad 3,9$ \\
\hline alt. Kapitalmarktanlage ( 8 v.H.) & in v.H. & $6,5 \quad 3,8$ & $6,5 \quad 3,8$ & $6,5 \quad 3,8$ & $6,5 \quad 3,8$ & $6,5 \quad 3,8$ & $6,5 \quad 3,8$ & $6,5 \quad 3,8$ & $6,5 \quad 3,8$ & $6,5 \quad 3,8$ \\
\hline
\end{tabular}

w (a) keine sinnvolle Angabe möglich 
satz linear an. Die Anfangsrenditen nach Steuern liegen beim Spitzensteuersatz immer über dem Kapitalmarktzins, so daß beim Investor keine Liquiditätsbelastung eintritt. Die ausgewiesene Rendite in der Defizitphase ist ein Durchschnittswert, den der Investor bis zum Zeitpunkt T1 erzielt. Bezugsgröße ist jeweils das ursprüngliche investierte Kapital. ${ }^{1}$ Beim Eingangssteuersatz differieren die Renditen im Zeitablauf stark, so daß der Durchschnitt kein repräsentativer Wert ist. Bei der Berechnung der Werte wurde von Wertsteigerungen abstrahiert, was über solch lange Zeiträume, vor allem unter der Annahme steigender Mieten, unrealistisch erscheint. Doch geht es in dieser Übersicht nur um die Ermittlung des Einflusses der Besteuerung. Da Wertsteigerungen nicht besteuert werden, können sie als prozentuale Bruttogröße mit den Nettorenditen in der Tabelle additiv verknüpft werden. ${ }^{2}$

1 Unter streng betriebswirtschaftlichen Gesichtspunkten müßten als Bezugsgröße nicht die historischen Anschaffungskosten zugrundegelegt werden, sondern das gebundene Kapital. Ohne Berücksichtigung von stillen Reserven entspricht dies den historischen Anschaffungskosten abzüglich der bis zum Betrachtungszeitpunkt vorgenommenen Abschreibungen. Da die steuerlichen Abschreibungen bei Wohnimmobilien aber keine verdienten Abschreibungen darstellen, sind hier die historischen Anschaffungskosten als Bezugsgröße geeigneter. Bezieht man die stillen Reserven mit in das Kalkül ein, müßte der jeweilige Zeitwert der Immobilie als Bezugsgröße gewählt werden. Da die Zeitwerte in den ersten Jahren aber nicht wesentlich von den historischen Anschaffungskosten abweichen dürften, können sie in den ersten Jahren näherungsweise zugrundegelegt werden.

2 Dabei sollte berücksichtigt werden, daß neu erstellter Wohnraum im Regelfall teuerer ist als vergleichbarer gebrauchter Wohnraum, so daß in den ersten Jahren noch nicht von Wertsteigerungen ausgegangen werden kann. 


\section{Teil 3: Maßnahmen zur Förderung der Nutzung und des Erwerbs selbstgenutzten Wohneigentums}

\section{A. Die Befreiung der Mietwerte von der Einkommensteuer}

Private Wirtschaftssubjekte können ihr Nettoeinkommen in der Periode der Entstehung entweder konsumieren oder sparen. Beides gehört in den Bereich der Einkommensverwendung und wird deshalb innerhalb der Einkommensteuer nicht berücksichtigt. Gesparte Einkommensteile werden von rational handelnden Wirtschaftssubjekten entweder auf dem Kapitalmarkt zur Verfügung gestellt (Finanzaktiva, Aktien) oder selbst real investiert (z.B. in vermietete Wohnimmobilien). In beiden Fällen ist mit der Ersparnisbildung außer der intertemporalen Konsumverlagerung das Erzielen von Erträgen verbunden. Die Erträge beruhen auf einem Marktvorgang, stellen einen Reinvermögenszugang dar und unterliegen somit konsequenterweise der Einkommensteuer. ${ }^{1}$

Es stellt sich die Frage, ob jede Verwendungsform des Einkommens, die nicht zu Erträgen auf dem Markt führt, Konsum darstellt, ob also über den Werteverzehr des angeschafften Gutes hinaus keine Erträge erwirtschaftet werden. Für die Anschaffung und Nutzung von selbstgenutztem Wohneigentum fragt es sich, ob damit nur ein Konsumgut verbraucht wird. Kommt man zu dem Ergebnis, daß über den Werteverzehr hinaus Erträge anfallen, handelt es sich nicht um den Verzehr eines Konsumgutes, sondern um eine Investition bzw. eine Vermögensanlage.

Die Auseinandersetzung um diese Problematik wurde in Deutschland Anfang der achtziger Jahre geführt. Anlaß war die Umstellung von der Investitionsgutzur Konsumgutlösung ${ }^{2}$ in der Einkommensteuer zum 1.1.1987. Bis zu diesem

1 Insofern ist das immer wieder vertretene Argument, daß es sich bei der Besteuerung von Kapitalerträgen um eine Doppelbesteuerung handelt, da die Ersparnisse bereits aus versteuertem Einkommen gebildet wurden, nicht zutreffend. Es handelt sich nicht um die Besteuerung des Vermögens, sondern seiner Erträge. Spricht man sich gegen eine Besteuerung von Kapitalerträgen aus, sind nahezu keine Einkünfte steuerbar. Auch die Lohneinkünfte bzw. der Unternehmerlohn (als Anteil am Gewinn) beruhen in Industriegesellschaften weitgehend auf Erträgen des Humankapitals.

2 Verschiedene Autoren sprechen auch von der "Privatgutlosung". Dieser Begriff ist in doppelter Hinsicht irreführend. Zum einen befand sich das Wohneigentum bis zum Übergang zur Konsumgutlösung im Regelfall bereits im Privatvermögen in 
Zeitpunkt wurde die Selbstnutzung von Wohneigentum (wenigstens prinzipiell) ${ }^{1}$ wie das Vermieten einer Wohnung behandelt. Bei dieser sogenannten Investitionsgutlösung war der Nettoertrag als Saldo zwischen der vergleichbaren Marktmiete abzüglich der Werbungskosten steuerpflichtig. Im Rahmen der Konsumgutlösung bleibt die Nutzung von Wohneigentum dagegen von der Einkommensteuer unberührt.

Es stellt sich die Frage, inwieweit mit der Befreiung der Mietwerte von der Einkommensteuer Subventionen verbunden sind. Die Betrachtung kann unter verschiedenen Aspekten erfolgen. Zunächst ist es sinnvoll zu klären, inwieweit es sich bei der Anschaffung und Nutzung von Wohneigentum aus ökonomischer Sicht um eine Investition oder um Konsum handelt. Bei der Frage um die Besteuerung von Erträgen selbstgenutzten Wohneigentums kann zwischen der finanzwissenschaftlichen und steuersystematischen Sichtweise getrennt werden. Nicht zu vernachlässigen sind aber auch psychologische und steuertechnische Aspekte.

\section{Selbstgenutztes Wohneigentum: Konsum oder Investition?}

Das selbstgenutzte Wohneigentum weist Unterschiede und Parallelitäten zu Konsum- und Investitionsgütern auf. Konsumgüter sind dazu bestimmt, unmittelbar der Bedürfnisbefriedigung zu dienen. Sie können in Verbrauchsgüter und Gebrauchsgüter unterteilt werden. Verbrauchsgüter dienen dem direkten Konsum. Ihr Einsatz zum Zweck der Bedürfnisbefriedigung erfolgt einmalig und hat den unmittelbaren Werteverzehr zur Folge. Ein typisches Beispiel hierfür sind Nahrungsmittel bzw. Dienstleistungen. Viele Konsumgüter, wenn nicht die meisten, sind dagegen zum Gebrauch über mehrere Perioden bestimmt. Ihre Nutzung hat nicht den unmittelbaren Verbrauch zur Folge, dieser findet im Zeitablauf mehr oder weniger nutzungsabhängig statt. Insofern weist

Abgrenzung zum Betriebsvermögen. Zum anderen ist der Begriff des Privatvermögens im Steuerrecht nicht unproblematisch, da sich in der Marktwirtschaft in Abgrenzung zum Staatsvermögen fast alles Produktivvermögen, also auch das Betriebsvermögen im Privateigentum befindet. Der Begriff der "Privatgutlossung" ist wertbehaftet und suggeriert eine Sphäre steuerlicher Unantastbarkeit.

1 Zur historischen Entwicklung der Nutzwertbesteuerung, vgl. Abschnitt A. 3. dieses Teils der Untersuchung. 
die selbstgenutzte Wohnimmobilie zunächst Parallelen zu langlebigen Konsumgütern auf.

Dennoch gibt es zwischen Wohnimmobilien und nahezu allen anderen Konsumgütern Unterschiede. Bei Gebrauchsgütern ${ }^{1}$ (Möbeln, Hausrat etc.) sinkt der Marktwert im Regelfall mit der Anschaffung stark ab. Auf den Gebrauchtmärkten sind sie oft nach kurzer Zeit nahezu wertlos, obwohl sie für den Eigentümer noch einen hohen Gebrauchswert besitzen können. ${ }^{2}$ Sie stellen daher nach ihrer Anschaffung nur in beschränktem Umfang verwertbares Vermögen dar. In Höhe der Anschaffungskosten vermindert sich die Nettovermögensposition weitgehend zum Anschaffungszeitpunkt. Bei Wohnimmobilien verhält sich dieser Sachverhalt anders. Trotz längerer Nutzung nimmt ihr Marktwert oft kaum ab, sondern wie die Erfahrung zeigt, im Regelfall langfristig zu. Sie stellen deshalb nach ihrer Anschaffung uneingeschränkt einen marktfähigen Vermögensgegenstand dar.

Bei Konsumgütern entspricht dem Konsum hauptsächlich der Werteverzehr bzw. die Abschreibung des Konsumgutes. Durch den raschen ökonomischen Werteverzehr (nicht unbedingt den technischen) bzw. durch die relativ starke Minderung des Marktwertes nach der Anschaffung hat die Kapitalbindung und damit die Verzinsung des gebundenen Kapitals nur eine geringe Bedeutung. Würden diese Güter als Kapitalanlagen behandelt, käme kein nennenswerter positiver Nettoertrag zustande. Dies mag der Hauptgrund sein, warum typische Konsumgüter - im Gegensatz zu Wohnungen - auf Märkten nicht vermietet werden.

Bei Immobilien verhält es sich umgekehrt. Die Kapitalbindung und die Kapitalverzinsung stehen absolut im Vordergrund. Der Nutzung der Immobilie steht in der jeweiligen Periode nur ein relativ geringer Werteverzehr gegenüber, die Nutzung ist aber in diesem Zeitraum mit relativ hohen Kapitalerträgen verbunden. Bei einer fünfzigjährigen Lebensdauer des Wohneigentums fallen in einer Nutzungsperiode 2 v.H. Abschreibungen auf den Gebäudeanteil an, aber weit darüber hinausgehende Kapitalerträge. Diese entsprechen den vergleichbaren Mietwerten. Der Bodenanteil unterliegt keinem wie auch immer gearteten Werteverzehr, er kann nicht "verkonsumiert" werden. In den einzelnen Peri-

\footnotetext{
1 Ausgenommen die Sonderfälle von Antiquitäten und Kunstgegenständen.

2 Einen Grenzfall stellt das Auto dar.
} 
oden fließen aber Grundrentenbestandteile zu und können genutzt werden. D.h. die Opportunitätserträge bestehen bei Konsumgütern hauptsächlich im Verzicht auf zukünftigen Konsum. Beim selbstgenutzten Wohneigentum dominieren dagegen Kapitalerträge in der Nutzungsperiode, ohne daß zukünftige Konsummöglichkeiten dadurch eingeschränkt werden, da das Vermögen selbst kaum berührt wird.

Eine weitere charakteristische Abgrenzung zwischen Konsumgütern und Investitionsgütern ist die Tatsache, daß Konsumgüter typischerweise aus dem verfügbaren Einkommen der laufenden Periode finanziert werden. Bei der Anschaffung einer Wohnimmobilie ist dies gerade nicht der Fall. ${ }^{1}$ Es muß auf gesparte Einkommensteile zurückgegriffen werden. Aus der Sicht des Wohnungseigentümers handelt es sich zunächst nur um eine Umschichtung von Vermögen. Der Erwerb einer Wohnung stellt somit stets eine Vermögens- bzw. Kapitalanlage dar, was den Eigentümern in der Regel auch bewußt ist. ${ }^{2}$ Wird das Wohneigentum mit Fremdkapital finanziert, wird im Umfang der Tilgung aus dem Einkommen der laufenden Periode gespart, und es entsteht Vermögen, welches statt auf dem Kapitalmarkt im selbstgenutzten Wohneigentum gebunden ist. Das gleiche gilt für Wertsteigerungen, die während der Nutzungszeit anfallen. Sie sind das Spiegelbild steigender Mieten bzw. steigender Nutzwerte und erhöhen das gebundene Kapital. Die Anschaffung selbstgenutzten Wohneigentums stellt somit eine Investition dar, der Konsum erfolgt erst in den Perioden der Nutzung in Höhe der Mietwerte. Einkommensentstehung und Einkommensverwendung fallen hier in den jeweiligen Perioden zusammen. In der volkswirtschaftlichen Gesamtrechnung werden die Mietwerte selbstgenutzten Wohneigentums deshalb als Wertschöpfung (Einkommen) des Wohnungssektors ausgewiesen.

1 Dies gilt allerdings auch für das Auto, das einen Grenzfall zwischen reinen Konsumgütern und Wohnimmobilien darstellt sowie für Möbel, die aber nach ihrer Anschaffung kaum noch marktfähiges Vermögen darstellen.

2 Vgl. Sachverständigenrat zur Begutachtung der Gesamtwirtschaftlichen Entwicklung, Jahresgutachten 1983/1984, Ziffer 570. 


\section{Zur steuerlichen Erfassung der Mietwerte ${ }^{1}$}

Grundsätzlich sollten alle Einkommen der Einkommensteuer unterliegen. Punktuelle Ausnahmen führen zu Minderungen der steuerlichen Bemessungsgrundlage und müssen durch Mehrbelastung anderer Einkunftsteile bzw. durch andere Steuern ausgeglichen werden.

$\mathrm{Zu}$ Beginn der Untersuchung wurde kurz auf die dem deutschen Steuerrecht zugrundeliegenden Einkommenstheorien eingegangen. Die Vertreter beider Theorien gingen unabhängig von ihren ansonsten unterschiedlichen Auffassungen über den Einkommensbegriff davon aus, daß bei der Selbstnutzung von Wohnimmobilien ein zu versteuernder Ertrag in Höhe des Nutzwertes vorliegt. ${ }^{2}$ Auch in der jüngeren finanzwissenschaftlichen Literatur wird die Steuerpflicht des Nutzwertes bejaht, ${ }^{3}$ allerdings nicht ausschließlich. Ebenso wird unter allokativen Gesichtspunkten die Investitionsgutlösung ausdrücklich befürwortet, da es die Allokationseffizienz im System der Einkommensteuer gebietet, daß jedes Einkommen grundsätzlich einmal zu besteuern ist. ${ }^{4}$

Vor allem von steuerjuristischer Seite wird kritisiert, daß die Nutzwertbesteuerung zwar von den Begründern der Einkommensbegriffe explizit vorgesehen wurde, daß sie aber innerhalb des jeweiligen Theoriengebäudes inkonsequent

1 Die Diskussion beschränkt sich auf die Erfassung der Nutzwerte selbstgenutzten Wohneigentums. Die Ergebnisse sind auch auf die Problematik der verbilligten Wohnraumüberlassung übertragbar. Es ist einem Vermieter freigestellt, Wohnraum verbilligt anderen Personen (meist Angehörigen) zu überlassen und die Werbungskosten in voller Höhe geltend zu machen, sofern die Miete mindestens 50 v.H. der ortsüblichen Vergleichsmiete entspricht (vgl. Abschnitt 162 Abs. 5 EStR März 1993). Diese unbefriedigende Regelung könnte nur dann gerechtfertigt werden, wenn die Differenz zwischen Marktmiete und tatsächlicher Miete beim Nutznießer als Einkommen besteuert werden würde.

2 Zum quellentheoretischen Besteuerungsansatz und zur Nutzwertbesteuerung vgl. Fuisting, B., a.a.O., S. 112. Zum Reinvermögenszugangsansatz vgl. Schanz, G. v., a.a.O., S. 6f und S. 22.

${ }^{3}$ So interpretiert beispielsweise Haller den Einkommensbegriff sehr weit und tritt für die Nutzwertbesteuerung aller langlebigen Konsumgüter ein. Vgl. Haller, H., a.a.O., S. 336ff; explizit spricht er sich für die Besteuerung der Nutzwerte selbstgenutzten Wohneigentums aus. Ebenso Musgrave, R.A. u.a., a.a.O., S. $118 \mathrm{f}$ u. S. 155f. Andel, N., Einkommensteuer, a.a.O., S. 340.

4 Vgl. Nachtkamp, H.H., a.a.O., S. 7 ff. 
sei. ${ }^{1}$ Diese Kritik erfolgt auf der Grundlage enger Wortauslegung. So sei eine Besteuerung nach der Reinvermögenszugangstheorie inkonsequent, weil im engeren Sinne nichts zugehe, sondern allenfalls keine Miete abgehe. ${ }^{2}$ Dieses Argument überzeugt nicht. Musgrave definiert den steuerbaren Reinvermögenszugang als Konsum zuzüglich der Erhöhung des Nettovermögens. ${ }^{3}$ Diese Definition ist schlüssig, da nichts konsumiert und gespart werden kann, was zuvor nicht als Einkommen entstanden ist. Diese Identität würde somit nur stimmen, wenn der Konsum bei der Selbstnutzung allein aus Abschreibungen bestehen würde.

Die Steuerreformkommission hat für eine Konsumgutlösung plädiert und darauf verwiesen, daß auch bei anderen Vermögenswerten nur die "tatsächlichen" Erträge steuerbar seien. ${ }^{4}$

In der Literatur wird diesem Argument aber folgendes entgegengehalten: "Bei diesem Argument werden aber die Kapitalerträge zu eng im Sinne von zuflieBenden Geldmitteln gesehen. Eine solche enge Fassung der steuerpflichtigen Einnahmen findet aber keine Deckung durch die gegenwärtige Steuerpraxis. So lautet $\& 8 \mathrm{EStG}$ :

(1) Einnahmen sind alle Güter, die in Geld oder Geldeswert bestehen ...

(2) Einnahmen, die nicht in Geld bestehen (Wohnung, Kost, Waren und sonstige Sachbezüge) sind mit den üblichen Mittelpreisen des Verbrauchsortes anzusetzen ...."

Von der steuerjuristischen Seite wird auch argumentiert, daß es sich bei der Nutzwertbesteuerung um einen singulären systemwidrigen Einzelfall handle, da ansonsten keine Besteuerung von eigenerstellten Gütern und Diensten bei

1 Zur Wiedergabe der in der juristischen Literatur vertretenen Auffassungen vgl. Göbel, M., Die private Eigenheiminvestition unter dem Einfluß der Besteuerung, Dissertation, Hamburg, 1989, S. $42 \mathrm{ff}$.

2 Vgl. ebenda, S. 46.

3 Vgl. Musgrave, R.A. u.a., a.a.O., S. 155.

4 Vgl. Gutachten der Steuerreformkommission 1971, a.a.O., Teil II, Ziffer 210.

3 Naust, H./Werth, G., a.a.O., S. 18. Der $\S 8$ Abs. 2 EStG ist in der heutigen Fassung leicht geändert worden: Einnahmen, die nicht in Geld bestehen Wohnungen, Kost, Waren und Sachbezüge), sind mit den ublichen Endpreisen am Abgabeort anzusetzen... 
Privatpersonen vorgenommen werde. ${ }^{1}$ Der Übergang zur Konsumgutlösung wird deshalb ausdrücklich befürwortet. ${ }^{2}$ Aus ökonomischer Sicht kann dieses Argument nicht überzeugen.

Es gibt keinen prinzipiellen Unterschied zwischen den (steuerpflichtigen) Entnahmen eines Gewerbetreibenden aus eigener Produktion für seinen Privathaushalt und den Quasi-Entnahmen des Produzenten von Wohnungsnutzung für den Eigenverbrauch. ${ }^{3}$ Der ökonomische Sachverhalt ist unabhängig davon, ob jemandem durch juristische Definition Unternehmereigenschaft zugebilligt wird oder nicht. ${ }^{4} \mathrm{Daß}$ es sich trotzdem um einen singulären Einzelfall im Steuersystem handelt, da bei nicht gewerbetreibenden Privatpersonen ansonsten keine Nutzwerte des eigenen Vermögens versteuert werden, stimmt insoweit. Allerdings läßt sich dies wegen der besonderen Bedeutung rechtfertigen. ${ }^{5}$

Außerdem sollte man die Entscheidung nicht zu eng an Einkommensdefinitionen festmachen. Einkommensbegriffe dienen dazu, steuerliches Einkommen aufgrund einer bestimmten Grundvorstellung zu definieren. Hinter den Einkommensbegriffen steht die Erfassung der steuerlichen Leistungsfähigkeit als anerkanntes Ziel, sowohl aus finanzwissenschaftlicher aber auch aus steuerjuristischer Sicht. ${ }^{6}$ Ein Wohneigentümer, der beispielsweise ein lastenfreies Wohneigentum nutzt, ist sicherlich leistungsfähiger als ein Mieter, der über das gleiche Markteinkommen verfügt.

Auch hat das Bundesverfassungsgericht betont, daß sich der Gesetzgeber bei der Besteuerung der Erträge selbstgenutzten Wohneigentums am "Gedanken der Steuergerechtigkeit orientiert" und daß er damit eine Regelung getroffen hat, die "eine ungleiche Behandlung der Eigenwohner und der Mieter vermeidet. ${ }^{\text {" }}$ Insofern kann die Einschränkung, daß nur das steuerbar sein soll, was auf

1 Vgl. Tipke, K./Lang, J., a.a.O., S. 201.

2 Vgl. ebenda, S. 201.

3 Vgl. Nachtkamp, H.H., a.a.O., S. 7.

4 Vgl. ebenda, S. 7.

5 Vgl. Andel, N., Einkommensteuer, a.a.O., S. 340.

6 Vgl. Teil 1, B. 2.

7 BVerfG, Urteil vom 3.12.1958, in: BStBl. 1959 I, S. 68.

${ }^{8}$ Ebenda, S. 68 
einem Marktvorgang beruht, nicht befriedigen. ${ }^{1}$ Steuertechnische bzw. Erfassungsprobleme spielen bei der Nutzwertbesteuerung eine untergeordnete Rolle. Der Sachverständigenrat, der für die Investitionsgutlösung plädiert, hat darauf hingewiesen, daß der Ansatz für den Mietwert wohl nicht der vollen Miete entsprechen werde, ${ }^{2}$ doch verfügen die Finanzämter über exakte Mietspiegel für die unterschiedlichen Wohnlagen in ihren Einzugsgebieten. ${ }^{3}$ Außerdem erstellen die meisten Gemeinden einen Mietspiegel bzw. gehen dazu über, solche zu erstellen. Der Mietspiegel ermittelt die Vergleichsmieten für privatrechtliche Auseinandersetzungen zwischen Mietern und Vermietern. Diese Daten können auch für steuerliche Zwecke herangezogen werden. ${ }^{4}$

Es gibt somit keinen Grund, das selbstgenutzte Wohneigentum steuerlich als Konsumgut zu behandeln. Die praktischen Konsequenzen der Nichterfassung der Nutzwerte werden deutlicher, wenn man das Wohneigentum mit anderen Kapitalanlagen bzw. auch mit der Situation des Vermieters vergleicht. ${ }^{5}$ Wird der Selbstnutzer beispielsweise mit dem Vermieter verglichen, der bei gleichem Einkommen und gleicher Nettovermögensposition sein Kapital in vermietetem Wohnraum investiert, ergibt sich folgendes unterschiedliche Bild.

Ein Wohnungseigentümer, der seine Wohnung vermietet, muß die Mieteinnahmen beispielsweise in Höhe von 15.000 DM als Einnahmen aus Vermietung

1 Es wurde zu Beginn der Untersuchung darauf hingewiesen, daß nach juristischer Lehrmeinung nur das steuerbar sei, was auf einem Marktvorgang beruht (vgl. Teil 1, B. 2.). Diese Verkürzung des Einkommensbegriffs ist finanzwissenschaftlich nicht gedeckt und stellt gerade bei der Selbstnutzung von Wohnimmobilien eine unbefriedigende Einschränkung dar.

2 Vgl. Sachverständigenrat zur Begutachtung der gesamtwirtschaftlichen Entwicklung, Jahresgutachten 1983/84, Ziffer 571.

3 Vgl. Oberbeckmann, H.-L., Das Wohneigentum als Gegenstand der Vermögenspolitik, in: Wohneigentum zwischen Vermögenspolitik und Wohnungspolitik, XVII. Königsteiner Gespräch - Referate und Diskussion, Schriftenreihe des Instituts für Städtebau, Wohnungswirtschaft und Bausparen, Bd. 37, Bonn 1982, S. 19.

4 Die Besteuerung der Erträge selbstgenutzten Wohneigentums war vor dem Übergang fiskalisch unergiebig. Dies war allerdings nur eine Frage der konkreten Ausgestaltung. Zur historischen Entwicklung und zur Ausgestaltung vgl. Abschnitt A. 3. dieses Teils der Untersuchung.

5 Diese Vergleiche werden u.a. vorgenommen von Naust, H./Werth, G., a.a.O., S. 18ff. Eekhoff, J., Wohnungspolitik, Tübingen 1993, S. 56ff. Göbel, M., a.a.O., S. $70 \mathrm{ff}$. 
und Verpachtung versteuern. Nach Abzug von Werbungskosten in Höhe von beispielsweise $5.000 \mathrm{DM}$ verbleibt ein zu versteuerndes Einkommen aus Vermietung und Verpachtung von 10.000 DM. Bei einem marginalen Steuersatz von 30 v.H. sind $3.000 \mathrm{DM}$ an Steuern zu bezahlen. Bezieht nun dieser Wohneigentümer seine Wohnung selbst, fallen ökonomisch gesehen Bruttoerträge in gleicher Höhe wie zuvor an. Entsprechen die Werbungskosten, die er zuvor als Vermieter geltend machen konnte, echten Aufwendungen, entsteht der gleich Reinertrag wie zuvor, ist nun aber aufgrund der Konsumgutlösung steuerfrei. In diesem Beispiel sind 3.000 DM weniger an Steuern zu bezahlen. An den Bruttoerträgen hat sich aber nichts geändert, nur daß im ersten Fall alle Erträge auf einem Marktvorgang beruhen und in letzteren nicht pekuniär als Nutzwert anfallen. Letztendlich läuft dies darauf hinaus, daß sich der Vermieter aus seinen Nettomieteinnahmen selbst keine vergleichbare Mietwohnung leisten kann.

Die gleiche Situation stellt sich für alle Steuerpflichtigen, die über sonstige Vermögensanlagen verfügen und deren Erträge auf einem Marktvorgang beruhen. Die Umschichtung des Vermögens in selbstgenutztes Wohneigentum ist aus steuerlichen Gründen c.p. die am meisten vorteilhafte, weil quantitativ eine der bedeutendsten Anlageformen, bei der die Erträge steuerfrei bleiben. ${ }^{1}$ Es handelt sich um einen klaren Verstoß gegen das Gebot der Besteuerung nach der Leistungsfähigkeit und zwar in diesem Fall in horizontalen Ausprägung, da grundsätzlich gleiche steuerliche Leistungsfähigkeit unterschiedlich besteuert wird. Neumark sieht in solchen Fällen den Gleichheitsgrundsatz verletzt. ${ }^{2}$ Fragt man, wem die Konsumgutlösung am meisten zugute kommt, so nehmen die Steuervorteile mit abnehmender Verschuldung und zunehmendem Mietwert zu. Sie begünstigen deshalb vor allem Altbesitzer, die über aufwendiges Wohneigentum verfügen und weitgehend entschuldet sind. ${ }^{3}$ Außerdem nehmen die Steuervorteile bei gleichen Nettomietwerten mit steigendem Einkommen zu, ${ }^{4}$ was gegen die vertikale Steuergerechtigkeit verstößt.

1 Eine Privilegierung der Kapitalerträge besteht im Deutschen Steuerrecht im wesentlichen noch für Kapitallebensversicherungen und neuerdings in Form des Sparerfreibetrages in Höhe von 6.000/12.000 DM für Besitzer von Kapitalvermögen.

2 Vgl. Neumark, F., a.a.O., S. 135.

3 Vgl. Oberhauser, A., Ein Verstoß gegen die Gerechtigkeit. Die Neuregelung der Besteuerung selbstgenutzten Wohneigentums, in: Wohnungswirtschaft und Mietrecht, 39. Jg., Heft 6, S. 163.

4 Vgl. ebenda, S. 163. 
Es stellt sich die Frage, weshalb die Nutzwertbesteuerung trotzdem auf so viel Widerstand gestoßen ist, daß sie abgeschafft wurde. Hier spielen wahrscheinlich psychologische Faktoren die ausschlaggebende Rolle. Wie bei der Besteuerung von Kapitalerträgen fehlt in weiten Teilen der Bevölkerung die Einsicht, daß sich Kapitalerträge nicht von Lohn- und Gewinneinkünften unterscheiden. Vielfach wird auch das irrtümliche Doppelbesteuerungsargument vertreten, da das Vermögen bereits aus versteuertem Einkommen gebildet sei - ein Argument, das beim selbstgenutzten Wohneigentum mit umso mehr Vehemenz vertreten wird, da dieses Vermögen im Regelfall nur unter großen Mühen und hohem Konsumverzicht gebildet wurde. Dahinter verbirgt sich wohl auch die Unwissenheit über den Zusammenhang zwischen dem Umfang der Bemessungsgrundlage des zu versteuernden Einkommens und der Höhe der Steuersätzen. D.h. die Belastung anderer Einkunftsteile durch eine Schmälerung der Bemessungsgrundlage wird nicht genügend berücksichtigt.

Die Selbstnutzung von Wohneigentum genießt in der politischen Wertung einen hohen Rang. ${ }^{1}$ Bisher hat jede Bundesregierung ihren Willen bekundet, günstige Voraussetzungen für die Bildung von Wohneigentum zu schaffen. ${ }^{2}$ Die Konsumgutlösung ist unter diesem Aspekt ein ungeeignetes Mittel, da die steuerlichen Entlastungen, die sich aus negativen Einkünften aus Vermietung und Verpachtung in den ersten Jahren ergeben, vom Wohneigentümer nicht genutzt werden können. ${ }^{3}$ Dieser Nachteil wird besonders deutlich, wenn man die Bemühungen der Steuerpflichtigen betrachtet, die Vorteile der Investitionsgutlösung zu nutzen und die Konsumgutlösung zu umgehen. Erwerben zwei Steuerpflichtige identische Wohnungen und vermieten sich diese gegenseitig, werden die Verluste aus Vermietung und Verpachtung von den Finanzbehörden nicht anerkannt (sog. Überkreuzmietmodell). ${ }^{4}$ Es ist ein Indiz für einen verfehlten Ansatz zur Begünstigung des selbstgenutzten Wohneigentums, wenn potentiellen Erwerbern, die es bei wenig Eigenkapital am schwersten haben, die

1 Vgl. Entwurf eines Gesetzes zur Neuregelung der steuerlichen Förderung selbstgenutzten Wohneigentums, BT-Drucksache 10/3633, S. 10.

2 Vgl. Hooven, E. van, Wohneigentum als Element der Sozialordnung, in: Handbuch der Sozialpolitik, Pfullingen 1988, S. 342.

3 Vgl. Teil 1, C. 2.

4 Vgl. Bundesfinanzhof, Urteil vom 19.6.1991, Az.: IX R 134/86. 
hohen Belastungen der ersten Jahre zu tragen, die Vorteile des Steuersystems, die jedem Vermieter offen stehen, verwehrt werden.

In der Literatur wird der Selbstnutzer nicht nur mit dem Vermieter bzw. sonstigen Vermögensanleger verglichen, sondern auch mit der Stellung des Mieters. ${ }^{1}$ Diese Vergleiche sind allerdings nicht unproblematisch, da es sich bei der Konsumgutlösung um den Verzicht auf die Besteuerung von Einkunftsteilen bei ihrer Entstehung handelt und nicht um die steuerliche Berücksichtigung von Konsumausgaben bzw. der Einkommensverwendung. Da aber bei diesem Vermögensgegenstand Einkommensentstehung und Einkommensverwendung zusammenfallen und sich in ihrer Höhe gerade entsprechen, liegt es nahe, zu fragen, ob die Konsumgutlösung nicht auch die Mieter diskriminiert. So können die steuerfreien Nutzwerte als Konsumausgaben, die aus dem Bruttoeinkommen getätig werden, interpretiert werden. Ebenso wie sie einem nichtpekuniären Ertrag entsprechen, stellen sie dann einen nichtpekuniären Aufwand dar.

Die Konsequenzen können anhand des oben beschriebenen Beispiels verdeutlicht werden. Um sich eine Wohnung mit einer Jahresmiete von 15.000 DM leisten zu können, muß ein Mieter bei einem Grenzsteuersatz von 30 v.H. Bruttoeinkommen in Höhe von 21.400 DM aufwenden. Um die Mieter den Selbstnutzern gleichzustellen d.h. sie nicht zu benachteiligen, wäre es deshalb denkbar, einen Mieterfreibetrag in Höhe der gezahlten Miete zu schaffen. Diese Forderung wurde im politischen Raum schon erhoben. Bei der öffentlichen Anhörung des Bundestags-Finanzausschusses zur Umstellung von der Investitionsgut- zur Konsumgutlösung befürwortete der Deutsche Mieterbund die steuerlichen Abzugsfähigkeit der Mieten als sozial notwendiges Gegengewicht zur Konsumgutlösung. ${ }^{2}$ Solche Mieterfreibeträge gab es bereits in der Vergangenheit, um die "Ungeheuerlichkeit" ${ }^{\text {"3 }}$ einer steuerlichen Nichterfassung von Mietwerten

1 Vgl. hierzu Naust, H./Werth, G., a.a.O., S. 18ff. Eekhoff, J., Wohnungspolitik, a.a.O., S. 56ff. Göbel, M., a.a.O., S. 70ff.

2 Vgl. Öffentliche Anhörung des Bundestags-Finanzausschusses vom 23. Oktober 1985, Protokoll Nr.47. Zitiert nach Wagner, W., Aus der Arbeit des Steuergesetzgebers, in: StuW 1/1986, S. 92.

3 Schanz, G.v., a.a.O., S. 35. Schanz verwies in diesem Beitrag darauf, daß ihm damals außer Mecklenburg kein Land bekannt sei, das die Nutzwerte selbstgenutzten Wohneigentums nicht erfaßte. Er nannte als Beispiel die Stadt Basel, die erst zum 1.10.1866 zur Investitionsgutlösung überging und es zuvor den Mietern als Ausgleich gestattete, die gezahlte Miete steuerlich geltend zu machen. 
selbstgenutzten Wohneigentums zu kompensieren. Zwar wären Selbstnutzer und Mieter durch diese Regelung formal gleichgestellt. Faktisch bliebe aber ein Durchbruch in der Besteuerung nach der Leistungsfähigkeit mit der Konsequenz, daß Konsumausgaben beim Mieter umso höher subventioniert werden, je höher der Grenzsteuersatz der Mieter und je höher die Mietausgaben sind. Ein einheitlicher Mietfreibetrag würde zwar dem letzten Einwand begegnen, doch wäre damit die faktische Gleichstellung mit den Selbstnutzern nicht erreicht, welche systembedingt den gesamten Mietwert aus Bruttoeinkünften bestreiten. Außerdem käme man dann nicht umhin, den Wohneigentümern die volle Absetzbarkeit ihrer Abschreibungen und Schuldzinsen (bzw. der Werbungskosten) zuzugestehen. ${ }^{1}$ Aus finanzwissenschaftlicher Sicht bleibt deshalb als befriedigende Lösung nur die Rückkehr zur Investitionsgutlösung, um zur Gleichheit in der Besteuerung zurückzukehren. Mit einer solchen Lösung ist bei einer Eigentümerquote von 40 v.H. aus politischen Gründen aber kaum zu rechnen.

Der Vergleich mit den Mietern zeigt ein weiteres Problem, das in Zukunft an Bedeutung gewinnen wird. Die Konsumgutlösung kollidiert mit dem Grundfreibetrag in der Einkommensteuer. Der Grundfreibetrag soll Einkommensteile der Steuerpflichtigen, die sie benötigen, um ihre soziokulturellen Mindestbedürfnisse (soziokulturelles Existenzminimum) zu decken, von der Besteuerung freistellen. Damit werden keine Subventionen gewährt, im engeren Sinne resultieren daraus keine progressionsabhängigen Steuererleichterungen, sondern die steuerliche Leistungsfähigkeit und der Steuertarif beginnen erst jenseits des Grundfreibetrags. Die Höhe des Grundfreibetrag des zur Zeit geltenden Steuertarifs (T90) genügt diesen Anforderungen nicht. Aufgrund eines Urteils des Bundesverfassungsgerichts ${ }^{2}$ ist damit zu rechnen, daß die Grundfreibeträge in Zukunft deutlich angehoben werden. ${ }^{3}$

Der Grundfreibetrag basiert auf einem Warenkorb, der die soziokulturellen Mindestaufwendungen für Mieten enthält. Er ist mit der Investitionsgutlösung

Vgl. Andel, N., Einkommensteuer, a.a.O., S. 341.

2 Vgl. Bundesverfassungsgericht, Beschluß vom 25. September 1992, abgedruckt in: DStR, H. 44, 1992, S. 1539-1543

${ }^{3}$ Bis zur neuen Festlegung des Grundfreibetrages wurde für Einkommensbezieher mit geringem Einkommen eine Einkommensteuerzusatztabelle mit erhöhtem Grundfreibetrag eingeführt. Vgl. BMF - Finanznachrichten, 4/93. 
vereinbar. Das Gesamteinkommen besteht im System der Investitionsgutlösung aus den um die Werbungskosten bereinigten Mieteinnahmen und den sonstigen Reineinkünften des Wohneigentümers. Von diesem Gesamteinkommen wird mit dem Grundfreibetrag u.a. der Teil des Einkommens von der Besteuerung freigestellt, den der Eigentümer zur Deckung seiner existentiellen Wohnbedürfnisse benötigt. Nur der darüber hinausgehende Teil der Einkünfte bzw. des Anteils des Mietwertes an den Gesamteinkünften, ist steuerpflichtig. Der Grundfreibetrag ist auch mit den notwendigen Ausgaben des Mieters vereinbar. Einkommensteile, die er zur Deckung seiner existentiellen Wohnbedürfnisse benötigt, werden von der Besteuerung freigestellt. Mieter und Wohneigentümer werden bei der Investitionsgutlösung mit dem Grundfreibetrags gleichbehandelt.

Mit dem Grundfreibetrag und der Konsumgutlösung verhält es sich anders. Von den Befürworten der Konsumgutlösung wird abgestritten, daß Einkunftsteile in Höhe der Mietwerte zugehen. Es wird vielmehr betont, daß allenfalls keine Miete abgehe. D.h. aber, daß kein Sachverhalt vorliegt, der den Mietanteil am Grundfreibetrag für Wohneigentümer rechtfertigt. Betrachtet man den relativ transparenten Fall des schuldenfreien Wohneigentümers und läßt sich auf diese Argumentation ein, so fragt es sich, warum dem Wohneigentümer der Mietanteil innerhalb des Grundfreibetrags gewährt werden soll. Innerhalb der Logik der Konsumgutlösung "verkonsumiert" er sein Vermögen und dies findet dann zweifelsohne nur in Form von Abschreibungen statt. $\mathrm{Zu}$ Ende gedacht hieße dies, daß dem Wohneigentümer nur die Abschreibungen, die auf eine Wohnung mit sozialer Mindestgröße und sozialem Mindeststandard entfallen, innerhalb des Grundfreibetrages gewährt werden dürften. Dabei wäre aber nicht von den steuerlichen Abschreibungen auszugehen, sondern von den tatsächlichen $\mathrm{Ab}-$ schreibungen in nominaler Höhe, da nur diese notwendig sind, um entsprechend dem Nominalwertprinzip die Nettovermögensposition zu erhalten. ${ }^{1}$ Letztendlich dürfte damit im Regelfall kein Mietanteil am Grundfreibetrag gewährt werden. Aus der Sicht der Investitionsgutlösung dürfte am Beispiel des schuldenfreien Wohneigentümers in jedem Fall kein Mietanteil am Grundfreibetrag gewährt werden, da bereits ein Mieterfreibetrag in Höhe des tatsächlichen Nettonutzwertes existiert.

1 Ansonsten käme es zu Privilegierungen gegenüber anderen Vermögensbesitzern, denen ein realer Kapitalerhalt aus den unvesteuerten Erträgen verwehrt ist. 
Wesentlich schwieriger ist der Fall des verschuldeten Wohneigentümers zu beurteilen. Wie sollen die Zinsausgaben bei ihm qualifiziert werden? Innerhalb der Logik der Konsumgutlöung wären sie wahrscheinlich existentiell notwendige Mindestausgaben. Vor allem wenn der Wohneigentümer hoch verschuldet ist, hat er im Regelfall höhere Lasten zu tragen als der Mieter. Daß aber die Wohneigentumsbildung bzw. die Lasten daraus zum sozialökonomischen Existenzminimum gehören, kann sicherlich bestritten werden. Soweit der Wohneigentümer über einen lastenfreien Anteil am Wohneigentum verfügt, der wiederum den absoluten Mindestverhältnissen genügt, wäre der Mietanteil am Grundfreibetrag zu streichen. Zinsaufwendungen, die darüber hinaus gehen, sind mit der Idee des Grundfreibetrages nicht vereinbar. Innerhalb der Logik der Investitionsgutlösung wäre der Mietanteil am Grundfreibetrag dann zu streichen, wenn die auf dem Wohnungsmarkt übliche Kapitalverzinsung (ca. 5 v.H.) bezogen auf den gebundenen Eigenkapitalanteil den Mietanteil am Grundfreibetrag überschreitet. In diesem Fall entspräche der steuerfreie Mietwert den existentiell notwendigen Mietaufwendungen.

Interessanterweise führen beide Betrachtungen, was den Grundfreibetrag in der Einkommensteuer angeht, zu nahezu gleichen Ergebnissen. Die Erwägungen dürften aber an steuertechnischen Problemen, dem Aufwand der Datenerhebung und Gestaltungsmißbräuchen scheitern. Fiskalisch handelt es sich jedoch um eine bedeutende Größenordnungen. Der Grundfreibetrag soll nach den Vorgaben des Verfassungsgerichtes auf ca. 12.000 DM angehoben werden. ${ }^{1}$ Bei einer Wohneigentümerquote von $40 \mathrm{v} . \mathrm{H}$. und berücksichtigungsfähigen Mindestaufwendungen für die Mietausgaben von monatlich $350 \mathrm{DM}$ beliefen sich die fiskalischen Mehreinnahmen durch eine vollständige Streichung des Mietanteils für Wohneigentümer am Grundfreibetrag bei einem Grenzsteuersatz von nur 20 v.H. bereits auf zweistellige Milliardenbeträge.

Daher kann es nicht befriedigen, das Problem aus technischen Gründen ungelöst zu lassen und den Grundfreibetrag bei der anstehenden Neugestaltung für alle Wohnungsnutzer auf 12.000 DM pro Person anzuheben. Die Konsumgutlösung ist wahrscheinlich irreversibel, doch hat es der Gesetzgeber bei der Gestaltung des Grundfreibetrages in der Hand, einen Teil des Schadens zu kompensieren. Am ehesten käme ein Verfahren in Frage, das pauschalierend gestaltet ist und

1 Vgl. Bundesverfassungsgericht, Beschluß vom 25. September 1992, a.a.O. 
einerseits Subventionen abbaut, andererseits aber hoch verschuldete Wohneigentümer nicht diskriminiert.

Zusammenfassend heißt dies, daß die Konsumgutlösung keine geeignete Maßnahme zur Förderung des Erwerbs selbstgenutzten Wohneigentums ist. Sie erschwert den Erwerb vor allem Wohneigentümern, die sich hoch verschulden müssen. Die Vorteile negativer Einkünfte aus Vermietung und Verpachtung können nicht genutzt werden. Bei geringem Eigenkapital ist es leichter, als Vermieter Vermögen in Immobilien zu bilden, statt als Selbstnutzer eine Wohnung zu erwerben. Es gibt aus finanzwissenschaftlicher Sicht keine plausiblen Gründe, den Nutzwert selbstgenutzten Wohneigentums nicht innerhalb der Einkünfte aus Vermietung und Verpachtung zu erfassen. Die Konsumgutlösung kommt vor allem Altbesitzern zugute, die über aufwendiges, weitgehend entlastetes Wohneigentum und hohes Einkommen verfügen. In zunehmendem $\mathrm{Maße}$ wird sie aber auch einer Generation von Erben zugute kommen. Da die Rückkehr zur Investitionsgutlösung aus politischen Gründen kaum in Frage kommt, sollte sie allerdings bei der anstehenden Neugestaltung der Grund- und Kinderfreibeträge in der Einkommensteuer berücksichtigt werden. Es kann kein befriedigendes Ergebnis einer Neugestaltung der Grundfreibeträge sein, wenn sich der lastenfreie Wohneigentümer im System der Konsumgutlösung und der Mieter mit dem gleichen Grundfreibetrag begnügen müssen.

\section{3. Überblick über die historische Entwicklung der steuerlichen Wohneigentumspolitik}

Die historische Entwicklung ist für die heutige Wohneigentumspolitik ohne Bedeutung. Der vorliegende Abschnitt kann deshalb vom eiligen Leser übergangen werden. Er dient dem interessierten Leser als Rückblick über nahezu 50 Jahre steuerliche Wohneigentumspoltik in Deutschland. Die Materie wäre auch eine interessante Fallstudie für die neue politische Ökonomie.

In Anbetracht der Argumente zugunsten einer Investitionsgutlösung erscheint der Übergang zur Konsumgutlösung 1987 nicht unbedingt nachvollziehbar. Der Systemwechsel brachte allerdings für die Eigentümer selbstgenutzten Wohneigentums faktisch keine allzu großen Änderungen, sondern war der Schlußpunkt einer historischen Entwicklung. Diese war dadurch gekennzeichnet, daß der Nutzwert als Bruttoeinkommenskomponente in zunehmendem Maße ver- 
nachlässigt wurde und die Werbungskosten aufgrund außerfiskalischer Zielsetzungen künstlich über die effektiven Kosten hinaus erhöht wurden. Die Entwicklung wird im folgenden kurz dargestellt, um die politische Entscheidung des Systemwechsels besser verständlich zu machen. Es handelt sich zum überwiegenden Teil um Geschichte. Deshalb wird auf die Darstellung umfangreicher Detailregelungen und auf den Nachweis der gesetzlichen Grundlagen verzichtet und auf die entsprechende Quellen verwiesen. ${ }^{1}$

Mit der Abschaffung der Nutzwertbesteuerung zum 1.1.1987² ging in Deutschland ein Besteuerungsverfahren zu Ende, das bis in die Anfänge des 19. Jahrhunderts zurückreichte. Zur Zeit der Jahrhundertwende war es gängige Praxis in nahezu allen Deutschen Staaten. ${ }^{3}$ Besteuerungsgrundlage war die vergleichbare Marktmiete. Die Festsetzung dieser Vergleichsmiete führte aber bei Einfamilienhäusern, die zum damaligen Zeitpunkt häufig "Villen" waren, ${ }^{4} \mathrm{zu}$ Streitigkeiten zwischen Finanzbehörden und Steuerpflichtigen. Um diesen Auseinandersetzungen aus dem Weg zu gehen, wurde der Nutzwert relativ niedrig angesetzt. Saldiert mit den erheblichen Kosten der Instandhaltung, die diese Villen verursachten, entstand damit im Regelfall dauerhaft ein negatives Einkommen, welches addiert mit den sonstigen Einkunftsarten zu Steuermindereinnahmen führte. Die ursprüngliche fiskalische Intention der Nutzwertbesteuerung verkehrte sich in ihr Gegenteil.

Als Reaktion darauf wurde die sogenannte Einfamilienhaus-Verordnung 1937 erlassen. Auf der Basis eines Einheitswertes (Basisjahr 1935), der zum damaligen Zeitpunkt weitgehend dem Marktwert der Einfamilienhäuser entsprach, wurde ein jährlicher Mietwert in Höhe von 3,5 v.H. (bzw. 3 v.H. für Gebäude, die vor 1925 erstellt wurden) des Einheitswertes als Nutzwert festgelegt. Dieser stellte einen Reinertrag dar, von dem angenommen wurde, daß er der Mindestverzinsung einer Kapitalanlage entspreche. Der Nutzwert hatte einen steuerlichen Nettosollertragscharakter. Das bedeutete, daß Werbungskosten wie Instandhaltungskosten, aber auch Abschreibungen nicht berücksichtigt wurden.

1 Zur historischen Entwicklung der Nutzwertbesteuerung, vgl., Gutachten der Steuerreformkommission 1971, a.a.O., S. 109ff. Göbel, M., a.a.O., S. $42 \mathrm{ff}$.

2 Mit Übergangsregelungen für vor diesem Zeitpunkt angeschaffte Wohnungen bis 1998.

3 Vgl., Schanz, G., a.a.O., S. 35.

4 Vgl. Gutachten der Steuerreformkommission, a.a.O., S. 110. 
Dem Steuerpflichtigen blieb die Möglichkeit, gezahlte Fremdkapitalzinsen als Werbungskosten geltend zu machen. Der maximale Abzug wurde allerdings auf die Höhe des pauschaliert angesetzten Nutzwertes begrenzt (pauschalierte Nutzwertbesteuerung). Die Zulässigkeit des Schuldzinsabzugs, aber auch die Begrenzung des Abzugs auf die Höhe des Nutzwertes waren insofern konsequent, als sich der Sollertragscharakter nur auf die Nettorendite des eingesetzten Eigenkapitals bezog. Es war nicht mehr möglich, einen steuerlichen Verlust auszuweisen.

Lag die Wohnung jedoch in einem Zwei- oder Mehrfamilienhaus, wurde die Miete der übrigen Wohnungen als Bruttovergleichsmiete herangezogen. Die tatsächlich angefallenen Werbungskosten konnten vom Steuerpflichtigen weiterhin für das gesamte Objekt geltend gemacht werden (Überschußrechnung). Durch die Zusammenfassung der Aufwendungen und Erträge für das gesamte Objekt blieben dem Steuerpflichtigen auf diese Weise in begrenztem Umfang immer noch Gestaltungsmöglichkeiten.

Sowohl die pauschalierte Nutzwertbesteuerung als auch die Überschußrechnung können als das Bestreben angesehen werden, den Nutzwert als Einkommenskomponente zu erfassen, um dem Ziel der Besteuerung nach der Leistungsfähigkeit gerecht zu werden. Sie dienten damit zentral fiskalischen Motiven. Mit der unterschiedlichen Regelung für Einfamilienhäuser auf der einen, Zweiund Mehrfamilienhäuser auf der anderen Seite wurde aber aus technischen Gründen eine Zweiteilung vorgenommen, die in der Steuerpraxis der folgenden Jahrzehnte zu erheblich unterschiedlichen Steuerbe- und -entlastungen führte.

Die fiskalische Intention der Nutzwertbesteuerung änderte sich in der Nachkriegszeit. Bedingt durch den enormen Wohnungsfehlbestand wurde die Besteuerung des selbstgenutzten Wohneigentums zunächst in den Dienst der Wohnungsbaupolitik und später auch in den Dienst der Vermögenspolitik gestellt. Mit der Einführung des $\S 7 \mathrm{~b} \mathrm{EStG}^{1}$ (1948) wurde ein Instrument geschaffen, das ursprünglich rein wohnungsbaupolitisch motiviert war. In seiner ersten Fassung wurde diese Vergünstigung sowohl für den Erwerb selbstgenutz-

1 Zur Entwicklung der gesetzlichen Regelungen vgl. Übersicht über die steuerrechtlichen Vorschriften der \$§ 7b, 10e, $10 \mathrm{f}$ und 52 Abs. $21 \mathrm{EStG}$, Anlage 1/4a zu Abschnitt 52 Abs. 5, EStR Oktober 1990. Zu den praktischen Konsequenzen vgl. Deutsche Wohnungswirtschaft, jeweiliger Jahrband. 
ten Wohneigentums als auch für den Mietwohnungsbau gewährt, sofern es sich um neu erstellten Wohnraum handelte. Diese Regelung hatte zwar mit der Nutzwertbesteuerung im engeren Sinne nichts zu tun, doch kann die historische Entwicklung im Verbund besser nachvollzogen werden. Beim § 7b EStG handelte es sich formal um eine Abschreibungsvergünstigung, ${ }^{1}$ die jedem Bauherren - unabhängig von der Nutzungsart des Gebäudes - gewährt wurde. Begünstigt war also der Erwerb bzw. die Erstellung von neuem Wohnraum.

Mit der Einführung des § 7b EStG wurde von nun an das Prinzip der generellen Irrelevanz von Werbungskosten und damit auch von Abschreibungen beim Einfamilienhaus durchbrochen. Die Abschreibungsvergünstigung konnten auch für Einfamilienhäuser geltend gemacht werden. Sie bestanden in der Gewährung von im Verhältnis zur Normalabschreibung zeitlich vorgezogenen Abschreibungssätzen. Die Summe der im Vergünstigungszeitraum gewährten Abschreibungssätze betrug allerdings bis zum Ende des Vergünstigungszeitraum nicht 100 v.H. Beim Einfamilienhaus konnten zwar die erhöhten Abschreibungssätze ebenfalls geltend gemacht werden, nach Ablauf des Vergünstigungszeitraums war aber eine Restwertabschreibung nicht möglich. Die Normal- bzw. Vollabschreibung galt immer noch - wie bisher - mit der niedrig angesetzten pauschalierten Nutzwertbesteuerung als abgegolten. Somit kam es nicht zu den Nachholwirkungen, die mit Abschreibungsvergünstigungen üblicherweise verbunden sind. ${ }^{2}$ Insofern handelte es sich bei der Abschreibungsvergünstigung nach § 7b EStG beim Einfamilienhaus faktisch um einen Einkommensteuerfreibetrag in Abhängigkeit von der Höhe der Anschaffungs-/Herstellungskosten mit progressionsabhängigen Subventionswirkungen.

Beim Zwei- oder Mehrfamilienhaus stellte sie dagegen eine echte Abschreibungsvergünstigung dar, die für die vermieteten und selbstgenutzten Teile in Anspruch genommen werden konnte. Nach Ablauf des Vergünstigungszeitraums war eine Abschreibung bis zu hundert Prozent vorzunehmen.

Der § 7b EStG wurde mit der Behebung des ärgsten Wohnraummangels als wohnungsbaupolitische Maßnahme insofern eingeschränkt, als er ab 1962 nur noch für selbstgenutzte Eigenheime sowie selbstgenutzte Eigentumswohnungen

1 Zur Wirkung von Abschreibungsvergünstigungen bei den Überschußeinkunftsarten vgl. Teil 2 B.

2 Vgl. hierzu auch Teil 2 B. 
geltend gemacht werden konnte. Vermögenspolitische Ziele kamen also hinzu. Der Neubau von selbstgenutztem Wohneigentum sollte mit dem zusätzlichen Aspekt geförderte werden, daß dadurch der Wohnraumbestand vergrößert wird. Bereits 1965 wurde die Restriktion der Eigennutzung ${ }^{1}$ für die Vergünstigung nach § 7b EStG wieder aufgehoben. Allerdings wurde die Begünstigung von nun an insoweit beschränkt, daß sie von jedem Steuerpflichtigen nur noch einmal im Leben in Anspruch genommen werden konnte. Das wohnungsbaupolitische Ziel wurde 1977 ganz aufgegeben. Die Abschreibungsvergünstigung, welche beim selbstgenutzten Einfamilienhaus nach wie vor den Charakter eines Freibetrages hatte, wurde auch für die Anschaffung von gebrauchtem Wohneigentum gewährt und diente damit nur noch der allgemeinen Förderung der Vermögensbildung.

Die Investitionsgutlösung wurde also in der Nachkriegszeit vom Gesetzgeber dazu genutzt, Steuervergünstigungen zu gewähren. Nicht fiskalische Ziele standen bei der Besteuerung im Vordergrund, sondern das Verfahren der Nutzwertbesteuerung wurde als lenkungs- und vermögenspolitisches Instrument eingesetzt.

Wie weit sich der Gesetzgeber vom eigentlichen Zweck der Nutzwertbesteuerung als steuerlicher Ertragsquelle entfernte, wird besonders an der Erfassung des Nutzwertes sichtbar. Während die Aufwandseite der Besteuerung mit entsprechenden Steuermindereinnahmen zugunsten des Steuerpflichtigen ausgebaut wurde, ist die Ertragseite beim Einfamilienhaus in zunehmendem Maße vernachlässigt worden. Die Bemessungsgrundlage für die Ermittlung des zu versteuernden Reinertrags, der Einheitswert, blieb zunächst bis 1974 auf dem Stand von 1935 eingefroren. Das bedeutete, daß alle in der Nachkriegszeit erstellten Gebäude auf den Wert des Jahres 1935 indexiert wurden. Da sich aber die Marktwerte bis zu diesem Zeitpunkt erheblich von diesen fiktiven Einheitswerten fortentwickelten, hatte dies zwei Konsequenzen:

Zum einen nahm die relative Bedeutung des Nutzwertes im Zuge des allgemeinen Mietanstiegs laufend ab, da er bei konstantem Hebesatz (Sollertragszins)

1 Dies wurde damit begründet, daß die permanente Nutzungskontrolle durch die Finanzbehörden im achtjährigen Vergünstigungszeitraum zu aufwendig sei. Vgl. Hoffmann, A., Das "unechte" Zweifamilienhaus - eine einkommensteuerrechtlich fragwürdige Einschränkung, in: Deutsche Wohnungswirtschaft 1/1981, S. 9. 
von 3,5 v.H. auf eine nominal festgeschriebene Bemessungsgrundlage erhoben wurde. Die zu zahlende Steuer blieb bei gleichbleibenden Steuersätzen absolut konstant. Da die Anschaffungskosten aber laufend stiegen, genügte ein immer geringerer Fremdkapitalanteil, damit die Nutzwertbesteuerung nicht mehr zum Tragen kam, da Fremdkapitalkosten bis zu Höhe des Nutzwertes geltend gemacht werden konnten. Faktisch hieß dies, daß ein immer größerer Eigenkapitalanteil bzw. der (Soll-)Ertrag daraus in Form des pauschalierten Nutzwertes steuerfrei blieb.

Bereits 1964 entsprachen die Einheitswerte von 1935 bei weitem nicht mehr den tatsächlichen Verhältnissen, so daß sich der Gesetzgeber zu einer Neufestsetzung der Einheitswerte entschloß. Bis zum Ende des Neubewertungsverfahrens (1974) galt die Einfamilienhausverordnung von 1937 mit ihren niedrig angesetzten Einheitswerten als Bemessungsgrundlage für die steuerliche Erfassung des Nutzwertes weiter. Mit dem neugeschaffenen § 21a EStG, der von 1974 an die alte Einfamilienhausverordnung ersetzte, wurden erstmals die neuen Einheitswerte von 1964 für die Nutzwertbesteuerung zugrunde gelegt. Diese Einheitswerte waren zwischenzeitlich bereits wieder veraltet. Deshalb wurde als Bemessungsgrundlage des Nutzwertes für das Jahr 1974 und später ein Wert in Höhe des 1,4 fachen des zum Jahr 1964 neu festgesetzten Einheitswertes zugrundegelegt. Unter der Annahme, daß das 1,4 fache des Einheitswertes von 1964 den tatsächlichen Verkehrswerten bei der Neueinführung des § 21a EStG entsprach, ${ }^{1}$ hätte beim alten Hebesatz zur Ermittlung des Nutzwertes (3,5 v.H.) wieder ein realitätsnaher Nutzwert der Besteuerung zugrundegelegen. Der pauschalierte Nutzwert wäre real in etwa in gleicher Höhe erfaßt worden wie bei der Einführung der Einfamilienhausverordnung 1935.

Der Gesetzgeber scheute anscheinend diese faktische Steuererhöhung und reduzierte den Hebesatz von 3,5 v.H. auf 1 v.H. der nunmehr realitätsnäheren Einheitswerte. Der Bruttosollertrag eines Einfamilienhauses wurde somit bezogen auf das investierte Eigenkapital von 3,5 v.H. auf 1 v.H. gesenkt. Damit

1 Dies kann allerdings bezweifelt werden. Es wird in der Literatur darauf hingewiesen, daß die Einheitswerte von 1964 bereits niedrig festgelegt waren und daß die Baupreise von 1964 bis 1974 um 79 v.H. stiegen, so daß eine Erhöhung der Einheitswerte um 40 v.H. zweifelsohne zu gering war. Vgl. Fecht, R., Zur Einkommensbesteuerung der Selbstnutzung von Wohneigentum, in: Finanzarchiv, 41. Jg., 1983, S. 478, Fußnote 8. 
blieben die neuen Einheitswerte für die Steuerlast nahezu ohne Bedeutung. An einem Beispiel verdeutlicht heißt dies, daß der zu versteuernde Nutzwert im Jahre 1974 nominal um ca. 20 v.H. ${ }^{1}$ stieg. Der Schuldzinsabzug blieb in seiner maximalen Höhe weiter auf den so ermittelten Nutzwert beschränkt. Der Nutzwert hatte beim § 21a EStG weiterhin einen Nettosollertragscharakter, so daß außer den zu diesem Zeitpunkt hauptsächlich vermögenspolitisch motivierten Abschreibungen nach § $7 \mathrm{~b}$ EStG keine weiteren Werbungskostenabzüge zulässig waren. Insofern folgte der neue \& 21a EStG in seiner Konzeption der alten Einfamilienhausverordnung von 1937, hatte quantitativ aber eine wesentlich geringere reale Bedeutung. Obwohl die Marktwerte der Einfamilienhäuser und damit auch die tatsächlichen Mietwerte bis zum Übergang zur Konsumgutlösung gegenüber der Bemessungsgrundlage von 1974 erheblich stiegen, wurde die steuerliche Erfassung der Nutzwerte bis zur Abschaffung 1986 nominal nicht mehr verändert.

Das Ergebnis dieser Entwicklung war, daß der steuerlich erfaßte Nutzwert eines Einfamilienhauses, abgesehen von der ca. 20 prozentigen Erhöhung 1974, im Zeitraum von nahezu 50 Jahren nominal konstant blieb und damit real weitgehend bedeutungslos wurde. Der Lebenshaltungsindex ${ }^{2}$ entwickelte sich in diesem Zeitraum von 100\% (1935) auf 484\% (1986), verfünffachte sich mithin nahezu.

Bei der Steuererhebung gilt das ökonomische Prinzip, daß der Grenzertrag der Steuererhebung zu den Grenzkosten noch in einem angemessenen Verhältnis stehen soll. Dies war hier scheinbar nicht mehr gegeben, was von den entsprechenden Verbänden bei der Diskussion um einen Systemwechsel zur Konsumgutlösung auch betont wurde ${ }^{3}$. Dieses Argument stimmt allerdings nur insoweit, als dies eine Frage der konkreten Ausgestaltung war. Mit der Abschaffung der Nutzwertbesteuerung wurde daher eine im Steuerrecht bereits weitgehend vorhandene Konsumgutlösung für Einfamilienhäuser formal auch als solche eingeführt.

1 Vgl., Lagerhans, P., Das eigengenutzte Einfamilienhaus und die Steuerreform, in: Deutsche Wohnungswirtschaft 5/1975, S. 104ff.

2 Vgl., Statistisches Bundesamt, Preisindex für die Lebenshaltung, Fachserie 17, Reihe 7, Bd. 1991, Werte umbasiert.

3 Vgl. beispielsweise Karl-Bräuer-Institut des Bundes der Steuerzahler, Zur Neuregelung der Eigenheimbesteuerung, Stellungnahmen, Nr.20., Wiesbaden 1984. 
Die pauschalierte Nutzwertbesteuerung hatte aber nicht nur Vorteile für die Eigenheimbesitzer. Durch die Begrenzung des Schuldzinsenabzugs auf die Höhe des Nutzwertes blieben die steuerlichen Entlastungen, die sich aus negativen Einkünften aus Vermietung und Verpachtung ergeben können, verwehrt. Für dieses Problem wurde für einen Teil der Eigenheimbesitzer eine Lösung gefunden, das Einfamilienhaus mit Einliegerwohnung.

Mit diesem Zweifamilienhaus, welches in seiner gewöhnlichen Ausgestaltung aus einer vom Eigentümer selbstgenutzten größeren Hauptwohnung und einer kleinen Wohnung (meist im Keller oder Dachgeschoß) bestand, konnte der Eigentümer die Überschußrechnung bei der Ermittlung der Einkünfte aus Vermietung und Verpachtung vornehmen. Dieses Vorgehen war umso interessanter, je höher der Fremdkapitalanteil am investierten Kapital war, denn der Schuldzinsabzug konnte nun in unbeschränktem Umfang in Anspruch genommen werden. Die Verlustphase der ersten Jahre konnte, saldiert mit anderen Einkunftsarten, zu Steuerminderungen genutzt werden.

Das Besondere an diesem Haustyp war, daß es nicht einmal erforderlich war, daß diese zweite Wohnung tatsächlich fremdvermietet wurde, sie mußte nur durch die Architektur als solche erkennbar sein. Es handelte sich mithin um ein "unechtes' Zweifamilienhaus". ${ }^{1}$ Als Mietwert wurde die ortsübliche Vergleichsmiete herangezogen. ${ }^{2}$ Im Ergebnis war dieses Haus von der Nutzungsseite ein Einfamilienhaus, wurde aber steuerlich als Zweifamilienhaus behandelt $^{3}$. Überstiegen diese Nutzwerte im Zeitablauf die Werbungskosten, im wesentlichen aber die Schuldzinsen, so konnte der Wohnungseigentümer sein Zweifamilienhaus in ein Einfamilienhaus steuerlich umdeklarieren und die Nutzwertbesteuerung nach der pauschalierten Nutzwertermittlung vornehmen lassen. Da diese aber selbst bei einem sehr geringen Verschuldungsgrad keine

1 Hoffmann, A., a.a.O., S. $8 \mathrm{ff}$.

${ }^{2}$ Mit dieser Regelung hätte aber das Verfahren der pauschalierten Nutzwertbesteuerung, das den Nutzwert auf der Basis von Einheitswerten festlegt, bei Einfamilienhäusern seine Rechtfertigung verloren, da es nun anscheinend wieder möglich war, eine ortsübliche Vergleichsmiete zu ermitteln.

${ }^{3}$ Die Mehrkosten der Einrichtung einer kleineren Einliegerwohnung wurden durch die erzielbaren steuerlichen Mehrentlastungen mehr als ausgeglichen, vgl.: DWW aktuell, in: Deutsche Wohnungswirtschaft 7/1982, S. 192. 
steuerliche Belastung darstellte, war dies eine Investionsgutlösung mit Konsumgutcharakter.

Ab 1982 war dieses Vorgehen aber nur noch dann zulässig, wenn die zweite Wohnung auch tatsächlich vermietet war. Insofern wurde wenigstens die äußerst fragwürdige Gestaltung des unechten Zweifamilienhauses eingeschränkt. Was aber blieb, war, daß nahezu gleiche ökonomische Sachverhalte zu höchst unterschiedlichen Steuerbelastungen bzw. Steuerentlastungen führten. Dieses wurde auch zu Recht kritisiert.

Zusammenfassend heißt dies, daß der Gesetzgeber die Nutzwertbesteuerung in der Nachkriegszeit vor allem für außerfiskalische Ziele nutzte, im wesentlichen für die Wohnungsbaupolitik und später für die Vermögenspolitik. Eine weitergehende Untersuchung der Zieleignung, vor allem der Eignung des §7b EStG für vermögenspolitische Zwecke, ist im Rahmen dieser Untersuchung nicht angebracht, doch erscheint das Vorgehen des Gesetzgebers aus steuersystematischer und verteilungspolitischer Sicht zumindest bedenklich, "weil die steuerliche Subvention umgekehrt proportional zum Subventionsbedürfnis bemessen ist (war, Anm. d.Verf.)"1.

Vor allem die Kritik an der unterschiedlichen steuerlichen Behandlung einzelner Wohnformen sowie der fiskalisch unergiebigen Ausgestaltung der Nutzwerterfassung führte dazu, daß Mitte der achtziger Jahre eine Neuregelung anstand. Vor dem Hintergrund ausgeglichener Wohnungsmärkte erübrigte sich das Instrument der Wohneigentumspolitik zur allgemeinen Wohnungsbauförderung. $\mathrm{Daß}$ sich der Gesetzgeber dazu entschloß, die Nutzwertbesteuerung zum 1.1.1987 gleich ganz aufzugeben, lag sicherlich mit daran, daß durch die häufigen Änderungen, unter dem Einfluß laufend variierender Zielsetzungen, das fiskalische Motiv der steuerlichen Erfassung des Nutzwertes aus den Augen verloren wurde. Vielleicht war dies aber auch auf den mangelnden politischen Mut zurückzuführen, zu Lasten der Altbesitzer eine der steuerlichen Leistungsfähigkeit tatsächlich angebrachte Nutzwertbesteuerung vorzunehmen. ${ }^{2}$

1 Tipke, K., Steuerrecht. Ein steuersystematischer Grundriß, 7. Auflage, Köln 1979, S. 245.

2 "Da wurde die Noch-Mehrheit der Mieter...... an die Wand gedrückt". Wagner, W., a.a.O. 
Lange Übergangsregelungen (bis 1998) sollen den Wohneigentümern, die sich zum Zeitpunkt des Wechsels noch in der fiskalischen Defizitphase befanden, garantieren, daß sie die für sich steuerlich optimale Ausgestaltung wählen können. So bleibt es ihnen freigestellt, im 12-jährigen Übergangszeitraum jederzeit eine Option zur Konsumgutlösung auszuüben. Dies werden sie regelmäßig dann tun, wenn die fiskalische Ertragsphase beginnen würde. Einschlägige Steuersparratgeber weisen deshalb darauf hin, notwendige Renovierungsund Instandsetzungsaufwendungen bei diesem Haustyp vor der Option zur Konsumgutlösung durchzuführen, da sie danach steuerlich nicht mehr geltend gemacht werden können. Daß es sich dabei durchaus um nennenswerte Beträge handeln kann, hat ein Steuerpflichtiger gezeigt, der im Jahr 1989 Erhaltungsaufwendungen in Höhe von 199.000 DM geltend machte, um 1991 seine Option zur Konsumgutlösung auszuüben. Im Gegensatz zu den Finanzbehörden ging das zuständige Finanzgericht davon aus, daß die Kosten anzuerkennen sind, da der Gesetzgeber mit solchen Konsequenzen habe rechnen müssen. ${ }^{1}$

Der politische Wille zur Förderung des Erwerbs selbstgenutzten Wohneigentums blieb aber dennoch bestehen, so daß dieses steuerliche Konsumgut auch weiterhin steuerliche Subventionen erfährt, welche im Teil 3. B dieser Untersuchung Gegenstand einer gesonderten Betrachtung sind.

\section{B. Die Förderung des Erwerbs selbstgenutzten Wohneigentums}

Wie sich in Teil 1 C.2. gezeigt hat, werden die Erwerber selbstgenutzten Wohneigentums, die über wenig Eigenkapital verfügen und daher darauf angewiesen sind, sich relativ hoch zu verschulden, durch die Konsumgutlösung innerhalb der Einkommensbesteuerung benachteiligt. In den ersten Jahren nach dem Erwerb übersteigen die Schuldzinsaufwendungen bei diesen Gruppen die Nutzwerte (vergleichbare Mietwerte), so daß sich unter Berücksichtigung sonstiger Werbungskosten (steuerliche Abschreibungen, etc.), wie auch beim vermieteten Wohnraum, negative Einkünfte ergeben würden. Die steuerlichen Entlastungen, die sich aus der Zusammenfassung mit den sonstigen steuerlichen Einkünften ergeben, bleiben den Erwerbern selbstgenutzten Wohneigentums durch den Systemwechel von der Investitions- zur Konsumgutlösung verwehrt.

1 Vgl. Finanzgericht des Saarlandes, Beschl. v. 26.2.1993, EFG 1993, S. 518, zitiert nach Schönhofer/Reinisch, HuG, Gruppe 2, S. 1142, (Heft 7) Oktober 93. 
Der Gesetzgeber hat versucht, diesem relativen Nachteil mit Sonderausgabenabzügen und Abzügen von der Steuerschuld im Rahmen der Einkommensteuer zu begegnen. Die Einführung dieser Maßnahmen erfolgte gleichzeitig mit dem Systemwechsel von der Konsumgut- zur Investitionsgutlösung zum 1.1.1987.' Auch wenn sich die Konsumgutlösung unter verteilungspolitischen Gesichtspunkten als unzulänglich erwiesen hat, sind die Fördermaßnahmen vor dem Hintergrund ihrer steuersystematischen Einstufung zu beurteilen.

\section{Die zentralen Fördermaßnahmen ( $\S 10 \mathrm{e}$ und $34 \mathrm{f}$ EStG) ${ }^{2}$}

Die im folgenden dargestellten und analysierten Regelungen beziehen sich jeweils auf die Grundkonzeption. Umfangreiche Detailregelungen werden außer acht gelassen, ${ }^{3}$ sie erschweren die Transparenz, sind aber nicht von grundsätzlicher Bedeutung. Die Begründungen durch den Gesetzgeber werden in der Fassung des ursprünglichen Gesetzes von 1986 berücksichtigt, um die Eignung der beschriebenen Maßnahmen für die angestrebten Ziele kritisch würdigen zu können.

Die Maßnahmen wurden im sogenannten Wohneigentumsförderungsgesetz (WohneigFG) verankert und bestanden zum Zeitpunkt ihrer Einführung aus drei Komponenten, der sogenannten Grundförderung, einer Vorkostenabzugsregelung sowie einer Familienkomponente in Form des im allgemeinen Sprachgebrauch so bezeichneten Baukindergeldes.

Zur Begründung der gesamten Gesetzesmaßnahmen hieß es: "Ziel dieser Neuregelung ist es, durch eine wirksamere und vertärkte familienausgerichtete Gestaltung der bisherigen Förderung die Voraussetzungen dafür zu schaffen, daß

1 Der Sytemwechsel bedingte aus Gründen des Vertrauensschutzes in die Gesetzgebung lange Übergangsregelungen für die alten Fördermaßnahmen nach § $7 \mathrm{~b}$ EStG. Diese laufen erst Ende 1998 aus. Sie verlieren im Zeitablauf zunehmend an Bedeutung. $\mathrm{Zu}$ ihrer generellen Wirkung vgl. Teil 3. A. Zur Detaildarstellung vgl. Schmidt, L., Einkommensteuerrecht, Kommentar, 11. Auflage, München 1992.

2 Auf die Darstellung und Analyse der Sonderregelungen nach dem Berlinförderungsgesetz wird verzichtet. Diese Regelungen haben ab dem 1.7.1991 infolge der Deutschen Einheit ihre Gültigkeit verloren. Sie unterscheiden sich von den analysierten Maßnahmen quantitativ, aber nicht qualitativ.

3 Zu Detailfragen vgl. Schmidt, L., a.a.O. 
möglichst viele Bürger, vor allem auch Familien mit Kindern, Wohneigentum erwerben können. "1 In dieser ursprünglichen Ausgestaltung wurde prinzipiell nicht zwischen dem Erwerb neu erstellten Wohneigentums und dem Erwerb aus dem Bestand differenziert. Dieses wurde damit begründet, daß vor allem in Ballungsräumen häufiger der Erwerb aus dem Bestand erfolge und diese Erwerbergruppe gegenüber Erwerbern von neu erstelltem Wohneigentum in ländlichen Regionen nicht benachteiligt werden solle. ${ }^{2}$

- Die zum 1.1.1987 in Kraft getretene Regelung ${ }^{3}$ sah als Grundförderung ( 10e Abs. $1 \mathrm{EStG}$ ) einen Sonderausgabenabzug von 5 v.H. der begünstigungsfähigen Anschaffungs- und Herstellungskosten über einen Zeitraum von 8 Jahren von der Bemessungsgrundlage des zu versteuernden Einkommens vor. Begünstigungsfähig waren Anschaffungs- und Herstellungskosten bis zu einer Obergrenze von $300.000 \mathrm{DM}$, wobei die Aufwendungen für das Grundstück nur zur Hälfte berücksichtigt wurden. Die maximale Minderung der Bemessungsgrundlage des zu versteuernden Einkommens betrug somit pro Jahr 15.000 DM, d.h. es konnten im achtjährigen Vergünstigungszeitraum Sonderausgabenabzüge in Höhe von insgesamt 120.000 DM vorgenommen werden.

- Neben dieser Grundförderung kann der Steuerpflichtige durch die sogenannte Vorkostenabzugsregelung Aufwendungen, die unmittelbar mit der Anschaffung oder Herstellung des Gebäudes verbunden sind, vor dem erstmaligen Bezug entstehen und im Falle der Vermietung oder Verpachtung Werbungskosten wären, ebenfalls als Sonderausgaben abziehen ( $\S 10$ e Abs. 6 EStG). Dies wurde folgendermaßen begründet: "Hierdurch wird sichergestellt, daß die in dem Bauoder Anschaffungszeitraum anfallenden Kosten, die bisher (Anmerkung des Verfassers: Regelung nach $\S 7 \mathrm{~b}$ EStG) bei eigengenutzten Wohnungen als Werbungskosten abgezogen werden konnen, insbesondere ein Damnum und andere Geldbeschaffungskosten auch zukünftig steuermindernd abgezogen werden können ". ${ }^{4}$

1 Entwurf eines Gesetzes zur Neuregelung der steuerlichen Förderung selbstgenutzten Wohneigentums, a.a.O., S. 10.

2 Vgl. ebenda, S. 10.

3 Vgl. WohneigFG vom 15.5.1986, BGBl. I, S. 730ff.

4 Entwurf eines Gesetzes zur Neuregelung der steuerlichen Förderung selbstgenutzten Wohneigentums, a.a.O., S. 16. 
- Das Baukindergeld ( $\S 34 \mathrm{f}$ Abs. 2 EStG) stellt eine zusätzliche Förderkomponente dar, die den besonderen Bedarf von Familien berücksichtigen soll. Steuerpflichtige, welche die Grundförderung in Anspruch nehmen, konnten in der ursprünglichen Ausgestaltung der Förderung für jedes Kind zusätzlich ihre Steuerschuld um 600 DM pro Jahr mindern. Diese Regelung existierte bereits beim alten Fördersystem im Rahmen der Investitionsgutlösung nach § 7b EStG, der Abzug war dort allerdings erst ab dem zweiten Kind möglich. Insofern wurde der Übergang zum neuen System dazu genutzt, die Familienkomponente auszubauen.

Die Regelungen nach den $\S \S 10 \mathrm{e} / 34 \mathrm{f}$ EStG können von jedem Steuerpflichtigen nur einmal im Leben für ein Objekt in Anspruch genommen werden. Familien bzw. Ehepaare können diese Regelung zusammen zweimal beanspruchen. Wer zum Zeitpunkt der Einführung der Neuregelung bereits einmal Abschreibungsvergünstigungen nach $\S 7 \mathrm{~b} \mathrm{EStG}$ in Anspruch genommen hatte, ist von den Fördermaßnahmen nach $\S 10 \mathrm{e}$ EStG ausgeschlossen (sogenannter Objektverbrauch, §10e Abs. 4 EStG).

Das beschriebene Fördersystem ist seit seiner Einführung als Reaktion des Gesetzgebers auf die inzwischen gestiegene Wohnungsnachfrage und die damit einhergehenden Immobilien- und Baupreissteigerungen, neuerdings auch aufgrund der angespannten Lage der öffentlichen Haushalte, quantitativ mehrfach ausgeweitet bzw. wieder eingeschränkt worden. Die Änderungen sind jeweils für die Steuerpflichtigen von Bedeutung, die Wohneigentum nach dem jeweiligen Änderungszeitpunkt erwerben. D.h. die Förderbestimmungen, die zum Zeitpunkt des Erwerbs bzw. der Erstellung gelten, sind individuell maßgeblich für den gesamten Förderzeitraum.

Zunächst wurde das Baukindergeld nach § 34f EStG als Abzug von der Steuerschuld zum 1.1.1990 auf 750 DM erhöht. Mit dem Steueränderungsgesetz 1991 erfolgte eine weitere Erhöhung zum 1.1.1991 auf nunmehr 1.000 DM für jedes Kind. ${ }^{1}$

Zusätzlich wurden im Steueränderungsgesetz 1991 die berücksichtigungsfähigen Anschaffungs- bzw. Herstellungskosten der Grundförderung zum 1.1.1991 auf 330.000 DM angehoben, wodurch sich der maximale Sonderaus-

1 Zum Baukindergeld vgl. auch Artikel 213a EStR, 1993 sowie Anlage 1/10a EStR, Oktober 1990. 
gabenabzug $^{1}$ in Höhe von jährlich 5 v.H. der begünstigungsfähigen Anschaffungs- bzw. Herstellungskosten von 15.000 DM auf 16.500 DM erhöhte. Die Summe der Sonderausgabenabzüge stieg dadurch für den gesamten Förderzeitraum auf 132.000 DM.

Das Steueränderungsgesetz 1992 brachte bereits weitere Änderungen, die rückwirkend $a b$ dem 1.10.1991 gelten. Ziel war, neben der quantitativen Ausweitung der Maßnahmen, eine Differenzierung der Ausgestaltung zugunsten des Erwerbs neu erstellten Wohneigentums. Es trat mithin zur verteilungspolitisch motivierten Förderung eine wohnungsbaupolitische Komponente hinzu. Durch die gleichzeitige Einführung von Einkommensgrenzen sollten auf der anderen Seite die Subventionen in den obersten Einkommensbereichen begrenzt werden.

Der Sonderausgabenabzug wurde von 5 v.H. auf 6 v.H. der geförderten Anschaffungs- bzw. Herstellungskosten in den ersten vier Jahren nach der Anschaffung bzw. Herstellung erhöht. Der maximale Sonderausgabenabzug stieg somit ab diesem Zeitpunkt in den ersten vier Jahren auf 19.800 DM, in den folgenden vier Jahren betrug er jeweils $16.500 \mathrm{DM}$, bzw. im gesamten Förderzeitraum 145.200 DM. In einzelnen Förderjahren nicht vorgenommene Sonderausgabenabzüge können bis zum Ende des achtjährigen Begünstigungszeitraums nachgeholt werden ( $\S 10 \mathrm{e}$ Abs. $3 \mathrm{EStG})$.

- Die Förderung wurde auf Einkommensbezieher mit einem zu versteuernden Jahreseinkommen von unter $120.000 \mathrm{DM}$ bei Ledigen und 240.000 DM bei Verheirateten begrenzt ( $\S 10 \mathrm{e}$ Abs. 5a). Diese Einkommensbegrenzungen gelten für die Grundförderung, die Vorkostenabzugsregelung und für das Baukindergeld ( $\$ 34 \mathrm{f}$ Abs. $4 \mathrm{EStG}$ )

- Das Baukindergeld wird wie bisher gewährt, es wird aber zusätzlich die Möglichkeit eingeräumt, einen Vor- bzw. Rücktrag des Baukindergeldes von bis zu zwei Jahren auch über den achtjährigen Vergünstigungszeitraum hinaus vorzunehmen, sofern die Steuerschuld des betreffenden Jahres nicht ausreicht, um die Vergünstigung (voll) in Anspruch zu nehmen ( $\$ 34$ f Abs. 3 EStG). Der gesamte Vergünstigungszeitraum dehnt sich somit auf 10 Jahre aus, wobei insgesamt auf die Steuerschuld von 12 Jahren zurückgegriffen werden kann.

1 Zur Entwicklung der Sonderausgabenabzüge vgl. I/4a EStR, März 1993. 
- Erwerber neuerstellten Wohneigentums können darüber hinaus in den ersten drei Jahren nach der Anschaffung einen begrenzten Schuldzinsenabzug ebenfalls in Form eines Sonderausgabenabzugs bis maximal 12.000 DM im Jahr vornehmen. Die gesamten Sonderausgabenabzüge erhöhen sich mithin auf max. 181.200 DM. Diese wohnungsbaupolitische Maßnahme ist als eine Reaktion des Gesetzgebers auf das starke Ansteigen des Kapitalmarktzinssatzes zu diesem Zeitpunkt zu sehen. Sie ist bis zum 31.12.1994 befristet, kann also bis einschließlich 1996 geltend gemacht werden. Die Vergünstigung kann unabhängig vom Einkommen in Anspruch genommen werden, ist also nicht an Einkommenshöchstgrenzen der Grundförderung bzw. des Baukindergeldes gebunden.

Wurden - abgesehen vom zeitlich befristeten Schuldzinsenabzug - bis zu diesem Zeitpunkt Erwerber neuerstellten Wohneigentums und Erwerber von Wohneigentum aus dem Bestand, prinzipiell gleichgestellt, so wurde die Förderung des Erwerbs aus dem Bestand hauptsächlich aus fiskalischen Gründen zum 1.1.1994 mit dem Gesetz zur Umsetzung des föderalen Konsolidierungsprogramms ${ }^{1}$ stark eingeschränkt.

- Die maximale Bemessungsgrundlage für die Grundförderung wird beim Erwerb aus dem Bestand von 330.000 DM auf 150.000 DM gesenkt. Die Abzugssätze von 6 v.h. in den ersten vier Jahren und 5 v.H. in den darauf folgenden vier Jahren bleiben jedoch unverändert. Der Erwerber von Wohneigentum aus dem Bestand kann mithin in den ersten vier Jahren nur noch Sonderausgabenabzüge in Höhe von 9.000 DM vornehmen (bis 31.12.1993 19.800 DM) und in den vier Jahren danach nur noch in Höhe von 7.500 DM (bis 31.12.1993 16.500 DM). Dem Erwerber gebrauchter Immobilien stehen somit im gesamten Zeitraum nur noch Sonderausgabenabzüge in Höhe von insgesamt 66.000 DM zu, gegenüber nach wie vor 181.200 DM beim Erwerb neuerstellten Wohneigentums. ${ }^{2}$

Vgl. BStBl. I 1993, S. 518.

2 Im Sinne dieses Gesetzes gilt eine Wohnung als "neu", sofern sie bis zum Ende des zweiten, auf die Fertigstellung folgenden, Jahres erworben wird. Insofern weicht der Gesetzgeber bei der Vergabe der ungekürzten Subventionen hier von der Definition für die Inanspruchnahme des begrenzten Schuldzinsenabzugs nach $\$ 10 \mathrm{e}$ Abs. 6 EStG ab, der ebenfalls nur beim Erwerb neuerstellten Wohneigentums gewährt wird, ab. Während nun ein Erwerber im Jahr der Fertigstellung beide Sonderausgabenabzüge geltend machen kann, bleiben einem Erwerber der das Objekt erst im zweiten Jahr nach der Fertigstellung anschafft nur noch die unge- 
Diese Einschnitte scheinen zunächst recht drastisch zu sein. Wie sich bei der quantitativen Betrachtung aber zeigen wird, werden vor allem Familien in den unteren Einkommensbereichen mit zunehmender Kinderzahl aufgrund der grundsätzlich problematischen Ausgestaltung des gesamten Fördersystems von diesen Beschränkungen weniger betroffen.

Neben diesen Maßnahmen, die das zentrale Instrumentarium für breite Schichten der Bevölkerung darstellen, gibt es noch einige Maßnahmen, die Erwerber von Wohneigentum bzw. Wohneigentümer unter besonderen Umständen betreffen ( $\S 10 \mathrm{f} / \mathrm{h}$ EStG und $\S 7$ FördergebietsG). Sie leiten sich aus dem dargestellten Instrumentarium ab und sind aus Gründen der Transparenz in Abschnitt 4 Gegenstand einer eigenen kurzen Würdigung. Ihre qualitative Beurteilung unterscheidet sich im wesentlichen nicht von der folgenden Beurteilung der vorgestellten Fördermaßnahmen. Alle heute gültigen Maßnahmen (nach dem 1.1.1994) sind in Übersicht 2 zusammengestellt.

\section{Kritische Würdigung}

Die steuersystematische und die verteilungspolitische Beurteilung des Fördersystems sind unmittelbar miteinander verknüpft. Die Erfassung und Besteuerung der individuellen Leistungsfähigkeit erfolgt mit Instrumenten, die sich aus eigenen Zielen ableiten und bei der Beurteilung konkreter Maßnahmen, die nicht der Besteuerung dienen, nicht zur Disposition stehen. Sie beruhen auf einem breiten Konsens und leiten sich aus den Wertgrundlagen der Sozialen Marktwirtschaft ab. Demgegenüber erfolgt eine verteilungspolitische Beurteilung auf der Grundlage eigener Zielsetzungen. Im Regelfall gilt, daß Maßnahmen, die steuersystematisch nicht zu rechtfertigen sind, auch nicht den konkreten verteilungspolitischen Zielsetzungen, aus denen heraus sie erfolgen, genügen.

kürzten Sonderausgabenabzüge der Grundförderung. Der Schuldzinsenabzug wird verwehrt. Für alle älteren Objekte gelten die Beträge der gekürzten Grundförderung. 
Übersicht 2

\begin{tabular}{|c|c|c|c|c|}
\hline \multicolumn{5}{|c|}{ Steuerliche Förderung des selbstgenutzten Wohneigentums } \\
\hline & Sonderausgabenabzüge & primäre Ziele & Grundlage & Abzugssätze \\
\hline 1. & $\begin{array}{l}\text { Grundförderung, maximal } \\
\text { förderungsfähige Anschaffungskosten } \\
\text { 150.000 DM, Einkommensgrenze } \\
\text { 240.000 DM (verh.) }\end{array}$ & $\begin{array}{l}\text { Förderung des Erwerbs selbstgenutzten } \\
\text { Wohneigentums }\end{array}$ & $\S 10$ e EStG & $\begin{array}{l}4 \text { Jahre x } 6 \text { v.H., } 4 \text { Jahre x } 5 \\
\text { v.H. }\end{array}$ \\
\hline 2. & $\begin{array}{l}\text { Grundförderung beim Erwerb von } \\
\text { Neubauten, maximal förderungsfähige } \\
\text { Anschaffungskosten } 150.000 \mathrm{DM} \text {. } \\
\text { Einkommensgrenze } 240.000 \mathrm{DM} \text { (verh.) } \\
\end{array}$ & $\begin{array}{l}\text { Förderung des Erwerbs selbstgenutzten } \\
\text { Wohneigentums }\end{array}$ & $\S 10 \mathrm{e} \mathrm{EStG}$ & $\begin{array}{l}4 \text { Jahre x } 6 \text { v.H., } 4 \text { Jahre } \times 5 \\
\text { v.H. }\end{array}$ \\
\hline 3. & $\begin{array}{l}\text { Förderung von Sanierungsaufwendungen } \\
\text { in Sanierungsgebieten und } \\
\text { Denkmalschutz }\end{array}$ & Sanierung des Wohnungsbestandes & $\S 10 \mathrm{fEStG}$ & 10 Jahre x 10 v.H. \\
\hline 4. & $\begin{array}{l}\text { unentgeltlich zu Wohnzwecken } \\
\text { überlassenen Wohnungen im eigenen } \\
\text { Haus, Förderung wie } 2 \text {. }\end{array}$ & Erhöhung des Wohnungsangebotes & $\S 10 \mathrm{~h} \mathrm{EStG}$ & wie 2 . \\
\hline \multicolumn{5}{|c|}{ Neue Bundesländer } \\
\hline 5. & $\begin{array}{l}\text { Aufwendungen für Herstellungs- und } \\
\text { Erhaltungsarbeiten an selbstgenutzten } \\
\text { Wohnungen, max. } 40.000 \mathrm{DM}\end{array}$ & $\begin{array}{l}\text { Sanierung selbstgenutzten } \\
\text { Wohneigentums }\end{array}$ & $\S 7$ & 10 Jahre $\times 10$ v.H. \\
\hline & Abzug von der Steuerschuld & primäre Ziele & Grundlage & Abzüge \\
\hline 6. & $\begin{array}{l}\text { Baukindergeld, Einkommensgrenzen wie } \\
\text { 1. u. } 2 \text {. }\end{array}$ & $\begin{array}{l}\text { Familienorientierte Zusatzförderung } \\
\text { zu 1. u. } 2 .\end{array}$ & $\S 34 \mathrm{f} \mathrm{EStG}$ & $\begin{array}{l}8 \text { Jahre } 1.000 \text { DM je Kind p.a., } \\
\text { als Abzug von der } \\
\text { Steuerschuld }\end{array}$ \\
\hline
\end{tabular}




\subsection{Steuersystematische Beurteilung ${ }^{1}$}

Die Grundförderung, die Vorkostenabzugsregelung und den beschränkten Schuldzinsenabzug hat der Gesetzgeber innerhalb der Sonderausgaben angesiedelt. Beim Erwerb bzw. der Selbstnutzung von Wohneigentum handelt es sich per Definition seit dem 1.1.1987 um privaten Konsum. Aufwendungen für den Konsum gehören in den Bereich der Einkommensverwendung und bleiben deshalb bei der Einkommensbesteuerung außer Betracht. Da die Aufwendungen, die der Steuerpflichtige tätigt, somit auch mit keiner Einkunftsart im Zusammenhang stehen, können sie weder als Werbungskosten noch als Betriebsausgaben geltend gemacht werden. Sie haben deshalb im System der Einkommensteuer bei der Ermittlung der objektiven Bemessungsgrundlage für das zu versteuernde Einkommen keinen Platz.

Die einzige technische Möglichkeit, die der Gesetzgeber hatte, um diese Abzüge von der Bemessungsgrundlage im Steuersystem unterzubringen, war die Form der Sonderausgaben. Das Institut der Sonderausgaben dient dazu, Sachverhalte, die im subjektiven Bereich liegen, steuerlich zu berücksichtigen. Sonderausgabenabzüge knüpfen nicht an der Einkommensentstehung, sondern an der Einkommensverwendung an. Diese Abzüge von der Bemessungsgrundlage sind nur in wenigen Fällen zu rechtfertigen, sofern man das Ziel der Besteuerung nach der Leistungsfähigkeit nicht aufgeben möchte. ${ }^{2}$ Sowohl der Wissenschaftliche Beirat beim Bundesministerium der Finanzen, als auch die Steuerreformkommission haben sich deshalb dafür ausgesprochen, Sonderausgaben im wesentlichen nur für grundsätzlich nicht disponible Einkommensteile zuzulassen. ${ }^{3}$ Dabei handelt es sich um Einkommensteile, über deren Verwendung der Steuerpflichtige nicht frei verfügen kann, deren Verwendung vielmehr durch staatliche Auflagen z.B. in Form von Zwangsbeiträgen bestimmt ist. Im

1 Die zentralen Kritikpunkte an den Maßnahmen des Wohneigentumsförderungsgesetzes und vor allem die quantitative Analyse sind zu finden in: Oberhauser, A./Rüsch, Ch., Wohneigentumsförderung an den Familien vorbei, in: Wirtschaftsdienst, 72. Jg., 1992, S. 315ff.

2 Der $\S 10$ EStG enthält außer dem $\S 10$ eStG eine Vielzahl von Sonderausgabenabzügen, deren Berechtigung jeweils eine eigene Betrachtung erfordert.

3 Vgl. Wissenschaftliche Beirat beim Bundesministerium der Finanzen, Gutachten zur Reform der direkten Steuern (Einkommensteuer, Körperschaftsteuer, Vermögensteuer und Erbschaftsteuer) in der Bundesrepublik Deutschland, a.a.O., S. $343 \mathrm{ff}$. Gutachten der Steuerreformkommission 1971, a.a.O., S. 122ff. 
wesentlichen sind dies die Vorsorgeaufwendungen für die Alterssicherung bzw. den Krankheitsfall. ${ }^{1}$

Grundlage der Besteuerung soll damit das disponible Einkommen sein, das sich von der objektiven Bemessungsgrundlage des zu versteuernden Einkommens im wesentlichen nur im Umfang der gesetzlichen Vorsorgeaufwendungen unterscheidet. Neben diesen Vorsorgeaufwendungen sind die Sonderausgabenabzüge nach $\S 10$ e EStG nun zur quantitativ bedeutendsten Position innerhalb des Instituts der Sonderausgaben geworden. Beim Erwerb neuerstellten Wohneigentums übersteigen sie während des Vergünstigungszeitraum die berücksichtigungsfähigen Vorsorgeaufwendungen durchschnittlicher Steuerpflichtiger sogar bei weitem.

In der Literatur wird stellenweise eine Analogie zwischen der Anschaffung von selbstgenutztem Wohneigentum und der privaten (Alters-)Vorsorge gebildet. Es wird davon ausgegangen, daß mit der Anschaffung von selbstgenutztem Wohneigentum der Steuerpflichtige individuelle Vorsorge für das Alter betreibt (lastenfreies Wohnen im Alter) und damit ein Abzug als Sonderausgaben ( $\S 10 \mathrm{e}$ EStG), in gleicher Weise wie für die Beiträge zur gesetzlichen Sozialversicherung zu rechtfertigen ist. ${ }^{2}$ Diese Analogie kann einer genaueren Analyse jedoch nicht standhalten. Die gesetzlichen Vorsorgeaufwendungen umfassen bereits die steuerlich förderungswürdige Altersvorsorgebeiträge, so daß es im Umfang der Sonderausgabenabzüge nach $\S 10 \mathrm{e}$ EStG zu einer Subventionierung von Vorsorgeaufwendungen über die förderungswürdige Mindestvorsorge hinaus kommt. Aufwendungen für die Altersvorsorge sind eindeutig von Zahlungen für die Vermögensbildung zu trennen. ${ }^{3}$ Die Wohneigentumsbildung stellt aber zweifelsohne Vermögensbildung dar. Außerdem unterliegen zumindest die Ertragsbestandteile bei den später empfangenen Rentenleistungen der Steuer-

1 Für nicht sozialversicherungspflichtige Steuerpflichtige, Freiberufler und Unternehmer sind freiwillige Vorsorgeaufwendungen ebenfalls in gleichem Umfang zu berücksichtigen, da diese Aufwendungen den Charakter von Quasizwangsbeiträgen haben. Vgl. Wissenschaftliche Beirat beim BMF, Gutachten zur Reform der direkten Steuern (Einkommensteuer, Körperschaftsteuer, Vermögensteuer und Erbschaftsteuer in der Bundesrepublik Deutschland, a.a.O., S. 343.

2 Vgl. Eekhoff, J., Wohnungspolitik, a.a.O., S. 50.

3 Vgl. Gutachten der Steuerreformkommission 1971, a.a.O., S. 127. 
pflicht, ${ }^{1}$ was beim selbstgenutzten Wohneigentum mit der Konsumgutlösung nicht mehr der Fall ist.

Die Ausgaben der Erwerber selbstgenutzten Wohneigentums bestehen in Abhängigkeit von der Verschuldung im wesentlichen aus Zins- und Tilgungsleistungen. Im Umfang der Tilgungsleistungen kommt es im Regelfall zur Vermögensbildung. ${ }^{2}$ Der Gesetzgeber gestattet es, in begrenztem Umfang Einkommensteile, die zur privaten Ersparnisbildung verwendet werden, als Sonderausgabenabzug geltend zu machen (z.B. Bausparkassenbeiträge). Es fragt sich deshalb, ob die Förderung nach $\S 10 \mathrm{e}$ EStG nicht entsprechend gerechtfertigt werden kann. Doch ist auch dies nicht der Fall, weil bei der Ermittlung der Bemessungsgrundlage des zu versteuernden Einkommens spezifische Formen der Einkommensverwendung, vor allem auch Aufwendungen zur Vermögensbildung, außer Betracht bleiben sollten. ${ }^{3}$ Diese sonstigen systemfremden Maßnahmen, die der Vermögensbildung dienen sollen, sind allerdings im Verhältnis zu den Maßnahmen des § 10e EStG quantitativ von untergeordneter Bedeutung.

Ähnlich verhält es sich mit Schuldzinsaufwendungen bzw. mit dem beschränkten Schuldzinsenabzug und der Vorkostenabzugsregelung, sofern sie sich auf Kapitalkosten beziehen. Der Aufwand für Schuldzinsen steht ebenfalls in

1 Die Form der heutigen steuerlichen Berücksichtigung von Alterseinkünften ist nach steuersystematischen und verteilungspolitischen Gesichtspunkten ebenfalls unbefriedigend ausgestaltet. Eine korrekte Besteuerung im Sinne der Einkommensteuer würde ein Freistellung von Vorsorgeaufwendungen für die private Altersvorsorge nach dem Korrespondenzprinzip nur dann rechtfertigen, wenn die später empfangenen Rentenleistungen in vollem Umfang der Besteuerung unterliegen würden, was heute nicht gegeben ist.

2 Dies gilt dann, wenn die Tilgungsleistungen größer als der nominale Werteverzehr sind, wovon im Regelfall ausgegangen werden kann.

3 Der wissenschaftliche Beirat beim Bundesministerium der Finanzen hat sich ebenfalls gegen eine Förderung der Vermögensbildung im Rahmen der Sonderausgabenabzüge ausgesprochen und statt dessen für die Gewährung von Sparprämien plädiert. Vgl. Wissenschaftlicher Beirat beim Bundesministerium der Finanzen, Gutachten zur Reform der direkten Steuern (Einkommensteuer, Körperschaftsteuer, Vermögensteuer und Erbschaftsteuer) in der Bundesrepublik Deutschland, a.a.O., S. 344. Die Sparprämien könnten mit der Steuerschuld verrechnet werden. Allerdings müßten Prämien, die nicht durch individuelle Steuerschulden gedeckt sind, ausbezahlt werden. 
keinem Zusammenhang mit einer steuerpflichtigen Einkunftsart, weshalb ein Abzug von der Bemessungsgrundlage der Einkommensteuer ${ }^{1}$ im Steuersystem keinen Platz mehr hatte. Im Umfang der gezahlten Schuldzinsen kommt es weder zu Vermögensbildung, noch dienen diese Ausgaben der Altersvorsorge; insofern sind sie getrennt zu betrachten. Es könnte sich nämlich die Frage stellen, ob es sich dabei nicht um eine Minderung des disponiblen Einkommens handelt, da der Geförderte diesen Zahlungsverpflichtungen zweifelsohne nachkommen muß. Doch können auch diese Sonderausgabenabzüge nicht gerechtfertigt werden. Die Aufwendungen, die getätigt werden, erfolgen für ein Konsumgut. Qualitativ unterscheiden sie sich nicht von den Zahlungsverpflichtungen, denen beispielsweise der Mieter nachkommen muß, auch wenn sie im Regelfall höher ausfallen. In dem Umfang, in dem diese Aufwendungen zur Sicherung der Existenz notwendig sind, werden sie bereits innerhalb der Grundfreibeträge bei der Besteuerung berücksichtigt. ${ }^{2}$

Die Sonderausgabenabzüge des $\S 10 \mathrm{e}$ EStG finden im Rahmen der Einkommensbesteuerung somit keine Rechtfertigung. Sie können auch nicht mit einem Verweis auf sonstige Sonderausgabenabzüge begründet werden, da sie weder Vorsorgeaufwendungen gleichzustellen sind, noch das disponible Einkommen tangieren und als vermögensbildende Maßnahmen innerhalb der Sonderausgabenabzüge systemfremd sind. Sie sind aus steuersystematischer Sicht ein Fremdkörper, was zum Zeitpunkt ihrer Einführung bereits bekannt war. ${ }^{3}$

Das sogenannte Baukindergeld ( $\S 34 \mathrm{f} \mathrm{EStG)} \mathrm{in} \mathrm{Höhe} \mathrm{von} 1.000 \mathrm{DM}$ je Kind, ist von den oben genannten Fördermaßnahmen zu unterscheiden. Es mindert nicht die Bemessungsgrundlage des zu versteuernden Einkommens, sondern kann von der Steuerschuld abgezogen werden. D.h., der Staat stellt hier nicht wie bei den Sonderausgabenabzügen Einkommensteile von der Besteuerung frei, sondern er verzichtet auf einen Teil der Steuerschuld. Dies bedeutet zunächst

$\mathrm{Zu}$ den Begriffen, objektive und subjektive Bemessungsgrundlage des zu versteuernden Einkommens vgl. Teil 1 B. 2. bzw. B. 3.

2 Ob diese Grundfreibeträge im heutigen Steuertarif zur Bestreitung der existenzsichernden Ausgaben genügen, ist umstritten, doch bedarf dies einer gesonderten Klärung und kann nicht mit anderen Zielsetzungen vermischt werden.

3 Vgl., Oberhauser, A., Stellungnahme vor dem Finanzausschuß des Deutschen Bundestages zu dem Gesetzentwurf der Bundesregierung zur Neuregelung der steuerlichen Förderung des selbstgenutzten Wohneigentums am 23.10.1985. 
nur, daß alle Geförderten die gleiche Subvention erhalten, sofern sie nach Abzug der Vorsorgeaufwendungen nach $\S 10$ e EStG über ein zu versteuernde Einkommen verfügen, bei dem die Steuerschuld hoch genug ist, damit die Vergünstigung in Anspruch genommen werden kann. Die Maßnahme scheint nur auf den ersten Blick unproblematisch zu sein. Sie setzt an der Existenz einer Steuerschuld an. Daran wird besonders deutlich, daß verteilungspolitische und fiskalische Ziele miteinander vermischt und nicht deutlich voneinander getrennt werden.

Es bleibt dem Gesetzgeber vorbehalten, aufgrund außerfiskalischer Zielsetzungen, hier aus verteilungspolitischen Zielsetzungen, Subventionen in Abhängigkeit von bestimmten Merkmalen zu gewähren. Diese Subventionen können getrennt von der Besteuerung ausbezahlt werden, wie dies beispielsweise beim Wohngeld oder beim Kindergeld geschieht. Sofern es der Gesetzgeber gestattet, einen Abzug von der Steuerschuld vorzunehmen, handelt es sich um die Verrechnung zweier Ansprüche. Zum einen um den Anspruch des Staates an den Steuerpflichtigen, eine im wesentlichen aufgrund objektiver Kriterien ermittelte Steuerschuld zu begleichen, und zum anderen um den für alle Bürger gleichen Anspruch an den Staat, aufgrund gleicher Merkmale eine Subvention zu empfangen.

Die Gewährung der Subvention über das Steuersystem ist mithin ein rein technischer Akt. Aus steuersystematischen Gründen gibt es hiergegen keinen Einwand. Sofern allerdings die Steuerschuld nicht ausreicht, um das Baukindergeld in Anspruch zu nehmen, müßte der entprechende Teil ausbezahlt werden. Dies geschieht im gegenwärtigen System nicht. Folglich handelt es sich nur noch bedingt um eine gleiche Subvention. Gerade diejenigen, die die Subvention am dringendsten benötigen, werden ausgeschlossen.

Das gesamte Fördersystem weist somit, zum Teil wegen laufend variierender Zielsetzungen, zum Teil aber auch von Anfang an, innere Widersprüche auf. Minderungen der Bemessungsgrundlage des zu versteuernden Einkommens sind nur zu rechtfertigen, sofern die subjektive steuerliche Leistungsfähigkeit durch die berücksichtigten Abzugsbeträge tatsächlich gemindert ist. Die Sonderausgabenabzüge des § 10e EStG sind dem irrtümlichen Glauben des Gesetzgebers zuzuschreiben, daß dies bei der Wohneigentumsförderung der Fall sei. Wenn dies zuträfe, dürfte es keine Einkommensgrenzen geben, da die Leistungsfähigkeit unabhängig von der Einkommenshöhe zurückgehen würde. Seit dem 
1.1.1992 können die Grundförderung, die Vorkostenabzugsregelung und das Baukindergeld jedoch nur in Anspruch genommen werden, sofern das zu versteuernde Jahreseinkommen unter 120.000 DM (240.000 DM bei verheirateten Steuerpflichtigen) liegt. Abgesehen von der allgemeinen Problematik derartiger Sprungstellen in Fördersystemen verwickelt sich der Gesetzgeber durch diese Einkommensgrenzen in Widersprüche. Da er eine einkommensabhängige Begrenzung für die Inanspruchnahme der Fördermaßnahmen für zulässig hält, bringt er implizit zum Ausdruck, daß durch die Wohneigentumsbildung eine Minderung der subjektiven steuerlichen Leistungsfähigkeit nicht vorliegt. Damit dürfte der gesamte $\S 10 \mathrm{e}$ EStG keine Berechtigung haben.

Das gleiche gilt für die Betrachtung der Maßnahmen des § 10e EStG im Zusammenhang mit der allgemeinen Vorgehensweise bei der Ermittlung des steuerpflichtigen Einkommens. Seit dem Veranlagungszeitraum 1993 gilt für geringverdienende Steuerpflichtige eine gesonderte Steuertabelle. Mit dieser Tabelle soll sichergestellt werden, daß der Lebensunterhalt (sozioökonomisches Existenzminimum) nach der Besteuerung aus dem eigenen Einkommen beglichen werden kann, sofern das aus dem Bruttoeinkommen möglich war ${ }^{1}$. Liegt das zu versteuernde Einkommen unter den Grenzen, unter denen die Einkommensteuertabelle mit den niedrigeren durchschnittlichen ${ }^{2}$ Steuersätzen zur Anwendung kommt, kann der Steuerpflichtige diese Tabelle nur in Anspruch nehmen, sofern er nicht aufgrund der Sonderausgabenabzüge des $\S 10 \mathrm{e}$ EStG unter diese Grenze fällt. ${ }^{3}$ Damit soll anscheinend sicher gestellt werden, daß sich Steuerpflichtige nicht ärmer darstellen, als sie in Wirklichkeit sind, und deshalb ungerechtfertigterweise in den Genuß der niedrigeren Steuersätze kommen. Diese Regelung ist genauso inkonsequent wie die Einkommensfördergrenzen. Wenn durch die Wohneigentumsbildung eine Minderung der steuerlichen Leistungsfähigkeit vorläge, müßte dies in allen Einkommensbereichen bei der Ermittlung der Steuerschuld ohne Vorbehalte berücksichtigt werden. Auch

1 Zur gesonderten Tabelle vgl. BMF - Finanznachrichten 4/93. Diese Maßnahme ist eine Reaktion des Gesetzgebers auf ein Urteil des Bundesverfassungsgerichts zur Verfassungswidrigkeit der Grundfreibeträge. Vgl. BVerfG, Beschluß vom 25.9.1992, a.a.O.

2 Die Grenzsteuersätze steigen in dieser Tabelle bis auf 67 v.H. an, wobei die Durchschnittsbelastung dennoch unterhalb der Belastung des normalen Steuertarifs bleibt, da relativ hohe Grundfreibeträge gewährt werden.

3 Vgl. BMF - Finanznachrichten 4/93. 
mit dieser Maßnahme bringt der Gesetzgeber folglich implizit zum Ausdruck, daß nach seiner Meinung die Sonderausgabenabzüge des §10e EStG die Bemessungsgrundlage für die Einkommensteuer eigentlich nicht berühren.

Neben diesen Widersprüchen, die in jüngster Zeit im wesentlichen auf knappe Haushaltsmittel zurückzuführen sind, besteht von Anfang an ein systemimmanenter Widerspruch, nämlich der gleichzeitigen Existenz von Minderungen der Bemessungsgrundlage nach $\S 10 \mathrm{e}$ EStG und von Minderungen der Steuerschuld nach $34 \mathrm{f} \mathrm{EStG.} \mathrm{Dazu} \mathrm{findet} \mathrm{sich} \mathrm{in} \mathrm{der} \mathrm{steuerjuristischen} \mathrm{Literatur} \mathrm{folgende}$ ironisch gemeinte Argumentation: "Geht man davon aus, daß die Subventionierung durch $\S 10 e$ ESt $G$... gerechtfertigt ist, weil die Sicherung des existenziellen Wohnbedarfs gefordert werden soll, so verstößt § $34 f E S t G$ (Baukindergeld, Anm.d.Verf.) gegen den Grundsatz der Besteuerung nach der wirtschaftlichen Leistungsfähigkeit. Denn der durch Kinder gesteigerte Wohnraumbedarf mu $\beta$ dann ebenfalls als unvermeidbar angesehen werden, so daß eine progressionsabhängige steuerliche Berücksichtigung geboten erscheint. "1

Zusammenfassend kann somit festgehalten werden, daß die Sonderausgabenabzüge des $\S 10 \mathrm{e}$ EStG steuersystematisch nicht zu rechtfertigen sind. Durch die konkrete Ausgestaltung dieser Maßnahme, aber auch im Verbund mit anderen Maßnahmen in der Einkommensteuer, hat sich der Gesetzgeber in Widersprüche verwickelt, die eine Neugestaltung notwendig machen.

\subsection{Verteilungspolitische Beurteilung}

Wie im vorangegangenen Abschnitt gezeigt wurde, sind die Sonderausgabenabzüge des $\S 10 \mathrm{e}$ EStG steuersystematisch nicht zu rechtfertigen. Da das Baukindergeld nicht ausgezahlt wird, wenn die Steuerschuld nicht ausreicht, um die Vergünstigungen dieser Maßnahme in Anspruch zu nehmen, läßt sie sich steuersystematisch ebenfalls nicht rechtfertigen, da es sich um eine unsystematische Kürzung der Steuerschuld handelt, die nicht auf einem echten verteilungspolitisch begründeten Anspruch des Steuerpflichtigen beruht.

Aus verteilungspolitischer Sicht läuft das Fördersystem damit aber den Anforderungen zuwider, die an verteilungspolitische Maßnahmen zu stellen sind. Die

1 Schmidt, L., a.a.O., S. 922. 
Subventionen steigen mit der Höhe des Einkommens, was auf die Progression in der Einkommensteuer zurückzuführen ist. Mit zunehmendem Einkommen ist aber davon auszugehen, daß die Aufwendungen der Wohneigentumsbildung in zunehmendem $\mathrm{Ma} ß$ aus eigenem Einkommen und Vermögen bestritten werden können. Die Subventionen nehmen mithin mit abnehmender Subventionsnotwendigkeit zu. Wenn der Wissenschaftliche Beirat beim Bundesministerium der Finanzen bei Verkürzungen der Bemessungsgrundlage der Einkommensteuer, die nicht auf einer Änderung der Leistungsfähigkeit beruhen, von einer "Pervertierung der Progression"1 spricht, so ist diese harte Kritik hier umso mehr begründet, als es sich auch noch um verteilungspolitisch motivierte Subventionen handelt. $\mathrm{Da}$ es bei den Maßnahmen nicht um die Berücksichtigung von Änderungen der steuerlichen Leistungsfähigkeit geht, kann deshalb auch nicht argumentiert werden, es handle sich dabei um die Umkehrung der Logik der Progression. Dieser folgenschwere Irrtum ist, wie bereits beim Baukindergeld im vorangegangenen Abschnitt dargelegt wurde, darauf zurückzuführen, daß fiskalische und verteilungspolitische Ziele nicht klar getrennt werden.

Die unglückliche Verknüpfung dieser Ziele wird sowohl in der wissenschaftlichen Literatur, als auch von seiten der verantwortlichen Politiker vorgenommen. So wird in der Literatur argumentiert ${ }^{2}$, die progressionsabhängige Wohneigentumsförderung sei deshalb gerechtfertigt, weil es dadurch bei einem Anspruch des Staates an den Bürger bliebe, nämlich auf den Anspruch auf die zu zahlende Steuer. Aufgrund der Wohneigentumsbildung verzichte der Staat zugunsten des Steuerpflichtigen vorübergehend auf diesen Anspruch. Sofern aber kein steuerpflichtiges Einkommen bzw. nicht in genügendem Umfang vorläge, sei es bei einer steuerlichen Wohneigentumsförderung konsequent, keine Subvention (bzw. in vermindertem Umfang) zu gewähren, da ansonsten der Anspruch des Staates, von seinen Bürgern Steuern zu erhalten, durch den Anspruch der Bürgers an den Staat, eine Subvention zu empfangen, ersetzt würde. Es käme zu einer Verlagerung des Grundsatzes von "Bürger unterhält den Staat" zu "Staat unterhält den Bürger"

1 Wissenschaftlicher Beirat beim Bundesministerium der Finanzen, Gutachten zur Reform der direkten Steuern (Einkommensteuer, Körperschaftsteuer, Vermögensteuer und Erbschaftsteuer) in der Bundesrepublik Deutschland, a.a.O., S. 377.

2 Zur folgenden Argumentation vgl. Eekhoff, J., Wohnungspolitik, a.a.O., S. 12.

${ }^{3}$ Ebenda, S. 52. 
Diese Sichtweise verkennt die Intention der Einkommensteuerpflicht auf der einen Seite und die von Subventionen in der Verteilungspolitik auf der anderen Seite. Zum einen läuft sie auf eine Umkehrung des in der Finanzwissenschaft veralteten Äquivalenzprinzips hinaus, das besagt, daß der Bürger nach Maßgabe der vom Staat empfangenen Leistungen Steuern zu zahlen habe. In der hier formulierten Form hieße dies, daß Sozialtransfers nur nach Maßgabe der zu zahlenden Steuer zu empfangen sind. Damit werden aber gerade diejenigen von Sozialtransfers ausgeschlossen, die diese am ehesten bedürfen. Der Sozialtransfer wird damit ad absurdum geführt, denn er wird mit zunehmender Leistungsfähigkeit, die in der progressiven Besteuerung zum Ausdruck kommen soll, empfangen.

Ebenso wird von politischer Seite mit nahezu gleicher Argumentation versucht, die progressionsabhängige Förderung zu verteidigen: "Ich sage Ihnen das ganz offen. Eigentumsförderung ist erwünscht und deswegen soll sie nach meiner Vorstellung auch in Zukunft an die individuelle Steuerlast geknüpft sein. Denn wer mit hohen Steuern einen hohen Anteil an der Finanzierung gesellschafticher Aufgaben trägt, der wird auch bei der Förderung mit einem entsprechend hohen Anteil zu beteiligen sein. ${ }^{m 1}$

Das fiskalische Ziel des Staates, Steuern mit einem progressiven Tarif aufgrund der individuellen Leistungsfähigkeit zu erheben, hat aber nichts mit dem verteilungspolitischen Ziel der Förderung des Erwerbs selbstgenutzten Wohneigentums zu tun. Werden verteilungspolitische Zielsetzungen mit fiskalischen Zielsetzungen verknüpft, so werden die Progression der Einkommensteuer bzw. das allgemein anerkannte Werturteil, das ihr zugrundeliegt, negiert. Auf der anderen Seite entfiele die Berechtigung für nahezu alle verteilungspolitischen Maßnahmen, da sie darauf gerichtet sind, denen etwas zukommen zu lassen, die bestimmte, aus politischer Sicht wünschenswerte Güter bzw. Nutzungen am Markt nicht allein aus eigener Leistung bestreiten können. Diese Bedürftigkeit kommt aber gerade in einer entsprechend niedrigen Steuerbelastung zum Ausdruck.

1 Schwaetzer, I., Wohnungsmarkt in der Zange knapper öffentlicher Mittel?!, Vortrags- und Diskussionsveranstaltung vom 24. Oktober in Königswinter, Bonn 1991, S. 12 . 
Die Idee, Wohneigentumsförderung überhaupt auf diese Weise zu betreiben, geht wohl nicht nur auf die unglückliche Vermischung zweier Ziele zurück, sondern ist auch aus der historischen Entwicklung erklärbar. Nicht zuletzt aber ist sie auf das mangelnde ökonomische Verständnis der Wirkungen von Minderungen der steuerlichen Bemessungsgrundlage, einmal auf der Ebene der Ermittlung der objektiven steuerlichen Leistungsfähigkeit und einmal auf der Ebene der Ermittlung der subjektiven steuerlichen Leistungsfähigkeit, zurückzuführen. ${ }^{1}$ Wie sich zeigen wird, können diese Wirkungen vollkommen verschieden sein. ${ }^{2}$

Das klassische Förderinstrument der Wohneigentumsbildung war bis zum Übergang zur Konsumgutlösung 1987 in der gesamten Nachkriegszeit die Abschreibungsvergünstigung nach $\S 7 \mathrm{~b}$ EStG. ${ }^{3}$ Nach dem Übergang zur Konsumgutlösung konnte diese Vergünstigung naturgemäß nicht mehr gewährt werden, da die Werbungskosten aus Vermietung und Verpachtung beim selbstnutzenden Eigentümer durch den Wegfall der Nutzwertbesteuerung (vergleichbarer Mietwert) entfielen. Es ist ein Beleg für die nicht hinreichende Differenzierung zwischen den Wirkungen von Abschreibungsvergünstigungen und Sonderausgabenabzügen, daß sich der Sonderausgabenabzug des $\S 10$ e EStG in ihrer Höhe und die Abschreibungsvergünstigung nach § 7b EStG zum Zeitpunkt des Systemwechsels nicht unterschieden. ${ }^{4}$ Die Steuerminderungen aus Sonderausgabenabzügen sind aber endgültiger Natur, während die Abschreibungsvergünstigungen - wenigstens prinzipiell - nur in dem vorübergehenden Verzicht auf Steuern bestehen. ${ }^{5}$ Während beim $\S 7 \mathrm{~b}$ EStG 40 v.H. der begünstigungsfähigen Kosten innerhalb eines Zeitraums von 8 Jahren abgeschrieben werden konnten, gestattete es der Gesetzgeber mit dem $\S 10 \mathrm{e}$ EStG in der ursprüng-

1 Zu den Unterschieden vgl. die Ausführungen zu den Grundlagen der Einkommensteuer im Teil 1 der Untersuchung, insbesondere B.2. bzw. B.3.

2 Vgl. Teil 1 B.2. bzw. B.3.

${ }^{3}$ Beim Einfamilienhaus bzw. bei Objekten, die nach der pauschalierten Nutzwertbesteuerung veranlagt wurden, handelte es sich bereits um einen Freibetrag und nicht um eine klassische Abschreibungsvergünstigung. Die Verteilungswirkungen waren insofern ebenfalls als äußerst unzulänglich einzustufen. Vgl. hierzu Teil 3 A.3.

4 Steuerpflichtige, die bis 1994 ihre Option zur Konsumgutlösung ausüben, können der Einfachheit halber die noch nicht vorgenommenn erhöhten Abschreibungsbeträge gleich als Sonderausgaben abziehen ( $\$ 52 \mathrm{Abs.21} \mathrm{EStG).}$

5 Zur Wirkung von Abschreibungsvergünstigungen vgl. Teil 2. B. 
lichen Ausgestaltung, daß ebenfalls 40 v.H. der begünstigungsfähigen Kosten über einen Zeitraum von 8 Jahren als Sonderausgaben geltend gemacht werden können. ${ }^{1}$

Im Gegensatz zum alten $\S 7 \mathrm{~b}$ EStG sind beim $\S 10 \mathrm{e}$ EStG die Baulandkosten zur Hälfte berücksichtigungsfähig. Damit wird das Bemühen um einen rekurrenten Anschluß deutlich. Bauland unterliegt nicht der Abschreibung, folglich bezog sich der $\S 7 \mathrm{~b}$ EStG, der unter steuersystematischen Gesichtspunkten formal eine Abschreibungsvergünstigung war, nur auf den Gebäudeteil. Unter steuersystematischen Kriterien war dies auch konsequent. Da es sich aber nun nicht mehr um Abschreibungen handelt, ist nicht einsichtig, warum die Baulandkosten nur zur Hälfte berücksichtigungsfähig sind. Unabhängig von der Struktur der Kosten (Bauland/Bebauungskosten) hängt die effektive Belastung des Erwerbers von den Gesamtkosten ab. Für den Erwerber, der beispielsweise ein Annuitätendarlehen zu bedienen hat, spielt es keine Rolle, aus welchem Grund er den Kapitaldienst zu tragen hat, ob aufgrund hoher Bebauungs- oder aufgrund von Baulandkosten. In der ursprünglichen Fassung des Gesetzentwurfes zählte der Grund und Boden überhaupt nicht zu den begünstigungsfähigen Anschaffungs- bzw. Herstellungskosten. ${ }^{2}$ Erst als Ergebnis einer Sachverständigenanhörung wurden in der Endfassung des Gesetzes die Kosten der Anschaffung des Grund und Bodens zu 50 v.H berücksichtigt. Damit sollten insbesondere Bevölkerungsgruppen mit geringem Einkommen und weniger aufwendigen Objekten erreicht werden ${ }^{3}$. Auch aus dieser Begründung kann geschlossen werden, daß der Wille des Gesetzgebers beim steuersystematischen Wechsel zur Konsumgutlösung zwar vorhanden war, daß aber über die qualitative Bedeutung dieses Schrittes nicht genügend Klarheit herrschte.

Kritiker verballhornten den $\S 10$ e EStG zum Zeitpunkt des Systemwechsels deshalb auch als "Sonderausgabenafa" (Sonderausgabenabschreibung). Bis heute ist der Begriff der "Abschreibungsvergünstigung für den privaten Bauherren" immer wieder in den Medien zu finden. Aber auch bei den verantwortli-

1 Vgl. Anlage 1/4a zu Abschnitt 52 Abs. 5 EStR.

2 Vgl. Entwurf eines Gesetzes zur Neuregelung der steuerlichen Förderung selbstgenutzten Wohneigentums, a.a.O.

3 Vgl. Beichelt, B., Aus der Arbeit des Gesetzgebers im Jahre 1986, in, Steuer und Wirtschaft 1987, S. 84.

4 Wagner, W., a.a.O., S. 92. 
chen Politikern und manchen Ökonomen hat sich das Bewußtsein für den steuersystematischen Unterschied und damit auch für die Unterschiede im Subventionsumfang nicht durchgesetzt. So gehen verantwortlichen Politiker noch heute davon aus, daß mit den Sonderausgabenabzügen nach § 10e EStG "Abschreibungsvergünstigungen"1 gewährt werden, bzw. vergleichen Ökonomen explizit die Effizienz der "Abschreibungsvergünstigungen nach $\S 10 e$ $E S t G^{m 2}$ mit der Effizienz alternativer Fördermaßnahmen.

Die nicht hinreichende Differenzierung in den Wirkungen wird auch an der Begründung der Vorkostenabzugsregelung ( $\S 10 \mathrm{e}$ Abs. $6 \mathrm{EStG}$ ) durch den Gesetzgeber sichtbar. Mit dieser Regelung soll sicher gestellt werden, daß Kosten, die in der Bauphase bzw. im Anschaffungszeitraum bei den Einkünften aus Vermietung und Verpachtung Werbungskosten darstellen würden, auch weiterhin geltend gemacht werden können. ${ }^{3}$ D.h. aber, daß das, was aus steuertechnischen Gründen bei den Werbungskosten nicht mehr untergebracht werden kann, unter anderem Namen bei den Sonderausgaben plaziert wird. Jenseits des steuersystematischen Fehlgriffs hat dies aber stark unterschiedliche ökonomische Wirkungen.

Die Vorkosten sollten nach der Begründung des Gesetzgebers die Finanzierungskosten in Form des sogenannten Disagios berücksichtigen ${ }^{4}$. Sie gelten darüber hinaus aber auch für Renovierungskosten vor dem Einzug ( $\S 10 \mathrm{e}$ Abs. 6 EStG). Das Disagio ist ein Abschlag, den Kreditinstitute auf eine eingegangene Kreditverpflichtung erheben. D.h., der Kreditnehmer erhält nicht die volle rückzahlungspflichtige Kreditsumme ausgezahlt, sondern einen verminderten Betrag. Im Umfang des Auszahlungsabschlages verringern sich dadurch für einen bestimmten Zeitraum (im Regelfall für 3 bis $10 \mathrm{Jahre}$ ) die Zinszahlungen. Finanzmathematisch wird dieser Abschlag so gewählt, daß sich die Summe aus

Schwaetzer, I., a.a.O., S. 68.

2 Vgl. z.B. Behring, K. u.a., Evaluierung wohnungspolitischer Instrumente. Aktuelle Probleme des Wohnungsmarktes und Ansatzpunkte für wohnungspolitische Initiativen, Schriftenreihe des Ifo-Instituts für Wirtschaftsforschung, Nr. 129, München 1991.

3 Vgl. Entwurf eines Gesetzes zur Neuregelung der steuerlichen Förderung selbstgenutzten Wohneigentums, a.a.O., S. 16.

4 Vgl. ebenda, S.16. 
der verminderten Zinszahlungen in der Zukunft und dem Abschlag zum vergleichbaren Kapitalmarktzins ergänzen.

Dieses Finanzierungsinstrument trägt mithin dazu bei, in den ersten Jahren nach dem Erwerb von Immobilien Liquiditätsprobleme zu mindern. Kann dieser Abschlag im Jahr der Auszahlung des Kredites im Rahmen der Werbungskosten geltend gemacht werden, wie es bei der Investitionsgutlösung der Fall war bzw. beim vermieteten Wohnraum heute noch der Fall ist, so führt dies zwar im gleichen Jahr zu Steuerminderungen, ab der ersten Periode aber, in der Mieterträge zu versteuern sind, kommt es bereits zu Nachholwirkungen. Den Mieteinnahmen, die steuerpflichtig sind, stehen durch die verminderten Zinsausgaben geringere Werbungskosten gegenüber, wodurch die Bemessungsgrundlage des zu versteuernden Einkommens höher ausfällt, als ohne Inanspruchnahme des Disagios. Steuerminderungen und -mehrbelastungen heben sich bei konstanten Grenzsteuersätzen in ihrer Summe nominal auf. Während der Vorteil des Disagios beim vermieteten Wohnraum lediglich aus einem Zinsvorteil besteht, indem Aufwendungen zeitlich vorgelagert steuerlich geltend gemacht werden können, besteht der Vorteil der Vorkostenabzugsregelung in einer endgültigen Subvention, die in Abhängigkeit von der Höhe des Einkommens gewährt wird.

Nicht anders verhält es sich bei Renovierungskosten. Bei der Investitionsgutlösung bzw. beim vermieteten Wohnraum handelt es sich um Ausgaben, die unmittelbar mit der Erzielung von Einnahmen verbunden sind. Diese können steuerlich auf zwei Arten berücksichtigt werden, entweder als sogenannte Werbungskosten im Jahr der Entstehung oder indem sie zu den Anschaffungskosten gezählt und im Zeitablauf abgeschrieben werden. Es sei an dieser Stelle dahingestellt, was im Fall der Vermietung gerechtfertigt ist. Doch wird sichtbar, daß diese Kosten, sofern sie im Jahr der Entstehung geltend gemacht werden, obwohl sie vielleicht erst im Zeitablauf als Aufwand in Form von Abschreibungen anfallen, in gleicher Weise wie beim Disagio unmittelbar ab dem ersten Jahr, in dem Mieterträge zu versteuern sind, zu Nachholwirkungen führen. Auch hier handelt es sich bei konstanten Grenzsteuersätzen lediglich um einen Zinsvorteil. Durch die Vorkostenabzugsregelung können diese Aufwendungen aber endgültig aus unversteuertem Einkommen bestritten werden. Insofern wurde das Ziel, die Erwerber selbstgenutzten Wohneigentums gegenüber Vermietern nicht zu benachteiligen - vermutlich aus Unkenntnis der 
unterschiedlichen Wirkungen - weit überschossen. Der Staat subventioniert mit dieser Regelung Konsumausgaben in Abhängigkeit vom Einkommen.

Dabei handelt es sich durchaus nicht um geringe Beträge. Bei geschickter Gestaltung können die Vorkostenabzüge des § 10e Abs. 6 EStG die Summe der im achtjährigen Zeitraum gewährten Sonderausgabenabzüge der ab dem 1.1.1994 verminderten Grundförderung (insgesamt 66.000 DM) übersteigen. Es sind solche Renovierungskosten als Vorkosten abziehbar, die keinen anschaffungsnahen Herstellungsaufwand darstellen. Dies wird analog zu den Einkünfte aus Vermietung und Verpachtung anhand Abschnitt 157 Abs. 5 EStR (Januar 1991) geprüft. Danach ist bei Aufwendungen, die im Zusammenhang mit der Anschaffung eines Gebäudes getätigt werden, regelmäßig nicht von anschaffungsnahem Aufwand, sondern von Vorkosten auszugehen, wenn diese Aufwendungen in den ersten drei Jahren nicht einen Betrag (Rechnungsbetrag ohne Umsatzsteuer) von 20 v.H. der auf das Gebäude entfallenden Anschaffungskosten übersteigen ${ }^{1}$. Die 20 v.H. Grenze richtet sich nicht nach den maximalen Beträgen, für die die Grundförderung gewährt wird, sondern nach den tatsächlich auf das Gebäude entfallenden Anschaffungskosten. Der Vorteil dieser Regelung besteht bei den Erwerbern älteren Wohnraums zum einen darin, daß die Förderhöchstgrenzen der Grundförderung durch hohe Instandsetzungskosten überschritten werden können, indem unrenovierter Wohnraum erworben wird. Zum anderen liegt der zentrale Vorteil darin, daß diese Kosten zu 100 v.H. geltend gemacht werden können, während sie als Bestandteil der Anschaffungskosten (bzw. als anschaffungsnahe Herstellungskosten) im achtjährigen Vergünstigungszeitraum nur zu 44 v.H. innerhalb der Sonderausgaben berücksichtigungsfähig sind (4 Jahre à 6 v.H. und 4 Jahre à 5 v.H.).

Die Vorkostenabzugsregelung und die Grundförderung beruhen somit auf zwei Irrtümern. Zum einen auf dem mangelnden Verständnis für die grundlegend unterschiedlichen Wirkungen von Minderungen der Bemessungsgrundlage, die einmal auf die Berücksichtigung von Kosten zurückzuführen sind, die mit einer

1 Bei dieser Grenze handelt es sich um eine sogenannte Aufgriffsgrenze d.h, solange der Steuerpflichtige mit seinen geltend gemachten Aufwendungen unter dieser Grenze bleibt, sind die Kosten in jedem Fall und unbedingt als Vorkosten abziehbar. Wird diese Grenze überschritten, heißt dies noch nicht, daß dies automatisch zur Annahmen von anschaffungsnahem Aufwand führt, sondern nur, daß der Sachverhalt durch die Finanzbehörden geprüft wird. (Vgl. Bundesfinanzhof, Urteil vom 23.9.1992, Az. XR 10/92). 
steuerlichen Einkunftsart in Zusammenhang stehen, zum anderen auf der Berücksichtigung von Aufwendungen, die im Rahmen der Sonderausgaben für ein Konsumgut getätigt werden. Der Irrtum beruht auch darauf, daß die verschiedenen Zielsetzungen, die fiskalischer und verteilungspolitischer Natur sind, nicht auseinander gehalten werden. Beide Zielen sind voneinander unabhängig.

Leicht differenziert, aber dem Kern nach nicht anders, ist der auf maximal 12.000 DM begrenzte und auf die ersten drei Jahre beschränkte Schuldzinsenabzug zu beurteilen. Er ist nicht an Einkommenshöchstgrenzen gebunden, sondern wird auch in Einkommensbereichen oberhalb von 120.000 DM (240.000 DM verh.) gewährt, in denen die Grundförderung und das Baukindergeld versagt bleiben. Voraussetzung für die Subvention ist, daß es sich um neu erstelltes Wohneigentum handelt. Diese Maßnahme ist daher weniger verteilungspolitisch motiviert. Nicht der Subventionsempfänger steht im Vordergrund. Die Maßnahme dient vielmehr wohnungsbaupolitischen Zwecken. Der Schuldzinsenabzug wird ebenfalls in Form eines Sonderausgabenabzugs gewährt und vermindert wie die Vorkostenabzugsregelung und die Grundförderung das zu versteuernden Einkommens. Die Höhe der Subvention ist wiederum von der Höhe des Einkommens bzw. des Grenzsteuersatzes abhängig. Die steuerliche Leistungsfähigkeit der Wirtschaftssubjekte wird aber auch hier nicht tangiert. Die Berechtigung zum Schuldzinsenabzug kann nicht mit dem Verweis auf den vermieteten Wohnungsbau gerechtfertigt werden. Wie sich in Teil 1 der Untersuchung gezeigt hat, ist der Schuldzinsenabzug dort gerechtfertigt, da es sich um Ausgaben handelt, die unmittelbar mit Erzielung von Einnahmen verbunden sind. Gerade diese Voraussetzung ist hier nicht gegeben.

Die Maßnahme des begrenzten Schuldzinsenabzugs ist fiskalisch von vergleichsweise untergeordneter Bedeutung. Die Subventionswerte bewegen sich in Abhängigkeit von dem zu versteuernden Einkommen zwischen $0 \mathrm{DM}$ und 19.080 DM. Es ist deshalb auch fraglich, ob sie in den oberen Einkommensbereichen tatsächlich zu einer Ausweitung des Wohnraumbestandes beitragen oder ob sich die Wirkungen nicht letztlich auf Mitnahmeeffekte begrenzen. Der begrenzte Schuldzinsabzug gewinnt aber dadurch an Bedeutung, daß auch von ökonomischer Seite ein Schuldzinsenabzug von der Bemessungsgrundlage des zu versteuernden Einkommens als effizientes Mittel der Wohneigentumsförderung angesehen wird. Nach einer Untersuchung des Ifo-Institutes wird von mehreren untersuchten Instrumenten die Möglichkeit der Geltendmachung von Schuldzinsen als Sonderausgaben bei der Einkommensbesteuerung als die 
zweiteffizienteste Förderart nach einem Abzug von Schuldzinsen von der Steuerschuld befürwortet. ${ }^{1}$ Ebenso wie bei den in Teil 2 erörterten Abschreibungsvergünstigungen, die gewährt werden, um den allgemeinen Wohnungsbau anzuregen, stellt sich die Frage, warum der Staat für die Erreichung des Subventionsziels, zusätzlichen Wohnraum zu schaffen, unterschiedlich hohe Beträge aufwendet. Aus der Sicht der Subventionsempfänger stellt dies einen Verstoß gegen die Gerechtigkeit dar, da sie unabhängig von ihrer Einkommenshöhe gleichermaßen zum Ziel, der Beseitigung des Wohnraummangels, beitragen. Erweist sich somit der Schuldzinsenabzug beim vermieteten Wohnungsbau als gerechtfertigt, so kann dieser Sachverhalt steuersystematisch nicht auf das selbstgenutzte Wohneigentum übertragen werden. Er scheidet somit auch als allgemeines Mittel der Wohneigentumsförderung aus steuersystematischen und verteilungspolitischen Gesichtspunkten aus.

Zusammenfassend kann festgehalten werden, daß die Fördermaßnahmen der Wohneigentumspolitik "einen massiven Versto $\beta$ gegen grundlegende Gerechtigkeitsprinzipien" 2 und damit insbesondere gegen verteilungspolitische Ziele darstellen. Wenn der Staat aus verteilungspolitischen Gründen eine Subvention gewähren möchte, so muß diese mindestens für alle gleich sein. $\mathrm{Da}$ sie bei der Wohneigentumsförderung mit zunehmendem Einkommen progressionsbedingt zunimmt, läuft einer verteilungspolitisch motivierten Subvention zuwider. Insofern hat sich in der jahrzehntelangen Wohneigentumspolitik qualitativ nicht viel geändert. Schrieb Tipke noch in der 7. Auflage zum § 7b EStG, daß dieser nicht gerechtfertigt sei, da die Vergünstigungen "umgekehrt proportional zum Subventionsbedürfnis bemessen sind" ${ }^{\prime \prime}$, so äußert er sich in der 13. Auflage zum $\S 10 \mathrm{e}$ EStG, daß dieser nicht gerechtfertigt sei, da der "Subventionsvorteil im umgekehrten Verhältnis zum Förderungsbedürfnis steht". ${ }^{4}$

1 Vgl. Behring, K., a.a.O.

2 Oberhauser, A., Ein Verstoß gegen die Gerechtigkeit, a.a.O., S. 163.

3 Tipke, K., a.a.O., S. 460.

4 Tipke, K./Lang, J., a.a.O., S. 656. 


\subsection{Beurteilung der familienorientierten Ausgestaltung}

Aus der Begründung des Wohneigentumsförderungsgesetzes geht hervor, daß es das erklärte Ziel des Gesetzgebers ist, insbesondere Familien mit Kindern den Erwerb selbstgenutzten Wohneigentums zu ermöglichen. Das gesamte Fördersystem ist aber nicht familienfreundlich ausgerichtet. Dies liegt hauptsächlich daran, daß die Subventionen der zentralen Fördermaßnahmen des § 10e EStG vom zu versteuernden Familieneinkommen abhängig sind. Während es in der vorangegangenen Betrachtung um die Beurteilung der vertikalen Verteilungswirkungen ging, steht bei der Beurteilung der familienorientierten Ausgestaltung die horizontale Gerechtigkeit im Vordergrund.

Einmal kann davon ausgegangen werden, daß gerade Familien gegenüber zwei einzelnen Erwachsenen bzw. gegenüber einem kinderlosen Ehepaar über ein geringeres Markteinkommen verfügen, da sich im Regelfall ein Ehepartner der Kindererziehung widmen muß. Damit liegt auch ihr zu versteuerndes Einkommen bei gemeinsamer Veranlagung in einer niedrigeren Progressionszone als in der Vergleichsgruppe.

Zum anderen ist dies darauf zurückzuführen, daß Familien im deutschen Einkommensteuersystem bereits durch gesonderte Regelungen (z.B. Splittingverfahren, Kinderfreibeträge) berücksichtigt werden. Beim Splittingverfahren wird das Familieneinkommen der Ehepartner so behandelt, als hätten sie es beide jeweils zur Hälfte erzielt. Die Steuerschuld entspricht dann dem Doppelten dessen, was sich für den einzelnen ergibt. Diese Regelung führt dazu, daß der Progressionseffekt des Steuertarifs gemindert wird. Je weiter die Einkommen der Ehepartner voneinander differieren, umso niedriger ist die Steuerschuld bei der gemeinsamen Veranlagung gegenüber derjenigen, die sich bei getrennter Veranlagung ergeben würde. Hat ein Ehepartner keinen Verdienst oder nur ein geringes Einkommen, was bei Familien mit Kindern häufig der Fall sein dürfte, führt diese Regelung dazu, daß die letzte Progressionsstufe, die auf das Familieneinkommen zur Anwendung kommt, weit unter der letzten Progressionsstufe eines Alleinstehenden mit gleichem Einkommen liegt.

Da die Subventionswerte der Sonderausgabenabzüge nach $\S 10$ e EStG von der Höhe der durchschnittlich letzten Progressionsstufe abhängt, die auf die Sonderausgabenabzüge zur Anwendung kommt, erhalten Familien mit gleichem Einkommen geringere Subventionen als ein alleinstehender kinderloser Steuer- 
pflichtiger mit gleichem Einkommen. An einem Beispiel dargestellt heißt dies, daß eine DM Sonderausgabenabzug für einen Alleinstehenden mit einem zu versteuernden Jahreseinkommen von 80.000 DM ein Subvention in Höhe von 0,41 DM bedeutet. Eine Familie, die über das gleiche Einkommen verfügt, erhält aufgrund der Splittingveranlagung aber nur eine Subvention in Höhe von 0,29 DM.

Dieser horizontale Nachteil ist nicht zu rechtfertigen. Es kann nicht argumentiert werden, daß es sich bei diesem Nachteil um einen relativen, aber keinen absoluten Nachteil handele, da Verheiratete gegenüber Ledigen ohnehin aufgrund des Splittingtarifs geringere Steuern zu zahlen haben und somit bei den Sonderausgabenabzügen nach $\S 10 \mathrm{e}$ EStG nur das an Subventionen weniger erhalten, was sie aufgrund des Splittingtarifs bereits an Vorteilen haben. Beide Effekte lassen sich nicht saldieren. Mit der Veranlagung nach dem Splittingtarif soll keine Subvention gewährt werden, sondern es soll der steuerlichen Leistungsfähigkeit von zwei Personen Rechnung getragen werden. Sofern das System der Splittingveranlagung keine Subventionen enthält, wovon heute weitgehend ausgegangen wird, handelt es sich bei den verminderten Subventionen aufgrund des $\S 10 \mathrm{e}$ EStG um einen endgültigen absoluten Nachteil. Diese Diskriminierung kann auch nicht damit gerechtfertigt werden, daß die Ehepartner die Vergünstigung des § 10e EStG zweimal in Anspruch nehmen können. Zum einen ist es selten der Fall, daß Ehepaare zwei eigengenutzte Objekte anschaffen. Zum anderen aber steht dies auch zwei Ledigen offen. Zweimal eine verminderte Subvention bleibt eine verminderte Subvention.

Die horizontale Benachteiligung von Familien wird durch die Kinderfreibeträge vergrößert. Die Kinderfreibeträge sollen zum einen die geringere steuerliche Leistungsfähigkeit von Familien mit Kindern berücksichtigen, zum anderen aber auch im Verbund mit dem Kindergeld einen Familienlastenausgleich herstellen, der den Sonderbedarfen der Familien Rechnung trägt. Durch diese Kinderfreibeträge verringert sich das zu versteuernde Jahreseinkommen gegenüber Ehepaaren ohne Kinder pro Kind um weitere 4.104 DM. Mit zunehmender Kinderzahl sinkt damit das zu versteuernde Jahreseinkommen von Familien, mit der Folge, daß auf die Sonderausgabenabzüge ein umso geringerer Progressionssatz mit entsprechend geringeren Subventionen zur Anwendung kommt, je höher die Kinderzahl ist. Damit werden Familien mit zunehmender Kinderzahl bei den Sonderausgabenabzügen ebenfalls diskriminiert. 
Die Regelung des Baukindergelds erlaubt, für jedes Kind 1.000 DM von der Steuerschuld abzuziehen. Voraussetzung für die Inanspruchnahme ist mithin, daß nach den gewährten Kinderfreibeträgen und den in Anspruch genommenen Sonderausgabenabzügen nach $\S 10 \mathrm{e}$ EStG überhaupt noch eine zu zahlende Steuerschuld verbleibt. Diese Wahrscheinlichkeit sinkt in mittleren Einkommenslagen mit zunehmender Kinderzahl. Je höher die Anzahl der Kinder ist, desto geringer ist die zu zahlende Steuerschuld. Da aber mit steigender Kinderzahl der formale Baukindergeldanspruch zunimmt, wird es bei gegebenem Einkommen mit zunehmender Anzahl der Kinder immer unwahrscheinlicher, daß das Baukindergeld überhaupt in vollem Umfang zum Tragen kommt. Vor allem beim Erwerb neuerstellten Wohneigentums hat sich das Baukindergeld im Zeitablauf zu einer Maßnahme entwickelt, die vor allem höheren Einkommensschichten zugute kommt.

Zusammenfassend kann gesagt werden: Die Förderung durch die Sonderausgabenabzüge des $\S 10$ e EStG ist nicht familienorientiert. Familien mit Kindern verfügen naturgemäß über ein niedrigeres zu versteuerndes Jahreseinkommen als kinderlose Doppelverdiener, wodurch sie progressionsbedingt eine geringere Subvention erhalten. Durch spezielle steuerliche Regelungen werden sie aber auch gegenüber Alleinstehenden mit gleichem Einkommen diskriminiert. Die Diskriminierung bei den Sonderausgabenabzügen nimmt mit zunehmender Kinderzahl weiter zu, da das zu versteuernde Einkommen mit steigender Kinderzahl abnimmt. Das Baukindergeld ist nur scheinbar ein Ausgleich. Es bedarf einer genaueren quantitativen Analyse, inwieweit und in welchem Umfang es zum Tragen kommt.

\section{Quantitative Erfassung der Subventionswerte}

Das Fördersystem hat durch die Ausweitungen der letzten Jahre neben qualitativen Aspekten vor allem eine erhebliche quantitative Bedeutung gewonnen. In den folgenden Abschnitten sollen die Subventionswerte in Abhängigkeit von den individuellen Familienverhältnisse und differenziert zwischen dem Erwerb neu erstellten Wohneigentums und dem Erwerb aus dem Bestand aufgewiesen werden. 


\subsection{Beim Erwerb neuerstellten Wohneigentums}

Um die Vergleichbarkeit zu gewähren, sind einige normierende Grundannahmen nötig. Es wird davon ausgegangen, daß das Einkommen der Steuerpflichtigen im gesamten betrachteten Vergünstigungszeitraum konstant bleibt und sich damit die Progressionssätze, die auf die Sonderausgabenabzüge zur Anwendung kommen, nicht ändern. Weiter wird davon ausgegangen, daß die maximale Förderung von $330.000 \mathrm{DM}$ in Anspruch genommen wird. Dies entspricht einem Anschaffungsvolumen von ca. $400.000 \mathrm{DM}$, da die Baulandkosten nur zur Hälfte berücksichtigt werden. Die Vorkostenabzugsregelung nach $\S 10 \mathrm{e}$ Abs. 6 wird in den Berechnungen nicht berücksichtigt. Sie hängt zu stark von den individuellen Verhältnissen ab, ${ }^{1}$ die schlecht normierbar sind. Die quantitative Bedeutung dieser Regelung sollte jedoch nicht unterschätzt werden.

In der Ausgangsbetrachtung wird vom Erwerb neu erstellten Wohneigentums ausgegangen, da sich hier die verteilungspolitischen Unzulänglichkeiten besonders kraß zeigen. Diese Betrachtung wird später um den Fall des Erwerbs aus dem Bestand, differenziert nach der alten und der neuen Regelung (ab dem 1.1.1994), modifiziert. Weiter wird zugrundegelegt, daß der Schuldzinsenabzug in vollem Umfang in Anspruch genommen wird. Dafür genügt es, wenn sich die Erwerber mit ca. 150.000 DM verschulden (Zinssatz 8 v.H.), was einer Verschuldungsquote von 37,5 v.H. bezogen auf die Förderungshöchstgrenze entspricht. Die durchschnittliche Verschuldungsquote der Erwerber beträgt heute ca. 60 - 70 v.H.; ${ }^{2}$ insofern ist diese Annahme realistisch.

Die Subventionswerte werden kumuliert für den gesamten Vergünstigungszeitraum ausgewiesen. Die Förderung ist leicht degressiv gestaltet. Sie fällt bei den Steuerpflichtigen, vor allem im mittleren Einkommensbereich durch die Möglichkeit, in einem Jahr nicht vorgenommene Sonderausgabenabzüge auf spätere Jahre vorzutragen, nicht unbedingt in den Jahren an, denen sie eigentlich zuzurechnen ist. Die zeitliche Förderdegression erreicht erst oberhalb bestimmter Einkommensgrenzen ihre volle Wirkung. In den Berechnungen wird davon ausgegangen, daß sich die Sonderausgabenabzüge gleichmäßig auf den

${ }^{1} \mathrm{Zu}$ ihrer generellen Beurteilung vgl. Teil 3 B 2.2.

Vgl. o.V., Vierzig Prozent des Familieneinkommens für das Eigenheim. in: FAZ vom 7.5.1993, S. 39. 
gesamten Förderzeitraum verteilen ${ }^{1}$. Da es sich um einen überschaubaren Subventionszeitraum handelt, werden die Subventionen aus Gründen der Transparenz als Zeitwerte und nicht als Barwerte ausgewiesen ${ }^{2}$. Der Begriff des zu versteuernden Jahreseinkommens soll, abweichend von dem im Einkommensteuerrecht verwendeten Begriff, als das zu versteuernde Einkommen vor Abzug der Kinderfreibeträge definiert werden. Auf diese Weise ist gewährleistet, daß die Subventionswerte in Abhängigkeit alternativer Familiensituationen miteinander vergleichbar sind. Für die unteren Einkommensschichten besteht seit dem Veranlagungszeitraum 1993 eine gesonderte Einkommensteuertabelle, bei der von sogenannten Erwerbseinkünften ${ }^{3}$ ausgegangen wird. Diese Regelung wird in diesem Abschnitt nicht berücksichtigt. Es wird von dem seit 1990 gültigen Steuertarif, T90, ausgegangen. Ab dem 1.1.1995 wird ein Solidaritätszuschlag auf die Steuerschuld von 7,5 v.H. erhoben, auch dieser wird im folgenden nicht berücksichtigt. Allerdings erhöhen sich die ausgewiesenen Subventionswerte (außer den Werten des Baukindergeld) ab diesem Zeitpunkt um diesen Prozentsatz.

Die saldierten Subventionen nach § 10e EStG sind für einen kinderlosen Alleinverdiener und für ein kinderloses Ehepaar in Abhängigkeit vom zu versteuernden Jahreseinkommen in Graphik 12 abgebildet. Für Alleinstehende bewegen sich die Subventionen von 0 DM, beginnend bei einem zu versteuernden Jahreseinkommen von 5.616 DM (Grundfreibetrag, darunter sind keine Steuern zu bezahlen) und steigen bis auf 89.904 DM bei einem zu versteuernden Einkommen von 120.000 DM. Ab diesem Einkommen entfällt die Grundförderung, und es kommt nur noch zu Subventionen durch den begrenzten Schuldzinsenabzug. Die Subvention des Schuldzinsenabzugs beträgt in der oberen Proportionalzone

1 Die ermittelten Subventionswerte weichen dadurch für den gesamten Förderzeitraum um bis zu ca. $650 \mathrm{DM}$ in den obersten Einkommensbereichen (Grundtarif) von den faktischen Subventionswerten ab. Die Abweichung kommt dadurch zustande, daß durch die gleichmäßige Verteilung der Sonderausgabenabzüge auf die einzelnen Förderjahre eine durchschnittlich geringfügig niedrigere Progressionsstufe zur Anwendung kommt.

2 Bei einem Vergleich der Barwerte wären die differenzierenden Wirkungen marginal stärker, da die Subventionen bei den höheren Einkommensbeziehern in früheren Jahren anfallen.

3 Zur genauen Regelung des Begriffs der Erwerbseinkünfte sowie zur neuen Einkommensteuerzusatztabelle, die seit dem Veranlagungszeitraum 1993 angewendet wird, vgl. BMF - Finanznachrichten 4/1993. 


\section{Grafik 12}

Kumulierte Entlastungseffekte der Sonderausgabenabzüge nach $\S 10 \mathrm{e} \mathrm{EStG}$, Erwerb neu erstellten Wohneigentums (Zeitwerte)

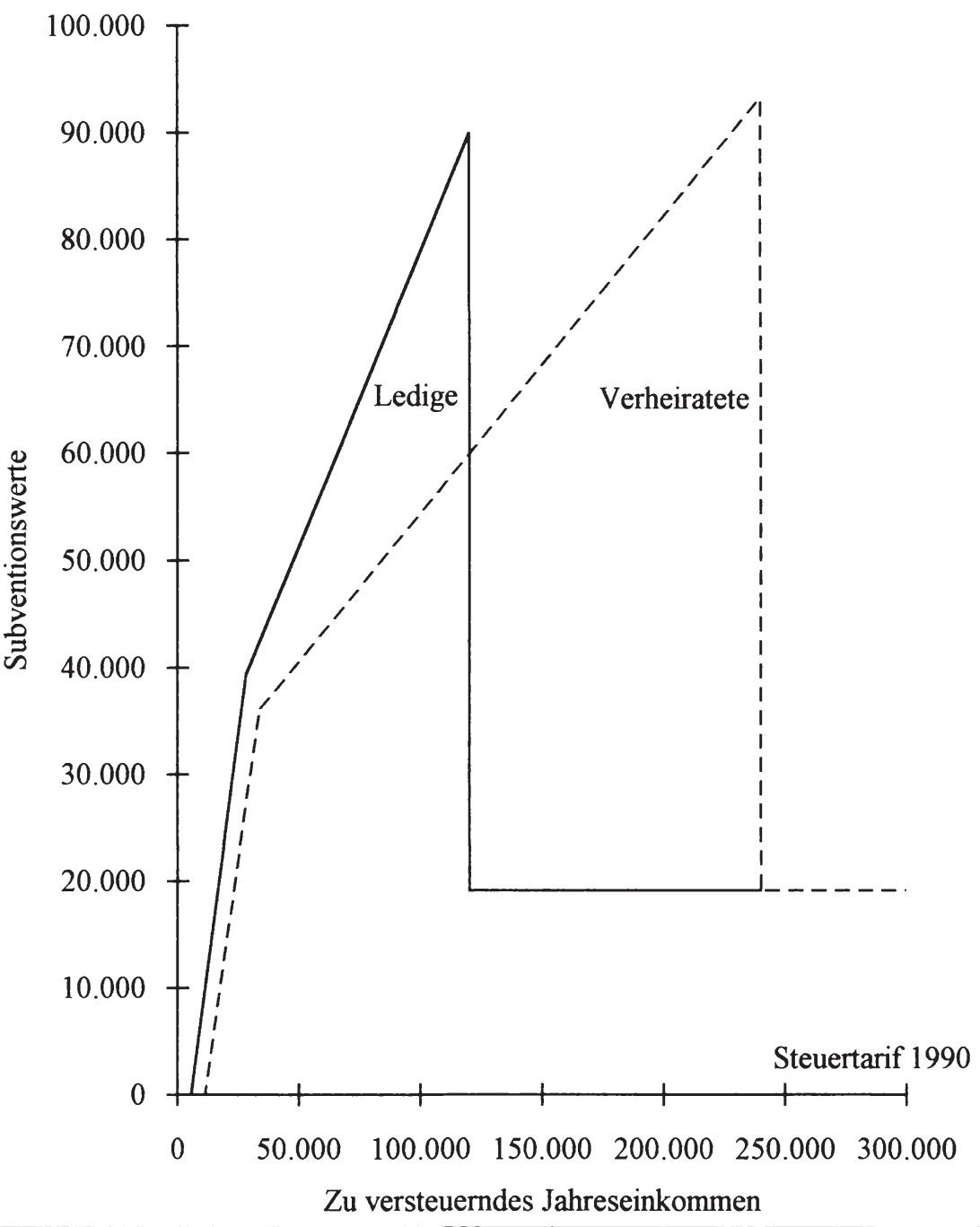


des Steuertarifs 19.080 DM. Die Knickstelle innerhalb des ansteigenden Teils der Graphik kommt dadurch zustande, daß unterhalb dieses Einkommens die Bemessungsgrundlage für das zu versteuernde Jahreseinkommen nicht ausreicht, um im gesamten Vergünstigungszeitraum - trotz Vortragsmöglichkeiten nicht ausgenutzter Sonderausgabenabzüge in einzelnen Jahren - die vollen Sonderausgabenabzüge geltend zu machen. Die Subventionswerte steigen unterhalb dieser Einkommensgrenze deshalb so rasch an, weil mit jeder Mark zusätzlichen Einkommens zum einen die Summe der wirksam werdenden Sonderausgabenabzüge steigt und zum anderen zusätzlich der Progressionseffekt zum Tragen kommt. Der langsamer ansteigende Teil der Kurve ist nur noch durch die Progressionswirkung gekennzeichnet.

Die zweite Kurve gibt die Subventionen wieder, die Verheiratete ohne Kinder erhalten. Beginnend von einem zu versteuernden Einkommen von 11.232 DM (zweifacher Grundfreibetrag) steigen die Subventionen mit zunehmendem Einkommen bis auf maximal 93.032 DM bei einem Einkommen von 240.000 $\mathrm{DM}$ an. Ab diesem Einkommen entfällt wiederum die Grundförderung, und es können ebenfalls nur noch die Subventionen durch den begrenzten Schuldzinsenabzug in Höhe von insgesamt knapp 19.000 DM geltend gemacht werden. Die Subventionswerte sind zum genaueren quantitativen Vergleich in Tabelle 6 dargestellt. Die Gesamtsubventionen liegen bei Verheirateten marginal über der maximalen Subvention eines Ledigen, da durch den Splittingtarif auf die Sonderausgabenabzüge an der Grenze zur oberen Proportionalzone ein leicht höherer durchschnittlicher Grenzsteuersatz zur Anwendung kommt.

Beim Vergleich der beiden Kurven in Grafik 12 fällt auf, daß Verheiratete gegenüber Ledigen bei gleichem Einkommen in den mittleren Einkommensbereichen eine zum Teil erheblich geringere Subvention erhalten. Die maximale Differenz tritt bei einem zu versteuernden Jahreseinkommen von 120.000 DM auf. Verheiratete erhalten gegenüber einem Ledigen bei gleichem Einkommen in diesem Einkommensbereich eine um ca. 30.000 DM geringere Subvention bzw. nur ca. 2/3 des Subventionsbetrages eines Ledigen.

Dieser horizontale Nachteil ist nicht zu rechtfertigen. Wie die Erörterung in Abschnitt 2.3. zeigte, kann dieser Effekt weder mit einem Splitting"vorteil" verrechnet werden, noch relativiert er sich durch die Möglichkeit für Ehepaare, diese Subvention zweimal in Anspruch zu nehmen. 


\begin{tabular}{|c|c|c|c|c|}
\hline \multicolumn{5}{|c|}{$\begin{array}{r}\text { Tabelle 6: Subventionswerte der Sonderausgabenabzüg } \\
\text { Abhängigkeit von der Familiensituation } \\
\text { Erwerb neu erstellten Wohneigentums }\end{array}$} \\
\hline \multirow{2}{*}{\begin{tabular}{c|} 
zu verst. \\
Einkommen (2)
\end{tabular}} & \multirow[b]{2}{*}{ ledig } & \multicolumn{2}{|c|}{ Familienstand } & \multirow[b]{2}{*}{4 Kinder } \\
\hline & & verh. & 2 Kinder & \\
\hline 0 & 0 & 0 & 0 & 0 \\
\hline 10.000 & 6.688 & 0 & 0 & 0 \\
\hline 20.000 & 23.544 & 13.384 & 816 & 0 \\
\hline 30.000 & 40.208 & 29.536 & 16.104 & 3.448 \\
\hline 40.000 & 45.688 & 37.896 & 32.656 & 19.040 \\
\hline 50.000 & 51.184 & 40.456 & 38.208 & 35.632 \\
\hline 60.000 & 56.832 & 43.408 & 41.144 & 38.880 \\
\hline 70.000 & 62.336 & 46.176 & 43.912 & 41.648 \\
\hline 80.000 & 67.704 & 48.696 & 46.448 & 44.192 \\
\hline 90.000 & 73.192 & 51.680 & 49.416 & 47.160 \\
\hline 100.000 & 78.688 & 54.176 & 51.928 & 49.672 \\
\hline 110.000 & 84.400 & 57.192 & 54.928 & 52.672 \\
\hline 120.000 & 89.904 & 59.960 & 57.696 & 55.440 \\
\hline 130.000 & 19.080 & 62.696 & 60.440 & 58.176 \\
\hline 140.000 & 19.080 & 65.472 & 63.208 & 60.944 \\
\hline 150.000 & 19.080 & 67.896 & 65.640 & 63.392 \\
\hline 160.000 & 19.080 & 70.976 & 68.720 & 66.448 \\
\hline 170.000 & 19.080 & 73.744 & 71.480 & 69.216 \\
\hline 180.000 & 19.080 & 76.480 & 74.224 & 71.960 \\
\hline 190.000 & 19.080 & 79.256 & 76.992 & 74.728 \\
\hline 200.000 & 19.080 & 81.616 & 79.360 & 77.112 \\
\hline 210.000 & 19.080 & 84.760 & 82.504 & 80.232 \\
\hline 220.000 & 19.080 & 87.528 & 85.264 & 83.008 \\
\hline 230.000 & 19.080 & 90.272 & 88.008 & 85.744 \\
\hline 240.000 & 19.080 & 93.032 & 90.776 & 88.512 \\
\hline 248.208 & 19.080 & 19.080 & 93.064 & 90.832 \\
\hline 256.416 & 19.080 & 19.080 & 19.080 & 93.032 \\
\hline und mehr & 19.080 & 19.080 & 19.080 & 19.080 \\
\hline
\end{tabular}

(1) Bei Gleichverteilung der Sonderausgabenabzüge über den gesamten Förderzeitraum

(2) vor Abzug der Kinderfreibeträge; Steuertarif 1990 
Die Benachteiligung von Familien bei den Sonderausgabenabzügen wird in Graphik 13 sichtbar. Mit zunehmender Kinderzahl erhalten sie bei gleichem Einkommen durch die Sonderausgabenabzüge des $\S 10 \mathrm{e}$ EStG weniger an Subventionen. Dies liegt an den Kinderfreibeträgen. In den untersten Einkommensbereichen bekommen sie überhaupt keine Subvention. Dieser Subventionsverlust, der auf die Kindern zurückzuführen ist, beträgt im untersten Einkommensbereich für eine Familie mit 2 Kindern beispielsweise ca. 12.000 DM (Vier-Kinder-Familie ca. 26.000 DM) im gesamten Förderzeitraum. Dies entspricht dem vertikalen Abstand der Linien in Grafik 13. Die Werte zur Graphik 13 sind ebenfalls in Tabelle 6 wiedergegeben. Die unscharfen Einkommensgrenzen in den obersten Einkommensbereichen kommen durch die Kinderfreibeträge zustande.

Das Baukindergeld bietet nur einen scheinbaren Ausgleich, da negative Beträge nicht ausbezahlt werden. Für jedes Kind können 1.000 DM von der Steuerschuld abgezogen werden. In den unteren Einkommensbereichen können bereits die Sonderausgabenabzüge nach § 10e EStG nicht bzw. nicht in vollem Umfang in Anspruch genommen werden, da das Einkommen zu gering ist. Daher verbleibt auch keine Steuerschuld, aus der das Baukindergeld gewährt werden kann. Diese Benachteiligung ist nur auf den ersten Blick auf den unteren Einkommensbereich begrenzt. Die genauere Betrachtung zeigt, daß dieses Problem bis weit in die mittleren Einkommensbereiche existiert. Inwieweit das Baukindergeld in vollem Umfang zur Geltung kommt, ist wiederum in Abhängigkeit von Einkommen und Kinderzahl in Tabelle 7 wiedergegeben. Damit eine Familie mit zwei Kindern den Baukindergeldanspruch für beide Kinder im jeweiligen Förderjahr überhaupt voll ausschöpfen kann, muß sie bereits über ein zu versteuerndes Jahreseinkommen von ca. 55.000 DM verfügen, eine Familie mit vier Kinder benötigt ein zu versteuerndes Jahreseinkommen von 72.500 DM. Das Bruttomarkteinkommen von sozialversicherten Arbeitnehmern liegt in diesen mittleren Einkommensbereichen um ca. 10.000 DM über dem ausgewiesenen zu versteuernden Jahreseinkommen, mithin bei $65.000 \mathrm{DM}$ bzw. 82.500 DM. Die Masse der Familien dürfte in diesen kritischen Einkommensbereiche bzw. darunter liegen.

Durch die Möglichkeit, für die Realisierung des Baukindergeldanspruchs einen Vor- oder Rücktrag um bis zu zwei Jahren, auch über den Vergünstigungszeitraum der Grundförderung hinaus, vorzunehmen, relativiert sich dieses Problem. So können Familien das Baukindergeld im ersten und zweiten Förder- 


\section{Grafik 13}

Subventionswerte der Sonderausgabenabzüge nach $\S 10$ e EStG in Abhängigkeit von der Familiensituation

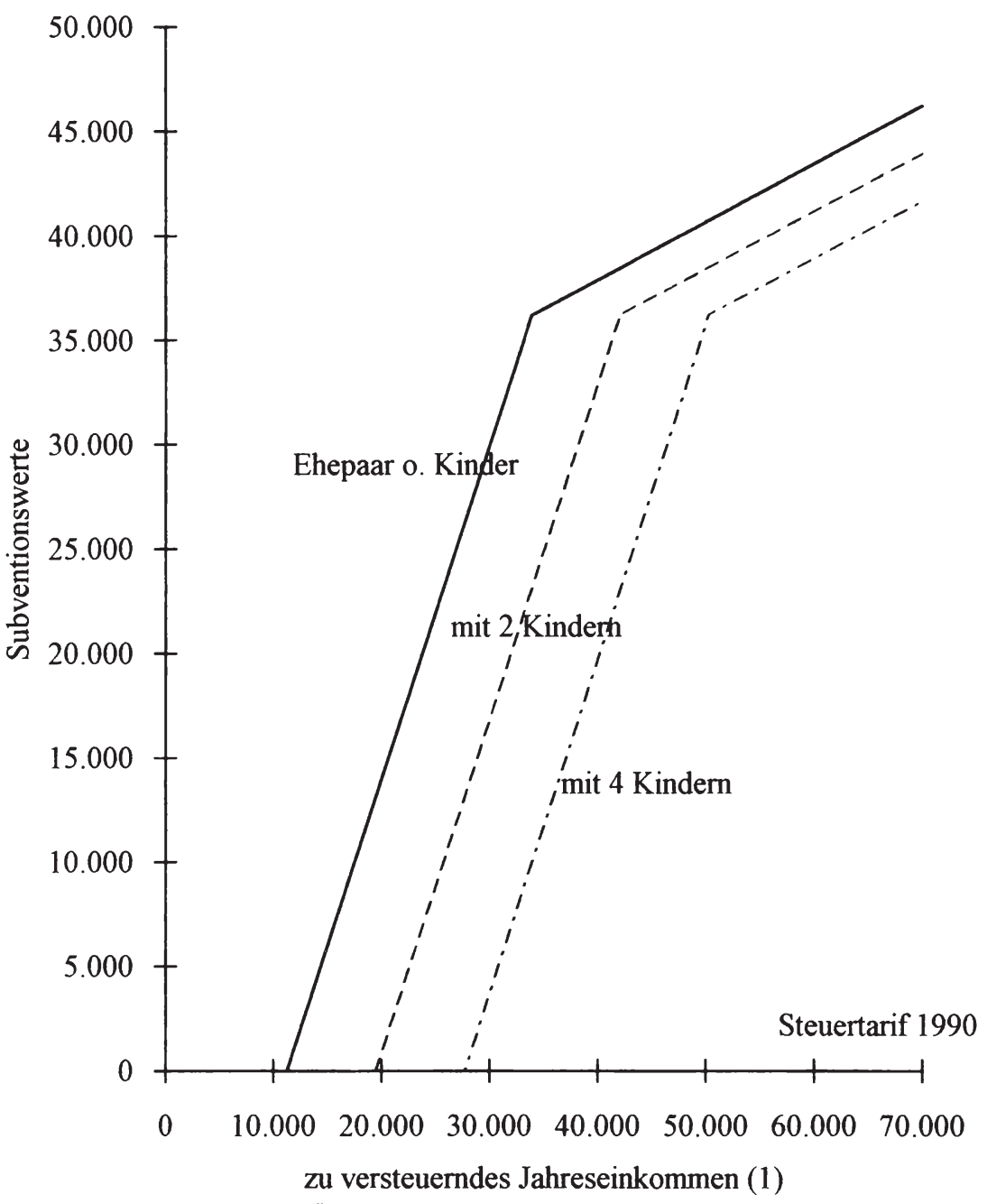

(1) vor Abzug der Kinderfreibeträge 


\begin{tabular}{|c|rrrrr|}
\hline \multicolumn{7}{|c|}{ Tabelle 7: Baukindergeld nach $\S 34 f$ EStG in Abhängigkeit von } \\
der Anzahl der Kinder (1) \\
Erinkerst. & \multicolumn{7}{c|}{ Anzahl der Kinder } \\
Einkmen (2) & 1 & 2 & 3 & 4 & 5 \\
\hline 37.500 & 0 & 0 & 0 & 0 & 0 \\
40.000 & 369 & 0 & 0 & 0 & 0 \\
42.500 & 841 & 61 & 0 & 0 & 0 \\
45.000 & 1.000 & 533 & 0 & 0 & 0 \\
47.500 & 1.000 & 1.026 & 246 & 0 & 0 \\
50.000 & 1.000 & 1.504 & 718 & 0 & 0 \\
52.500 & 1.000 & 1.992 & 1.191 & 410 & 0 \\
55.000 & 1.000 & 2.000 & 1.673 & 882 & 102 \\
57.500 & 1.000 & 2.000 & 2.163 & 1.357 & 574 \\
60.000 & 1.000 & 2.000 & 2.664 & 1.842 & 1.046 \\
62.500 & 1.000 & 2.000 & 3.000 & 2.336 & 1.525 \\
65.000 & 1.000 & 2.000 & 3.000 & 2.862 & 2.035 \\
67.500 & 1.000 & 2.000 & 3.000 & 3.375 & 2.532 \\
70.000 & 1.000 & 2.000 & 3.000 & 3.898 & 3.040 \\
72.500 & 1.000 & 2.000 & 3.000 & 4.000 & 3.556 \\
75.000 & 1.000 & 2.000 & 3.000 & 4.000 & 4.082 \\
77.500 & 1.000 & 2.000 & 3.000 & 4.000 & 4.617 \\
80.000 & 1.000 & 2.000 & 3.000 & 4.000 & $\mathbf{5 . 0 0 0}$ \\
82.500 & 1.000 & 2.000 & 3.000 & 4.000 & 5.000 \\
\hline
\end{tabular}

(1) 3. bis 8 . Förderjahr, bei Gleichverteilung der Sonderausgabenabzüge nach $\S 10$ e EStG

(2) vor Abzug der Kinderfreibeträge; Steuertarif 1990 
jahr aus der bezahlten Steuern der beiden Jahre vor der Anschaffung erhalten. Baukindergeld, das sie in den Förderjahren 3 bis 8 nicht in vollem Umfang in Anspruch nehmen können, dürfen sie auf die beiden auf die Grundförderung folgenden Jahre, somit auf das Jahr 9 und 10 nach der Anschaffung, vortragen und aus der Steuerschuld dieser beiden Jahre bestreiten. Für den einzelnen Steuerpflichtigen entsteht daraus ein Optimierungsproblem, das er für seine individuellen Verhältnisse ohne fachkundigen Beratung wahrscheinlich schwer zu durchschauen vermag.

Durch die Nachholmöglichkeiten wird zwar mehr formale Gerechtigkeit bei der Vergabe der Subventionen erreicht, doch werden diese Subventionen erst in späteren Jahren wirksam, in denen die schwierige Anfangsphase mit meist hohen relativen Einkommensbelastungen für die Familien überstanden ist.

Wie problematisch die konkrete Ausgestaltung des Baukindergeldes ist, wird besonders an folgendem Fall deutlich. In den mittleren Einkommensbereichen kann es in Abhängigkeit vom zu versteuernden Jahreseinkommen und der Anzahl der Kinder dazu kommen, daß eine Familie, die bereits Wohneigentum erworben hat, durch die Geburt eines weiteren Kindes nicht nur für dieses Kind kein Baukindergeld erhält, sondern den Baukindergeldanspruch für ein bereits vorhandenes Kind verliert. Dies kommt dadurch zustande, daß aufgrund des zusätzlichen Kinderfreibetrages die nach Abzug aller Sonderausgaben verbleibende Steuerschuld abnimmt und damit die Grundlage für das Baukindergeld eines schon vorhandenen Kindes erodiert wird.

Anscheinend ist es nicht beabsichtigt, daß das Fördersystem flexibel auf Änderungen der Familiengröße reagiert, es wird davon ausgegangen, daß sich die Geförderten an das System anpassen. Mit der Möglichkeit, nicht ausgenutzte Sonderausgabenabzüge in spätere Jahre zu verlagern, soll auch Familien mit schwankendem Einkommen die Möglichkeit gegeben werden, die Subventionen der Sonderausgabenabzüge in späteren Jahren nachzuholen. "Eine Verteilung ist besonders vorteilhaft für Steuerzahler, die in einem Jahr wegen zu geringer Steuerschuld - zum Beispiel wegen Erziehungsurlaubs - die Vergunstigung nicht voll ausnutzen können"1.

1 Bundesministerium für Raumordnung, Bauwesen und Städtebau, Bausteine zum eigenen Heim; Das wohnungspolitische Programm der Bundesregierung 1992, S. 15 . 
Wie wirklichkeitsfremd das Fördersystem ist, wird gerade an dieser Aussage deutlich. In den Jahren, in denen die Erwerber die staatliche Förderung am dringendsten benötigen, beispielsweise wegen Arbeitslosigkeit, bleibt ihnen staatliche Hilfe verwehrt. Geht es ihnen in späteren Jahren wieder besser, springt die Hilfe wieder ein. Manche Familien werden sie dann vielleicht auch wegen privater Insolvenz nicht mehr benötigen. "Besonders interessant ist eine Verschiebung in Folgejahre für Steuerzahler, die in der Zukunft mit erheblichen Einkommenssteigerungen - und damit auch mit einem erheblich höheren Grenzsteuersatz - rechnen"I.

Mit diesen Aussagen stellt sich dem Betrachter die Frage, ob hier überhaupt willentlich Verteilungspolitik betrieben wird. Für den Durchschnittsbürger gestaltet sich die Einmal-im-Leben-Aktion des Immobilienerwerbs im Regelfall zu einem Liquiditätsproblem und nicht zu einem Renditekalkül, wann bzw. in welchen Jahren und wie das optimale Steuersparmenü zusammengestellt wird. Die Mindestanforderung an eine rationale Wohneigentumspolitik muß es sein, daß sie mit einer im Zeitablauf konstanten Förderung den Erwerbern eine gewisse Sicherheit hinsichtlich der Wechselfällen des Lebens gibt.

Ein erwähnenswerter Nebenaspekt ist die Praxis der Vergabe des Baukindergeldes. Bei lohnsteuerpflichtigen Arbeitnehmern wird es dadurch berücksichtigt, daß auf der Lohnsteuerkarte für jedes Kind ein Freibetrag von 4.000 DM eingetragen wird ${ }^{2}$. Erst im Lohnsteuerjahresausgleich wird der Abzug von der Steuerschuld vorgenommen. Damit erhalten Steuerpflichtige mit einem marginalen Grenzsteuersatz von unter 25 v.H. bis zum Jahresausgleich eine zu geringe und Steuerpflichtige mit einem darüberliegenden Grenzsteuersatz eine zu hohe Subvention im jeweiligen Förderjahr. Konkret heißt dies für eine Familie mit zwei Kindern, daß sie über ein zu versteuerndes Einkommen vor Abzug der Sonderausgabenabzüge nach § 10e EStG und der Kinderfreibeträge von ca. 86.000 DM verfügen muß, damit der Baukindergeldanspruch im Jahr des Anspruchs voll zu Geltung kommt. Dies entspricht einem Bruttoverdienst für sozialversicherte Arbeitnehmer von ca. 95.000 DM. Auf der anderen Seite erhalten Steuerpflichtige mit einem Einkommen darüber einen zinslosen Kredit bis zu maximal 1.120 DM im obersten Einkommensbereich für jedes Kind

1 Bundesministerium für Raumordnung, Bauwesen und Städtebau, Bausteine zum eigenen Heim, a.a.O., S. 16.

2 Vgl. § 39a Abs. 1 EStG. 
(2.120 DM Steuerminderung, abzüglich 1.000 DM Anspruch). Es ist nicht einsichtig, warum nicht einfach die monatliche Steuerschuld auf der Lohnsteuerkarte um 83,33 DM für jedes Kind gekürzt wird (1.000 DM/12). ${ }^{1}$

\subsection{Beim Erwerb aus dem Bestand}

\section{a. Subventionswerte bis Ende 1993}

Die Sonderausgabenabzüge unterscheiden sich beim Erwerb aus dem Bestand von den Sonderausgabenabzügen beim neuerstellten Wohneigentum bis Ende 1993 lediglich um den beschränkten Schuldzinsenabzug von insgesamt 36.000 DM in den ersten drei Jahren. Die daraus resultierenden Vergünstigungen bewegen sich in Abhängigkeit vom individuellen Grenzsteuersatz von 0 DM ausgehend bis auf ca. 19.000 DM an der Grenze zur oberen Proportionalzone. ${ }^{2}$ Die gesamten Subventionen, die auf die Sonderausgabenabzüge gewährt werden, unterscheiden sich in den mittleren und oberen Einkommensschichten von den in Tabelle 6 ausgewiesenen Werten beim Erwerb aus dem Bestand um diese Beträge. In den unteren Einkommensgruppen weichen die Subventionen beim Erwerb aus dem Bestand deshalb nicht von den in Tabelle 6 ausgewiesenen Subventionswerten $\mathrm{ab}$, weil die Bemessungsgrundlage des zu versteuernden Einkommens bei diesen Einkommensgruppen beim Erwerb von neu erstelltem Wohneigentum nicht ausreicht, um den beschränkten Schuldzinsenabzug zusätzlich zu den anderen Sonderausgabenabzügen geltend zu machen. Oberhalb der Einkommensgrenze von 120.000 DM, bzw. 240.000 DM bei Verheirateten, werden beim Erwerb aus dem Bestand keine Subventionen gewährt.

Für das Baukindergeld heißt dies, daß die in Tabelle 7 ausgewiesenen Einkommensgrenzen, ab denen das Baukindergeld in voller Höhe wirksam wird, beim Erwerb aus dem Bestand um ca. 4.500 DM niedriger liegen. An einem Beispiel aus Tabelle 7 verdeutlicht bekommt eine Familie im jeweiligen Jahr das volle

1 Bei Selbständigen wird das Baukindergeld in seiner korrekten Höhe bei den Vorauszahlungen der Einkommensteuer berücksichtigt.

2 Der maximale Subventionswert liegt leicht darunter, da an der Grenze zur oberen Proportionalzone im Einkommensteuertarif auf diese Sonderausgabenabzüge der Spitzensteuersatz von 53 v.H. noch nicht zur Geltung kommt. 
Baukindergeld für zwei Kinder bereits ab einem zu versteuernden Jahreseinkommen von 50.500 DM und nicht erst ab einem Einkommen von 55.000 DM.

Auf die Subventionen beim Erwerb aus dem Bestand, die hier zugrundegelegt sind, wird nicht weiter eingegangen, da dieser Fall nur noch für Erwerber zutrifft, die Wohneigentum vor dem 31.12.1993 erworben haben. Um die Bedeutung der einschneidenden Subventionsminderungen ab dem 1.1.1994 zu veranschaulichen, wurden aber die Subventionen der Sonderausgabenabzüge beim Erwerb aus dem Bestand beispielhaft für eine Familie mit zwei Kindern inclusive des wirksamen Baukindergeldes in Abhängigkeit vom zu versteuernden Familieneinkommen in Grafik 14 dargestellt.

Die obere Linie zeigt die gesamten Subventionen, die diese Familie im 10jährigen Vergünstigungszeitraum unter Berücksichtigung aller Verlagerungsmöglichkeiten bei den Sonderausgabenabzügen und unter Berücksichtigung aller Vor- und Rücktragsmöglichkeiten beim Baukindergeld, auch über den achtjährigen Vergünstigungszeitraum der Grundförderung hinaus, in Anspruch nehmen kann. Die darunter liegende, gestrichelte Linie gibt die Subventionen wieder, die allein auf die Sonderausgabenabzüge zurückzuführen sind. Die Subventionen der Sonderausgabenabzüge bewegen sich wiederum von $0 \mathrm{DM}$ bei einem zu versteuernden Familieneinkommen von 19.440 DM bis auf maximal 74.928 DM bei einem zu versteuernden Familieneinkommen von 248.208 DM. Die Differenz zwischen der gestrichelten Linie und der oberen Linie sind die Subventionen des Baukindergeldes in Höhe von konstant 16.000 DM, soweit sie in voller Höhe wirksam werden.

\section{b. Die Einschränkung der Maßnahmen ab 1994}

Der Gesetzgeber hat die Wohneigentumsförderungsmaßnahmen zum 1.1.1994 erheblich eingeschränkt. Die Bemessungsgrundlage für den Erwerb von Wohneigentum aus dem Bestand wird von 330.000 DM auf 150.000 DM gesenkt. Die Abzugssätze von 6 v.H. in den ersten vier Jahren bzw. 5 v.H. in den folgenden vier Jahren bleiben unverändert. Hierdurch wird die Förderung stärker zugunsten des Erwerbs neu erstellten Wohneigentums ausgerichtet. Bei dieser Einschränkung dürften allerdings fiskalische Motive und damit das Ziel des Subventionsabbaus ausschlaggebend gewesen sein. 


\section{Grafik 14}

Kumulierte Entlastungseffekte der Sonderausgabenabzüge nach $\S 10$ e EStG einschließlich Baukindergeld ( $\$ 34 \mathrm{f} \mathrm{EStG}$ ) für eine

Familie mit zwei Kindern nach der alten und der neuen

Regelung, beim Erwerb von Wohneigentum aus dem Bestand (Zeitwerte)

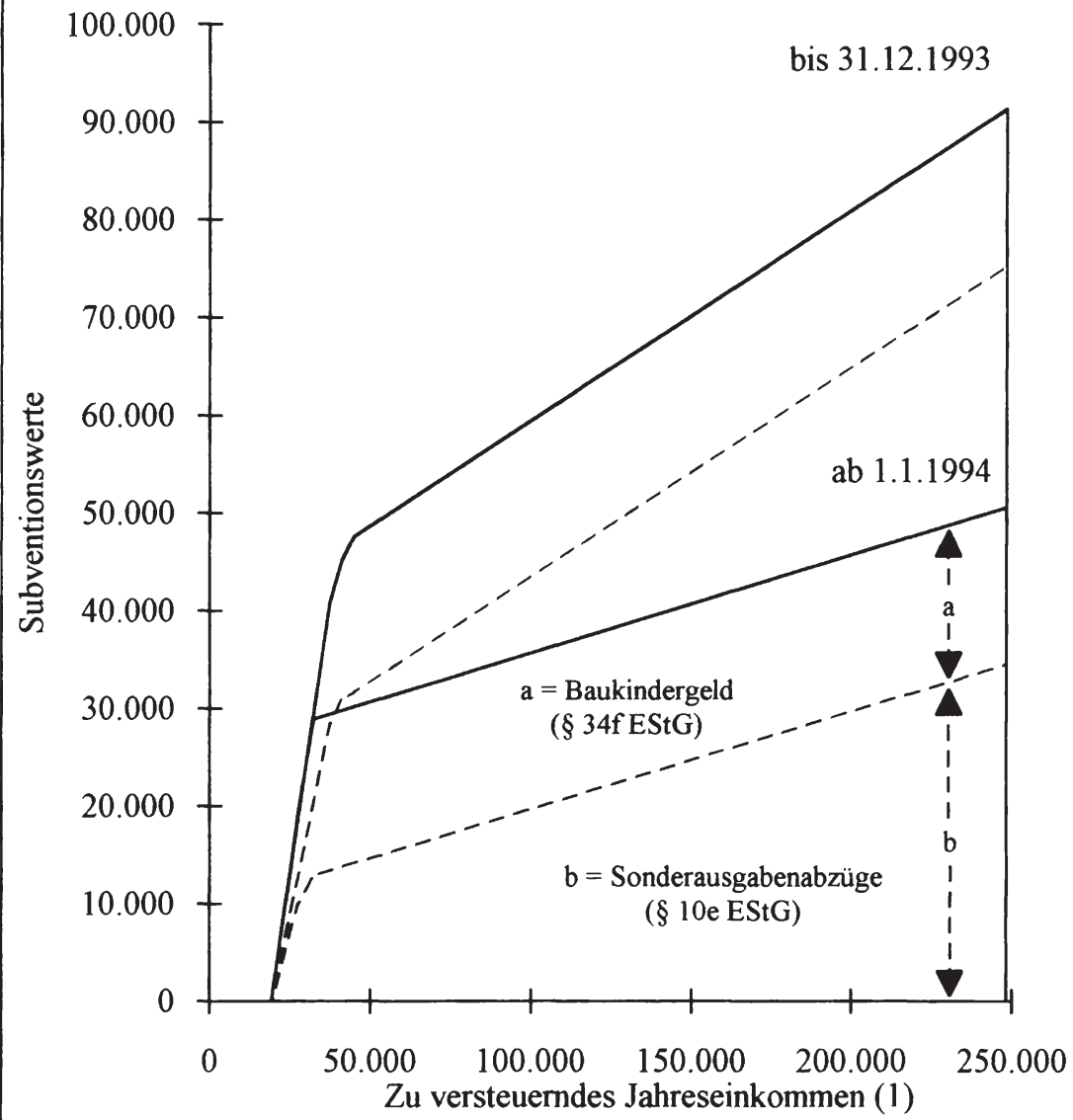

Annahmen: Gleichverteilung der Sonderausgabenabzüge über den gesamten Förderzeitraum; Berücksichtigung aller Vor- und Rücktragsmöglichkeiten beim Baukindergeld.

(1) vor Abzug der Kinderfreibeträge 
Bei genauer Betrachtung führt diese Maßnahme aber wenigstens im Ergebnis zu mehr Subventionsgleichheit. In den unteren Einkommensbereichen wirkt sich die Maßnahme für Familien in Abhängigkeit von der Kinderzahl u.U. überhaupt nicht aus. Dies erklärt sich dadurch, daß in dem Umfang, in dem diese Einkommensbezieher keine Sonderausgabenabzüge mehr geltend machen können, das Baukindergeld verstärkt wirksam wird. D.h., diese Familien verlieren Subventionen aufgrund der verminderten Bemessungsgrundlage der Sonderausgabenabzüge, wodurch sich ihre Steuerschuld nach den Sonderausgabenabzügen erhöht. Dadurch wird aber wiederum eine Grundlage für die Inanspruchnahme des Baukindergeldes geschaffen. Mit zunehmendem Einkommen schwächt sich dieser Effekt rasch ab, und es kommt zu echten Subventionsminderungen.

Die Subventionen, die nach dieser neuen Regelung für eine Familie mit zwei Kindern noch wirksam werden, sind ebenfalls aus Grafik 14 ersichtlich. Es zeigt sich, daß Familien mit einem geringen Jahreseinkommen überhaupt keine Subventionsminderungen erleiden. Andererseits werden in den oberen Einkommensbereichen unnötig hohe Subventionen abgebaut, da diese Einkommensgruppen nach der alten Regelung in ungerechtfertigtem Maße privilegiert waren. In den mittleren Einkommensbereichen liegen die sogenannten Schwellenhaushalte. Das sind die Familien, die aufgrund ihres Leistungsvermögens und ihrer Präferenzen als Erwerber von Wohneigentum in Frage kommen, die Belastungen aber ohne staatliche Hilfe schwer oder nicht tragen können. Diese bekommen die Einschränkung relativ am stärksten zu spüren. Es fragt sich, ob durch die erheblichen Subventionsminderungen in diesen Einkommensbereichen (Abstand zwischen den beiden durchgezogenen Linien) die Fördermaßnahmen noch greifen. Die Subventionswerte der Grundförderung und die Subventionen des Baukindergeldes sind in Abhängigkeit vom Einkommen und der Familiensituation aus Tabelle 8 bzw. 9 ersichtlich.

Kinderlose Ehepaare und Alleinverdiener erhalten zum Teil erheblich geringere Subventionen. Durch die Einschränkung der Fördermaßnahmen wird damit aber die ursprüngliche Intention des Gesetzes, verstärkt Familien mit Kindern zu fördern, indirekt besser erfüllt, indem die einkommensunabhängig gedachte Familienkomponente, das Baukindergeld, relativ stärker zum Tragen kommt. Allerdings bleibt es bei einem relativen Vorteil.

Die Wohneigentumsförderung dürfte durch diese starken Einschränkungen bei den Schwellenhaushalten an Wirksamkeit verloren haben. Der Gesetzgeber hat 
Tabelle 8: Subventionswerte der Sonderausgabenabzüge nach $\S 10 \mathrm{e}$ EStG in Abhängigkeit von der Familiensituation (1)

Regelung ab 1994, Erwerb von Wohneigentum aus dem Bestand

\begin{tabular}{|c|rrrr|}
\hline zu verst. & \multicolumn{4}{|c|}{ Familienstand } \\
\cline { 3 - 5 } Einkommen (2) & ledig & verh. & 2 Kinder & 4 Kinder \\
\hline 0 & 0 & 0 & 0 & 0 \\
10.000 & 6.688 & 0 & 0 & 0 \\
20.000 & 14.112 & 12.728 & 816 & 0 \\
30.000 & 16.128 & 13.432 & 12.656 & 3.448 \\
40.000 & 18.128 & 14.624 & 13.792 & 12.968 \\
50.000 & 20.008 & 15.424 & 14.608 & 13.792 \\
60.000 & 22.152 & 16.432 & 15.616 & 14.792 \\
70.000 & 24.160 & 17.656 & 16.824 & 15.992 \\
80.000 & 26.168 & 18.424 & 17.608 & 16.784 \\
90.000 & 28.168 & 19.672 & 18.848 & 18.016 \\
100.000 & 29.984 & 20.416 & 19.600 & 18.784 \\
110.000 & 32.192 & 21.416 & 20.600 & 19.784 \\
120.000 & 34.200 & 22.712 & 21.880 & 21.056 \\
130.000 & 0 & 23.408 & 22.592 & 21.776 \\
140.000 & 0 & 24.728 & 23.904 & 23.072 \\
150.000 & 0 & 25.408 & 24.584 & 23.768 \\
160.000 & 0 & 26.408 & 25.592 & 24.768 \\
170.000 & 0 & 27.760 & 26.936 & 26.104 \\
180.000 & 0 & 28.400 & 27.584 & 26.768 \\
190.000 & 0 & 29.792 & 28.952 & 28.128 \\
200.000 & 0 & 30.400 & 29.576 & 28.752 \\
210.000 & 0 & 31.392 & 30.584 & 29.760 \\
220.000 & 0 & 32.816 & 31.992 & 31.160 \\
230.000 & 0 & 33.392 & 32.576 & 31.752 \\
240.000 & 0 & 34.840 & 34.008 & 33.184 \\
248.208 & 0 & 0 & 34.840 & 34.008 \\
256.416 & 0 & 0 & 0 & 34.840 \\
und mehr & 0 & 0 & 0 & 0 \\
\hline
\end{tabular}

(1) Bei Gleichverteilung der Sonderausgabenabzüge über den gesamten Förderzeitraum

(2) vor Abzug der Kinderfreibeträge; Steuertarif 1990 


\begin{tabular}{|c|rrrrr|}
\hline \multicolumn{6}{|c|}{ Tabelle 9: Baukindergeld nach $\S 34 \mathrm{f}$ EStG in Abhängigkeit von } \\
der Anzahl der Kinder (1) \\
Erwerb von Wohneigentum aus dem Bestand \\
Einkommen (2) & 1 & 2 & 3 & 4 & 5 \\
\hline 22.500 & 0 & 0 & 0 & 0 & 0 \\
25.000 & 266 & 0 & 0 & 0 & 0 \\
27.500 & 738 & 0 & 0 & 0 & 0 \\
30.000 & 1.000 & 431 & 0 & 0 & 0 \\
32.500 & 1.000 & 902 & 123 & 0 & 0 \\
35.000 & 1.000 & 1.378 & 595 & 0 & 0 \\
37.500 & 1.000 & 1.864 & 1.067 & 287 & 0 \\
40.000 & 1.000 & $\mathbf{2 . 0 0 0}$ & 1.546 & 759 & 0 \\
42.500 & 1.000 & 2.000 & 2.056 & 1.253 & 472 \\
45.000 & 1.000 & 2.000 & 2.554 & 1.736 & 944 \\
47.500 & 1.000 & 2.000 & 3.000 & 2.228 & 1.420 \\
50.000 & 1.000 & 2.000 & 3.000 & 2.730 & 1.906 \\
52.500 & 1.000 & 2.000 & 3.000 & 3.241 & 2.402 \\
55.000 & 1.000 & 2.000 & 3.000 & 3.761 & 2.906 \\
57.500 & 1.000 & 2.000 & 3.000 & 4.000 & 3.443 \\
60.000 & 1.000 & 2.000 & 3.000 & 4.000 & 3.967 \\
62.500 & 1.000 & 2.000 & 3.000 & 4.000 & 4.500 \\
65.000 & 1.000 & 2.000 & 3.000 & 4.000 & $\mathbf{5 . 0 0 0}$ \\
67.500 & 1.000 & 2.000 & 3.000 & 4.000 & 5.000 \\
\hline & & & 0 & \\
\hline \multicolumn{7}{|c}{ Anzahl der Kinder } \\
\end{tabular}

(1) 3. bis 8. Förderjahr, bei Gleichverteilung der Sonderausgabenabzüge nach $§ 10$ e EStG

(2) vor Abzug der Kinderfreibeträge; Steuertarif 1990 
mit den Einschränkungen deutlich gemacht, daß er für die Wohneigentumspolitik, was den vermögenspolitischen Aspekt angeht, nur noch in relativ begrenztem Umfang Subventionen gewähren möchte. Umso mehr sollte dies ein Anlaß sein, für die Zukunft nach effizienteren Maßnahmen zu suchen. ${ }^{1}$

\section{c. Die Wirkung in Verbindung mit der gesonderten Veranlagung für Steuerpflichtige mit geringem Einkommen}

Seit dem Veranlagungszeitraum 1993 gilt für Steuerpflichtige mit geringem Einkommen eine gesonderte Steuertabelle. ${ }^{2}$ Ausgehend vom Begriff der sogenannten Erwerbseinkünften bleiben Einkünfte bis 12.041 DM für Ledige bzw. 19.115 DM für Verheiratete steuerfrei. Oberhalb dieser Einkünfte steigt der Tarif stark progressiv an (maximale Grenzbelastung 67 v.H.) und wird ab Einkünften von 15.011 DM bei Ledigen bzw. bei 22.787 DM bei Verheirateten in den normalen Einkommensteuertarif 1990 übergeleitet.

Für die Subventionen des $\S 10 \mathrm{e}$ EStG bzw. des Baukindergeldes bedeutet dies, daß Familien beispielsweise mit zwei Kindern (vier Kindern) mit einem zu versteuernden Einkommen vor Abzug der Kinderfreibeträge unter 27.319 DM (35.527 DM) überhaupt keine Förderung mehr erhalten, da sie nun steuerlich entsprechend ihrer effektiven Leistungsfähigkeit veranlagt werden. Dies bringt einen Subventionsverlust bei der Grundförderung im gesamten Förderzeitraum von ca. 12.000 DM mit sich. Zusätzlich verlieren sie Baukindergeld, das durch die Verlagerungen auf Steuerjahre außerhalb des Vergünstigungszeitraums hätte geltend gemacht werden können, in Höhe von ca. 6.000 DM (vier Kinder ebenfalls 6.000 DM). Die Subventionswerte der Grundförderung sind unter Berücksichtigung der Einkommensteuerzusatztabelle in Tabelle 10 und 11 wiedergegeben.

1 Vgl. Oberhauser, A./Rüsch, Ch., Wohnungspolitik für Familien, Familienorientierte Förderung des Erwerbs selbstgenutzten Wohneigentums unter besonderer Berücksichtigung der Situation in den neuen Ländern, 2. Aufl., Grafschaft 1994, insbesondere das Konzept der Finanzierungshilfen. Bei einem gesamten fiskalischen Aufwand von ca. 22.000 DM (Barwert, Zinssatz 8 v.H.) kann bei geschickter Gestaltung von wohneigentumspolitischen Maßnahmen eine Senkung der Kapitalbelastung von bis zu 2,5 v.H. in den ersten Jahren erreicht werden, bezogen auf ein Volumen von 400.000 DM.

2 Vgl. BMF - Finanznachrichten 4/93. 
Tabelle 10: Subventionswerte der Sonderausgabenabzüge nach $\S 10$ e EStG in Abhängigkeit von der Familiensituation (1)

Neuregelung ab 1994, beim Erwerb von Wohneigentum aus dem Bestand

\begin{tabular}{|c|c|c|c|c|}
\hline \multirow{2}{*}{\begin{tabular}{|c|} 
zu verst. \\
Einkommen (2)
\end{tabular}} & \multicolumn{4}{|c|}{ Familienstand } \\
\hline & ledig & verh. & 2 Kinder & 4 Kinder \\
\hline 0 & 0 & 0 & 0 & 0 \\
\hline 10.000 & 0 & 0 & 0 & 0 \\
\hline 20.000 & 14.112 & 4.032 & 0 & 0 \\
\hline 30.000 & 16.128 & 13.432 & 12.240 & 0 \\
\hline 40.000 & 18.128 & 14.624 & 13.792 & 12.968 \\
\hline 50.000 & 20.008 & 15.424 & 14.608 & 13.792 \\
\hline 60.000 & 22.152 & 16.432 & 15.616 & 14.792 \\
\hline 70.000 & 24.160 & 17.656 & 16.824 & 15.992 \\
\hline 80.000 & 26.168 & 18.424 & 17.608 & 16.784 \\
\hline 90.000 & 28.168 & 19.672 & 18.848 & 18.016 \\
\hline 100.000 & 29.984 & 20.416 & 19.600 & 18.784 \\
\hline 110.000 & 32.192 & 21.416 & 20.600 & 19.784 \\
\hline 120.000 & 34.200 & 22.712 & 21.880 & 21.056 \\
\hline 130.000 & 0 & 23.408 & 22.592 & 21.776 \\
\hline 140.000 & 0 & 24.728 & 23.904 & 23.072 \\
\hline 150.000 & 0 & 25.408 & 24.584 & 23.768 \\
\hline 160.000 & 0 & 26.408 & 25.592 & 24.768 \\
\hline 170.000 & 0 & 27.760 & 26.936 & 26.104 \\
\hline 180.000 & 0 & 28.400 & 27.584 & 26.768 \\
\hline 190.000 & 0 & 29.792 & 28.952 & 28.128 \\
\hline 200.000 & 0 & 30.400 & 29.576 & 28.752 \\
\hline 210.000 & 0 & 31.392 & 30.584 & 29.760 \\
\hline 220.000 & 0 & 32.816 & 31.992 & 31.160 \\
\hline 230.000 & 0 & 33.392 & 32.576 & 31.752 \\
\hline 240.000 & 0 & 34.840 & 34.008 & 33.184 \\
\hline 248.208 & 0 & 0 & 34.840 & 34.008 \\
\hline 256.416 & 0 & 0 & 0 & 34.840 \\
\hline und mehr & 0 & 0 & 0 & 0 \\
\hline
\end{tabular}

(1) Bei Gleichverteilung der Sonderausgabenabzüge über den gesamten Förderzeitraum

(2) vor Abzug der Kinderfreibeträge;

Steuertarif 1990 (T90); Einkommensteuerzusatztarif 1993 (T93) 
Tabelle 11: Baukindergeld nach $\S 34 \mathrm{fEStG}$ in Abhängigkeit von der Anzahl der Kinder (1)

Regelung ab 1994, beim Erwerb von Wohneigentum aus dem Bestand

\begin{tabular}{|c|c|c|c|c|c|}
\hline \multirow{2}{*}{$\begin{array}{c}\text { zu verst. } \\
\text { Einkommen (2) }\end{array}$} & \multicolumn{5}{|c|}{ Anzahl der Kinder } \\
\hline & 1 & 2 & 3 & 4 & 5 \\
\hline 22.500 & 0 & 0 & 0 & 0 & 0 \\
\hline 25.000 & 266 & 0 & 0 & 0 & 0 \\
\hline 27.500 & 738 & 0 & 0 & 0 & 0 \\
\hline 30.000 & 1.000 & 431 & 0 & 0 & 0 \\
\hline 32.500 & 1.000 & 902 & 0 & 0 & 0 \\
\hline 35.000 & 1.000 & 1.378 & 0 & 0 & 0 \\
\hline 37.500 & 1.000 & 1.864 & 1.067 & 0 & 0 \\
\hline 40.000 & 1.000 & 2.000 & 1.546 & 759 & 0 \\
\hline 42.500 & 1.000 & 2.000 & 2.056 & 1.253 & 0 \\
\hline 45.000 & 1.000 & 2.000 & 2.554 & 1.736 & 944 \\
\hline 47.500 & 1.000 & 2.000 & 3.000 & 2.228 & 1.420 \\
\hline 50.000 & 1.000 & 2.000 & 3.000 & 2.730 & 1.906 \\
\hline 52.500 & 1.000 & 2.000 & 3.000 & 3.241 & 2.402 \\
\hline 55.000 & 1.000 & 2.000 & 3.000 & 3.761 & 2.906 \\
\hline 57.500 & 1.000 & 2.000 & 3.000 & 4.000 & 3.443 \\
\hline 60.000 & 1.000 & 2.000 & 3.000 & 4.000 & 3.967 \\
\hline 62.500 & 1.000 & 2.000 & 3.000 & 4.000 & 4.500 \\
\hline 65.000 & 1.000 & 2.000 & 3.000 & 4.000 & 5.000 \\
\hline 67.500 & 1.000 & 2.000 & 3.000 & 4.000 & 5.000 \\
\hline
\end{tabular}

(1) 3. bis 8 . Förderjahr, bei Gleichverteilung der Sonderausgabenabzüge nach $\S 10$ e EStG

(2) vor Abzug der Kinderfreibeträge; Steuertarif 1990

Steuertarif 1990 (T90); Einkommensteuerzusatztarif 1993 (T93) 


\section{Die abgeleiteten Fördermaßnahmen \\ (§§ $10 \mathrm{f} / \mathrm{h}$ EStG und $\S 7$ FördergebietsG)}

Die Regelungen der $\S \S 10 \mathrm{f} / \mathrm{h}$ EStG dienen nicht der Begünstigung breiter Schichten der Bevölkerung, sondern betreffen den Erwerb, die Erstellung bzw. Sanierung von Wohneigentum unter besonderen Bedingungen. Sie lehnen sich an die Regelungen der Grundförderung nach $\S 10 \mathrm{e}$ EStG an. Ihre Beurteilung unterscheidet sich qualitativ nicht wesentlich von der Beurteilung der Grundförderung. Sie werden aus Gründen der Vollständigkeit an dieser Stelle gesondert nachgetragen. Der $\S 7$ FördergebietsG ist auf die neuen Bundesländer beschränkt.

- Der $§ 10$ EStG dient der Subventionierung von Sanierungsaufwendungen an Baudenkmäler bzw. von Wohnungen in "Sanierungsgebieten und städtebaulichen Entwicklungsbereichen $" .^{1} \S 10$ f Abs. 1 EStG zielt auf die Subventionierung von Erwerbern von Sanierungsobjekten ab. Die Voraussetzungen, um diese Vergünstigungen in Anspruch zu nehmen, sind an die Voraussetzungen der $\S \S 7 \mathrm{~h} \mathrm{bzw}$. 7i EStG gekoppelt. Der $\S 10$ f Abs. 2 EStG zielt demgegenüber auf die Subventionierung von bereits vorhandenem Wohnraum ab. Bei den Regelungen der Absätze 1 und 2 des § 10f EStG können Sanierungsaufwendungen bzw. Instandsetzungsaufwendungen in Höhe von jährlich 10 v.H. innerhalb eines Zeitraums von 10 Jahren ohne Obergrenzen als Sonderausgaben geltend gemacht werden. Der Vorteil gegenüber der Grundförderung nach § 10e EStG besteht darin, daß bei der Grundförderung insgesamt nur 44 v.H. der berücksichtigungsfähigen Kosten geltend gemacht werden können. Abs. 1 stellt die Erwerber von selbstgenutztem Wohneigentum mit den Erwerbern von Sanierungsobjekten, die den Wohnraum vermieten, gleich - Abs. 2 den Wohneigentümer mit dem langjährigen Vermieter, der entsprechende Investitionen vornimmt.

Die Sonderausgabenabzüge des $\S 10 \mathrm{f} \mathrm{EStG}$ entsprechen in ihrer Höhe und in ihrer zeitlichen Verteilung exakt der Höhe der Abschreibungsvergünstigungen der $\S \S 7 \mathrm{~h} / \mathrm{i}$ EStG. Die Regelungen machen nochmals die mangelnde Differenzierung des Gesetzgebers zwischen den Wirkungen von Minderungen der objektiven Bemessungsgrundlage der Einkommensteuer und den Wirkungen von Änderungen der subjektiven Bemessungsgrundlage deutlich. Aus Sonderaus-

1 Vgl. hierzu auch die Ausführungen zum § 7h EStG, Teil 2B, 3.2.b. 
gabenabzügen resultieren endgültige progressionsabhängige Subventionen, während Abschreibungsvergünstigungen nur eine vorübergehende Steuerstundung darstellen. ${ }^{1} \mathrm{Da}$ die Subventionen der Abschreibungsvergünstigungen i.e.S. nur in der Differenz zwischen den linearen Abschreibungssätzen und den erhöhten Abschreibungssätzen liegen, wird der Selbstnutzer durch die Regelungen des § $10 \mathrm{f} \mathrm{EStG} \mathrm{bereits} \mathrm{im} \mathrm{Subventionszeitraum} \mathrm{höher} \mathrm{begünstigt.} \mathrm{Betrachtet}$ man die Parallelitäten zwischen beiden Regelungen, fällt nochmals auf, daß der Gesetzgeber Subventionen, die durch die Konsumgutlösung steuersystematisch nicht mehr bei den Abschreibungen eingeordnet werden können, in die Sonderausgabenabzüge verlagert.

Nutzt der Wohneigentümer das Objekt nicht bis zum Ende des Vergünstigungszeitraums selbst, sondern vermietet es, kann er alle noch nicht in Anspruch genommenen Sonderausgabenabzüge im Jahr des Übergangs zur Einkunftserzielung abziehen. Diese Regelung weicht von den Regelungen der Sonderausgabenabzüge nach § $10 \mathrm{e}$ EStG ab, bei denen die nicht ausgenutzten Sonderausgabenabzüge nur auf in Zukunft eigengenutzte Wohnungen übertragen werden können.

Der § 10h EStG ist die logische Fortführung bzw. auch das Ergebnis der Konsumgutlösung. Sofern ein Wohnungseigentümer in oder im Zusammenhang mit seinem eigenen Wohngebäude neuen Wohnraum schafft und ihn Angehörigen auf Dauer kostenlos zur Nutzung überläßt, kann er die gleichen Sonderausgabenabzüge wie beim Erwerb neu erstellten Wohneigentums in Anspruch nehmen, entsprechend den Regelungen der Grundförderung des § 10e EStG (also ohne begrenzten Schuldzinsenabzug). Vor dem Übergang zur Konsumgutlösung waren die Nutzwerte von kostenlos überlassenem Wohnraum beim Nießbraucher in Höhe der vergleichbaren Marktmiete steuerpflichtig. Im Gegenzug konnte der Wohneigentümer die Werbungskosten aus Vermietung und Verpachtung steuerlich geltend machen. Da der Wohneigentümer innerhalb der Konsumgutlösung für den neuen Wohnraum nicht auf Abschreibungsvergünstigungen zurückgreifen kann, weicht der Gesetzgeber wiederum auf die Sonderausgabenabzüge aus.

${ }^{1}$ Vgl. hierzu auch die Auseinandersetzung mit der Vorkostenabzugsregelung nach \& 10e EStG. Teil 3 B 2.2 
- Der $\$ 7$ FördergebietsG dient der Subventionierung von Instandsetzungsmaßnahmen an Wohneigentum in den neuen Bundesländern. Er stellt indirekt eine Erweiterung der Vorkostenabzugsregelung nach § 10e Abs. 6 EStG dar. Die Vorkostenabzugsregelung gestattet es, Instandsetzungsmaßnahmen bis zu maximal 20 v.H. der Anschaffungskosten gebrauchten Wohneigentums als Sonderausgabenabzug geltend zu machen. ${ }^{1}$ Der Vorteil liegt auch hier in einem Sonderausgabenabzug von 100 v.H. anstelle von 44 v.H. innerhalb der Anschaffungskosten. Durch den $\S 7$ FördergebietsG wird die Vorkostenabzugsregelung, soweit sie sich auf Instandsetzungsaufwendungen bezieht, für das Gebiet der neuen Bundesländer auf bis zu 40.000 DM erweitert. Kosten können bis zu dieser Höhe gleichmäßig als Sonderausgabenabzüge über einen Zeitraum von 10 Jahren verteilt werden. Diese Regelung wird wohl vor allem von Mietern, die ihre Wohnung im Rahmen der Privatisierung erwerben, in Anspruch genommen werden. Durch die Senkung der berücksichtigungsfähigen Anschaffungskosten im Rahmen der Grundförderung nach § 10e EStG auf 150.000 DM beim Erwerb von Wohneigentum aus dem Bestand hat die Bedeutung dieser Regelung zugenommen. Die Subventionswerte dürfen jedoch nicht überschätzt werden. Bei den zumeist niedrigen Einkommen in den neuen Bundesländern resultiert daraus eine jährliche Steuerersparnis von ca. 1.000 DM (Grenzsteuersatz 20 v.H.) bzw. 1.500 DM (30 v.H).

1 Auch die Vorkostenabzugsregelung lehnt sich an Regelungen des vermieteten Wohnraums an, hat aber gänzlichst unterschiedliche Wirkungen. Vgl. Abschnitt 2.2. 


\section{Teil 4: Ergebnisse und Schlußbemerkungen}

\section{A. Ergebnisse}

Die vorliegende Untersuchung beschäftigt sich mit der Wohnungsbau- und Wohneigentumspolitik im Rahmen der Einkommensteuer unter steuersystematischen, verteilungspolitischen und fiskalischen Aspekten. Der steuersystematische Hintergrund bzw. die steuerliche Normalerfassung der Aufwendungen und Erträge wurde ebenfalls kritisch gewürdigt.

\section{Ergebnisse des 1. Teils ${ }^{1}$}

A.1. Wohnimmobilien sind dadurch gekennzeichnet, daß die Mieteinnahmen im Verhältnis zum investierten Kapital in den ersten Jahren keine mit der Kapitalmarktrendite vergleichbare Verzinsung erreichen. Bei hohem Fremdkapitalanteil an der Finanzierung kommt es zu einem negativen Liquiditätssaldo, da die Aufwendungen für den Kapitaldienst höher sind als die Mieteinnahmen. Die Mieteinnahmen überteigen erst durch den allgemeinen Mietanstieg und durch Tilgungen beim Fremdkapital die Fremdkapitalzinsen. Die Liquiditätsbelastung der ersten Jahre ist Anknüpfungspunkt für eine rationale Wohnungspolitik.

A.2. Auch wenn die Mieteinnahmen unter den Ausgaben für den Fremdkapitaldienst liegen bzw. die Mieteinnahmen nicht alternativen Kapitalmarkterträgen entsprechen, sollte dennoch nicht von einem Verlust gesprochen werden, da die Gesamtrendite nur unter Berücksichtigung der Wertentwicklung des Objektes ermittelt werden kann. Wächst der Wert des Immobilienvermögens mindestens mit der Inflationsrate, genügt eine Mietrendite in Höhe des realen Zinssatzes, damit die Investition mit einer Kapitalmarktanlage konkurrieren kann.

- C.1. Die steuersystemtisch differenzierte Erfassung der Immobilienerträge, im Rahmen der Gewinneinkunftsarten einerseits und im Rahmen der Überschußeinkunftsarten andererseits, läßt sich nicht rechtfertigen. Die Masse der Wertsteigerungen fällt dadurch steuerfrei an. Es widerspricht den Gerechtig-

${ }^{1}$ Die Abschnittsnummern beziehen sich auf die entsprechenden Kapitel aus der Gliederung. 
keitskriterien, die der Einkommensteuer zugrundeliegen, wenn gleiche ökonomische Sachverhalte steuerlich unterschiedlich behandelt werden.

- C.2. Durch die synthetische Einkommensbesteuerung und durch den progressiven Steuertarif nehmen die Liquiditätsentlastungen bei hohem Fremdkapitalanteil mit zunehmendem Einkommen zu, wodurch steuerliche Entlastung und individuelle Sparfähigkeit kumulieren. D.h, je höher das Einkommen des Investors ist, desto geringer kann der Eigenkapitalanteil sein, ohne daß eine Liquiditätsbelastung eintritt. Soweit die steuerlichen Verluste auf echten Verlusten beruhen, die auch unter Berücksichtigung von Wertsteigerungen, die in der Besteuerungsperiode anfallen, eintreten, handelt es sich allerdings nicht um Subventionen.

Es ist für Investoren mit zunehmendem Grenzsteuersatz nicht rational, im Wohnungsbau Eigenkapital zu binden bzw. im Zeitablauf durch Tilgung zu bilden, solange andere steuerfreie Kapitalanlagen möglich sind, während die Schuldzinsen des Fremdkapitals in voller Höhe als Werbungskosten geltend gemacht werden können. Diese asymmetrisch steuerliche Berücksichtigung von Soll- und Habenzinsen führt bei privaten Wirtschaftssubjekten dazu, daß sie über den Kapitalmarkt aus steuerlichen Gründen ihre eigenen Schuldner und Gläubiger zugleich sind. In der Praxis haben sich deshalb Finanzierungsformen entwickelt, die unter fiskalischen und verteilungspolitischen Aspekten nicht akzeptabel sind. Der fiskalische Verlust, der für den Wohnungssektor in der Einkommensteuerstatistik augewiesen wird, ist deshalb nicht nur auf schlechte Erträge und direkte Subventionen im Wohnungssektor zurückzuführen, sondern beruht auch auf der Steuerbefreiung der Erträge anderer Anlageformen.

Die Erwerber selbstgenutzten Wohneigentums, die sich hoch verschulden müssen, sind gegenüber Vermietern von Wohnungen diskriminiert, da sie die steuerlichen Entlastungen von negativen Einkünften aus Vermietung und Verpachtung und die Gestaltungsmöglichkeiten bei der Finanzierung nicht nutzen können.

C.3. Wertsteigerungen sind Teil der erzielten Einkünfte aus Vermietung und Verpachtung. Nur durch ihre Einbeziehung in die Bemessungsgrundlage des zu versteuernden Einkommens läßt sich der zu versteuernde Periodenertrag ermitteln. Es ist nicht konsequent, alle Kosten auf der Aufwandsseite in voller Höhe zu berücksichtigen, auf der Ertragsseite jedoch nur die Mieten, wodurch 
steuerliche Verluste ausgewiesen werden können, die unter Berücksichtigung von Wertsteigerungen der betreffenden Periode keine Minderung der Nettovermögensposition darstellen.

Die Erfassung der Wertsteigerungen, die der Intention der Einkommensteuer entspricht, würde deshalb die periodische Erfassung der nichtrealisierten, realen Wertsteigerungen im Rahmen der Einkünfte aus Vermietung und Verpachtung erfordern. Dieses Vorgehen scheitert aber an steuersystematischen (Nominalwert-, Realisationsprinzip) und technischen Problemen (Erfassungsproblemen). Ein singuläres Abweichen von diesen Prinizipien ist auf dem Wohnungsmarkt nicht denkbar. Hierzu wäre vielmehr eine grundlegende Einkommensteuerreform erforderlich, die diese Probleme generell für alle Einkunftsarten löst.

Ein praktikable Lösung wäre eine Besteuerung der realisierten nominalen Wertsteigerungen, ähnlich wie dies heute bei den Gewinneinkünften der Fall ist. Diese Vorgehensweise ließe sich am ehesten rechtfertigen, da die Schuldnergewinne der Inflation und die Zinsvorteile gegenüber einer Versteuerung der nicht realisierten Wertsteigerungen eine Übermaß an Besteuerung relativieren. Soweit Eigenkapital gebunden ist, wird es durch die nominale Besteuerung dem Geldvermögen gleichgestellt. Negative Auswirkungen auf den Wohnungsbau sind vorübergehend denkbar, weshalb eine solche Umstellung im Steuersystem nur bei ausgeglichenen Wohnungsmärkten vorgenommen werden sollte.

Unerwünschte Allokationswirkungen (sog. Sperreffekte), die durch eine Besteuerung der realisierten Wertsteigerungen eintreten können, dürfen für den Markt für bebaute Grundstücke (Wohnungsmarkt) nicht überbewertet werden. Um diese zu umgehen, wäre eine Regelung in Anlehnung an den § $6 \mathrm{~b}$ EStG denkbar. Allerdings sollte ein Übertrag stiller Reserven auf den Wohnungsmarkt beschränkt bleiben und nur für Gebäudeinvestitionen, nicht aber für den Bodenerwerb zugelassen werden. Das würde darauf hinauslaufen, daß der überwiegende Teil der Wertsteigerungen erst beim Erbnachlaß besteuert werden könnte. Dies würde keine eigene Steuer erfordern, sondern könnte Teil der Einkommensteuer sein, wodurch die unzulängliche periodische Erfassung des Reinvermögenszugangs nachträglich teilweise korrigiert würde.

$\mathrm{Da}$ die Probleme der steuerlichen Erfassung von Wertsteigerungen ähnlicher Natur sind wie beim Betriebsvermögen, wäre eine steuersytematische Erfassung 
der Einkünfte aus Vermietung und Verpachtung bei den Gewinneinkunftsarten statt bei den Überschußeinkunftsarten zu erwägen.

Die Wertsteigerungen des selbstgenutzten Wohneigentums sind innerhalb der Einkommensteuer kaum noch erfaßbar. Der Reinvermögenszugang läßt sich nur unter Berücksichtigung von Werbungskosten ermitteln, was nach dem Übergang zu Konsumgutlösung nur noch schwer möglich ist.

\section{Ergebnisse des 2. Teils - vermietete Wohnungen -}

A.2. Abschreibungen sind bei den Überschußeinkunftsarten systemwidrig. Es ist nicht konsequent, bei der Besteuerung negative Wertänderungen in Form von Abschreibungen gelten zu lassen und positive Wertänderungen in Form von Wertsteigerungen steuerlich nicht zu erfassen. Abschreibungen sind die kalkulatorische Vorwegnahmen eines nutzungsbedingten Werteverschleißes. Hält ein Investor ein Gebäude bis zum Ende des Nutzungszeitraums, ergeben sich gegen die lineare Abschreibung keine gravierenden Bedenken. Wird das Objekt jedoch vorzeitig veräußert, muß die Differenz zwischen dem steuerlichen Buchwert und dem Veräußerungserlös bzw. den historischen Anschaffungskosten eigentlich nachversteuert werden (und umgekehrt). Dabei handelt es sich nicht um eine Versteuerung von Wertsteigerungen, sondern um eine Anpassung der kalkulatorischen steuerlichen Aufwendungen an die tatsächlichen Verhältnisse. $\mathrm{Da}$ dies nicht geschieht, ist es für Investoren rational, nach starken Immobilienpreissteigerungen bzw. nach längeren Zeiträumen ihre Objekte zu veräußern und alternative zu erwerben. Damit können die Abschreibungen steuerfrei auf die Wiederbeschaffungskosten übertragen werden. Fiskalisch bedeutet dies, daß der Werteverzehr eines Gebäudes in Abhängigkeit von der Häufigkeit des Eigentümerwechsels mehrfach zu Steuerminderungen führt.

Eine Veräußerung ist fiskalisch nur dann neutral, wenn die Wertsteigerungen im engeren Sinne ebenfalls beim Veräußerer versteuert werden, da der Erwerber seine Abschreibungen von den Anschaffungskosten vornimmt. Entschließt sich der Gesetzgeber nicht, den Veräußerungserlös mit in die Besteuerung aufzunehmen, wäre es als kleine Reform sinnvoll, daß der Erwerber den steuerlichen Restbuchwert des Veräußerers zu übernehmen hat.

A.3. Instandsetzungsaufwendungen können im Jahr der Verausgabung unmittelbar steuerlich geltend gemacht werden. Sie stellen eine Reinvestition von 
Abschreibungen dar. Da diese steuerlich bereits durch die Normalabschreibung in der Vergangenheit berücksichtigt wurden, wird der gleiche Sachverhalt steuerlich zweimal berücksichtigt. Eine korrekte Erfassung des Reinvermögenszugangs würde es erfordern, daß Instandsetzungsaufwendungen aktiviert werden und in Zukunft entsprechend der Nutzung abgeschrieben werden. Für Investoren ist es deshalb rational, vor der Veräußerung eines Objektes umfangreiche Instandsetzungsaufwendungen durchzuführen, um den steuerfreien Veräußerungserlös zu erhöhen.

Sofern der Gesetzgeber sich auch zukünftig nicht dazu entschließt, die Differenz zwischen dem steuerlichen Buchwert und den tatsächlichen Gegebenheiten zum Veräußerungszeitpunkt zu erfassen, könnten Instandsetzungsaufwendungen sofort abzugsfähig bleiben, wenn der Erwerber den steuerlichen Buchwert des Veräußerers übernehmen muß.

- B.2. Abschreibungsvergünstigungen sind steuersytematisch nicht zu rechtfertigen. Abschreibungen dienen dazu, dem wirtschaftlichen Werteverzehr Rechnung zu tragen. Sie haben nichts mit wohnungspolitischen Zielsetzungen gemeinsam. Besonders problematisch sind Abschreibungsvergünstigungen im Mietwohnungsbau, da die Nachholwirkungen, mit denen diese Subventionen verbunden sind, bei Immobilien des Privatvermögens durch Veräußerung umgangen werden können. Die Abschreibungsvergünstigungen des § $7 \mathrm{EStG}$ bzw. des § 4 FördergebietsG sind aufgrund ihrer Höhe vom Ziel der Berücksichtigung des wirtschaftlichen Werteverzehrs vollkommen losgelöst und haben vor allem im Fall der vorzeitigen Veräußerung Freibetragscharakter.

Aus Abschreibungsvergünstigungen resultieren Subventionen, die mit steigendem Einkommen zunehmen. Es ist ein Verstoß gegen grundlegende Gerechtigkeitsprinzipien, wenn ein gleicher Beitrag zu Zielerreichung in Abhängigkeit vom Grenzsteuersatz unterschiedlich subventioniert wird. Der Wissenschaftliche Beirat beim Bundesministerium der Finanzen bezeichnet die Vergünstigungen, die aus solchen Maßnahmen resultieren als eine "Perversion der Progression"." Durch den Einfluß, den Abschreibungsvergünstigungen auf Liquidität und

1 Wissenschaftlicher Beirat beim Bundesministerium der Finanzen, Gutachten zur Reform der direkten Steuern (Einkommenkommensteuer, Körperschaftsteuer, Vermögensteuer und Erbschaftsteuer) in der Bundesrepublik Deutschland, a.a.O., S. 104. 
Rentabilität haben, wird die Verteilung des Immobilienvermögens zu einer Funktion des Grenzsteuersatzes. Die Nettorenditen des investierten Kapitals nehmen mit steigendem Einkommens zu. Insofern werden die üblichen Wirkungen der Besteuerung auf den Kopf gestellt. Besonders problematisch ist dies bei den extremen Abschreibungsregelungen des $\S 4$ FördergebietsG, da sich die Neuvermögensbildung in den neuen Ländern in der Hand von Bürgern aus den alten Bundesländer konzentriert.

Abschreibungsvergünstigungen stellen einen ineffizienten Einsatz fiskalischer Mittel dar. Mit zunehmendem Grenzsteuersatz resultieren daraus Mitnahmeeffekte. Die fiskalischen Belastungen, die Abschreibungsvergünstigungen verursachen, erreichen bei einzelnen Maßnahmen bis zu 90 v.H. des vom Investor investierten Kapitals.

C. Die fiskalische Gesamtbelastung der Erstellung neuen Wohnraums ist nicht unabhängig von der Förderung. Es stellt sich die Frage, ob der Staat mit den Fördermaßnahmen zur Verteuerung des Bauens beiträgt. Zumindest bietet das Fördersystem keine Anreize, damit Wohnraum kostensparend erstellt wird. Abschreibungsvergünstigungen setzen an den Kosten an, sie sind deshalb keine marktkonforme Maßnahme, da die Knappheitsverhältnisse verzerrt werden. Damit wird der effiziente Umgang mit knappen Mitteln geschwächt und unter Berücksichtigung von Irrationalitäten außer Kraft gesetzt. Zu erwägen wäre daher eine Förderung, die am Wohnraum (pro Quadratmeter oder Wohneinheit) anknüpft. Zumindest müßten die begünstigungsfähigen Herstellungskosten in ihrer Höhe begrenzt werden.

\section{Ergebnisse des 3. Teils - selbstgenutztes Wohneigentum -}

A.1. Die Konsumgutlösung stellt keine geeignete Maßnahme zur Förderung der Vermögensbildung in Form selbstgenutzten Wohneigentums dar. Sie ist eine einseitige Begünstigung von Altbesitzern, die über aufwendiges Wohneigentum verfügen und nur noch in geringem Maße verschuldet sind. Sie erschwert die Anschaffung von Wohneigentum für Familien mit geringem Eigenkapital. Aus finanzwissenschaftlicher Sicht gibt es keinen Grund, den Nutzwert selbstgenutzten Wohneigentums nicht zu erfassen. Die Freistellung der Nutzwerte von der Einkommensteuer diskriminiert alternative Kapitalanlagen, vor allem aber auch die Mieter, da sie ihre Mietausgaben aus versteuertem Einkommen bestreiten müssen. Die Konsumgutlösung steht im Widerspruch zum Grundfreibetrag in 
der Einkommensteuer. Bei der anstehenden Erhöhung der Grundfreibeträge ist die Konsumgutlösung zu berücksichtigen. Dies bedeutet beispielsweise, daß der Mietanteil am Grundfreibetrag für entschuldete Wohneigentümer gestrichen werden muß.

- B.2. Die Sonderausgabenabzüge nach $\S 10 \mathrm{e}$ EStG können steuersystematisch nicht gerechtfertigt werden. Der Gesetzgeber hat sie weitgehend den Abschreibungsvergünstigungen nachgebildet, ohne die unterschiedlichen Wirkungen zu berücksichtigen. Sie sind weder Vorsorgeaufwendungen, noch tangieren sie das disponible Einkommen. Als vermögensbildende Maßnahme haben sie als Abzug von der Bemessungsgrundlage ebenfalls keine Rechtfertigung. Die Subventionen, die durch die Sonderausgabenabzüge gewährt werden, nehmen progressionsbedingt mit steigendem Einkommen zu. Durch die Abhängigkeit vom Einkommen laufen sie damit verteilungspolitischen Zielsetzungen des Gesetzgebers zuwider. Sie stellen einen ineffizienten Einsatz fiskalischer Mittel dar, da es mit zunehmendem Einkommen zu Fehlförderungen kommt. Sie sind ein Verstoß gegen die Subventionsgerechtigkeit, der umso schwerer wiegt, weil es sich um eine verteilungspolitisch motivierte Maßnahme handelt. Bei geringerer fiskalischer Belastung stehen weit bessere Instrumente zur Verfügung. ${ }^{1}$

Das Baukindergeld nach $\S 34 \mathrm{f} \mathrm{EStG}$ ist nur scheinbar eine gleiche Subvention für alle Anspruchsberechtigten, da es nicht ausbezahlt wird, wenn die Steuerschuld nicht ausreicht, um es (voll) in Anspruch zu nehmen. Bereits in mittleren Einkommensschichten kommt es mit zunehmender Kinderzahl nicht (voll) zum Tragen. Wenn die Steuerschuld nicht ausreicht, um es in Anspruch zu nehmen, müßte es ausbezahlt werden.

\section{B. Schlußbemerkungen}

Die Eigenschaften von Investitionen in Wohnimmobilien machen es schwierig, eine Besteuerung der Erträge vorzunehmen, die dem Ideal der Einkommensteuer entspricht. Einiges könnte bei der Normalbesteuerung allerdings besser gemacht werden, um die Diskrepanzen zwischen der Besteuerung der sonstigen

1 Vgl. Oberhauser, A,/Rüsch, Ch., Wohnungspolitik für Familien, a.a.O., insbesondere das Instrument der Finanzierungshilfen. 
Einkunftsarten und der Einkünfte aus Vermietung und Verpachtung abzubauen. Daraus müssen sich nicht zwangsläufig negative Auswirkungen auf das Wohnungsangebot ergeben.

Durch den charakteristischen Verlauf der Liquiditätsbelastungen und durch das Steuersystem sind Wohnimmobilien auch ohne Fördermaßnahmen für Anleger mit hohem Einkommen geradezu prädestiniert. Die Wertsteigerungen, die auf diesem Markt stattfinden, können in einzelnen Jahren den Wert der gesamten Vermögensneubildung übersteigen. Empirisch zeichnet sich diese Anlageform durch einen besondere Resistenz gegen Geldentwertungen aus. Eine breite Vermögensstreuung genießt bei nahezu allen politischen Parteien einen hohen Wert und wäre besonders in Form von Wohneigentum wünschenswert.

Umso unverständlicher ist es, daß die steuerlichen Maßnahmen, die der Staat zur gezielten Subventionierung im Wohnungssektor einsetzt, die Vermögenskonzentration verstärken. Ohne erkennbaren Grund sind nahezu alle Förderinstrumente so ausgestaltet, daß die Subventionen mit steigendem Einkommen zunehmen. Besonders bei der Wohneigentumspolitik steht der Instrumenteneinsatz damit in krassem Widerspruch zu den vom Gesetzgeber explizit formulierten Zielen. Insgesamt sind die Förderinstrumente weder mit den Zielen der Einkommensteuer, noch mit den Zielen der Vermögenspolitik vereinbar. Nahezu alle verstoßen gegen den Gleichheitsgrundsatz, da gleiche Beiträge zur Zielerreichung unterschiedlich hoch subventioniert werden bzw. die Subventionen im umgekehrten Verhältnis zum Subventionsbedarf stehen. 


\section{Literaturverzeichnis}

Andel, N., Einkommensteuer, in: Handbuch der Finanzwissenschaft (HdF), Bd. II, 3. Aufl., Tübingen 1980, S. $332 \mathrm{ff}$

Andel, N., Finanzwissenschaft, Tübingen 1983

Beater, A., Die Abgrenzung des gewerblichen Grundstückshandels von der privaten Vermögensverwaltung anhand des Quellengedankens, in: Steuer und Wirtschaft (STuW), 1/1991, S. 33ff

Becker, H., Finanzwissenschaftliche Steuerlehre, München 1990

Behring, K. u.a., Evaluierung wohnungspolitischer Instrumente. Aktuelle Probleme des Wohnungsmarktes und Ansatzpunkte für wohnungspolitische Initiativen, Schriftenreihe für Wirtschaftsforschung, Nr. 129, München 1991

Beichelt, B., Aus der Arbeit des Gesetzgebers im Jahre 1986, in: Steuer und Wirtschaft (StuW), 1987, S. 84ff

Bundesfinanzhof, Entscheidung 122, 300, in: Bundessteuerblatt (BStB1.) II, 1977, S. 606

Bundesminister der Finanzen, Abgrenzung zwischen privater Vermögensverwaltung und gewerblichem Grundstückshandel, IV B 2 - S 2240 - 61/91, in: Bundessteuerblatt (BStBl.) I, 1990, S. 884ff

Bundesminister der Finanzen, AfA bei Gebäuden nach Ablauf eines Begünstigungzeitraums, IV B 3 S - S 2181 - 3/92, in: Bundessteuerblatt (BStB1.) I, 1992, S. 415ff

Bundesministerium der Finanzen, Gutachten der Steuerreformkommission 1971, Schriftenreihe des Bundesministeriums der Finanzen, Heft 17, Bonn 1971

Bundesministerium der Finanzen, Schreiben betr. negative Einkünfte aus Vermietung und Verpachtung im Rahmen von sogenannten Bauherrenmodellen sowie geschlossenen Immobilienfonds, in: Bundessteuerblatt (BStBl.) I, 1990, S. 366ff

Bundesministerium der Finanzen, Schreiben v. 19.5.1993, in: Bundessteuerblatt (BStBl.) I, 1993, S. 406 
Bundesministerium der Finanzen, Finanznachrichten 4/93

Bundesministerium für Raumordnung, Bauwesen und Städtebau, Bausteine zum eigenen Heim; Das wohnungspolitische Programm der Bundesregierung 1992, Bonn 1992

Bundesministerium für Raumordnung, Bauwesen und Städtebau, Baulandbericht 1993, Bonn 1993

Bundesrat, Entwurf eines Gesetzes zur Neuregelung der Absetzung für Abnutzung bei Wohngebäuden, Bundesratsdrucksache, 61/64

Bundesregierung, Bericht der Bundesregierung über die Entwicklung der Finanzhilfen des Bundes und der Steuervergünstigungen für die Jahre 1989 bis 1992, (Dreizehnter Subventionsbericht), Bonn 1991

Bundestag, Entwurf eines Gesetzes zur Neureglung der steuerlichen Förderung selbstgenutzten Wohneigentums, BT-Drucksache 10/3633

Bundesverfassungsgericht, Urteil vom 3.12.1958, in: BStBI. 1959, I, S. 68

Bundesverfassungsgericht, Urteil vom 22.2.1984, 1 BvL 10/80, in: BVerfGE $66,214,223$

Bundesverfassungsgericht, Beschluß vom 25. September 1992, abgedruckt in: DStR, H. 44, 1992, S. 1539ff

Costede, J., Grundfragen der Absetzungsbefugnis wegen Abnutzung, in: Steuer und Wirtschaft (StuW), 1/1986, S. 44ff

Deutsche Wohnungswirtschaft, DWW aktuell, in: Deutsche Wohnungswirtschaft, 7/1982, S. $192 \mathrm{ff}$

Eekhoff, J., Wohnungs- und Bodenmarkt, Tübingen 1987

Eekhoff, J., Wohnungspolitik, Tübingen 1993

Ehlers, E., Gewerblicher Grundstückshandel - Versuch einer Systematisierung unter Berücksichtigung der neuesten höchstrichterlichen Rechtssprechung, Teil I in: Deutsches Steuerrecht (DStR), 1989, S. 687ff und Teil II, S. $729 \mathrm{ff}$ 
Einkommensteuerkartei der OFD München, Karte 4.1. § 21 Abs. 2, zitiert nach Schönhofer/Reinisch, Haus- und Grundbesitz in Recht und Praxis, Loseblattsammlung, 15/1/S. 10, September 1992

Fecht, R., Zur Einkommensbesteuerung der Selbstnutzung von Wohneigentum, in: Finanzarchiv, 41. Jg., Tübingen 1983, S. 476ff

Finanzgericht des Saarlandes, Beschluß vom 26.2.1993, EFG 1993, S. 518, zitiert nach Schönhofer/Reinisch, Haus- und Grundbesitz in Recht und Praxis, Loseblattsammlung, Gruppe 2, S. 1142, Heft 7, Oktober 1993.

Finanzgericht Köln, Urteil vom 21.9.1988, in: EFG 1989, S. 114ff

Fleischmann, G., "Ein Generationsgeschenk für steuergeplagte Anleger", in: Frankfurter Allgemeine Zeitung (FAZ) v. 29.10.1993, S. 41

Fuisting, B., Die Preußischen direkten Steuern, 4. Bd, Grundzüge der Steuerlehre, Berlin 1902

Gewos, Institut für Stadt-, Regional und Wohnforschung, zitiert nach: Frankfurter Allgemeine Zeitung (FAZ) v. 11. Februar 1994, S. 43.

Göbel, M., Die private Eigenheiminvestition unter dem Einfluß der Besteuerung, Dissertation, Hamburg 1989

Haller, H., Die Steuern, 2. Aufl., Tübingen 1974

Hoffmann, A., Das "unechte" Zweifamilienhaus - eine einkommensteuerrechtlich fragwürdige Einschränkung, in: Deutsche Wohnungswirtschaft (DWW), 1/1981, S. $8 \mathrm{ff}$

Hooven, E. van, Wohneigentum als Element der Sozialordnung, in: Handbuch der Sozialpolitik, Pfullingen 1988

Jaser, G., Werbungskosten beim Haus und Grundbesitz, in: Schönhofer/Reinisch, Haus- und Grundbesitz in Recht und Praxis, Loseblattsammlung, Gruppe 15 I, S. 70/1987

Jaser, G., Erhöhte Absetzung für Wohnungen mit Sozialbindung (§ 7k EStG), in: Schönhofer/Reinisch, Haus- und Grundbesitz in Recht und Praxis, Loseblattsammlung 15///150i, Januar 1991 
Karl-Bräuer-Institut, Zur Neuregelung der Eigenheimbesteuerung, Karl-BräuerInstitut des Bundes der Steuerzahler, Stellungnahmen, Nr. 20, Wiesbaden 1984

Lagerhans, P., Das eigengenutzte Einfamilienhaus und die Steuerreform, in: Deutsche Wohnungswirtschaft (DWW) 5/1975, S. 104ff

Mietrechtsänderungsgesetz, 4. Mietrechtsänderungsgesetz, in: Bundesgesetzblatt (BGBl), I, S. 1257

Musgrave, R.A., u.a., Die öffentlichen Finanzen in Theorie und Praxis, 2. Band, 4. Aufl., Tübingen 1988

Nachtkamp, H.H., Grundsätze der Besteuerung - Steuerlicher Einkommensbegriff - Konsequenzen, in: Wohnungspolitik an der Wende, XIX. Königsteiner Gespräche - Referate und Diskussionen, Schriftenreihe des Instituts für Städtebau, Wohnungswirtschaft und Bausparwesen e.V., Band 39, Bonn 1984

Naust, H./Werth, G., Marktwirtschaftliche Reformen in der Wohnungspolitik, Institut für empirische Wirtschaftsforschung der Universität des Saarlandes, Forschungsberichte, Heft 52, Saarbrücken 1984

Neumark, F., Grundsätze gerechter und ökonomisch rationaler Steuerpolitik, Tübingen 1970

Oberbeckmann H.-L., Das Wohneigentum als Gegenstand der Vermögenspolitik, in: Wohneigentum zwischen Vermögenspolitik und Wohnungspolitik, XVII. Königsteiner Gespräch - Referate und Diskussionen, Schriftenreihe des Instituts für Städtebau, Wohnungswirtschaft und Bausparen, Bd. 37, Bonn 1982

Oberhauser, A., Die Eignung der Wertschöpfungsteuer als Gemeindesteuer, in: Kommunale Finanzen und Finanzausgleich, Schriftenreihe des Vereins für Socialpolitik, NF 32, Berlin 1964, S. $241 \mathrm{ff}$

Oberhauser, A., Wertzuwachssteuer, in: Handwörterbuch der Wirtschaftswissenschaften, Band 8, Tübingen 1980, S. $667 \mathrm{ff}$

Oberhauser, A., u.a., Eigentumsbildung im Wohnungsbau, Lübeck 1982 
Oberhauser, A., Das Schuldenparadox, in: Jahrbücher für Nationalökonomie und Statistik, Band 200, 1985, S. 333ff

Oberhauser, A., Stellungnahme vor dem Finanzausschuß des Deutschen Bundestages zu dem Gesetzentwurf der Bunderegierung zur Neuregelung der steuerlichen Förderung des selbstgenutzten Wohneigentums am 23.10.1985

Oberhauser, A., Ein Verstoß gegen die Gerechtigkeit. Die Neuregelung der Besteuerung selbstgenutzten Wohneigentums, in: Wohnungswirtschaft und Mietrecht, 39. JG., 1986, Heft 6, S. 163ff

Oberhauser, A./Rüsch, Ch., Wohneigentumsförderung an den Familien vorbei, in: Wirtschaftsdienst, 72. Jg., 1992, S. 315ff

Oberhauser, A./Rüsch, Ch., Wohnungspolitik für Familien, Familienorientierte Förderung des Erwerbs selbstgenutzten Wohneigentums unter besonderer Berücksichtigung der Situation in den neuen Ländern, 2. Aufl., Grafschaft 1994

o.V., Vierzig Prozent des Familieneinkommens für das Eigenheim, in: Frankfurter Allgemeine Zeitung (FAZ) vom 7.5.1993, S. 39

Peffekoven, R., Freibetrag oder Steuerkredit?, in Finanzarchiv, Neue Folge, Bd. 30, 1971, Tübingen 1972, S. 392ff

Peffekoven, R., Persönliche allgemeine Ausgabensteuer, in Handbuch der Finanzwissenschaft (H.d.F.), Bd. II, 3. Aufl., Tübingen 1980, S. 418ff

Roscher, W., System der Volkswirtschaft, Bd. 1: Grundlagen der Nationalökonomie, 1883

Sachverständigenrat zur Begutachtung der gesamtwirtschaftlichen Entwicklung, Jahresgutachten 1983/84, Stuttgart 1983

Sachverständigenrat zur Begutachtung der gesamtwirtschaftlichen Entwicklung, Jahresgutachten 1992/93, Stuttgart 1991

Schanz, G.v., Der Einkommensbegriff und die Einkommensteuergesetze, in: Finanzarchiv 13. Jg., Tübingen 1896, S. 1 ff

Schmidt, L., Einkommensteuerrecht, Kommentar, 11. Aufl., München 1992 
Schönhofer/Reinisch, Haus- und Grundbesitz in Recht und Praxis, Loseblattsammlung, Haufe Verlag Freiburg i.Br., Stand: 1.5.1994

Schwaetzer, I., Wohnungsmarkt in der Zange knapper öffentlicher Mittel?!, Vortrags- und Diskussionsveranstaltung vom 24. Oktober in Königswinter, Bonn 1991

Standortsicherungsgesetz, Bundesgesetzblatt (BGBl) 1993 I., S. 1569

Statistisches Bundesamt, Finanzen und Steuern, Fachserie 14, Reihe 7.1, Einkommensteuer 1986, Wiesbaden 1991

Statistisches Bundesamt, Preisindex für die Lebenshaltung, Fachserie 17, Reihe 7, Bd. 1991

Statistisches Bundesamt, Fachserie 17, Reihe 5, 4. Quartal 1992

Statistisches Bundesamt, Statistisches Jahrbuch 1993, Wiesbaden 1993

Steueränderungsgesetz vom 25.2.1992, in Bundesgesetzblatt (BGBl.) 1992, S. 297 und Bundessteuerblatt (BStB1.) I, 1992, S. 146

Steuergesetze, Textsammlung mit Verweisen und Sachverzeichnis, Loseblattsammlung, Beck Verlag München, Stand 1. Januar 1994

Steuerrichtlinien, Textsammlung der Verwaltungsvorschriften des Bundes zum Steuerrecht mit Verweisen und Sachverzeichnis, Beck Verlag München, Stand 30. September 1993

Tipke, K., Steuerrecht. Ein steuersystematischer Grundriß, 7. neubearbeitete Auflage, Köln 1979

Tipke, K./Lang J., Steuerrecht, Ein steuersystemtischer Grundriß, 13. völlig überarbeitete Auflage, Köln 1991

Verband Deutscher Makler VDM, zitiert nach: Bauherrenratgeber, Bauen \& Finanzieren, Fellbach Dezember 1992

Volk, R., Vergleich der Vergünstigungseffekte der verschiedenen investitionsfördernden Maßnahmen, Frankfurt 1993 
Wagner, W., Aus der Arbeit des Steuergesetzgebers, in: Steuer und Wirtschaft (StuW) 1/1986, S. 89ff

Wissenschaftliche Beirat beim Bundesministerium der Finanzen, Gutachten zur Reform der direkten Steuern (Einkommensteuer, Körperschaftsteuer, Vermögensteuer und Erbschaftsteuer) in der Bundesrepublik Deutschland, Nr. 27 vom 11. Februar 1976, abgedruckt in: Der Wissenschaftliche Beirat beim Bundesministerium der Finanzen, Entschließungen, Stellungnahmen und Gutachten 1949-1973, hrsg. vom Bundesministerium der Finanzen, Tübingen 1974, S. 326ff

Wissenschaftliche Beirat beim Bundesministerium der Finanzen, Gutachten über Probleme und Lösungsmöglichkeiten einer Bodenwertzuwachsbesteuerung, Nr. 22 vom 5. Dezember 1975, abgedruckt in: Der Wissenschaftliche Beirat beim Bundesministerium der Finanzen, Gutachten und Stellungnahmen 1974-1987, hrsg. vom Bundesministerium der Finanzen, Tübingen 1988, S. $31 \mathrm{ff}$

Wohneigentumsförderungsgesetz vom 15.5.1986, BGBI. I, S. 730ff

Zeitschrift für das gesamte Kreditwesen, Sonderausgabe, Heft 2, 1993/94 


\section{FINANZWISSENSCHAFTLICHE SCHRIFTEN}

Band 1 Werner Steden: Finanzpolitik und Einkommensverteilung. Ein Wachstums- und Konjunkturmodell der Bundesrepublik Deutschland. 1979.

Band 2 Rainer Hagemann: Kommunale Finanzplanung im föderativen Staat. 1976.

Band 3 Klaus Scherer: Maßstäbe zur Beurteilung von konjunkturellen Wirkungen des öffentlichen Haushalts. 1977.

Band 4 Brita Steinbach: "Formula Flexibility" - Kritische Analyse und Vergleich mit diskretionärer Konjunkturpolitik. 1977.

Band 5 Hans-Georg Petersen: Personelle Einkommensbesteuerung und Inflation. Eine theoretisch-empirische Analyse der Lohn- und veranlagten Einkommensteuer in der Bundesrepublik Deutschland. 1977.

Band 6 Friedemann Tetsch: Raumwirkungen des Finanzsystems der Bundesrepublik Deutschland. Eine Untersuchung der Auswirkungen der Finanzreform von 1969 auf die Einnahmenposition der untergeordneten Gebietskörperschaften und ihrer regionalpolitischen Zieladäquanz. 1978.

Band 7 Wilhelm Pfähler: Normative Theorie der fiskalischen Besteuerung. Ein methodologischer und theoretischer Beitrag zur Integration der normativen Besteuerungstheorie in der Wohlfahrtstheorie. 1978.

Band 8 Wolfgang Wiegard: Optimale Schattenpreise und Produktionsprogramme für öffentliche Unternehmen. Second-Best Modelle im finanzwirtschaftlichen Staatsbereich. 1978.

Band 9 Hans P. Fischer: Die Finanzierung des Umweltschutzes im Rahmen einer rationalen Umweltpolitik. 1978.

Band 10 Rainer Paulenz: Der Einsatz finanzpolitischer Instrumente in der Forschungs- und Entwicklungspolitik. 1978.

Band 11 Hans-Joachim Hauser: Verteilungswirkungen der Staatsverschuldung. Eine kreislauftheoretische Inzidenzbetrachtung. 1979.

Band 12 Gunnar Schwarting: Kommunale Investitionen. Theoretische und empirische Untersuchungen der Bestimmungsgründe kommunaler Investitionstätigkeit in NordrheinWestfalen 1965-1972. 1979.

Band 13 Hans-Joachim Conrad: Stadt-Umland-Wanderung und Finanzwirtschaft der Kernstädte. Amerikanische Erfahrungen, grundsätzliche Zusammenhänge und eine Fallstudie für das Ballungsgebiet Frankfurt am Main. 1980.

Band 14 Cay Folkers: Vermögensverteilung und staatliche Aktivität. Zur Theorie distributiver Prozesse im Interventionsstaat. 1981.

Band 15 Helmut Fischer: US-amerikanische Exportförderung durch die DISC-Gesetzgebung. 1981.

Band 16 Günter Ott: Einkommensumverteilungen in der gesetzlichen Krankenversicherung. Eine quantitative Analyse. 1981.

Band 17 Johann Hermann von Oehsen: Optimale Besteuerung. (Optimal Taxation). 1982.

Band 18 Richard Kössler: Sozialversicherungsprinzip und Staatszuschüsse in der gesetzlichen Rentenversicherung. 1982

Band 19 Hinrich Steffen: Zum Handlungs- und Entscheidungsspieiraum der kommunalen Investitionspolitik in der Bundesrepublik Deutschland. 1983.

Band 20 Manfred Scheuer: Wirkungen einer Auslandsverschuldung des Staates bei flexiblen Wechselkursen. 1983. 
Band 21 Christian Schiller: Staatsausgaben und crowding-out-Effekte. Zur Effizienz einer Finanzpolitik keynesianischer Provenienz. 1983.

Band 22 Hannelore Weck: Schattenwirtschaft: Eine Möglichkeit zur Einschränkung der öffentlichen Verwaltung? Eine ökonomische Analyse. 1983.

Band 23 Wolfgang Schmitt: Steuern als Mittel der Einkommenspolitik. Eine Ergänzung der Stabilitätspolitik? 1984.

Band 24 Wolfgang Laux: Erhöhung staatswirtschaftlicher Effizienz durch budgetäre Selbstbeschränkung? Zur Idee einer verfassungsmäßig verankerten Ausgabengrenze. 1984.

Band 25 Brita Steinbach-van der Veen: Steuerinzidenz. Methodologische Grundlagen und empirisch-statistische Probleme von Länderstudien. 1985.

Band 26 Albert Peters: Ökonomische Kriterien für eine Aufgabenverteilung in der Marktwirtschaft. Eine deskriptive und normative Betrachtung für den Allokationsbereich. 1985.

Band 27 Achim Zeidler: Möglichkeiten zur Fortsetzung der Gemeindefinanzreform. Eine theoretische und empirische Analyse. 1985.

Band 28 Peter Bartsch: Zur Theorie der längerfristigen Wirkungen 'expansiver' Fiskalpolitik. Eine dynamische Analyse unter besonderer Berücksichtigung der staatlichen Budgetbeschränkung und ausgewählter Möglichkeiten der öffentlichen Defizitfinanzierung. 1986.

Band 29 Konrad Beiwinkel: Wehrgerechtigkeit als finanzpolitisches Verteilungsproblem. Möglichkeiten einer Kompensation von Wehrungerechtigkeit durch monetäre Transfers. 1986.

Band 30 Wolfgang Kitterer: Effizienz- und Verteilungswirkungen des Steuersystems. 1986.

Band 31 Heinz Dieter Hessler: Theorie und Politik der Personalsteuern. Eine Kritik ihrer Einkommens- und Vermögensbegriffe mit Blick auf die Leistungsfähigkeitstheorie. 1994.

Band 32 Wolfgang Scherf: Die beschäftigungspolitische und fiskalische Problematik der Arbeitgeberbeiträge zur Rentenversicherung. Eine Auseinandersetzung mit der Kritik an der lohnbezogenen Beitragsbemessung. 1987.

Band 33 Andreas Mästle: Die Steuerunion. Probleme der Harmonisierung spezifischer Gütersteuern. 1987.

Band 34 Günter Ott: Internationale Verteilungswirkungen im Finanzausgleich der Europäischen Gemeinschaften. 1987.

Band 35 Heinz Haller: Zur Frage der zweckmäßigen Gestalt gemeindlicher Steuern. Ein Diskussionsbeitrag zur Gemeindesteuerreform. 1987.

Band 36 Thomas Kuhn: Schlüsselzuweisungen und fiskalische Ungleichheit. Eine theoretische Analyse der Verteilung von Schlüsselzuweisungen an Kommunen. 1988.

Band 37 Walter Hahn: Steuerpolitische Willensbildungsprozesse in der Europäischen Gemeinschaft. Das Beispiel der Umsatzssteuer-Harmonisierung. 1988.

Band 38 Ulrike Hardt: Kommunale Finanzkraft. Die Problematik einer objektiven Bestimmung kommunaler Einnahmemöglichkeiten in der gemeindlichen Haushaltsplanung und im kommunalen Finanzausgleich. 1988.

Band 39 Jochen Michaelis: Optimale Finanzpolitik im Modell überlappender Generationen. 1989.

Band 40 Bernd Raffelhüschen: Anreizwirkungen der sozialen Alterssicherung. Eine dynamische Simulationsanalyse. 1989.

Band 41 Berend Diekmann: Die Anleihe- und Darlehenstransaktionen der Europäischen Gemeinschaften. 1990.

Band 42 Helmut Kaiser: Konsumnachfrage, Arbeitsangebot und optimale Haushaltsbesteuerung. Theoretische Ergebnisse und mikroökonometrische Simulation für die Bundesrepublik Deutschland. 1990. 
Band 43 Rüdiger von Kleist: Das Gramm-Rudman-Hollings-Gesetz. Ein gescheiterter Versuch der Haushaltskonsolidierung. 1991.

Band 44 Rolf Hagedorn: Steuerhinterziehung und Finanzpolitik. Ein theoretischer Beitrag unter besonderer Berücksichtigung der Hinterziehung von Zinserträgen. 1991.

Band 45 Cornelia S. Behrens: Intertemporale Verteilungswirkungen in der gesetzlichen Krankenversicherung der Bundesrepublik Deutschland. 1991.

Band 46 Peter Saile: Ein ökonomischer Ansatz der Theorie der intermediären Finanzgewalten Die Kirchen als Parafisci. 1992.

Band 47 Peter Gottfried: Die verdeckten Effizienzwirkungen der Umsatzsteuer. Eine empirische allgemeine Gleichgewichtsanalyse. 1992.

Band 48 Andreas Burger: Umweltorientierte Beschäftigungsprogramme. Eine Effizienzanalyse am Beispiel des "Sondervermögens Arbeit und Umwelt". 1992.

Band 49 Jeanette Malchow: Die Zuordnung verteilungspolitischer Kompetenzen in der Europäischen Gemeinschaft. Eine Untersuchung aufgrund einer Fortentwicklung der ökonomischen Theorie des Föderalismus. 1992.

Band 50 Barbara Seidel: Die Einbindung der Bundesrepublik Deutschland in die Europäischen Gemeinschaften als Problem des Finanzausgleichs. 1992.

Band 51 Ralph Wiechers: Markt und Macht im Rundfunk. Zur Stellung der öffentlich-rechtlichen Rundfunkanstalten im dualen Rundfunksystem der Bundesrepublik Deutschland. 1992.

Band 52 Klaus Eckhardt: Probleme einer Umweltpolitik mit Abgaben. 1993.

Band 53 Oliver Schwarzkopf: Die Problematik unterschiedlicher Körperschaftsteuersysteme innerhalb der EG. 1993.

Band 54 Thorsten Giersch: Bergson-Wohlfahrtsfunktion und normative Ökonomie. 1993.

Band 55 Li-Fang Chou: Selbstbeteiligung bei Arzneimitteln aus ordnungspolitischer Sicht. Das Beispiel der Bundesrepublik Deutschland. 1993.

Band 56 Harald Schlee: Einkommensteuerliche Behandlung von Transferzahlungen. Zur Neuordnung der Familienbesteuerung sowie der Besteuerung von Versicherungsleistungen und Sozialtransfers. 1994.

Band 57 Alexander Spermann: Kommunales Krisenmanagement. Reaktionen baden-württembergischer Stadtkreise auf steigende Sozialhilfekosten und Einnahmenausfälle (198092). 1993.

Band 58 Otto Roloff / Sibylle Brander / Ingo Barens / Claudia Wesselbaum: Direktinvestitionen und internationale Steuerkonkurrenz. 1994.

Band 59 Claudia Wesselbaum-Neugebauer: Internationale Steuerbelastungsvergleiche. 1994.

Band 60 Stephanie Miera: Kommunales Finanzsystem und Bevölkerungsentwicklung. Eine Analyse des kommunalen Finanzsystems vor dem Hintergrund der sich abzeichnenden Bevölkerungsentwicklung am Beispiel Niedersachsens unter besonderer Berücksichtigung des Landkreises Wolfenbüttel und seiner Gemeinden. 1994.

Band 61 Wolfgang Schert: Die Bedeutung des kaldorianischen Verteilungsmechanismus für die gesamtwirtschaftlichen Wirkungen der staatlichen Neuverschuldung. 1994.

Band 62 Rainer Volk: Vergleich der Vergünstigungseffekte der verschiedenen investitionsfördernden Maßnahmen. 1994.

Band 63 Hans-Georg Napp: Kommunale Finanzautonomie und ihre Bedeutung für eine effiziente lokale Finanzwirtschaft. 1994. 2., unveränderte Auflage 1994.

Band 64 Bernd Rahmann / Uwe Steinborn / Günter Vornholz: Empirische Analyse der Autonomie lokaler Finanzwirtschaften in der Europäischen Gemeinschaft. 1994. 
Band 65 Carsten Kühl: Strategien zur Finanzierung der Altlastensanierung. 1994.

Band 66 Stephan Boll: Intergenerationale Umverteilungswirkungen der Fiskalpolitik in der Bundesrepublik Deutschland. Ein Ansatz mit Hilfe des Generational Accounting. 1994.

Band 67 Karl Justus Bernhard Neumärker: Finanzverfassung und Staatsgewalt in der Demokratie. Ein Beitrag zur konstitutionellen Finanztheorie. 1995.

Band 68 Christian Haslbeck: Zentrale versus dezentrale Internalisierung externer Effekte bei unvollständiger Information. 1995.

Band 69 Regina Müller: Horizontale oder vertikale Transfers zur Durchsetzung eines horizontalen Finanzausgleichs. 1995.

Band 70 Christian Hockenjos: Öffentliche Sportförderung in der Bundesrepublik Deutschland. Darstellung und finanztheoretische Analyse. 1995.

Band 71 Manfred Rosenstock: Die Kontrolle und Harmonisierung nationaler Beihilfen durch die Kommission der Europäischen Gemeinschaften. 1995.

Band 72 Christian Rüsch: Wohnungsbau- und Wohneigentumspolitik im Rahmen der Einkommensteuer. Eine Analyse unter steuersystematischen, verteilungspolitischen und fiskalischen Aspekten. 1996. 
Christian Rüsch - 978-3-631-75254-8

Downloaded from PubFactory at 01/11/2019 06:40:21AM

via free access 